\title{
BASIO
}

POLICT
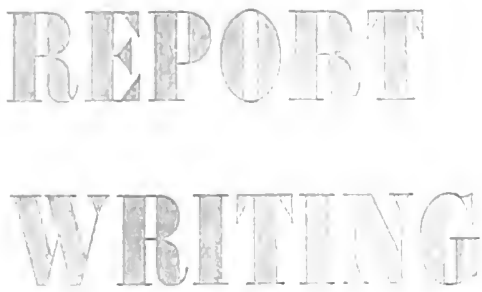

A LIEN E. GAMARGE, PEDD. Supervisor of

Law Enforcement Training Sacramento State College Sacramento, Cajifornia

With a Foreword by PAUL B. WESTON

Deputy Chief Inspector New York City

Police Department (ret.)

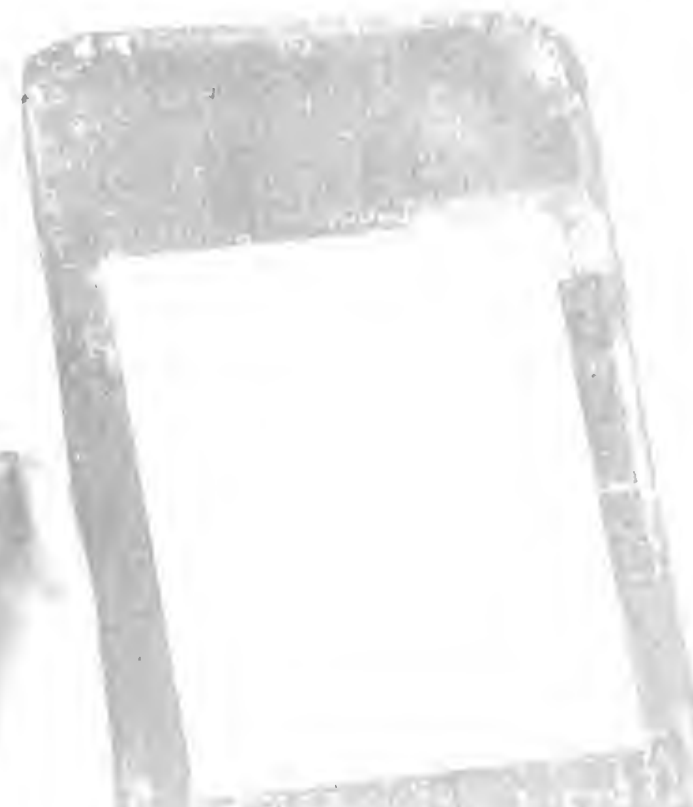


"I believe the author's instructional material on the collection, selection, and arrangement of material in police reports is realistically keyed to the learning level of the great mass of policemen and is the finest available material for police training officers and policemen interested in self-improvement. "From the Foreword by PAUL B. WESTON

A police officer, student, and teacher, Doctor Gammage writes with the authority of the lectureplatform supported by years of experienceas a working policeman. He makes no claim that this manual is a panacea, but he is convinced that thorough study and application of the principles and procedures presented will produce better report writers.

The introduction sets forth purposes, values, and principles involved in the preparation of reports. It is an effort to sell the practicing officer the idea that IN SUBMIT TING SUPERIOR REPORTS HE NOT ONLY IS DOING A PROFESSIONAL JOB FOR HIS DEPARTMENT BUT IS CONTRIBUTING TO HIS OWN PROFESSIONAL GROWTH.

Part II is A GUIDE TO IMPROVE DICTION, SPELLING, CAPITALIZATION, ABBREVIATIONS, SENTENCE STRUCTURE, PUNCTUATION, and PARAGRAPHING. It is inability in these mechanical aspects that causes the average police report to fall short of ideal.

The third section deals with form preparation. Fornıs utilized are the result of study of many in current use and are those developed with a view to emphasizing the desirability of narrative presentations. 
From the collection of the

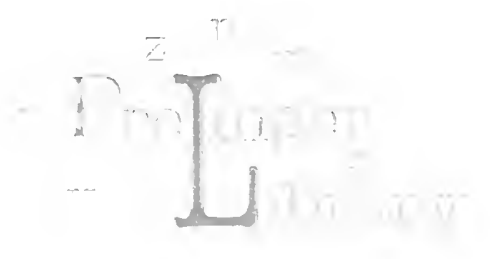

San Francisco, California

2008 



\section{BASIC POLICE REPORT WRITING}


A Monograph in

THE POLICE SCIENCE SERIES

\author{
Edited by \\ V. A. LEONARD \\ Professor of Police Administration \\ II ashington State University \\ Pullman. W'ashington
}




\section{BASIC \\ POLICE REPORT WRITING}

B)

ALLEN Z. GAMMAGE, Ph.D.

Supereisor of Law Enforcement Training

Sacramento state College

Sarramento, California

With a Foreword by

PAUL B. WESTON

Depuly Chief Inspector

Neal York City Police Department (ret.)

Ansistanl Professor

sacramento state college

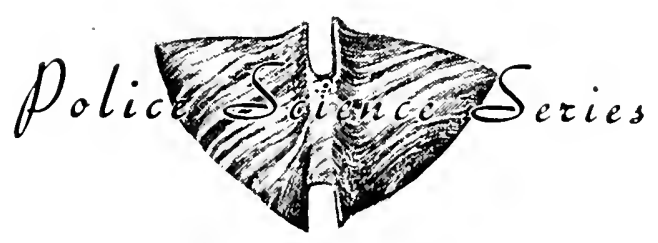

CH A R L ES C TH O M A S - PU B L I S H E R springfield - Illinois - U.S.A. 


\section{CHIRLES C THOMIS - PUBLISHER}

BANNERTONE House

301-327 Last Lawrence Arenue, Springfield, Illinois, U.S.A.

This book is protected by copyright. No part of it may be reproduced in any manner without written permission from the publisher.

(1) $196 l, b y$ CHIRLES C THONAS - PUBLISHER

Library of Congress Catalog Card Number: 60-14743

With THOMAS BOOKS careful atlention is given to all details of mamufacturing and design. It is the Publisher's desire to present books that are satisfartory as to their physical qualities and artistic possibilities and appopriate for their particular use. THOMAS BOOKS will be true to those lau's of quality that assure a good name and good will. 
FREE LIBRARY OF PHILADELPHIA

Dedicated to my aunt. Mrs. Ed Snead 



\section{FOREWORD}

$\mathrm{O}$

AN OpERATIONAl LEVEL, the ability to describe a fugitive in a word picture that is a graphic representative of reality means prompt and rapid apprehension of criminals; sufficient aptitude to include all the essential elements of a crime in the lew words of a court complaint means the people of the community will have an opportunity to convict a suspect of the crime charged; and the skill to sketch a police incident of today in some deptl may mean the solution of tomorrow's crime.

On an administrative level, the words of police officers form the reports that make up the raw data whose compilation and study permits management to exercise the necessary control for the expert and efficient administration of a police mit.

In this text the qualities of factual prose necessary for police reports are thoroughly explained in an anatomical study of the mechanics of police report writing. Dr. Gammage sums up, without the waste of a single word, the selection and use of words, the structure of sentences, and the development of paragraphs. Almost in passing, he tells his readers of suitable stopping places in thei: reports as he presents simple principles on the art of punctuation.

A police officer, student, and teacher, Dr. Gammage writes with the authority of the lecture platform supported by years of experience as a working policeman. An excellent combination to launch new procedures in ferreting out facts during field note tak. ing, and detailing methods for recording them in a manner which permits the officer to marshal his facts according to a definite plan when he must report the incident and describe the police action taken.

I believe the author's instructional material on the collection. selection, and arrangenent of material in police reports is realistically keyed to the learning level of the great mass of policemen 
and is the finest available material for police training officers and policemen interested in self-improvement.

Dr. Gammage has recognized and apparently solved the legitimate claims of both the formal and the informal levels of language usage and is to be complimented on the fact that he has avoided the dogmatic narrowness of the prescriptive grammarians, though he has provided the police profession with a text which is not only instructional, but which will also serve as a ready reference to the appropriateness and correctness of the various forms of police reports, and the language used in their preparation.

A Texan by birth and avocation, Dr. Gammage preaches the doctrine of direct sentences, for "telling 'em straight." This text is not a grammar book, though grammatical errors are detailed and some grammar introduced to show why such errors hinder the successful communication of ideas. In hard-hitting "plain talk" the author explains the parts of speech and the relation of writing to thinking. He also explores the need for developing a style of writing which will reflect an officer's thinking in order that he may tell a story which subordinates the minor phases of an incident or police action, and hits the reader right between the eyes with the main idea.

The emerging police profession may also erect another mile post since this book standardizes the methodology of police reports. Dr. Gammage has established national standards against which to evaluate the prevailing practices of an individual policeman or a police department. The author has studied the standard practices of the top police mits in the Inited States, both large and small, and questioned police officers of all ranks who have qualified as experts by field experience. Therefore, it can be safely stated that this book is an authoritative reproduction of accepted report writing procedures in reasonably prudent police departments.

Paul B. IVeston

Deputy Chief Inspector

New York City Police Department (ret.) 


\section{PREFACE}

I

THE AUTHOR's PERSONAL experience and as the result of interviews and discussions with people in the police field, he is conrinced that one of the greatest roids in the police procedures fretd is in the area of police report writing. Police practitioners at the performance level continue to struggle with their reports. Administrators express a high degree of dissatisfaction with the routine reports submitted. Most interested parties agree that the deficiencies stem from a lack of knowledge of the fundamentals on the part of the report witer. They also state that almost all recruit and refresher courses offered in the academies fail to accomplish the job of preparing police personnel in the art of report writing.

This manual was written with the hope that it will solve some of the problems of both the practitioner and administrator as they relate to operational reporting. The author makes no claim that this manual is a panacea, but he is convinced that thorough study and application of the principles and procedures presented will cause the reader to become a better report writer.

The introduction is designed to acquaint the reader with the purposes, values, and principles involved in the preparation of reports. It is an effort to sell the practising oflicer the idea that in submitting superior reports he not only is doing a professional job for his department but is contributing to his own professiomal growth.

Part II is a guide to improre diction, spelling, capitalisation. abbreviations, sentence structure, punctuation and paragraphing because it in inability in relation to these mechanical aspects that the average police report olten falls short of the ideal.

The third part deals with form preparation. The forms utilized are the result of study of many in current use and are those developed with a view to emphasizing the desinability of narrative presentations. Beginning with field note tahing as the fonndation 
of operational reports, the reader is taken through the entire process from the recording of a reported incident to the many specialized forms used in reporting investigations, arrests and the identification of persons. 


\section{ACKNOWLEDGMENTS}

T

HE AUTHOR is DEEPLy grateful to I.t. J. I. Ross of the berkeley, California, Police Department; Lt. Edward T. Naylon, Hollywood, Florida; Chicf Bernard I. Gamire, Tucson, Arizona; Deputy Chief C. I. Staylor, Norfolk, Virginia; Superintendent Francis S. McGarvey, Division of State Police, Albany, New York; Chiel Michael Murphy of the New York City Police Department; and Sgt. Jannes Nance of the Sacramento Connty Sheriff's Office, all of whom contributed departmental forms and/or suggestions for the book.

He also owes a special debt of gratitude to Mrs. Carol Larsen and Mr. Paul B. Weston, Deputy Chief Inspector, N.Y.C.P.D. (ret.), who read the manuscript and offered their most helpful suggestions.

Last, but not least, thanks to Professor Nicholas DeLucia who provided the photographs and Miss I ois Mouchett who worked so faithfully in typing the manuscript.

A.7.C. 



\section{CONTENTS}

P'sis

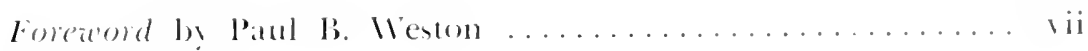

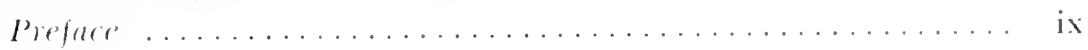

\section{P.IRT I. INTROIOUCTION}

Chapte'

1. Definitions, Purposes, and Types of Police Repore ..... 5

11. Values and Principles in Police Reporting ........... !

\section{PART II. MECHANICS OF REPORT WRITING}

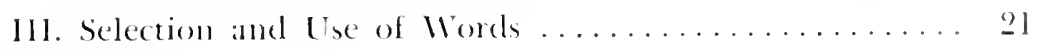

IV. Spelling . . . . . . . . . . . 31

V. Cilpitalization and Numbers ............... 51

I. Abbreviations ................... 57

VIl. Sentence Structure .................. 62

V'lll. Punctuation .................... 67

1X. Paragraph Comstruction ................ TS

X. Eeliting and Criticising the Report ............. s?

\section{PART III. REPORTING POLICE OPERATIONS}

X1. Field Note Taking .................. 93

XII. Reporting the Calse ................... 109

XII. Reporting the Preliminary Investigation . . . . . . . . . 19.4

XIV. Special Preliminary Investigation Reports . . . . . . . 143

XV'. Patrol Service Reports . . . . . . . . . . . . . . 168

XVl. The Supplementary Progress Report .............. Isl

XVII. Special Supplementary Investigation Reports . . . . . . . . I9.

XVIH. Final Investigation Reports ............... 2l"

XIX. Arrest Reports ......................

XX. Property Control Report .................. 296 
Chapter

XXI. Identilication Reports

Appendix

A. Elements of Grammar . . . . . . . . . . . . 269

B. Uniform Classification of Crimes . . . . . . . . . 279

C. Description of Property ................. 280

Bibliography .............................. 305

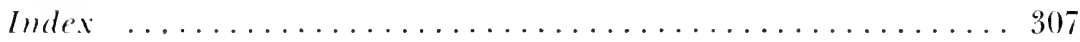


BASIC POLICE REPORT WRITING 



\section{PART I}

INTRODUCTION 



\section{Chapter I}

\section{DEFINITIONS, PURPOSES, AND TYPES OF POLICE REPORTS}

\section{W}

LBSTER'S NEW Colbegnte Dictionary defines a report as an account of some subject specially investigated or an official statement of lacts. According to this definition, police reports may be written or oral; they may be detailed or brief; they may be simple or complex; they may be prepared by anyone in the department from the chief to the patrolman on the beat. In any event, police reporting has become one of the most significant processes in modern police operations. Reports result from the fact that someone has asked for them and needs them for immediate or future use. They are made to be read and used.

The larger the police department, of course, the greater the demand for reports. This is true because more information of diflerent kinds is required and because more people are at different places where things are happening. The chief of a large department finds it necessary to have a greater division of labor, to hire more employees, to delegate more activities to subordinates, to supervise a greater number of people, and often to watch over a larger area.

Yet, any chief is responsible for all of the basic activities of his department. He must know what is going on throughout his agency, and in all departments, large or small, the principal way to determine what is going on is to require reports, to nse proper reporting procedures, and to utilize the results.

In fact, the field of police reporting, broadly interpreted, is the field of police commmnications. At whatever point work is divided and delegated, the process of reporting begins. At whatever point policy is formulated or modified, the process of reporting is a "must." In govermment generally, as well as in police agencies, the matter of communicating is complex and presents a continming problem. All sorts of information must, of course, flow upward and 
downward through the department; but, in addition, and equally important in many cases, information must somehow be reported outward, across, and around. The setting of police reporting, then, is the entire field of communications. This means that the process of police reporting has at its disposal all of the ways and means available in the broader field. This inchudes oral and written techniques and all of the known media developed for the exchange of information and ideas. But police experience indicates that written communication, in most cases, is the most effective; and, in any case, is the form of communication which presents greater problems for the department and the reporter.

\section{PURPOSES OF REPORTS}

In general, a police agency develops its reporting system to serve four key purposes: (1) to account upward and outward for its activities and for the justification of its program; (2) to report upward and outward information concerning progress, future needs and plans, and decisions being made or which may be made; (3) to report upward for purposes of administrative control; and (4) to inform downward in the organization concerning policies. program, organization resources, procedures, and all other matters concerning the work in the agency.

In reporting upward and outward the police agency takes into account the police organization itself: the mayor or city manager: the city council; the central government-wide service agencies such as the department of finance and the civil service commission; and the general public. In reporting downward in the organization the department must take into consideration all of the levels of responsibility and any special units or staffs which need to be kept informed of matters contained in a given report. In any of these situations a report may serve the useful purpose of interpreting facts, transmitting information, analyzing problems or situations, educating employees and others, accounting to superior authority, or controlling within the department itself.

\section{TYPES OF POLICE REPORTS}

In fact, the many purposes served by police reports and our system of administrative independence have given rise to a number 
and variety of reports which, in some departments, are actually appalling. As a result, the job of conducting a systemat ic discussion of police reports is almost impossible. But speaking in broad terms and in a rather elementary way, we may classify all police reports into two groups: informal and fomal.

An informal report usually is a letter or memonandum or any one of many prescribed or used in day-by-day police operations. It customarily carries three items besides the text proper: date submitted, subject, and persons or person to whom submitted. It may, however. contain many items of administrative importance along with the subject matter of the text. Actually, most police reports may be placed in this category.

A formal report suggests the full-dress treatment, including cover, title page, letter of transmittal, summary sheet, text, appendixes, and perhaps an index and bibliography.

Another helpful plan for classifying police reports is based on the purpose of the report. Under this plan, any police report may be classified as either a performance, fact-finding, technical, problem-determining, or problem-solution report. The performance report contains information as to the status of an activity, activities, or operations. The fact-fuding report involves the gathering and presentation of data in logical order, without an attempt to draw conclusions. A technical report presents data on a specialized subject. The problem-determining report attempts to find the causes underlying a problem or to fund whether or not a problem really exists. The problem-solution report analyzes the thought process that lies behind the solution of a particular problem. It may include all of the elements found in the other types of reports, including presentation of data collected, discussion of possible solutions to the problem, and an indication of the best solution.

On the other hand, these rather informative classifications offer very little help in establishing a systematic arrangement of a veritable mass of police reports. I cet's speak in more specific terms. For our purposes, police reports may be categorized as operational reports, internal business reports, technical reports, and smmmary reports.

Operational reports include those relating to the reporting of police incidents, investigations, arrests, inclentification of per- 
sons, and a mass of miscellaneous reports necessary to the conduct of routine police operations. Internal business reports relate to the reporting necessary to the management of the agency and inchude financial reports, personnel reports, purchase reports, equipment reports, property maintenance reports, and general correspondence. As stated earlier, technical reports may present data on any specialized subject, but usually relate to completed staff work and add to the specific knowledge necessary to proper functioning of police management. Summary reports furnish intelligence information necessary to the solution of crime, accident, and police administrative problems. In addition, public reports in this category are made in recognition of the importance of public attitude toward police operations and serve the useful purpose of keeping executive and legislative authority and the general public informed as to problems, progress, and needs of the police agency.

\section{SCOPE OF THIS BOOK}

This book deals only with the first category-operational reports. These reports are the raw materials from which administrative reports are clerived; thus, in directing efforts toward improving these basic reports, the author believes that the whole of the reporting process can be improved. 


\title{
Chapter II
}

\section{VALUES AND PRINCIPLES IN POLICE REPORTING}

\begin{abstract}
$\mathrm{T}$
$O$ SOME ExTENT, THE sllEF number and variety of police reports serve to illustrate their continuing value; but, in the final analysis, one might rightfully say that the benefits derived from police reports are those associated with the entire police records system because reports are the raw materials from which records systems are made. Like the records thenselves, a direct relationship exists between the efficiency of the departunent and the quality of its reports and reporting procedures.
\end{abstract}

\section{VALUES TO THE DEPARTMENT}

The progressive police administrator utilizes reports to the fullest extent in making decisions necessary to the management of his department. Much of the information necessary to arrive at sound decisions is gleaned from administrative reports that give a picture of present conditions and problems faced by the department, of the work of individual employees, and the activities of whole units dealing with these problens.

The efficient police administrator utilizes reports to determine the character, extent, location, and time of occurrence of crimes and other incidents requiring police action. With this information, he identifies police hazards, isolates the particular elements requiring attention, and directs his energies to eliminating the hazards or reducing their potency. Reports relating to traffic control aid in the determination of engineering, educational, and enforcement activities that will solve a particular trathe problem. They aid the police administrator in the distribution of manpower; and, when shifts occur in action repuiring police attention, they tell the administrator where to concentrate his striking power. I'sing reports as an accounting device and a means of analysis of operations, certain measuring sticks, standards, or comparisons may be applied in appraising police efliciency. 
Police reports aid in the fixing of responsibilities so that employees may be held accountable for performance. They register assignments, and provide a check on the accomplishment of tasks. Adequate reports provide one of the principal aids to supervising officers in the management of personnel and help them in their routine work by showing the progress of investigations and revealing deficient and improper liandling of cases. Successful prosecution of criminals often depends upon the quality of the reports submitted in an investigation, and these same reports contain a wealth of information useful in the identification and recovery of persons and property and the preservation and presentation of evidence in colurt.

As the principal medium of communication in a department, police reports tend to integrate the various branches of the agency into one coordinated unit. They are useful in keeping the public informed of police problems and accomplishments, providing property inventories and records of equipment use, fostering the financial backing and sympathetic support necessary to the accomplishment of programs, preparing the departmental budget, managing the department's fiscal affairs, and formulating plans so necessary in meeting future needs.

\section{VALUES TO OUTSIDE PERSONS AND AGENCIES}

On the other hand, the benefits derived from reports do not stop with the department. Prosecutors and the courts use them in preparing complaints and determining the specific violation that will be charged. They assist the court in determining the punishment that will fit the offender. In simple offenses some judges follow the practice of accepting the officer's report, reading it to the defendant, and passing judgment.

Most police departments also permit representatives of the newspapers to read investigation reports. Since the press will print stories in any case, it is generally desirable to save the time and energies of newsmen and police ollicers by allowing reporters to obtain facts as they are gathered by the investigating officer. In the long run, the utilization of reports in this way establishes improved public relations and eliminates highly colored statements made by individuals with personal interests at stake. 
Reports are the principal somere of information in the department's efforts to assist other agencies. Erery police department is frequently called upon to assist others. Adequate reports facilitate notification of the police in other cities conceming wanted and missing persons, lost property, stolen automobiles, and other important matters. This pooling of effort and information is a "must" in combating the modem criminal who moves rapidly from one area to another. Police reports are also useful in calling pertinent conditions to the attention of other departments and agencies. They include such items as fire hazards, violations of health rules and the building code, damaged pavements and sideralks, defective street lights, and a multitude of similar matter. These municipal departments concerned often utilize the reports of the police department when they are being sued for alleged acts of negligence. Federal security and enforcement agencies find that reports maintained in local departments are among their most valuable assets in conducting their investigations, and other govermmental agencies and private individuals find in them the answers to many of their questions when involved in surveys and other types of research.

\section{VALUES TO THE INDIVIDUAL OFFICER}

In fact, we might continue indefinitely to enumerate the benefits and uses of police reports as aids to the department, the counts, other govermmental agencies, nersmen, and private individuals. But what about you as a practicing police oflicer? Are police reports also designed to help you? Yes. If you have not discorered it previously, you will find them to be a stockpile of information. If you do your job well, you will check reports daily in the nomal conduct of your job. Reports permit an interchange of information between you and other officers which can be accomplished in no other way. They are one of your principal sources of information in conducting investigations. The alphabetical tiles of almost any department contain thousands of name cards. These cards are searched daily by officers in checking a suspect's story, locating persons for the purpose of executing warrants of arrest, obtaining the names of friends in the process of locating wanted and missing persons, and clearing crimes to which subjects have confessed 
responsibility. Reports are especially helpful in the passing of a case from one officer to another, providing the necessary continuity in an investigation when you must take over on another officer's day off; when there is a change of beat; or when, as a detective, you continue an investigation after the preliminary stages are complete. In preparing cases for court. you must rely almost entirely upon reports previously made by you or others. Reports are the only source of information for the disposition of a case; they tell you whether the subject should be prosecuted, reprimanded, or subjected to some other treatment.

In the final analysis, your own reports should be of greatest concern to you because they are colored by your personal qualities. In all probability they reveal more about you than you realize. They say something about your education, training, experience, industry, ambition, initiative, resourcefulness, and oftentimes your fears. When they are evaluated by your superiors, they reveal your capabilities and incapabilities and establish a basis for commendation or criticism.

\section{PRINCIPLES OF GOOD REPORT WRITING}

All of the above facts should prove the importance of police reports to you and to everyone who works for a police department, but the answer to the problem of reports and reporting procedures does not depend upon mere appreciation of values. The real answer lies in the quality of the end product. Quality is the result of accomplishment of basic principles; and, in this regard, all police reports from a simple, brief memo to a complex, formal, investigation report require the application of certain standards. In summary, any police report should be clear, pertinent, brief, complete, current, accurate, fair, properly classified, informative, and objective. In addition, it should be submitted in proper form and on time. These standards or principles stem from the fact that reports are written to satisfy a need, and in order to satisfy the need they must satisfy the reader. In the first place, the reviewer is likely to be a busy man. His time is precious and his calendar allows him little time for creative work or concentration. In the second place. reports are regularly read by people beyond the man 
10 whom they are addressed. When a report is 60 go beyond the section, bureatu, or division, special care must be exerciscd to inchule adequate background information and to be sure that the report is complete. In the third place, the reader is depending upon the report to make his own decisions. I'sually he must rely on the clarity, completeness, accuracy, fainess, and objectivity of a report and accept it as his own. With these facts in mind let's take a closer look at the rules.

\section{The Report Should Be Clear}

Unless your report is as simple and direct as possible, it is not likely to be accepted or used. It should inchude a clear statcment of objectives or purpose so that the reader can quickly evaluate it against this stated objective.

\section{The Report Should Be Pertinent}

Your report should deal exclusively with the stated objective or the subject or functions with which it states it is concerned. If other subjects are introduced, they should be related to the major one, and the relationship should be made clear.

\section{The Report Should Be Brief}

Although brevity is a relative matter and should depend upon the mature of your report and the use that will be made of it, it should be brief enough to be useful, but not so briel as to raise questions about its validity. Brevity is achieved by avoiding verbosity and needless repetition, unnecessary detail, and all matters not bearing on the subject under discussion. It includes the ability to make your report unified, colserent, and emphatic.

\section{The Report Should Be Complete}

Within the dimensions of the assignment or stated objective. your report must be sufficiently exhaustive so that the reader can use it with confidence. Although again this is a relative matter, completeness means reporting all the facts you have learned which have a bearing on the problem or case. Partially stated facts anc as misleading as falsehoods. They can create a false picture in the 
mind of the reviewer and canse him to make decisions which appear ridiculous in view of the complete set of facts. The reviewer will know only as much about the problem or case as your report to him. He must make a decision solely on what he has read and not on what you have in mind. You must put into the report all the pertinent and relevant information developed during the course of your investigation: leave nothing to the reviewer's imagination.

\section{The Report Should Be Current}

Unless the information in your report is up-to-date as of the time of its use, it is likely to cause umwise or eren erroneous decisions. Therefore, your report should be carefully dated, not only with respect to the time it was written, but as of the time the investigation ended. In some situations even a few hours may render the information obsolete.

\section{The Report Should Be Accurate}

Unless your report is as accurate as possible, it may be embarrassing to you, the chief, and to others. If there are errors of substance or judgment, it raises doubts with respect to your methods of investigation, the preparation of the report, or in the competence of the person or persons who evaluated it. In order to be accurate, you must conform to the truth. A report is an exart recitation of the facts obtained without any addition or subtraction. A fact is that which you know to be a fact by the use of any or all of your five senses. Any other information is hearsay; it must be given at the proper time and place in the report and labeled as such.

\section{The Report Should Be Fair}

Regardless of the type of report, fairness is essential to a good report. In some reports it may be difficult for you to be unbiased, but you must make every effort to recognize your difficulty and to eliminate its influence on your report. One way to achieve fairness is to report all of the facts. Nothing should be concealed or withhekd because it tends to weaken your case or because it doesn't fit 
your conchusion. Faimess can be achieved by kecping an open mind. Take farts as you find them. Preconceived theories, theories based on guesses, may canse you to attempt to warp, twist, contort, and even to concoct facts to fit these previous ideas. If you remember that as a report writer you are basically a fact-funcler, you will eliminate this pitlall.

\section{The Report Should Be Properly Classified}

If the substance of your report deals with secret or classified information; or, if the nature of the report is one requiring confidential treatment $n$ ntil it is released, this should be clearly stated.

\section{The Report Should Be Informative}

Your report should present the subject understandably and give proper emphasis to the matter requiring attention or action. Where appropriate or possible, altemative actions should be suggested together with the advantages and implications of each.

\section{The Report Should Be Objective}

As a rule, the tone and content of your report should be entirely free of propaganda. This should apply to the detail, to the points of emphasis, and to altemative recommendations if they are made. Even if recommendations are made in the report, they should be supported by evidence which gives them the quality of reliability. If personal opinion is included, it should be presented at the appropriate time and place and clearly labeled.

\section{The Report Should Be Written in Proper Form}

Form refers to the arrangement of the material presented, the visual shape of the document, the mechanical set-up. It relers to anything that will make your report more easily read and useful as a reference. It includes, among other things, proper paragraphing, proper indentation, proper underscoring, proper capitalization, or any device which sets out the inportant phases of the report. Form includes the proper setting forth of the various headings of the report and the pertinent material of each. It refers to the proper inclusion of exhibits. It refers to the neatness of the report, the 
spelling, abbreviations, punctuation and preciseness of expression. If your report can be read easily, if the reviewer can find without difficulty those parts in which he is primarily interested, and if the document can be used effectively for later reference, the report form is adequate.

\section{The Report Should Be Presented On Schedule}

Unless your report is made promptly and according to schedule, it may lose its effectiveness or, worse still, may arrive alter the need for it has passed. In order to take no undue risks in this matter you should plan the completion of your report ahead of the deadline. This allows for deliberate re-reading or even the adding of last minute data or events. It also allows a margin of time in which to present your report before the reviewer begins to be concerned about its being presented on time. And, if you wish to supplement your written report with an oral presentation, your opportunity to do so is enhanced if you are ahead of schedule.

\section{REWARDS FOR GOOD REPORT WRITING}

As an employee of a police department you must never lose sight of the constantly useful purpose of police reports and the standards involving in writing them. If you keep these things in mind, you will be more willing to do the hard work necessary to learn how to write good reports. As in any other job, your rewards from report writing will depend upon how well you grasp the opportunities as they continually come your way. If you are a practicing police officer, these opportunities occur each and every day. Do the best job possible in writing your routine reports. Supervisors read them; administrators often see them. You should not be surprised at the fact that opinions as to the quality of all of your work are formulated, to a great degree, by the quality of the reports that you normally submit. Reports are the best gauge of the pride you take in your work, the interest you manifest, the abilities you possess, and the knowledge you have accumulated.

When you write outstanding reports, you open the door to other opportunities. Assume, for example, that an unsatisfactory condition is causing someone in a responsible position in the de- 
partment to want to make changes. I cel's assmme, in the serent place, that your past reporting eflots have been so outstanding that this responsible person selects you to investigate and report your fundings. Assume, in the thirel place, that you fafter hard work, mial and crom, some sweat and blocel) come up with a proposal that is adopted and fomml succestul. Although these assmmptions are strictly hypothetical, you may be certain that, if these statements were fact, you would be in an enviable position to enjoy the highest respect of your superiors and to assme cren greater responsibilities in the luture.

On the other land, it is impossible to do your job as required mless you know how to wite acceptable reports. The complexity of modem police departments, the pressures of routine operations, and the way police work is donc make report writing as necessary as routine patrol and the inspection of police hazards. Because the final worth of a report depends upon its being read and understood, the demand for carefully prepared and clearly writen reports is unending. The ability to write reports will not only satisfy the needs of the department, other agencies, and individuals, but will also enable you to prove that you know something and can express it. If no other rewards were possible, the priceless feeling of satisfaction resulting from a job well done should be worth the price you pay in the process of learning. One of the better ways to achieve this satisfaction is to eliminate the mechanical defects in your reports. Part $I I$ is an effort to help you to do this. 

PART II

MECHANICS OF REPORT WRITING 



\section{Chapter III}

\section{SELECTION AND USE OF WORDS}

I

$x$ POLICE REPORT WRIMIX, WOrds are your only tools of communication. They are symbols of neaning. but unfortmately you cant be sure that the meaning you give to a word will be the same as the meaning your reader will give to it. Communication actually begins when you fund a word to express a neaning; it is not complete until your reader has understood. Cause him to understand through the use of an adequate vocabulary and the sclection of the right words to carry your ideas to him.

\section{VOCABULARY}

Your vocabulary is the supply of words which you possess for use in writing. This supply consists only of those words which you can use effectively. Your vocabulary grows in proportion to the demands made upon it. Any officer who can get along in his rork with a few hundred words is not likely to leam more. Memorizing ten new words a day does no good, muless there is occasion to use the new words. On the other hand, any actire police oflicer writes reports each and every day; report writing offers an excellent opportunity to use a vocabulary. Ordinarily, new words or new meanings for familiar words are first encountered in reading. Thus extensive reading of literature in the police field is recommended. One of the best ways to improve your vocabulary is to cultivate the habit of accurate reading, trying to see exactly why an author uses a particular word.

Along with careful reading, learn how to use the dictionary and then use it. A dictionary is very carefully edited, and every symbol, abbreviation, or change of type means something. The signs are explained in the introductory section, and you need to be familiar with those in the dictionary that you most often consult. A good dictionary contains a great deal of useful information 
besides definitions. You will find the pronunciation, spelling of comparative and superlative forms, and the etymology of words. If you hecome thoroughly interested in a word and learn about it, this word probably will become a part of your vocabulary.

In your report miting, you must develop the habit of looking for the exact word that expresses your meaning, rather than writing the first word that comes to your mind. Instead of writing that the attitude of the witness was uncooperative, try to find a word that indicates more precisely the grounds for your disapproval. Accurately discriminating the meaning of the words you write will increase your vocabulary and make possible a more precise expression of your ideas in reports.

\section{DICTION}

Sour choice of words, or diction, can be the source of great difficulty between you and your reader. What can you do to prerent misunderstanding?

\section{Define Your Audience}

When you sit down to write a report, one of the first thoughts that should come into your mind is: Who will read what I write? Remember that you are writing for real people in the police department, probation department, district at torney's office, or maybe for the gencral public. As a general rule, material written for the chiel of police or the district attorney is not suitable for the patrolman with lesser experience or academic background; on the other hand, the fact that your reader may have a college degree should not encomage you to force difficult witten materials on him. Yon reports can be simple enough to be read with ease by a poor reader and yet be interesting enough to hold the attention of a good reader. Define your audience and keep your writing at a level that they will understand.

\section{Adjust Your Words to An Appropriate Reading Level}

Much of your reader's ability to understand what you write depends upon his education and experience. General surveys of the formal educational level of personnel in police departments 
reveal that a majority of policemen, supervisors, and atministat tive persomnel have completed high scheol traning.

What does this mean to you as a repont writer in a police department? Simply this. If you wam your reponts to be combortalsly muderstood by most readers, adjust the reading level at least two grades below the educational level of the majority who are to be reached. Police persomel represent the arerage reading public. and surveys have also revealed that widely populan reading material goes no higher than the temh grade. Why: Because people can combortably molerstand material up to the tenth grade level; only a relatively small portion of the population feels at cane with more dillicult reading. Forced to read material above the triellthgrade level, your reader finds it increasingly diflicult to understand. When you give him easy reading, he gets the meanimg you intend. He never says that reading is too clear. He may, however. say that your ideas are too simple, but that is another matter.

You may feel that these rules are oversimplified - that they ignore the large number of people in the department who have gone beyond the twelfth grade and who should, therefore. be able to read and master difficult reading materials. You are on the defensive, though, for your reader, no matter what his education and experience, will be grateful for easy reading. Why make him work harder than necessary just because you can do the task? State your ideas simply by the use of words that your reader readily understands. Reports in a police department, for patrolman or chief. should not get in the way of the work to be done.

Read your daily newspaper. Reader's Digest, or Time. Notice the level of reading material presented. The publishers of these periodicals know the reading level of the average reader and keep their publication at that level. This should he a good guide for gou in establishing a reading level for your reports.

\section{Use Words That Are Specific. Concrete, and Definite}

I ragne statement is not only dull and mmimpressive. but almost empty of meaning. Ceneral statements and abstract words have their uses, but most people orerdo them in the hope of somnd- 
ing impressive or of concealing their ignorance. Use concrete terms like ran, limped, or crawled instead of a general term like proceeded or a colorless word like went. You are supposed to know exactly what you mean; if you don't, vague general terms will not help you and probably will convey the wrong idea to your reader.

Abstract words are difficult to understand because they do not represent experiences which your reader can mentally see, feel, hear, touch, or smell. Concrete words, on the other hand, are more likely to have meaning because they are related to the five senses. They deal directly with experiences common to both you and your reader. If you want to get your idea across to your reader, use concrete words. Abstract words increase difficulty; concrete words improve readability.

\section{Be Concise}

Unnecessary words dihute your writing. They will often suggest that you do not know, or do not care about, what you are saying; for beating around the bush is a common trick of writers who are trying to cover up a lack of real content. If what you have to say is worth saying, it should be concentrated and emphatic.

Conciseness is not the same as brevity. It is relatively easy to be brief; you just leave out details and say less. Conciseness, on the other hand, means saying the same thing in fewer words. It is not always a virtue to be brief, for the details are often necessary. But it is always good practice to be concise.

Wordiness is often caused by the bad habit of restoring to ready-made phrases and sentence patterns. Many people can't write dark without adding the adjective pitch. You should eliminate stilted and automatic phrasing and wordiness when you proofread your report. First drafts should be carefully edited and revised to eliminate wordiness.

V'ery often a single word will do the work of a whole mouthful of words - and do it better. A single little word, for example, may take the place of a group of words, like these:

of the order of magnitude of .......... about

for the purpose of $\ldots \ldots \ldots \ldots \ldots \ldots \ldots$ for

in the nature of $\ldots \ldots \ldots \ldots \ldots \ldots$ like

along the lines of $\ldots \ldots \ldots \ldots \ldots \ldots$ like 


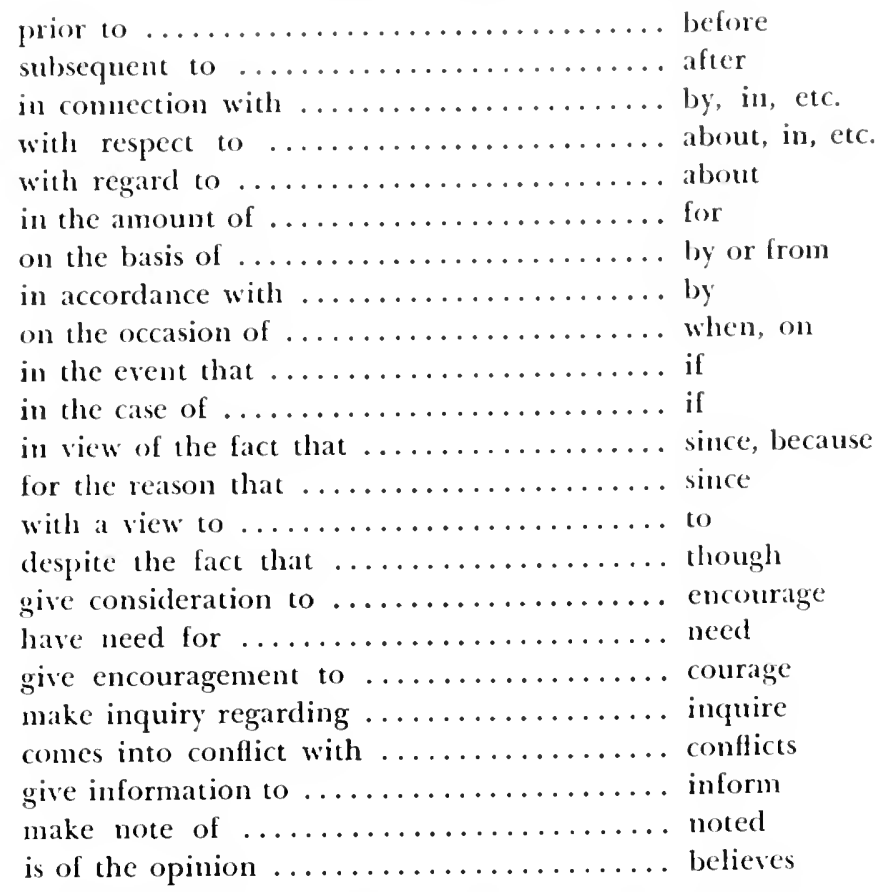

Sometimes you can make a word or two do the work of a whole clause, like this:

information which is of a confidential nature . . confidential information

\section{Avoid the Use of Unnecessary Legal Terms}

All police operations are based on laws; it is not strange that many legal terms are used in police reports. Some of these are necessary. However, too many of them impart an undesirable legalistic flavor. Let's "ditch" the umnecessary legal phrases. In addition to sounding legalistic, they are stuffy; and some are hard to understand.

For this

Substitute this

in lieu of in place of

the other party the other person

interrogated the witness asked the witness

such statement this statement

said informant the informant

hold in abeyance wait, postpone action the subject typewriter this typewriter 
Let's completely eliminate hereath, hereto, herein, hereby, thereof, therein, thereon, and the aforesaid.

\section{Avoid Technical Words}

Like legal terms, technical language can be very accurate and useful. But when your reader doesn't have a technical background these words can be very discouraging to him, Don't use fine distinctions in words when these distinctions are not needed. Some writers often spend time quibbling about technical niceties which have no real meaning for the reader. When you must use technical words, and you think that your reader will not understand them, explain them.

\section{Avoid the Use of Elaborate Words}

Probably one of the better ways to suffer criticism in police reporting is to become addicted to fancy, overformal, psendotechnical language. In this kind of report, the officer never "does" anything; he always "performs" it. Nor does he "begin" an investigation; he "initiates" or "inaugurates" it. Then he doesn't merely "end" it; he "terminates" or "consummates" it. "Phony" formality will drive you to substitute stuffy words for plain ones: "secure" for "get," "utilize" for "use," "effectuate" for "carry out," ascertain" for "learn," or "subsequent to" for "after." A determined effort to keep your reports free of unnecessary elegant and stilted language will pay. This kind of language is harder for anyone to understand. It takes longer to read and raises roadblocks against communication. Choose the simplest word that clearly carries your meaning, for simplicity is the essence of dignity and strength.

\section{Aroid Bookish Words}

Words or phrases may also be described as bookish or plain. Although it is not suggested that you eliminate bookish words from your vocabulary, they are words that appeal to but few readers; plain ones reach everybody.

For this Substitute this

Accordingly, consequently ........... And so

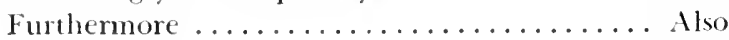

Hence, thus $\ldots \ldots \ldots \ldots \ldots \ldots \ldots$ Therefore 
Likewise $\ldots \ldots \ldots \ldots \ldots \ldots \ldots \ldots \ldots \ldots$. nnd

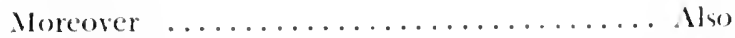

Nevertheless .................. But

That is to say ................. In other words

To be sure $\ldots \ldots \ldots \ldots \ldots \ldots \ldots \ldots$ of course

Converely ..................... () the other hand

\section{Avoid Trite Words}

Words or phrases may also be labeled as trite or fresh. Trite words or phrases are those that have been so overworked that they have become stale and common; fresh ones, although in ordinary use, attract your reader because of their simplicity.

\section{Trite}

Instead of this

Ifford an oppor

Are desirous of ................ Want to

Experience has indicated that .......... We leamed

In a mamer similar to ............. Like

It is recommended that consideration

be given to ................. We recommend that

In at situation which ............. When

Makes provisions for .............. Does

Takes appropriate measure ............ Acts, does

The fullest possible extent .......... The most

This department is cognizant of ......... We know

With due regard for $\ldots \ldots \ldots \ldots \ldots \ldots \ldots$ for

\section{Avoid Scatterbrain Words}

More troublesome even that useless words are "scatterbrain" words. This kind of word scatters its meaning over a wide area. It can mean so many different things that a reader must figure out what idea it is supposed to have. Many times he can't tell.

Here is an excerpt from a technical police report. Italics show the scatterbrain words:

The policy of the police department with respect to the men during off-duty hours is that they should be used in a ratio to on-duty men in a proportionate amount to be predicated on the extent of the emergency.

A reader can figure out what the italicized words mean if he thinks a bit. The trouble is that these words don't focus on the 
subject matter. The message that the words sought to communicate was fairly simple. It could have been stated as follows:

The police department may need to use off-duty men during emergencies, but these men should be used as sparingly as possible.

\section{Avoid Smothered Verbs}

To communicate knowledge, you must communicate ideas and relationships between ideas. A verb is a relation-showing word. A smothered verb, then, is one that is kept from clearly showing a relationship. A verb is smothered when it is buried inside another word. Some smothered verbs are italicized in the following sentence:

It has been pointed out that, in the police department, careful initial selection and classification are important procedures in eliminating potential maladjusted personnel.

Each of the italicized verbs, because it is buried in another word, has lost its power to state a clear relationship. You can restore the power of the verb by linking an idea to it. For example, the first smothered verb in the sentence quoted is select, buried in selection. It prompts the question: Who selects what? To answer that question, create this thought: The police department selects people. Through the same type of reasoning you can either restore the other verbs in the sentence or eliminate them completely. Your revised sentence might read like this:

As has been said, if the police department selects and classifies persomnel carefully at the outset, it will have fewer maladjusted people.

\section{Use the Level of Diction Appropriate to the Situation}

Certain words are appropriate in formal or literary writing. Police reports are informal by nature. Do not use literary terminology. On the other hand, colloquial terms, popular slang, and vulgar words should not be used unless in direct quotation. For the most part the informal English of the educated is appropriate; use other forms only when you must.

\section{Use Proper Grammar}

Some of the more common errors in diction result from lack of understanding of grammar. Don't be guilty of grammatical errors. Follow these rules. 
Don't substitute an adjective for an adrerbial construction.

Hrong: The suspect was real surprised when lie saw us.

Right: The supect was really suppried when he saw us.

Hiong: The conclition of the victim was some inproved.

Right: The condition of the viotim was somewhat improved.

Note: After verbs of the senses (look, somud, smell, taste, feel), following be.se'm, appear, an adjective is used mnless the verb expresses action.

The witness looked angry. (adjective)

The witness looked at us angrily. (adverb)

Don't split your infmitives.

Wrong: Ile agreed to readily go with us. (split infunitive)

Right: He reallily agreed to go with us.

Don't substitute a preposition for a conjunction.

Wrong: The investigation report is not acceptable without the officer signs it.

Right: The investigation report is not acceptable unless the offucer signs it.

Wrong: The victim was fond of athletics like other boys are.

Right: The victim was fond of athletics as other boys are.

Don't use an adverb for a noun clause or phrase.

Wrong: The reason the witness was there was because he was asked to remain.

Right: The reason the winess was there was that he was asked to remain.

Don't use a pronoun that cloes not agree in number with the nomn to which it refers.

Hrong: There may be many types of patrol in a single police department, but its principles of organization will be the same.

Right: There may be many types of patrol in a single police department, but their principles of organiation will be the sime.

Aroid double negatives. Negatives are not to be used with hardly, scarcely, omly, and but when these words are used in the same sense as only.

Wrong: The victim states that she hasn't no place to go.

Right: The victim states that she has no place to go.

lliong: The lour of us couldn't hardly pull the victim from the river.

Right: The four of us could hardly pull the victim from the river.

Wrong: There arasn't but one place to look.

Right: There a'res but one place to look. 
Aroid unnecessary repetition. Repetition for emphasis is sometimes uschul, but repetition often serves no purpose. This is true of the words in parentheses.

This will enable an officer to conduct arrests more effectively (than if he waits until at later date).

The survey is nearly complete (at the present time).

The situation calls for quick (and expeditious) action.

The (hief of police is authorized to (do and) perform the following (designated) duties (and functions).

\section{A FINAL SUGGESTION ABOUT WORDS}

Now, if you really want to do something about words, proofread each report that you submit. Follow the suggestions as presented in this mantual. On a long-term basis, follow some suggestions by sammyers. They will aid you in the selection of words and in increasing your rocabulary.

1. Equip yourself with the following books:

Jebster's New Collegiate Dictionary, G. \&. C. Merriam Co.

Fernald's English Synonyms and Antonyms, Funk and Wagnalls Company.

Roget's Thesaurus of English Jords and Phrases, Garden City Publishing Company.

Opdycke's Get It Right, Funk and Wagnalls Company.

2. Every day select from your reading or from what you hear two words to be looked up in the dictionary, in the thesaurus, and in the book of synonyms.

3. Say the words aloud until you know their correct pronunciation.

4. Use the words in a written statement about something that interrests you.

5. Tell a friend or working partner about the two words.

6. Occasionally select two words you have been using for a long time. Look them up. lou will be surprised to know how many of them have useful hidden meanings-meanings that will serve you when you must find words to make your ideas clear to certain groups or pasticular readers.

Words are the expression of your thoughts. Get as many of them as you can; they will help you to make your thoughts clear to others. know your words so that you can be friendly with them and not fight them. They are not slaves they are friends. ${ }^{1}$

\footnotetext{
${ }^{1}$ celbs S. Santmycrs: Practical Report Writing. Scranton: Laurel Publishers, 1950, p. 16.
} 


\section{Chapter IV}

\section{SPELLING}

$\mathbf{P}$

ROBABLY THE BeST EVIDFyCF of ignorance and laziness in police report writing is poor spelling. There is no legitinate excuse for it because every word in a report can be spelled correctly without taxing the mentality of the writer. People are not born knowing how to spell, nor has ability to spell much to do with intelligence. It is almost entirely a matter of habit; therefore, poor spellers need not be disconraged. If you are a poor speller, a reasonable anomnt of persistent practice will make a satisfactory speller out of you.

It is not necessary to learn all of the more than 600,000 words that are in the dictionary. Actual smreys indicate that a lew hundred words cause most of the trouble. Really difficult words are seldom misspelled. You can always look them up. The words that cause trouble are everyday words like receive and occured, which are used so frequently that no one goes to the bother to look them up.

\section{HOW TO LEARN TO SPELL PROPERLY}

Every squadroom should have a good dictionary as permanent epuipment. If the police agency does not fumish one, you and others should pool a few cents each and buy one.

Another very valuable book to any report witer is a publication by the Gregg Publishing Division of McGraw-Hill Company. This book, 20.000 Wrords, is so small that you can hold it in the palm of your hand. Twenty thousand words are spelled, divided, and accented. Its value rests in the saving of time in looking for words. The book is based upon the very truthful assumption that, in nine cases ont of ten, when you go to the dictionary it is to find how to spell a word or how to divide it at the end of a line. Much space has been saved by the elimination of short, easy words that present no spelling problem and others that are seldom used. Restricting the list to the words actually needed makes the rords 
that you need much more easily found. You can find the word you need in this book in a few seconds.

After writing a report, check the entire rough draft for misspelled words. Look up all words that seem to be misspelled.

If you are a poor speller, practice constantly in trying to inprove your spelling. Form a habit of looking at words letter by letter. Most people read without seeing individual letters at all, so that ordinary reading will not suffice. Spell the words out, a letter at a time; say them out loud; write the letters as you say them. A word of caution, use this technique only with the idea of improving your spelling; it won't improve your reading speed or comprehension.

In reading words letter for letter you will discover certain danger spots. You will find that a single vowel in the word or a combination of two letters is the danger spot. Locate these danger spots and concentrate on them.

By concentration on the word you may be able to spell many words of which you have had some doubts. Words of more than one syllable are made up of a stem word and a prefix or suffix. The word disappoint is made up of the verb appoint and the prefix dis. Spell the word appoint, add the prefix dis, and you have spelled your troublesome word correctly. Become familiar with the common prefixes and suffixes; they will prove very helpful in your spelling.

A list of several hundred words is included in the pages which follow. These are the words commonly misspelled by most police report writers. Learn how to spell all of them.

Finally, some common words can be spelled by rule. The rules are presented also. However, you should be cautioned that spelling rules may give you trouble rather than help you. If you use a rule, be sure that you know what the rule is and where it applies. Learn the rules and experiment; see if they help. If they help you, use them; if they do not, pay no attention to them.

\section{THE SPELLING RULES}

\section{Consonants and Vowels}

All words are made of consonants or vowels or a combination of them. The vorels are $a, e, i, o, u$, and sometimes $w$ and $y$. All other letters of the alphabet are consonants. 


\section{Basic Spelling Rules}

Words of one syllable and words of nore than one syllable accented on the last syllable and ending in a single consonant preceded by a single vowel-double the final consonant before adding a suflix beginning with a rowel.

The word run is a single syllable word ending in a consonant, $n$. The consonant is preceded by a single vowel, $u$. Thus, when something is added to the end of the word (a suffix) double the final consonant, n....

The suspect was seen ruming from the scene.

bag baggage hot hottest fun funny

The word occur has two syllables. The accent is on the last syllable, cur. Thus, the above rule also applies. occur occurred preter preferred

NOTE: If the accent shifts when the suffix is added, the consonant is not cloubled.

For example, the accent shifts in the word prefer when the suffix ence is added. Thus the resulting word is spelled preference.

Words ending in a silent $e$ usually drop the $e$ before adding a suffix beginning with a vowel, but retain the $e$ before a suffix beginning with a consonant.

For example, the word hope ends in a silent $e$. The final $e$ is dropped before adding the suffix ing. Thus, we have hoping.

On the other hand, the $e$ is retained when the suffix ful is added because the suffix begins in a consonant. Thus, the resulting word is spelled hopeful.

Exceptions: Words ending in ce and ge retain the $e$ belore suffixes beginning with $a$ or $o$, such as able and ous. The final $e$ is also retained to prevent mispronunciation or confusion in meaning.

Examples: courage courageous peace peaceable singe singe singeing (not to be confused with singing)

Words ending in y preceded by a consonant change $y$, to $i$ when adding a suffix beginning with a vowel. On the other hand, the final $y$ is retained when the suffix begins with $i$.

For example, the word fry ends in $y$. The $y$ changes to $i$ when the suffix ed is added. (fried) study studied

The word study ends in $y$ and the final $y$ is retained when the suffix ing is added. (studying) 
Words with the ei or ie combination nsually have $i$ before $e$ except after $c$ or when someded as $a$. A final $i e$ is changed to $y$ when the suffix begins with $i$.

The word believe offers a good example of the first part of the rule.

In the word receize the $e i$ or ic combination is preceded by $c$; thus, the $e i$ combination is used.

In the word die the ie is changed to $y$ before a syllable beginning with $i$, Thus, we have dying.

Exceptions may be found in such words as neither, foreigner, financier, seize, forfeit, their, weird, heights, and leisure.

A word ending in $y$ preceded by a consonant forms its plural by changing $y$ to $i$ and adding es.

The word baby ends in $y$. The $y$ is preceded by $b$ a consonant. Thus, the plural of baby is spelled babies.

lady ladies ally allies

A noun ending in y preceded by a vowel forms its plural by ad$\operatorname{ding} s$.

The word zalley ends in $y$. The $y$ is preceded by the rowel $e$. Thus,

the plural of zalley is spelled valleys.

Proper names ending in $y$ do not change $y$ to $i$ even thongh preceded by a consonant.

$$
\text { Murphy Mfurphys Mary Marys }
$$

A word ending in $o$ preceded by a vowel forms its phural by ad$\operatorname{ding} s$.

$$
\text { folio folios radio radios }
$$

A word ending in o preceded by a consonant usually forms its plural by adding es.

$$
\text { cargo cargoes tomato tomatoes potato potatoes }
$$

Some exceptions include murical terms such as alto, solo, etc.

Most words ending in $f$ or fe form their plurals by changing $f$ or fe to $y$ and adding es.

$$
\begin{aligned}
& \text { thicf thieves knife knives self selves } \\
& \text { leat leaves wife wives life lives }
\end{aligned}
$$

Words ending in ful form their plurats by adding $s$. barrelful barrelfuls cupful cupfuls 
Componmel words lom their pluals by addings to the principal word.

\author{
son-in-latw soms-in-latw \\ sep-father sep-lathors \\ colitor-in-chied editors-in-dief
}

Words derived from a loreign language usually retain their loreign plumal fomms. Sometimes two lomms are permissible.

us changes 10 i almmums almmi

a changes to ac alumna alummae

am rlanges to a memoramchm memoranda cumiculum curricula

on changes to a phenomenom phenomena criterion criteria

\title{
WORIS MOST COMMONLY MISSPLLED IN POLICE REPORTS'
}

A

alsosb

abduction

absurd

accept

accessories

accident

accommodate

accompaniment

accumulate

accurate

accustom

ache

achievement

acknowledgment

acquaintance

acquainted

acquitted

across

additional

adjust

achmission

adultery

advantagcous advertisentent

advice

advise

affidavit

affirmative

aggravate

again

aiplane

aisle

alcohol

alimony

allotment

all right

alternative

although

altogether

always

amateur

ambitious

among

amputation

ammosement

analye

analysis immiversary

announce

antmal

atmmulment

answer

antique

anxiety

anxious

apologize

apparatus

apponel

apparent

appeasance

application

appreciation

appropriate

arson

arrangement

artificial

assembly

assistance

associate

assortment

alletics

${ }^{1}$ Leam this list of words, ten words at a lime. (once you have mastered them, the atuhor belieres that most of your spelling problems in police reponts will be alt an end. 


\begin{tabular}{|c|c|c|}
\hline attendance & cereal & cough \\
\hline attribute & character & could \\
\hline authentic & cliauffeur & counterfeit \\
\hline atuthoritative & choose & country \\
\hline atutomatic & circle & coupon \\
\hline atuxiliary & circumference & courteous \\
\hline awkward & circumstance & creditor \\
\hline & citisen & criminal \\
\hline $\mathbf{B}$ & coercion & criticism \\
\hline bacteria & coincide & customary \\
\hline ballot & collar & cylinder \\
\hline bandage & collision & \\
\hline beginning & colonel & $\mathbf{D}$ \\
\hline behavior & color & deceased \\
\hline benefited & column & deceptive \\
\hline bequeath & coming & decision \\
\hline bicycle & commercial & defensive \\
\hline bigamy & commission & definition \\
\hline blackmail & committee & delegate \\
\hline bookkeeping & committed & demonstration \\
\hline bouquet & committing & dependent \\
\hline breadth & community & descendant \\
\hline brevity & competition & description \\
\hline brief & complainant & desperate \\
\hline built & complexion & device \\
\hline bulletin & compulsory & diagonal \\
\hline buoyance & conscience & diaphragm \\
\hline burglary & conscientious & different \\
\hline business & conscious & dilapidated \\
\hline C & conspicuous & disappear \\
\hline calendar & conspiracy & disappoint \\
\hline calmpaign & construction & disastrous \\
\hline candiclate & contagious & discipline \\
\hline carrying & continue & discrepancy \\
\hline cashier & convenience & dispatched \\
\hline casualty & conviction & disperse \\
\hline casualties & cooperate & disposition \\
\hline catastrophe & corporation & clisease \\
\hline ceiling & corps & dissatisly \\
\hline cemetery & corpse & dissipation \\
\hline censor & correspondence & (iistinction \\
\hline
\end{tabular}




\begin{tabular}{|c|c|c|}
\hline divicle & Februar! & Lumuiliate \\
\hline derent & leminime & \\
\hline drunkenness & tibers & I \\
\hline & ficlitious & irleal \\
\hline $\mathbf{E}$ & finall! & ignorance \\
\hline carly & linancial & illiterate \\
\hline can! & lorcible & immeringy \\
\hline cight & formula & imagmation \\
\hline electricity & forty & immediately \\
\hline eligible & fourteen & imminent \\
\hline eliminate & framdulent & inpouticut \\
\hline embarrass & friend & imperfect \\
\hline emberlement & fulfill & implement \\
\hline chuergency & furniture & impromptur \\
\hline employment & & impression \\
\hline enemy & G & inadequate \\
\hline cnough & gambling & inaugurate \\
\hline cuthusiasm & gange & incessantly \\
\hline enviroment & genuine & inciclentally \\
\hline equipment & govermment & incomparable \\
\hline cquivalent & gratification & incorrigible \\
\hline erpecially & grievance & incredible \\
\hline etc. & guarantee & indecent \\
\hline every & guard & inclefinite \\
\hline evidence & guessed & independent \\
\hline exiggerate & guest & indicate \\
\hline except & guidance & indict \\
\hline exercise & gymmasium & inclifferent \\
\hline excuse & & inclividual \\
\hline existence & $\mathbf{H}$ & inevitable \\
\hline experience & half & infamous \\
\hline explanation & handkerchief & informant \\
\hline expression & hatughty & ingenious \\
\hline extortion & hazard & ingredient \\
\hline & lleight & initial \\
\hline $\mathbf{F}$ & hereditary & imitation \\
\hline labric & hicleous & inoculate \\
\hline lacilitate & loliday & inquiry" \\
\hline familiar & homicide & inquisitive \\
\hline fascinating & horizontal & inscribe \\
\hline latucet & litmane & inscription \\
\hline
\end{tabular}




\section{insensible \\ insinuate \\ instead \\ instinct \\ insurance \\ intellectual \\ intelligent \\ intercept \\ intersect \\ interrogate \\ interrogative \\ interview \\ intimidation \\ intoxication \\ invasion \\ investigation \\ irresistible \\ irrigate \\ isolate \\ J \\ jealous \\ juclgment \\ juvenile}

K

kllaki

know

knowledge

L

label

laboratory

larceny

later

latter

leclger

legal

legion

leisure lenient

lenguh

liable

liabilities

library

license

lieutenant

lightning

jikely

loncliness

loose

lose

M

maintain

maintenance

magacine

majority

malicious

management

maneuver

manual

natly

margin

marriage

masculine

maturity

meant

meclal

medical

meditate

memorize

microphone

mileage

miniature

minority

minute

miscellaneous

mischievous

misspell nuolemize

monotonous

morale

nomountainous

murmur

muscle

museum

\section{O}

obligation

obscure

obstacle

occasion

occupant

occurrence

occurred

odor

offense

offensive

official

often

omission

once

opinion

opponent

opportunity

opposite

optimism

orchestra

outrageous

overrun

$P$

painful

pamphlet

paragraph

parallel

parenthesis

partial

participate 


\begin{tabular}{|c|c|c|}
\hline yastemise & privilege & reeluece \\
\hline pustime & proseclure & reterence \\
\hline paltience & progress & reluse \\
\hline perlentrain & pronoumce & relutible \\
\hline penalise & promunciation & relecarsal \\
\hline pertorm & proplecy & religious \\
\hline perhalps & proposition & remedial \\
\hline peril & prosecute & renembrance \\
\hline perimeter & prostitution & remittance \\
\hline persecule & psichology & repealt \\
\hline permissible & publicity & repetition \\
\hline persererance & pulse & resintance \\
\hline perional & pursuit & resolution \\
\hline personnel & $Q$ & hhthm \\
\hline presistent. & guarint & ricliculous \\
\hline perspiration & quality & rigicl \\
\hline persuade & quers & robbery \\
\hline $\begin{array}{l}\text { perversion } \\
\text { phisical }\end{array}$ & questionmaire & $\mathrm{S}$ \\
\hline phy sician & quiet & sibotige \\
\hline picniching & quinine & sacrifice \\
\hline polygamy & quite & salary \\
\hline pleasant & quotient & salute \\
\hline premonomia & $\mathbf{R}$ & satisfactory \\
\hline pousers. & racial & Saturlay \\
\hline ponession & raid & schedule \\
\hline posture & raise & schene \\
\hline practical & ratio & scarcel! \\
\hline practice & ration & scenc \\
\hline precise & reaclily & science \\
\hline prediction & realize & scissors \\
\hline prealicament & really & scout \\
\hline preterable & receile & seretars \\
\hline prejuclice & receipt & serluction \\
\hline peliminary & receive & seice \\
\hline premines & recupe & sentence \\
\hline prepanation & recognise & separations \\
\hline prescription & recolleel & vergeant \\
\hline presence & recommend & several \\
\hline prevalent & recreation & shewel \\
\hline
\end{tabular}


slriek

sieve

signature

similar

since

sincerely

singular

sophisticated

species

specimen

statement

statistics

statue

stalute

strictly

stomach

strangulation

strategy

subject

subpoena

subtle

succeed

successful

sulfocation

sugar

superintendent

supersede

suite

summons

surely

suspect

surprise

surrender

susceptible

suspicion

sympathy

$\mathbf{T}$

technique

telpplone temperamental

temperance

temperature

testimony

theater

thermometer

thorough

thought

throat

thieves

together

tongue

tonight

tournament

traffic

tragedy

tragic

tranquil

translation

transpose

treacherous

treasurer

trespassing

trouble

truancy

truly

Tuesday

typewriter

typical

U

umbrella

umpire

unanimous

undoubtedly

milon

until

urgent

usually

utensil utlilty

V

vacancy

vacuum

vagrancy

validity

valley

vanquish

variety

vegetable

vehicle

velocity

vengeance

verbal

vermin

version

vertebra

vertex

vertical

victim

victory

village

violin

visible

vitamin

vivid

volumn

volunteer

W

warehouse

warrant

wealth

weather

IIednesday

weiglity

reird

welfare

wholly 
wiry

women

wrestle

I

$x$ ray, $n$.

x-ray, adj., v.

xylophoue
I

vacht

yawn

veast

vearn

vield

young
Z

cal

calous

/(ro)

/est

riglag

inc

\section{HOMONYMS}

Hononyms are simple words; those in use by all people each and every day. They are words having the same, or nearly the same, pronunciation; but they differ from each other in origin, meaning, and spelling. An error in the use of such words is an error in spelling. Study the following list carefully; misuse of such words is common in police reports.

\section{List of Homonyms}

\section{A}

accede

exceed

accept

except

access

excess

aisle

isle

altar

alter

ascent

assent

aught

ought

\section{B}

bale

bail

bare

bear
To comply with.

To surpass.

To take. receive.

To exclucle.

Admillance, admission.

Surplus.

A passagewal between rows of seats.

An island.

A place of worship.

To change.

fot of rising: motion upward.

Consent.

Anything: slightest thing.

Should: is obligated.

I bundle or package of goods; to make into bale or bales.

loset tree or liberate from arrest on sceurity.

Naked: mnconcealed; simple; unfurnished.

Plantigrade carnivorous mammal. 
basis

bisses

been

bin

bertls

birth

boarder

border

born

borne

bough

bow

brake

break

brickal

bridle

buy

by

bye

C

calendar

calender

callvas

canvas

cappital capitol

cole

sceet

cell

sell
A gromudwork or fundamental principle ol anything.

The plural of base; the parts of things on which they rest.

A part of the verb "to be."

Receptarle for any commodity.

A sleeping place on a ship or railway car; situation.

The ate of coming into life; lineage: desent; origin.

One who is furnished with food, for a compensation.

The outer part or edge of anything.

Lnnate; inherited.

Pant participle of verb "to bear."

Portion of a tree.

The forepart of a ship: a weapon for discharging arrows.

A mechanical device for checking the motion of a rehicle.

To separate; interrupt; fracture; violate.

1 marriage.

The head-stall by which a horse is controlled; a restraint.

To purchase.

I preposition.

Aside: in reference to position, direction of purpose.

Bereord of time.

Finishing machine used in the nanufacture ol paper. cloth.

A strong cloth.

To solicit thoroughly: to scrutinize.

Mones invested; seat of government.

Government building.

To grant; give up.

That from which plant life grows.

I mall room in a prison; a small cavity.

rhe ate of selling. 


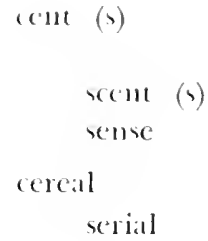

counsel

currant

current

\section{D}

dear

deer

deference

difference

descent

decent

dissent
1-100 ol a dollats: at (oin or coims of this 1.11110

(odor on edore lele by persom or amimal. somul perception and reasoming.

III gralis lool.

Arangerl in a series: appearing in successice momblers.

1 yicleling 11$]$, a of territory, property or riglus.

I mecting of a group.

1 group of singers.

Irenti-four sleects of paper.

I strims of a musical instrument: notes in himmoms.

I string: a measme of wood.

Summon to appear in comrt: to quote.

The act of secing; perception.

Local positum: gromel plot.

Rough. large.

Dircetion: part of a dinner, action taken, i subject in school.

lhat which fills or completes.

Tis comgratulate.

Letters.

Letter and newspaper witers.

In ascmble ol men or wiment smmmoned for deliberation.

In attorne?: alvice.

I small fruit.

Tide: electricits: belonging to the present.

Lenedi: precious: costly.

A name for ruminants the male of which hate bameled horns.

Respect: comtesy: regard for others wishes. Coulikeness.

Going down: coming down.

Propes: right: suitable.

Diflerence ol opinion; disagreenent. 
desert

dessert

dew

due

done

ton

dun

dual

duel

dye

die

dyeing

dying

\section{F}

fair

fare

feat

feet

forth

fourth

G

gamble

gambol

grate

great

\section{H}

hail

Irale

liall

haul

lieal

heel

liear

here
To forsake: abandon.

1 course of fruit, sweets, etc.

Moisture in little drops.

Owed or owing; payable; proper; tribute or fee.

A part of the verb "to do;" completed; cooked sulficiently.

To take on; invest with.

A dull brown color; an urgent request for payment of a debt.

Expressing or composed of the number two.

A combat between two persons with deadly weapons.

To change the color.

To cease to live; finish.

The act of changing color.

At the point of death; about to die.

Beautiful: blond; just.

Cost of travel.

Notable achievement or performance.

Parts of the human body.

Onward in time, place, or order; forward.

One of four equal parts.

Play for money; to squander.

Dance or skip about; frolic.

A trame of iron bars holding the fuel in a furnace: to produce a harsh sound; to reduce to small particles by rubbing.

Eminent; foremost; large: many.

Froren raindrops; a call or salutation.

Healthy: hearty.

A large room; a passageway.

To pull or draw; a single catch.

To restore to health: remedy.

The batck part of the human foot.

To perceise by the ear; to listen to.

This place. 
heard

herd

heir

air

hoar

whore

hoard

horde

hoarse

horse

hole

whole

hour

our

I

incite

insight

indict

inclite

instance

instints

its

it's

\section{K}

knew

new

\section{L}

lead

led

leased

least

lessen

lesson

load

lode
P'ant tense of the rerb "to hear."

1 collection of sheep or cattle; crowd.

One who succeets another in possession of property.

The mixture of gases which we breathe; the atmospliere.

White: ancicnt.

A prostitute.

A treasurer laid up secretly.

$A$ vast multitude: a large crowd.

Rough and harsh in sound.

I hoofed animal used for riding or drawing burdens.

A carity: hollow place: a difficulty or dilemma.

All of anything.

A measure of time; sixty minutes.

I possessive pronoun.

To cause trouble, uprising.

An inner knowledge; understanding.

To charge with an offense.

To compose and write (a document).

Example; case; illustration.

Particular moments of time.

A posensive pronoun.

Contraction of "it is."

P'ast tense of the verb "to know."

Recent in origin: modern: fresh.

A metal.

Guided. pant tense of the verb "to lead."

Past tense of verb "to lease."

The mallest of two or more things.

To make smaller.

That which a pupil learns: exercise.

To lay a burden on or in.

I vein of ore. 
loan

lone

\section{II}

manner

1) $1110 \mathrm{r}$

mantel

mantle

ninctal

mettle

miner

minor

$\mathbf{N}$

none

nun

\section{O}

ordinance

ordnance

\section{P}

pain

pane

pair

pare

pear

pitssed

past

patience

patients

peace

piece

plinin

plane

pore

pour

preceelence

precedents
That which one lends or borrows.

Solitary.

Method: habit; custom: aspect.

I district: a district over which a feudal lord held authority.

I narrow ormamental blab over a fircplace.

$\therefore$ loose cloak or cape; a sheath.

I harcl substance having certain physical characteristics.

Spirit: fortitude; temperament.

An underground worker in a mine.

Under full age of majority; less.

Not any.

A lemale desoted to a religious life and sechusion.

I local law enacted by a municipal govemment.

Arms; munitions.

Plinsical or mental suffering.

1 winclow glass.

Two things of a kind.

To cut away little by little; reduce.

1 fleshy, edible fruit.

Past tense of the verb "to pass;" went by: Having been; gone by; completed.

The quality of being patient.

Thone who sulter pain: persons under medi(al) treatment.

State of rest or tranquillity: calm.

1 part of anything.

Simple: Hat land.

A tool for smoothing a surface.

I minute hole in the skin.

To cumpty: send forth: give vent to; utter.

Priority; superior rank.

previous acts used as guides. 
presence

presents

primeipal

principle

profit

prophet

\section{R}

rain

reign

rein

raise

raze

read

reed

residence

residents

light

rite

write

wright

role

roll

rote

wrote

\section{S}

sail

sale

scall

seem

serge

surge the state or quality of being present.

Gilts.

Chicl: the original sum; the head of a chool.

I lumdancmut tmoth; a settled rule of action.

Pocmialy ginin; to bencfit; reap an advanlage.

One who loretells future events.

Water in drops from the clouds.

Io exercise authority over; to rule.

The stratp of a brille; an instrument for turloning: restrain.

To cause to rise: lift up: elevate: originate or produce: collect.

To level to the ground: blow out.

Peruse.

I large coarse grass, with jointed hollow stems: tube of musical instrument.

Place of abode.

Those who elwell in a place.

Conect: privilege.

Ceremons.

To inscribe by hand.

I workman: an artificer.

I part in a play; a function assumed by anvone.

To cause to revolve by turning over and over.

Mechanical repetition; learning without understanding.

Pats tense of the verb "to write."

I sheet of camvas spread to catch the wind. Ihe act of selling: a market; auction.

The line formed by sewing two pieces of cloth together.

Tor appear: look; pretend.

1 twilled woolen cloth.

1 large wave or billow; great roll or pull. 


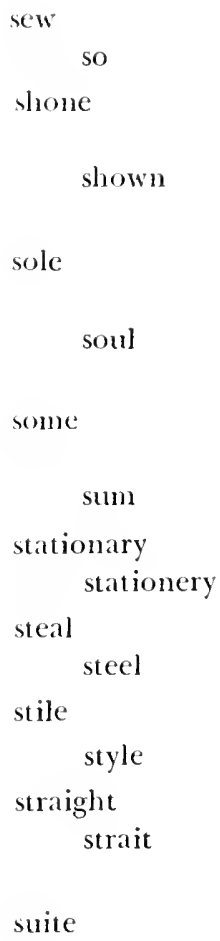

To unite or fasten together with thread. An alverb: in a like manner or degree.

Past tense ol the verb "to shine;" was bright or beatutiful.

Past tense of the verb "to show;" exhibited.

The unclersicle of the foot; a flat fish.

The spiritual or immortal part in man; conscience.

Denoting an indeteminate number or quantity.

Whole; total.

Staying in one place.

Writing supplies.

To take without right.

Iron refined with carbon.

A fence; barrier.

Fashion.

Not crooked or curved.

Narrow strip of water connecting two bodies of water.

A number of things used or classed together.

Not sour; pleasant.

Teardrop.

A row or rank.

Tight: stretched: snug.

Past tense or verb "to teach."

A group of players or workers.

To be prolific; full.

An expression of time of action; drawn tightly: rigid.

Phural of tents.

A possessive pronoun.

A particular place.

Contraction of "they are."

Past tense of verb "to throw."

From end to end of. 
to

too

two

troop

trompe

V

vain

valle

vein

vary

rery

\section{W}

wade

weighed

waist

waste

wares

wears

way

weigh

weak

week

whose

who's

rood

would

\section{Y}

your

you're
Preponition.

Jore that chough; also.

()ne and one.

I body of ooldiers.

1 company of performers or actors.

Lmpu: deceitful: conceited.

Weatheroch.

One of the vesch which convey blood from the arteries to the heart.

To change.

An adverls; atronely; identical wo: the same.

To walk through any substance that yields to the feet.

Past tense of the verb "to weigh."

Part of the body: garment.

Needless destruction: useless consumption.

Goods; merchandise.

To impair or waste by time, urage, friction; carries as covering on the body.

A road: route.

To ascertain the weight of; reflect on carefully.

Feeble: soft: unfortified.

Seren diays.

1 possessive pronoun.

A contraction of "who is."

A collection of growing trees; solid part of trees.

An auxiliary verb.

Possessive pronoun.

lou are.

\section{DIVISION OF WORDS}

Although the improper division of words is not technically an error in spelling, a mistake of this type makes the reading of the 
report diflicult and leaves the impression that the word has been misspelled. Follow these rules in the division of words.

Divide words only between syllables.

rever-sal depart-ment tem-per

Single-syllable words should never be divided.

Irrong. wei-ght wh-ich sei-ze

Never separate a single letter trom the rest of the word.

Irrong: sewe-r printe-r p-rogram

Aroid two-letter divisions, and never carry over two letters only.

Wrong: tatble su-ture eve-ry

When a final consonant is doubled before a suffix, the additional consonant goes with the suffix.

run-ning bid-ding control-ling

When two consonants come together between two vowels, divide betreen the consonants.

mil-lion struc-ture adran-tage

It is usually possible to maintain fairly even right-hand margins without dividing words. Aroid dividing words as much as powible. 


\section{Chapter V}

\section{CAPITALIZATION AND NUMBERS}

I

Most police REPORTIX the tendency is to orercapitalize. Capitalization is not to be used as a neans of emphasis. Other technigues are used for that purpose. In some instances the thought is changed when words are capitalized. When police deparment is written in lower case it relers to the organizational entity within a level of gorernment. For example:

A large part of any city govermmental budget is that of the police department.

When Police Deparment is capitalized, the rords mean that a specific police department is the present subject of discussion.

A large part of the city budget is that of the Police Department. (In this case Police Department means, for example, the Detroit Police Department).

Two principles, (1) that each sentence begins with a capital letter, and (2) that every proper name and most words derived from a proper name begins with a capital letter, cover most of the need for capitalization. Further rules are made to establish uniformity in doubtful cases.

\section{CASES CALLING FOR CAPITALIZATION}

\section{In the Sentence}

Capitalize the first letter of the first word of each sentence.

.ll evidence wats properly marked or labeled.

When incomplete sentences are used as complete thought, capitalize.

More delaty. Less efficiency.

Nothing to hope for.

Direct (puotations, quotations, slogans, and mottoes that appear within a semence must be capitalized, whether quotation marks are lised or not. 
The suspect said, "Give me the dough!"

The slogan, Best evidence. was adopted.

Capitalize the first letter of the first word in any entmeration when the enumeration is presented in columms.

l'atrolmen must:

(a) Protect the crime scene

(b) Irrest the suspect, if possible

(c) Interview witnesses and the victim.

(d) Call tor a special investigator, il needed.

\section{Capitalization of Proper Nouns and Adjectives}

Names of persons, places, institutions, organizations, goveming bodies, and political parties are capitalized.

Robert Williams was born in Arkansas.

He atcented The University of Arkansas and was a member of Pi Sigma Alpha.

At present, he is living at 318 Mariposa Drive. Los Angeles, Califormia.

This is a problem for the Los Angeles County Sheriff's Department.

The condition of his clothing indicated that he had fallen in the Colorado River.

Names of races and languages are capitalized.

He belongs to the Cancasian race.

The winess spoke Russion, French, and German.

Names of religious sects, words designating God, and names of parts of the Bible are capitalized.

The suspect states that he believes in God, reads the New Testament regularly, is a member of the Methodist Church, and fears the Almighty.

Names of historic epoclss and events are capitalized.

Questioning revealed that he was in the military service during llorld llar 11.

Any title of honor or respect preceding a proper name is capitalized.

Ciaprain Roe, a student of human relations, took the responsibility for contacting $D r$. Doe. 
Capitalize a mate name.

Frigiclaire

Parker Perm

Common momms treated as proper names are capitalized. In institution, event, or any pre-cminent item may be capitalized it comtext or custom makes it clear that one is singled ont.

the Rock (Mlattral)

the First llorld llar

Capitalize words derived from proper names. The most common of these are adjectires.

linglish-speaking people

Eisenhoreer jacket

\section{Words Indicating Family Relationship}

Words indicating lamily relationship are capitalized if they are not modified by a possessive adjective or an article.

The boy stated, "I asked Father for the key."

He anked his father for the key.

\section{Sections of the Country}

The word east, west, and north, and south are capitalized when they refer to sections of the commy.

The manner of speech of the suspece indicated that he was from the Somth.

He always went south for the winter.

\section{Names Indicating Time}

The names of the days of the week, months of the year, and special holidays are capitalized.

We matle our first contact with the suspect on Hednesday. January 6 .

He had remained ont of the state since Thanksgiving doy.

Titles of Books, etc.

Every word in the titles of books, magazines, documents, and newspapers-except articles, prepositions, and conjunctions-is capitalized.

The witness had been reading Gone with the llind. 


\section{Capitalization of Abbreviations}

Such abbreviations as Jr., Sr., Ph.D., R.F.D., Mr., and Mrs., are capitalized.

Although a.m1. and p.un. are ustually written in lower case letters, it is preferable to capitalize them in preliminary and supplementary inrestigation reports.

John Jones, $J r$, is the son of Dr. John Jones.

We arrived at the scene at 9 P.M.

\section{CASES NOT CALLING FOR CAPITALIZATION}

Don't capitalize the first word of a sentence inserted within another when it is separated by parentheses or dashes.

The men who were assigned were moved (this had been decided preriously) to a different location.

Don't capitalize the first word of a slogan that is grammatically dependent on what precedes.

He passed the word along that "we must get our man."

Don't capitalize enumerations within a sentence.

Patrolmen must: (1) protect the crime scene, (2) arrest the suspect, if possible, (3) interview wintesses and the rictim. and (4) call for a special investigator, if needed.

Don't capitalize institutions and geographical terms unless they are used with a proper noun.

This is a problem for the sheriff's department.

The condition of his clothing indicated that he had fallen in the river.

Don't capitalize names of the seasons of the year.

If usually went south for the winter.

Don't capitalize points of the compass unless they refer to specific sections of the contutry.

The witness indicated that the perpetrator had traveled west.

Don't capitalize trade nanes used as common noums. (Many trade names quickly become common nouns; and, if used to 
designate the sont ol anticle rather than the makes, they are unt (apitalized.)

kolitk

rictrola

$$
\text { polinoid }
$$

\section{NUMBERS}

In literary terms police reports are categorized as techuical witings. In this type of witing numerals are used except at the beginning of a sentence.

We recovered 16 typewritess valued at $\$ 1,+50$.

sixteen typewrites valued at $\$ 1.750$ were recovered.

\section{Numbers Written As Numerals}

Quantities and measmencents are always expressed as figmes. These include ages, dates, homs with a.m. and p.m., street numbers, page numbers, sums of money, statistics, room numbers, divisions of books, decimals, percentages, mit modifiers.

$\begin{array}{ll}35 \text { years } & \$ 35.50 \\ \text { April } 3 \text { to Junc 11, } 1959 & 1,346 \text { inmates } \\ 11: 30 \text { A.M. } & .75 \\ 318 \text { Morgan Way } & 35 \text { per cent (") } \\ \text { Room 25 } & 5 \text {-day week, 10-foot pole } \\ \text { P.- } 140 & \end{array}$

\section{Military Unit Names}

In the Air Force, mits up to and including an air division are designated with Arabic numerals. Names of the numbered air forces are spelled out.

732d Bomb Squadron

2d Air Division

245th Fighter Group

Filth Air Force

348 Fighter Wing

In the Amy and Marine Corps, mits up to and including the division are designated with Arabic numbers. The corps name is written with a Roman mmesal: III Corps. The field amy number is spelled ont: First Army. The army group goes back to the designation of Arabic numbers: 2d Amy Gromp.

8end Infantry Regiment

7(b) . \.. Brigate

ed Infantry Division 
In the Nany the mumber of a task force is witten in Arabic: Task Force 58 . The lleet number is witten in full: Fifth Fleet.

\section{Numbers Spelled Out}

Spell out numbers beginning a sentence.

Four officers were assigned to cover the house.

Forty-thee officers were called for extra duty.

Spell ott ntmbers tused in correction with serions and dignified subjects.

the Thirteen (Original States

the Seventy-Eighth Congress

spell out numbers of less than 100 preceding a compound modifier comtaining a figure.

two ${ }^{1}$, -inch boatels

twelve 6-inch barrels

but

120 $1 / 1$-inch boarts

spell out indefinite expressions or round numbers.

the early thirties

between two and three thousand hours

a hunetred hours

one hmolred-odd stolen articles

Spell out fractions standing alone.

one-half inch

five one-thousandths 


\section{Chapter VI}

\section{ABBREVIATIONS}

B

ReVIT is stressen ix mosr police reporting, and this is good policy. Filing space must be conserved; time and energies of those who read and write reports should not be wasted. Reports should be as briel as possible so long as they convey the idea intended by the writer, Thus, in an effort to be brief as well as to conserve space and energies, some abbreviations are premitted.

However, it is imperative that abbreviations must not be used to the extent that clarity is sacrificed. Some officers seem to have it driving compulsion to use abbreviations; their reports are not comprehensible. Many police agencies adopt their own system; others tolerate any and all abbreviations used by each indiridual writer. There is clanger in either of these practices, because any person who reads reports made in these departments may experience difficulty in interpretation. Those abbreviations permitted should be only those that enjoy alde acceptance.

Furthermore, abbreviations should be aroided as much as possible in narrative sections of preliminary and supplententary investigation reports. Acceptable abbreviations may be used more freely in the routine completion of the many other required forms and in the reporting of incidents, arrests, and the identification of criminals. Any acceptable abbreviation is appropriate in the reporting of tabulated information, footnotes, cross-referencing. and similar materials.

Where abbreviations are permissible, the use of accepted ones will not result in confusion. The dictionary is the last resort for a comprehensive list of accepted abbreviations. For example. It $e^{\circ}$ ster's Nea Collegiate Dictionary gives thousands of them. The most common problem which you will enconnter in report writing are discussed in the rules which follow. 


\section{NAMES ANI) TITLES}

Commonly used terms of report such as Mr., Mrs., Messrs., Jr., and Sr. are abbreviated.

Such abbreviations as Dr., Rev., Hon., Gov., and Gen. are properly used before full names of persons but not before surnames only.

Prof. Roy G. Hillman not Prof. Hillman

Do not abbreviate Christian (given) names except in situations where the name has appeared earlier in the report. In such cases care should be exercised in writing the accepted abbreviation of the name.

I'm., Edw., Jas., Thos., etc.

Titles and degrees following a proper name are abbreviated. The abbreviations are capitalized.

Mr. John Henry Sellman. M..t.

With the exception of the use of $v$. or vs. for versus, titles of writings should never be abbreviated.

State v. Smith

The word, company, should not be abbreviated unless used as part of a proper name.

We did not receive a complaint from the company.

We received a complaint from the $\mathrm{R}$. C. Richardsons Co.

The words victim and suspect, are used so frequently in investigation reports that it is permissible to abbreviate them after the words have been spelled out for the first time. Capitalize the abbreviations when you use them.

$V$. equals victim

S. equals suspect

\section{DATES AND PLACES}

Dates and places are higly significant in police reports, especially investigation reports. Be very careful when you use them.

Names of all the days of the week and several months of the year may be abbreviated. 
Mon., Tues., Iled.,Thurs, Fri., Sat., Sun.

Jan., Feb. Mar., the., Sept., Ort., Not., Dece.

Nole: Never abbreviate . Mpril. May, Jume, and July.

Locations are extremely important in police reports, and the possibilities of error are 100 great when they are abbreviated. Do not abbreviate the names of cities and states unless you are confronted with such words as fort, mount, point and port as a part of the name.

P. H IuIOII

St. Louis

Ft. Worch

The letters, U.S.A., may be used as abbreviation of the I'nited States of America.

The words avenue, boulezard, street, etc., may be properly abbreviated when used as part of a proper name.

Ave'. Blud., Pl., St.

He lives at 32I8 Carol St.

The forms $d, n d, r d$, st, and th may be used after date and place numbers in all police reports.

We met the suspect on the 20 th of $A$ pril.

Note: A period is not used after this type of abbreviation.

The points of the compass are abbreviated. Capitats and a period are used.

$$
\text { N., E., S., H., N.E., S.E., N.H., S.H.. }
$$

Abbreviations should be used to indicate time of day. The letter or letters of the abbreviation should be capitalized. The ab. breration is followed by a period.

12 N. (Noon), 10 A.M., 3:20 P.M., I2 P.M. or I2 M. (Miduight)

(P...I. etc.)

\section{CAPITALIZATION AND PUNCTUATION OF ABBREVIATIONS}

If the word for which the abbreviation stands is capitalized, the abbreviation must be capitalized.

Note: The time element is so important in police reports that A.M., P.M., N., and M. should be capitalized. With few exceptions, abbreviations should be followed by periods.

I) r. Aite. N. 
If the word lor which the abbreviation stands is hyphenated, the abbreviation should be hyphenated.

$$
\text { ft.llb. foot-pound }
$$

Certain short words, most of them derived from Latin, are not abbreviations: thus, they are not followed by a period.

ria, ad, circa, et, finis, in re, par, per cent, pro, re. iersus

The letters of radio and telerision stations are witten in capitals, but no period follows.

$$
\text { ITFAS KCCC }
$$

Names of lighways, both state and national, may be abbreviated. Each of these abbreviations should be followed by a period.

$$
\text { ('.S. So S. Ha' }
$$

\section{ABBREVIATIONS AND THEIR PLURALS}

Most abbreviations from their plurals by adding $s$ to the singular; others form their plurals by doubling the initial letter used as the singular number abbreviation.
art.. arts., (article. articles)
bk., bks., (book. books)
ch.,chs., (chapter, chapters)
fig.,figs., (figure, figures)
1., 11.. (line, lines)
no., nos.. (number, numbers)
p., pp., (page, pages)
par., pars., (paragraph, paragraphs)
pl.. pls.. (plate. plates)
pt.. pts., (part. parts)
sec., secs., (section, sections)
vol., vols, (volume, volumes)

Other Iatin abbreviations have no plual forms.

e.s. (exempli gratia) lor example

i.e. (id est) that is

ib., ibid. (ibidem) the same, in the same place, from the same sumce.

i.q. (idem quid) the same as

in loc. (in loco) in its place

op. cit (opere citate) in the work cited or mentioned 


\section{GENERAL IBBREVIATIONS}

In business and commercial writing, abbreviations mumber in the thousands. These are permissible in police reports. Many of them may be found in John B. Opdycte's book, Ciet II Righl. As stated earlier, a most comprehensive list is araibable in llebster's New Collegiale Diclionary.

The following are a few general abberiations acceptable in all types of police reports:

$$
\begin{aligned}
& \text { art., article lut. lieight } \\
& \text { co.d., cash on delivery wi., weight } \\
& \text { fo.b., free on board s clollar } \\
& \text { pkg.. package a at } \\
& \text { ry., railway } \not \subset \text { cent } \\
& \text { Lenglh nical and public reports) } \\
& \text { in., iucl } \\
& \text { ft., foot Area and Volume } \\
& \text { yd.. yard sq. in.., square inch } \\
& \text { mi., mile (s) (u. in., cubic incli } \\
& \text { Itright } \\
& \text { gr.. grain Capacity } \\
& \text { dr.. dram gill (s) (should not be abbreviated) } \\
& \text { o/., ounce p1.. pint } \\
& \text { cwt., hundredweight gl., quat } \\
& \text { ton (s) should not be ab- gall, gallon } \\
& \text { breviated pk.. peck } \\
& \text { bu., bushel } \\
& \text { bbl., barrel }
\end{aligned}
$$

Note: Most of the abbreviations above are followed by a period. Some weights and measmes abbreviations are not followed by a period.

\begin{tabular}{ll} 
Ureight & \multicolumn{1}{c}{ Capacity } \\
kg kilogram & kl kiloliter \\
hg hechogram & ll hectoliter \\
dkg dekagram & dkl dekiliter \\
ggram & I liter \\
dg decigram & dl deciliter \\
cg centigram & d centiliter \\
mg milligram & ml milliliter
\end{tabular}




\section{Chapter VII}

\section{SENTENCE STRUCTURE}

\section{W}

ORDS ARE COMBINED INTO A sentence, which is the basic unit for communicating an idea. A sentence may mean something to you, but unless it communicates the same meaning to your reader, it is not good. If you wite a careless sentence, you make work for your reader. In this kind of sentence you may hide the meaning in faulty construction and force him to backtrack to get your ideas. Or you may annoy him because you fail to make an idea clear.

\section{USE SIMPLE SENTENCES}

It was the fashion many years ago to write sentences running well over a humdred words. Today educators clearly show that writing can be more easily read and remembered if sentences are short. To write clearly, avoid using involved sentences. Why ask your reader to waste mental effort trying to determine what you are trying to say in long, wordy sentences. Tell him the facts in short, brisk, sentences.

On the other hand, aroid the monotonous style of one short sentence after another. Try to vary sentence length and construction. After several short sentences, write a long one. In general, however, keep the average sentence to about twenty words.

\section{WRITE CLEAR SENTENCES}

What can go wrong with your sentences? Why do they lack clarity? The following examples illustrate some common difficulties (words in italics show weak points in the sentences):

\section{Lack of Parallelism in Construction}

Express parallel ideas in words with the same grammatical construction.

Awkward: Bricfly, the functions of the executive officer are to adrise the chief, trasmit his instructions, and the supervision of the execution of his decisions. 


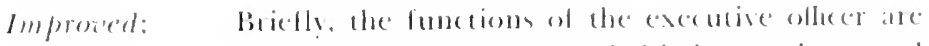
(1) advise the chief, tramsmit his imstrutions, and ulperrine the execution of his dee isions.

\section{Dangling Modifiers}

111 modilying wonds and phrases should be placed where they can't cause combusion. A dangling modifier refers to a nord which it can't sensibly modily.
Confusing:
Approaching the rits from the somble side. the capitol busilding cant be reen.
Improsed: I person approathing the city from the south side all cally see the capitol building.
Confusing: In searching a prisoner, the wall method should be weed.
Improved: In rearching a prisoner, we the wall mechod.

\section{Squinting Modifiers}

Avoid using "spuinting modifiers"-modifiers that refer to either of two parts of a sentence.

Confusing: Hidlen Valley is the place where the Blankville Police Deparment said early today the suspeet had lled.

Improved: Early today the Blankville Police Deparment sitid that the suspect had fled to Hidken V'alley.

\section{Use of Passive Voice}

For direct statement of an idea, make the subject of your sentence perform the action (active voice); do not let the subject be acted upon (passive voice).

Ineffective: Before he attempts to form a directive, an appratisal of the situation must be mate by the chiel.

Improved: Before the chief attempts to lomm a directire, he must make an appraisal of the situation.

The ineffective sentence also shows a change of subject-liom "he" to "appraisal of the situation." The improved sentence keeps the same subject-"chief" and "he."

\section{Shift From Passive to Active Voice}

Use the active voice in all clauses of a sentence, rathes than shift from passive to active. 
Ineffective: In 1958, the personnel of the police elepartment was increased by fifty men, and lour licutenants supplanted the sergeants.

Improsed: In 1958, the police department increased its persomnel by fifty men, and four licutemants supplanted the sergeants.

\section{Indirect Phrasing}

Express your idea directly instead of indirectly. Frequent use of there is and there are weakens emphasis.

Ineffective: There are lour types of contmol with which each supervisor should be familiar.

Improaed: Each supervisor should know four types of control.

Frequent use of it is ... indicates an indirect approach. The direct approach is clear and more forceful.

$\begin{array}{ll}\text { Trite: } & \text { It is believed that ... } \\ & \text { It is assumed that ... } \\ & \text { It is recommended that ... } \\ & \text { It is directed that ... } \\ \text { Improved: } & \text { We believe that ... } \\ & \text { We assume that ... } \\ & \text { We recommend that ... } \\ & \text { We want ... }\end{array}$

\section{Lack of Emphasis}

Make the structure of a sentence show what is important and what is not. Subordinate less important etements.

Ineffective: A special enforcement squal can, and frequently does, operate indepentently, but it nomally operates as part of the division.

Improved: Normally operating as a part of the division, a special enforcement squad can, and often does. operate independently.

\section{Lack of Coherence}

I sentence has coherence when ideas fit together in a pattem that is easy to understand. The idea to be emphasized should come either furst or last in the sentence-not in the middle.

Ineffective: In oreler to enable the will of the chief to be understood unmistakibly, a standard sequence... 
for all eneneral orders is prescribed to iusture that all esential instractions are corected.

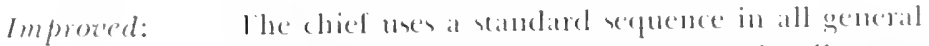

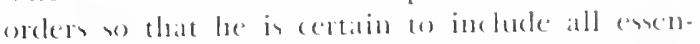
tial imstructioms and to make himedl hull! molerstoosl.

\section{Ambiguity}

Re-think all of votm sentences: you maly need to rewrite some ol them becanse the meaning is not clear.

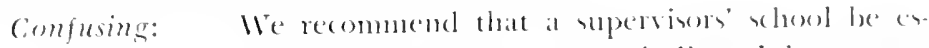
tablished in oreles that an indicated low ruper-

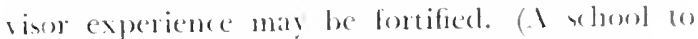
imsure poor superisery experience is mosel!)

Improsed: We recommend that a mpervisors achool be eatablished to improve supervinion.

Confusing: At the completion of thi recruit trainimg a repert will be sulmutted to the chief estimating the cillect and value of some. (A report estimating the value of the training is a gool ideat: a report entinating the value of the chich may not!)

Improened: It the completion of this reonit training a report on the new methods of intruction will be submitted to the chice.

\section{WRITE EFFECTIVE SENTENCES}

Sentences can be clear, yet not effective; that is, parts of a sentence arranged one way seem to be more pleasing to the reader than any other arrangenent. Training and experience will soon lead you to recognize and select one sentence orer another, eren though they both concen the same idea. Read the following examples. Which sentence in each group did you select?

1. (a) The text of a radio message will be given with an few works as possible, maintaining clarity. without making the mesiage rague or ambiguous.

(b) With as few words as pessible, maintaining clarily, with. out making the message vague or ambiguous, the text of the radio messige will be given.

(c) The text of a raclio menage will be as brief as pomible and clear, without making it rague or ambiguous.

(d) The lext of a ralio meraige will be clear and an buted an pessible: at the rame time it sluomld not be vague or ambiguous. 
2. (a) These violations recur again and again.

(b) These violations recur.

(c) These violations are such as to be recurring in nature.

(d) These violations happen again and again.

3. (a) Should patrolmen persist in making these errors, gross offenders should be disciplined.

(b) Patrolmen who continue to make these errors should be disciplined.

(c) If gross offenders among patrolmen who persist in these errors continue to do so, they should be disciplined.

(d) Discipline all patrolmen who make these errors.

4. (a) The instructor's being experienced in tactics adds interest to) his course.

(b) The instructor is experienced in tactics which adds interest to his course.

(c) The instructor's experience in tatics adds interest to his course.

(d) The fact that the instructor is experienced in tactics adds interest to his course. 


\section{Chapter VIII}

\section{PUNCTUATION}

\section{$\mathbf{R}$}

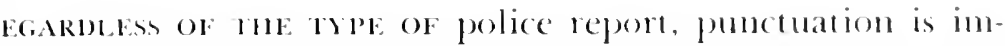
portant. But there are not, nor should there he, any special rules regarding punctuation in police reports. The purpose of punctuation is to help your reader, and your aim should be to make the report as clear as possible to him. It is the customary little marks. called punctuation, that do detemine whether a sentence is clear or lias a doubtful meaning.

In lact, your punctuation serves two principal purposes in a report: (I) it separates the written matter into sentences and subdivides the sentences into word gromps, and (2) it lets yom reader know that you have presented the writing for his convenience. Even when punctuation is not an absolute necessity, to prevent misunderstanding, you should insert punctuation to make the meaning clear at a glance.

In spite of the fact that the rules of punctuation are fairly well defined and the next several pages are devoted to them, you should not feel inhibited because of them. People differ in matters of judgment and intention. A witer often has a considerable leeway in making a choice of the punctuation which he will use. However, you must be sure of three things: (1) that the punctuation you use enables you to convey your intentions, $(\boldsymbol{q})$ that your intentions are made absolutely clear to the reader, and (3) that you know how to use the punctuation marks which you use.

It is true that many police officers harbour eroncons conceptions regarding the value of punctuation in their reports. They often reason that brevity is so important that punctuation should be eliminated as much as possible. Although brevity is important, clarity camnot be sacrificed in the interest of the former. Others may think, since they do not know how to punctuate, that a secretary or some person in the records division will insent the necessary 
punctuation. On the other hand, no person understands your intentions at rell as you do; no one else can be trusted to convey your intended meaning. Eren the rough draft of you report should be punctuated as correctly as possible without interfering with your trend of thought. Obvious errors in punctuation should never appear in your finished product.

The oflicer who does not know how to punctuate his report should leam. Yet. to those who lack background this is no easy task. They must not only learn what to do but must practice it until it becomes a matter of habit. A knowledge of grammar is necessary to proper punctuation. legin by studying one or several granmar books. Progress from grammar to the rules of punctuation as presented in this manual; study and refer to the rules constantly. Study the appendix material on "Elements of Grammar" when you need an immediate guide. Practice by constructing sentences of your om and punctuating them according to the rules. Proofread every piece of material before you submit it.

Remember this. I punctuation mark should be used as an aid to clear understanding. When it does not render the meaning more plain or bring out some point of definite adrantage, a good rule to follow is, Do not punctuate.

In the following paragraphs the rules have been simplified. The illustrations should help you to learn them.

\section{THE PERIOD (.)}

I'se a period at the end of a declarative or an imperative sentence.

We arrived alter the suspect had left the scene.

IVill you please make our report. (Polite request)

I'se a period after an abbreviation.

The unpeet entered the store at approxinately 9 P.M.

S. $I$ (smpert 1) entered his home through the rear exit.

Ise a period after initials.

Roy L. White was listed in the report an the victim.

R. $1 /$. Smith, Jr.. atrived at? $P .3 /$.

\section{THE (OUESTION MARK (?)}

I'se a question mark after a question or alter that part of a sentence which askis a question. 
Mre you going:

Who: What: When: Where: How: Wh?

"Who in this gromp knowe this man?" the oflece anked.

\section{THE EXCLAMATION MARK (!)}

I se an exclamation math atter an expression of smprise at strong enotion.

What a case this is!

Help! Police:

Stop! I Thicl!

\section{THE COMMA (,)}

I'se a comma before comolinating conjunctions and. bul, o). nor, for which join two independent clanses. (An independent clause is a group of wouds which contain a subject and a verb and represent a complete thought.)

The supece drove his own car. and his victim vent with him.

Certain rital evidence was discosered, but we obtained a vearh wartalut before we got it.

We must strike first, or later we will be sorry.

I believe the witness, for he has always told us the muth.

Use commas to set off appositives. (All appositive is a word or phrase which immediately follows a nom or promom and denotes the same person, place, or thing.)

()ur winess, the brother of the anctim, arrived early at couts.

The chane encted in Batkersfeld, an oil center in Califormiat.

Note: Appositives which are closely related are not set off by colnumas.

This is my co-morker Tom Hamilon.

I misell will wite the report.

Ise commans to set off wouls or phases that are used paranthetically or independently.

He was, ate believed, a person to be watched.

The other plan. howerter, is less dingerous.

les, I think you we right.

Firit. I thall write my report.

lloweret, he is wrong.

I'sc a comma to separate two or more coordinate (equal) ad jectives which modify the same nomm.

The crime scene was a large, gloomy room. 
Note: If the adjectives are closely related or comnected by and, the connma is omitted.

The crime scene was a large and glonmy room.

The victin wore a new sport coat. (closely related)

I'se a comma after an adverbial clause or an absolute phrase at the begiming of a sentence. It also is ustually used after an introductory participial phrase. (See Appendix A for explanation of these terms.)

Haing pulled the boat upon the bank, the officers started their search on loot through the forest. (participial phrase)

When we opened the door. the suspect dashed from the rom. (aclierbial clause)

flthough we arrived early, the suspect had made his contact. (aclverbial chase)

His car having been taken from him, the victim walked fre miles to the nearest town. (participial phrase)

U'se commas to separate words, plurases, or clauses in series.

The suspect's clothing contained red, white, and black fibers. (Note that a comma may not be used before the and)

The laboratory technician lound fingerprints on the table, under the chairs, and on the window sills.

We did not know when he would arrive, what he would say. The victim was tall, dark, and handsome.

Use commas to set off expressions like "he said" from direct quotations.

The suspect saitl, "Give me the dough!"

"I'l] be there," he said, "at two o'clock."

"I'll be back tomorrow;" he replied.

I'se commas to set off nouns in direct address.

"Give me the money, sucker."

"Ihis, fellow's, is the answer."

I'se commas to set off nou-restrictive clauses and phrases. (A non-restrictive clause or phrase does not limit or change the meaning of the sentence, but gives additional information.)

Mr. Ray Coleman, whom we had contacted earlier, gave us the desired information.

We worked at the ball gane, althongh ate had intended to atork on the cass.

()thece simon, ferting that he would arvie too late, used his red light and sirell. 
I'se a comma alter a statement followed by a shomt question dependent 1 pen it.

lon will go wo the police station wish us, ant you.

I'se a comma to indicate the omission of a werd or words which ane necessary to complete the meaning of a sentence.

the company had a factory in lon lugeters another, in Niow York: and at third, in Mlanta.

[xe a comma to aroid conlusion in reading.

veer photographing. the laboratery technician dusted for fingerprints.

L'se commas to set off transposed or inserted modifiers.

In old house, bleak and dingy, sood alone on the hill.

Ihe supect. by areming forcefully. won his perint.

Ise commos to set off contrasting expressions.

The rictim, not the suspect, had written the note.

Ihe suppect. eaen more than his associates. had wanted to confers.

I'se commas to set off each item after the first in an address or date.

The report inclicated that he lived at 923 Ninth street, blank-

rille. California.

Sacramento 18, Callifomia

June 19, 1959.

I'se a comma after mild interjections.

The supeet had sated. "Well. what do you think?"

I'se a comma before Sr., Jr., titles following a name, between a title and the name of an organisation, and between smaller and larger geograplical mits.

John Smith. Jr.

L. I. foner, Ph.D.

Chiet, Disivion of Adminintraton

comertionville. Iowat. Enited States

In numbers, a commul stands after each group of thee digits, comting from the right.

The expendisures of the force in 1954 were $\rightarrow$ I.823.158.50.

The population of the cily in 1.50 .325$.

Vote: Write insmance police mumbers, serial mmmbers. strect numbers and order mumbers as follows: 
The case number is $34 \mathrm{~L} 126$.

The insurance policy found in the safe contained the number, 1345678.

II is adress is 6000 Norton Way.

\section{THE SEMICOLON (;)}

I'se a semicolon between wo independent clauses of a compound sentence when the conjunction is omitted.

We arrived at the scene at 9 A.M: We contacted the victim.

I'se a semicolon before such conjunctive adverbs as the following words when they join independent clauses:

$\begin{array}{llll}\text { so } & \text { thus } & \text { moreover } & \text { accordingly } \\ \text { then } & \text { therefore } & \text { furthermore } & \text { consequently } \\ \text { yet } & \text { however } & \text { hence } & \text { nevertheless } \\ \text { still } & \text { bevides } & \text { otherwise } & \text { finally }\end{array}$

I did not write the report; consequently, I did not complete the investigation.

Police reports are required: thus, they are necessary.

The semicolon is usually used before a coordinating conjunction which commects the independent clauses of a compound sentence containing internal punctuation.

The witness, who was with us, did not want to go to police headquarters; but I persuaded her to go.

The semicolon is usually used between the items in a series if there are commas within the items.

The following items were selected: scissors, for cutting: strong cord, for binding; and heary wrapping paper, for packaging.

\section{THE COLON (:)}

I'se a colon to introduce a list or a summarizing word. phase, or clause.

The three common methods used in the development of fingerprints are listed in the order of their importance: poider, iodine. and siluer nitrate.

He harl only one idlea: escape.

When he entered the house, he had only one motive: that he might deprize the owner of her jewelry.

Revults were as lollows: better moral. less arork. increased salarios. and improsed public relations. 
l'se a colom with a quotation whem say of a subutitule lom say has heen omitted.

The captain turned: "Who gatse the order:"

I'se a colon to introduce a long or formal puotation.

Mr. Walter R. Scott hats the following to saly about the rederetopment of iodincedereloped lanent fingerprines whith poweler:

vluough it can be done, it is mot atribable to atlempl 10 inten-

sify or rederelop iodine-dereloped integes with poweder for several reasons: e. g. il an inpression on paper is tresh . .

I'se a colon in expressing time to separate hours and minutes.

The report was made Wednestay, () onber 31,1959, al $4: 15$ P.X.

\section{QUOTATION MARKS (" ")}

Use quotation marks to set off the exact words spoken or write ten by another person.

The suspect said. "Gel your hauds in the air."

"I will go," the arrentee sind, "if you insist."

Caution: Do not use quotation marks to set ofl indirect quotations.

He sail that he would go.

Did he say that he would go:

I'se single quotation marks to set off quotations within quotations.

He asked. "Who wrote "Practical Fingerprinting?"."

Use quotation marks or molerscorings to indicate titles of newspaper and magazine articles, etc.

The wituess stated that he was realing "Gone with the Wind."

He gets hie stock quotalions from The New York Times.

Also use quotation manks or underscorings to call attention to particular words.

In questioning the supeet. we noticed that he used too many

"and's" in his talk.

The why is the motive ol the crime.

When two or more paragraphs are quoted, quotation marks are used at the beginning of each paragraph and at the end of the last palragraph.

"Nuch has been said about ... (The paragraph follows.) 
"The resule can be accomplishert .... (The next paragraph followi.)"

I'se quotation marks to enclose slogans and mottoes.

He hat a "do or die" attitude.

I'se qutotation marks to enclose misnomers, slang expressions, or ordinary words used in an arbitrary way.

He gave the gun to his "mouthpiece."

she has a reputation as a "chippy."

When other punctution is needed in comnection with quotation marks, adhere to the following rules: (1) a comma or a period is always placed within quotation marks, and (2) other punctuation marks are placed within quotation marks only if they are a part of the quotation.

He asked. "Shall we search the house?"

bicl he say, "The area will be searched?"

\section{THE DASH (-)}

I'se a dash to separate sudden interruptions from the main thought.

He told me-oh, ] can't remenber what he said.

Rot Smith-doni you remember him-we arrested him on another accasion.

I'se a clash in place of a colon after a question mark or an exclamation point.

How an this be explaincel:-the suspect did not return to the rene.

I'se dashes to set off appositives containing items separated by (ommans and to set off smmmarizing expressions and afterthoughts.

Many qualities-honesty, tact, initiative-are necessary to a good investigator. ((appositive)

Honcety, tact initiative-all of these characteristics are necessary

to a goost investigator. (smmmarising expression)

John Jones is in jail again-nothing new for John. (afterthought)

Yotu may abbreviate a date by using dashes.

$1-11-59$ or 1 1 11,59

\section{THE APOSTROPHE (')}

I'se the apostrophe to shom possession.

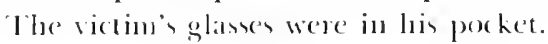


Singular and plumal noums not ending in s form the possessive by adding s. Singular and plural notums ending in s, add the apostroplie omly.

.11 the ladies drewer were collected as eridence.

Proper nouns of one syllable cuting in sustally fomm the possessive by adding the apostrophe and s. When you use proper nouns of more than one syllable, add the apostrophe only.

John's clothes were on the bed.

ir. Williams' car was impounded.

In joint ownership or in compontend words the apostrophe or the apostrophe and $s$ is adeled to the last word only.

We arrived at Hendrix-Jholen's depantment store at 9 P...I.

He stated that it wat his son-in-law's property.

Caution: The apostrophe is never used with the possessire pronomns, hers, its, oms, yours, theirs.

I'se the apostrophe to indicate the omission of a letter or letters in contractions. (A contraction is the combination of two rords to fomm only one.)

It's arm diay.

He a'ouldn'l confess.

bon't onit necessary punctuation.

Use the apostrophe and s to form the plural of letters. figmes. symbols. and words used in a special sense.

In the statement, the a's and the ois were written much alike.

In the comsersation. he used too many and's.

\section{PARENTHESES ( )}

You may use parentheses to enclose suplementary or explanatory material.

The number of aecidents (see Chart 15) has increased.

The gold Elgin watch ('Item \#3) was recovered.

I comma, if one is necessmy. comes after the second parenthesis, not betore the first. If the parenthetical element itself is a sentence, the period is omitted: a question mark or exclamation point is retained.

1s the fugitive opened fire (it was a .15 caliber antomatic). all movenent ceased.

Is the lugitive opened fore (was it a 45 caliber automatic $)$, all nusement ceased. 
Use parentheses when numerals are placed in formal enumeration within a sentence.

The functions of the special investigator are: (1) to locate the physical evidence, (2) to prevent contamination, (3) to collect the evidence, (4) to mark or label with adequate identifying information, and (5) to place it in proper containers for transportation to the laboratory.

Note that the comma which indicates end of an item in the series precedes the parentheses and that the numeral follows the coordinating conjunction.

\section{BRACKETS [ ]}

Use brackets to enclose corrections, interpolations, and supplied omissions added to a quotation by a person quoting.

"Fingerprints developed in iodine vapors are temporary in nature [when exposed to air]; however, they dissipate slowly."

\section{THE HYPHEN (-)}

The hyphen is usually used with two or more words forming a compound adjective preceding a noun.

The victim wore at tailor-made suit.

Ise a hyphen with compound numbers from twenty-one through ninety-nine.

We asked the witness thirty-fizle well-directed questions.

I'se a hyphen to indicate the division of a word in syllables at the end of a line when the remainder of the word is carried to the next line.

Additional information was not available, but the remainder of the evidence was delivered to the property derk.

\section{ITALICS}

In typed material show italics by underlining.

Ise italics to distinguish letters, words, or phrases from the rest of the sentence so that the thought can be quickly comprehended.

The comma is used to separate word., phrases, or clauses in series when they are not comnected by and. 
I'se italies to indicate foreign words appeatring in English text, moless the words have been atclopted into the English language.

the unpere win considered persona non grata.

\section{OMISSION}

Show onission of material by use of a row of asteristis betore a quotation when a large part of it has been monited.

A series of three periods (fom when the preceding scontence has been brought to a close) indicate onission within guoted material. The omission is usually a word or phrase, but it may consist of sereral sentences. It may come at the end of a sentence or in the middle of it.

"Mere words will not constitute an arrest, while on the other hand no actual physical touching is essential .... there can be no arrest without either touthing or submission." 


\title{
Chapter $I X$
}

\section{PARAGRAPH CONSTRUCTION}

\begin{abstract}
A
LTHOlgh paragraphing presexts no real problems in the many established forms in police reporting, it is a problem in narrative selections of preliminary and supplementary investigation reports. In these reports sentences are combined into paragraphs. Paraghaphs set the pattern of organization for most of the report. If paragraphs are well organized and follow each other logically, you present an orderly development of thought. and your report can be easily read and appreciated. The following suggestions should prove helpful in your paragraph construction.
\end{abstract}

\section{USE SHORT PARAGRAPHS}

Long paragraphs, like long sentences, involve the reader in unnecessary difficulties. A paragraph is a grouping of sentences related to a single idea. Long paragraphs force your reader to hold many relationships in his mind until he gets to the end. If you break an idea into smaller units or paragraphs. your reader can move easily from one element to the next without undue effort. Try to hold your paragraphs to 100 words or less. A page of solid print looks formidable. Give the reader of your report more white ipace.

\section{MAKE THE MEANING OF EACH PARAGRAPH COMPLETE}

At the same time, there is always the danger that you will be brief but obscure. Common sense should tell you that the number of words in your paragraph is not so important as the clearness of the icleas you present. Your paragraphs should not read like telegrams.

\section{GIVE YOUR READER A REST}

Furthermone, experience has taught us that there is a limit to the period of attention that a reader can give to a report. When 
this period is orer, his mind becomes tired, and a clear molerstanding of what he is reading stops. This means that you must give him rest periods. The paragraph is the principal means by which this is done. The diffeulty of the writen material will comtrol, to a great degree, the lrequency of these periods. Some subjects must be handled in smaller portions than others. When your rewite your report. try to determine how much your reader will be able to absorb in one period of attention. Remenber that your reader will need periods lor rest.

\section{FOCUS YOUR READER'S ATTENTION}

But alter the rest, you have the responsibility of recapturing his attention and focusing it upon the next topic of discussion. Your principal tool is a topic sentence. The new topic may be put forward immediately in the next paragraph, it may be stated and later repeated for emphasis, it may be delayed for a few sentences, or left until the end of the paragraph. In any case, your reader should be made to leel that he is moring safely in some known direction.

\section{HOLD YOUR READER'S ATTENTION}

When you have your reader's attention focused on the topic of discussion, you should hold on to it-hold on until you have said what you want to say. Although it is admitted that this is in part a human thing which involves talent or natural ability, techniques are arailable that have been found useful in the arangement of paragraphs. The most important of these deals with the order in which the sentences are aranged in the paragraph and with the use of link words and phrases.

The most common pattern of arangement of sentences in a paragraph in basic police reports is the narrative or time order. You simply follow a series of events in the order in which they happened.

(1) 9:49 P.M., 2-8-59, Reporting officers received a radio call reporting a grand theft at Room 109, Blankville Imn.

(2) 9:55 P.M., 2-8-59, Reporting officers talked with the rictim, Mr. Everet L. Rex, of Route 1. Tecumseh, Kansas, at the Blankville [111, Room 109, Mr. Rex stated that he is a truck driver for 
Cross Comntry Van Lines of Siond City, lowal agent for llelu Van Lines), and is staying over night at the Golel City Notel. 1951 West sth Arenue.

(3) The victim related that at approximately 5:30 P.M., 2-8-59. he was served by a young blond bartenter (female) at Ralph's Club, 1842-7th Avenue, Blankville, and that during a conversation with her he learned that she would be oll duty at 6:00 I'.N. and agreed to meet him at the Surf Club, 114I-J6th Arenue, Blanksville. He further alleged that it was agreed that they would go out to dimer and she would stay the night with him at a motel for 525.

(4) Mr. Rex further stated that he met the suspect as agreed at the Surf Club at approximately 6:30 P.M.. 9-8-59. Victim alleges that they went from the Surt Club to the Blankville $I n n$ in an Ace cab, which was allegetly driven by a person by the name of "George." He stated that they hat thinner in the blankville $\mathbf{l m}$ at approximately 7:00 P.M. and registered for a room (Room 109) at Blankville Inn at approximately 9:30 P.M. this date.

(5) Victim further asserted that upon returning from the shower at approximately 9:40 P.M., the blond, a wrist watch, and $\$ \mathbf{2 6 0}$ were missing. He stitted that the money (13 $\$ 20$ bills) had been removed from his wallet and the wallet returned to his trouser pocket.

(6) The complainant described the suspect as: WFA: 23 years, blond hair, 5\%", $13 \mathrm{I}$ pounds, wearing a dark coat and white dress with sequins. Victim asserts that suspect went by the name of "Kathy."

The order of your ideas is not the only way to hold your reader's attention. Use simple and effective link words and phrases to look back at the preceding sentence or forward to the one coming. These words and phrases are so useful in the linking of sentences together that Santmyers in his book, Practical Report IVrit$i n g$. presents a long list of them. They are rearranged here in alphabetical order for your use as a Jater reference.

I accordingly

after

again

although

another

at any rate

at least
B

besides

by and large

by the way

C

certainly

consequently

conversely
E

cqually so

especially

F
first
finally
for example
for instance




\begin{tabular}{|c|c|c|}
\hline lor this prupose & $N$ & surely \\
\hline lurther & natlually & $T$ \\
\hline lunthemore & nevertheless & He ane \\
\hline $\begin{array}{l}\text { II } \\
\text { henee }\end{array}$ & $\begin{array}{l}\text { next } \\
\text { notwithstandling }\end{array}$ & $\begin{array}{l}\text { the other } \\
\text { then }\end{array}$ \\
\hline I & $\mathrm{O}$ & therefore \\
\hline incleed & of course & third \\
\hline in lact & on the contran! & to this end \\
\hline in particulat & on the other hand & 100 \\
\hline $\begin{array}{l}\text { in spite ol } \\
\text { in this way } \\
\text { in truth }\end{array}$ & $\begin{array}{r}\mathbf{R} \\
\text { really }\end{array}$ & $\begin{array}{l}\text { muly } \\
\text { truth to tell } \\
\text { W }\end{array}$ \\
\hline litsty & $\begin{array}{c}\mathbf{S} \\
\sec (m) \mathrm{d}\end{array}$ & with this in vicw \\
\hline M & so & $\mathbf{Y}$ \\
\hline moreover & still & yet \\
\hline
\end{tabular}

\section{TIE YOUR PARAGRAPHS TOGETHER}

You also should use these same words and phrases, along with many others, to move smoothly from one paragraph to another. Transition words may be used to show the position of a paragraph in a series, as backward reference, or as forward reference. When you want to be absolutely sure of your transition, you may use entire clauses or sentences.

\section{TIE YOUR SECTIONS TOGETHER}

When your report is long and the subject nnatter is complex, you have still another problem. You must guide, direct, and reassure your reader. If you don't, he may get lost in the material. So, when you are sure you need them, use entire paragraphs to tie the various sections of your report together. For convenience of discussion, let us say that those used in this manner are either introductory, transition, or summary paragraphs. 


\title{
Chapter X
}

\section{EDITING AND CRITICIZING THE REPORT}

\begin{abstract}
A
FTER you WORK FOR a winle with techniques of clear report writing. you begin to think more clearly. Your thinking becomes more concrete. However, it is unlikely that you will ever turn out your best work in a first draft. A major step in effective report witing will always be careful editing.

Writing is an art and, as with all arts, skill in it comes only with practice. Even the more experienced writers find that from original writing to final copy writing is a time-consuming process. It is a process of rewriting, deleting, inserting, and recopying, with progressirely more emphasis on rethinking to achieve economy of expression. Even the experienced report writer finds the task of editing his own work a difficult one. It is natural for the writer to read into his own writing what he intended to say rather than what he actually said.

The key technique in learning to write clearly is learning to rewrite. Rewrite anything that isn't clear. This chapter suggests how to go about editing and rewriting.
\end{abstract}

\section{PERSONAL METHOD OF REVIEW}

When you are editing your own report, you should do your best to switch your viewpoint to that of the reader. A good way to accomplish this is to lay your report aside for a day or two before editing it. But seldom can you follow this practice in the police department. You need to become a constant critic of your own reports.

You will do a better job of editing if you read aloud. You should read the report two or three times. Follow these steps:

\section{First Reading}

Check the content of the report.

Is the report based upon facts? 
Is it based upon somend reasoning?

boes it contain sufficient information?

Are more cxamples needed?

Do the facts need more interpretation?

Has too much material been included?

Wre the sources of information the best obtainable?

\section{Second Reading}

Check the effectiveness of organization.

Is the subject stated clearly?

Is the subject advanced in clear-cut and logical stages:

Is the connection between stages clear?

\section{Third Reading}

Check diction, sentence structure, paragraphing, and typographical style.

Are the words appropriate to the reader and situation?

Has the report been adjusted to an appropriate reading level?

Are words specific and concrete, rather than vague and abstract?

Have too many legal, technical, elaborate, bookish, and trite worls been used?

Are the sentences simple, clear, and effective?

Can sentences be improved by deleting "deatheads," replacing "scatterbrain" words, and digging out smothered verbs?

Do the paragraphs convey the meaning intended, focus and hold the attention of the reader, tie together, and move smoothly from one to the other?

Is the grammar correct?

Ire words spelled or abbreviated correctly?

Are words, phrases, clauses, and sentences properly punctuated?

\section{Rewrite}

Rewrite your report in the order indicated. First, change the content in places where changes are necessary. Second, rewrite and rearrange for effectivness of organization, Third, correct your diction, sentence structure, paragraphing, and typographical style. You may find that to do a good job even requires a fourth reading. If that is the case, use your fourth step to correct spelling, abloreviations, punctuation, and grammar. It may actually save you some time in the long rum. 


\section{PARTNER METHOD OF REVIEW}

Regardless of the energies you exert, you will find that you have limitations as a critic of your own writing. Your word choice may be abstract, your sentences too long and involved, your organization confused, your neaning obscure-any of a number of faults nuy be present without your being aware of them. What then? How can you eliminate misinterpretation and misunderstanding:

In the police department you work with others-in the same vehicle, in the same office or another down the hall. Try your report on your partner or the man next to you. Have him serve as a disinterested reader.

Even if he can tell you nothing more than that the meaning is not clear, he is providing necessary criticisu; he is facing you with the responsibility of finding out why the meaning didn't get across and then doing something about it.

If he can tell you that you have failed to bring out essential facts in the investigation, that the solution to your problem is illogical, that you are too wordy, or that the organization does not follow a natural sequence-then he is a valuable critic. Strangely enough, your partner may be able to do all of this and more, if you ask him to become your reader. He doesn't need special training for this work-just common sense and an attitude of doing for you what he would like you to do for him.

Here are a few ideas about what to look for in your partner's report and what to suggest in conference with him:

\section{Meaning}

Is the meaning of the report clear? If not, point out those things that confuse you. Ask him to tell you what he means. Work out with him a statement that is clear to both of you.

\section{Over-all Organization}

Your partner's difficulty may be over-all organization. If so, talk over the total report with him. What is he trying to say? To whom? Ask him to jot down the main ideds he wants to put orer. His notes will serve as a rough outline. If major points within the re- 
port are well-developed, total organization can sometimes be inproved by shifting whole paragraphs.

\section{Word Choice}

Is the writer showing ofl? Does he use too many legal and technical terms? Does he conceal meaning in big words? Suggest replacing showy words with simpler words, common words for legal and technical terms. Use the dictionary to find the easier word. Help him to discover smothered verbs, and rescue them. Iocate and remove "scatterbrain" words.

\section{Sentence Structure}

Are his sentences grammatically correct? If not, make proper notations in the margins. Are sentences too long and involved? If so, suggest breaking long sentences into two or more sentences, putting main ideas in separate sentences.

\section{Paragraphs}

Are paragraphs too long? Suggest that he give the reader frequent rest periods. Does the thought move easily from one point to another? If there are sudden jumps, suggest transitional words, phrases, or paragraphs, or an additional sentence as a transitional device.

\section{Level of Abstraction}

If there is need for support of generalization with more specific material, suggest more specific examples or concrete rather than abstract words.

\section{COPYREADING MARKS}

I imited rewriting, minor corrections, and changes to conform to style are usually necessary in even the final draft. If these corrections are minor-inserting punctuation, a letter or a word, or substituting a phrase-they can be made in the text of the material without making the copy illegible. The symbols which may be found at the end of this chapter (called copyreading marks by editors and printers) are useful in editing reports. You may find these useful in editing your own report or that of your partner. 
When you edit your report, remember that compliance with good typographical style is a "must" if your report is to be easy to read. Typographical style has to do with capitalization, spelling, punctuation, figures, abbreviations, addresses, and titles. Consistency is probably the most important principle of style. If you do not capitalize $r$ in Colorado river the first time in your report, continue the practice; do not later write Colorado River. If you use the expression theater, continue to use that spelling; don't change to theatre. (See the example of neatly edited copy at the end of this chapter.)

The following marginal notes may be useful in editing copy tunder the partnership method of review:

agree ....... Pronoun and antecedent, or subject and verb clon't agree

amb ....... Ambiguous word or phrase

apos ........ Insert apostrophe

awk ....... Awkward construction of word or sentence

sbw ....... Scatterbrain word; replace with a specific word

cap ......... Capital letter needed

clear? ....... Is this clear?

coh ......... Coherence; sentence lacks clear order and connection; related parts are not together

colloq ...... Colloquial expression

concr ....... Use concrete word rather than abstract

dead ........ Deadhead word; eliminate it

dng ....... Dangling expression-lacks connection

emph? ...... Is this arrangement emphatic?

fig ....... Use figure, rather than spelling out

frag ....... Fragment of a sentence

gr ........ Faulty grammar

jarg ........ Jargon

Ic ........ Use lower case letter

Meaning ..... Word or sentence is not clear

P........ Paragraph needed

No ........ No paragraph needed

pass ........ Passive voice; should use active

pn ........ Punctuation needed

ref? ........ To what does this pronoun refer?

rep ........ Repetition, redundancy

smo-verb ..... Smothered verb

sp $\ldots \ldots \ldots$ incorrect spelling

str $\ldots \ldots \ldots$ Construction is not parallel 
tense ....... Change tense of verb

Ir ........ Tramspose letters, words, elencents, ete.

trite ....... Word or cxpression overworked

true? ....... Is this a true statement

vague ....... Need more details

wordy ....... Should be shortened 
$\underset{\text { the chief }}{\stackrel{\text { research }}{\text { and develomment section }}}$

tntelligence Zureau

The (capt. excuse? (0) men

Captain R. S. Smith is ixt?

He will go to morrow

Ye washere today

To earnestly desire

presentat/aifn

J. F. Smith, a former rof ficer

infallible neas/ure

Froblem[solution type

Repor't wherein neriodic information

of operation is recorded

](1) $\mathrm{He}$ interprets

JSection IC

Copyreading :larks $C$

9 Trirty men reported

idt

John Rosmith

"'ondayg the first

as follors 0

yet not effective(

well-organized

style $e^{(-)}$formal, informal

äcop hater

Hamilton's

(?)

cannọt

available

emphásis
Type in capital letters

Copltalize the letter indicated

Type in lower case letters

Spell out

Abbreviate or use figures

Bring together, no space

Separate, insert space

Transpose words

Transpose letters

Insert a word

Delete a letter and close up

Cran a word

Delete words and close up

Indent or move to right

Center this on the page

Yove to left

Begin a paragraph

Jelete punctuation mark

Insert a period

Insert a comma

Insert colon

Insert semicolon

Insert Hyphen

Insert dash

Insert quotation narks

Insert apostrophe

Is this correct?

Let it stand

Delete a word

A single letter is wrong 
Here's an example of a neatly edited copy:

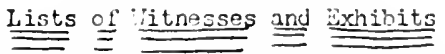

In thetinal report of a case it is necessary or or advantagenus to present a list of witnosses to the reader. This list contains 6 (1) the names and addresses of those persons who have information about the case ${ }_{0}(2)$ a brief sentence indicating the natiure of the testimony each will givo. Reference may be made by paragraph number to the details whrell mention is made of the witness and his information. "The final hoading of a report is usually titled list of exhibits. This list names the articles classified as exhibits. Lach must be adegrately described. 

PART III

REPORTING POLICE OPERATIONS 



\section{Chapter XI}

\section{FIELD NOTE TAKING}

\section{$\mathrm{T}$}

11F FOUNDATION OF ADEQUATE operational reporting is field note taking. Field notes may be taken by a complaint clerk on a conplaint nemo at the time of the receipt of a complaint at headquarters, or they may be taken by an officer on his beat in the performance of his routine duties at the scene of a criminal investigation or by him when assigned or assisting in an investigation. Regardless of the time and place, they are the raw materials from which operational reports are made and are the chief aids in reaching one of the end products of police work, namely the successful prosecution of offenders. Field notes represent the original source material employed in writing case sheets, arrest sheets, prelimimary investigation reports, supplementary investigation reports, and other related records; they form the basis for future action to be taken in any given case.

Field notes are necessary because of the inability of people to remember. A good memory is a wonderful asset, but very few persons have cultivated this faculty to such an extent that all cletails can be recalled at a later time. You should not rely upon your memory. It may be several hours after the commission of the crime or the receipt of a complaint before you have the opportunity to write your report. You should not be burdened by the task of trying to remember those incidents that can be jotted down. A written record impresses the incident more indelibly on your mind, and a reference to a lew words in your notebook, on many occasions, will act as a mental hitching post for a train of connected thoughts relating to the event.

A notebook is the index to your memory when you testify in court. When you rely upon your memory alone, you will be uncertain and indefunite in your answers to questions asked by attorneys. Keep in mind that your memory is likely to fail at critical 
moments, particulary when you are trying to recall seemingly minor but important details such as measurements, directions, and the exact words spoken by a victim, witness, or suspect.

I aw enforcement is a business; adequate reporting is a vital part of this business. You should remember that absolute thoroughness and accuracy in all things are of the greatest importance. In lact, if your department does not already do so, it would do well to establish defmite rules and regulations requiring you and others in the department to maintain field notebooks, to carry them at all times while on duty, and to follow prescribed procedures in the matter of your field note taking.

\section{PRINCIPLES OF FIELD NOTE TAKING}

Crime data should be recorded in your notebook clearly, completely, comcisely, and accurately.

Clear notes are neat, legible, and understandable. You should not use shorthand in the taking of notes unless there are others in the department who can read your system.

Complete notes cover all the details of the crime: What? When? Where? Who? How? Why? and information regarding negative, unusual, and missing facts. To minimize overlooking some of the elements of completeness, some officers have found it helpful to paste to the inside cover of their notebooks the following words: Who, What, Where, When, Why, and How. No matter how complicated and detailed your report may be, if these six questions have not been answered, you don't have a good report. Remember that some insignificant thing on which you place little value might be the very thing which would make a positive connection to a person known to be operating in another jurisdiction: make notations of even the most insignificant facts. This means taking notes on all unusual or out of the ordinary acts committed during, before, or after the perpetration of the crime. Complete note taking also involves sketching the crime scene during the initial period of the investigation and recording measurements.

Concise notes are brief ones with the essential facts included. They are notes that are not complicated by unnecessary and incomprehensible words, phrases, and abbreviations. Be sure that 
your motes contain only the necessary inlormation and are understandable.

Accurate notes include: (1) the correct time and date; (2) the correct nanes of all persons present or otherwise involved, including oflicers as well as stispects, witnesses, ete; (3) the complete and correct residence address, business address, and telephone numbers of all persons concerned; (4) an exact description of the crime scenc: (5) accurate description of property and motor vehicles involved; and (6) case, arest, and indentification numbers when they are available. Accurate note taking also involves the elimination of slang and vulgarisms unless they have a direct bearing on the case. In the event that you enter them in your notes as a part of a suspect's statement, they should be enclosed in epotation manks. Your own opinions have no place in the notes. Cause your notes to form a word picture of the investigation based upon lacts alone.

\section{USING THE FIELD NOTEBOOK}

Your notebook, when properly selected and maintained, is just about the most important law enforcement tool that you have at your disposal. It not only serves as your memory, it is your guide in the interrogation of witnesses, victim, and suspects. You should use it in the subsequent writing of your reports and as a ready reference when you appear in court. Make it useful in serving all purposes, not just one purpose.

\section{Using the Notebook in Interrogations}

The application of your field notes to the techniques of interviewing can be acquired only through experience and the use of certain fundanental practices.

Interrogations are delicate situations, and many people are overawed, frightened, or even panic-stricken by your authority. So, in most cases your approach should be friendly, helpful, and informal. Good will and excellent public relations, which may have taken the department years to establish, can almost ranish during a poorly conducted interview. One rude and ill-mannered officer can destroy public respect for his lellow officers. Also, though 
the complainant may be nervous and seemingly uncooperative, he may be a very prominent citizen; the suspect may not be the perpetrator of the crime, and he may be a reporter who works for a very influential newspaper!

Keep your notebook out of sight until you have studied the situation carefully and have gained the confidence of the person involved. A successful officer sells himself and his department by being calm, thorough, business-like, and friendly. Ise your notebook only when you are sure that note taking will be of benefit. rather than harm to the case.

You'll find that the ordinary complainant won't be reluctant to talk freely about the case. However, if he is emotionally upset, it is better for you to get a rapid-fire verbal account and then ask him to repeat the story slowly in order that adequate notes can be taken.

When you are dealing with a witness, you should first appeal to him for his help. This also can be done in a friendly, businesslike manner. When the witness is sympathetic toward the cause, he will probably rolunteer some information. As in the interview with the complainant, allow him the courtesy of a verbal statement before you enter any information in the notes. In some instances you will find that a witmess will be agreeable to signing a short statement covering his knowledge of the offense. Get this information once you have the facts recorded in your notes.

Of course, the suspect offers your most difficult problem. He is prone to refuse to talk under any circumstances and especially in the presence of a notebook; therefore, discuss the issue with him and, if he commits himself to a story, bring out the notebook and go over the matter with him again. This is not to say that this is the only way. There are many occasions where circumstances alter the situation and a different procedure might be advisable. Use common sense in the matter.

Regardless of the person being interviewed, field notes are most useful when you pay particular attention to what is being saicl. Your notes take on a special meaning when notations are made on the emphasis on words or phrases and the stress on certain ideas that were made by the interviewee. Notations made on im- 
portant terms, tome of voice, attitude, mannerisms, and other peculiarities of the person interviewed will pay off in your efforts to solve the crime.

\section{Using the Notebook in Court}

Many times complete, clear, concise, and accurate notes have been wholly responsible for the successful ontcone of a prosecution; and, by the same token, poorly recorded, inadequate, and inaccurate notes have resulted in mnecessary acquittals which have brought criticism and cliscredit upon the department and embarrassment to the investigating oflicer.

While the primary purpose of note taking is to prepare the preliminary investigation report on a given offense, you should not lose sight of the fact that notes can and will be used in court, and, on occasion, as an aid in testifying.

State law generally permits a ritness to refresh his memory as to facts by the use of anything written by himself, or under his direction, at the time the fact occurred, immediately thereafter, or at any other time when the facts were still fresh in his memory. However, the writing must be produced for the benefit of all persons concerned and may be seen by the adverse party, who may, if le chooses, cross-examine the witness upon it and read it to the jury. Thus, you may testify from your field notes, though you retain no recollection of the particular facts.

When you work with a partner on a case. it is permissible for only one of you to keep the notes so long as they apply to what both of you saw, did, and heard while together. But you should make certain that both of you read and initial the notes at the time they are made. Through this technique the two of you can preserve your competency to testify from the notes should the opportunity present itself.

\section{NECESSARY NOTE TAKING EQUIPMENT}

Just as the carpenter must be equipped with his hammer and saw or the physician his scalpel and forceps, you must be properly equipped for the performance of your note taking task. Trio writing instruments, preferably fountain pens, are a "must." 
There is no miversal type of notebook which will suit all individuals. Writing habits, penmanship style, and type of writing medium are the governing factors. Yet, you should remember that a notebook mutst be carried at all times and should be of a size. which will not detract from your efficiency or appearance. The following suggestions are offered as a guide.

1. Obtain a $33 / 4 \times 63 / 4$ flexible, leather, Jooseleaf notcbook. This type is easily carried in your pocket and provides adecquate space for writing notes (see Fig. 1).

2. Equip the notebook with visible index tabs to separate the various sections of the notebook (see Fig. 2).

3. Provide sections for offense reports (preliminary investigation reports), follow-up, arrests. vagrants, wanted and missing persons, outside wanted and missing persons, military "wants," stolen automobiles, stolen bicycles, miscellancous inlomation, and others that your individual situation may demand.

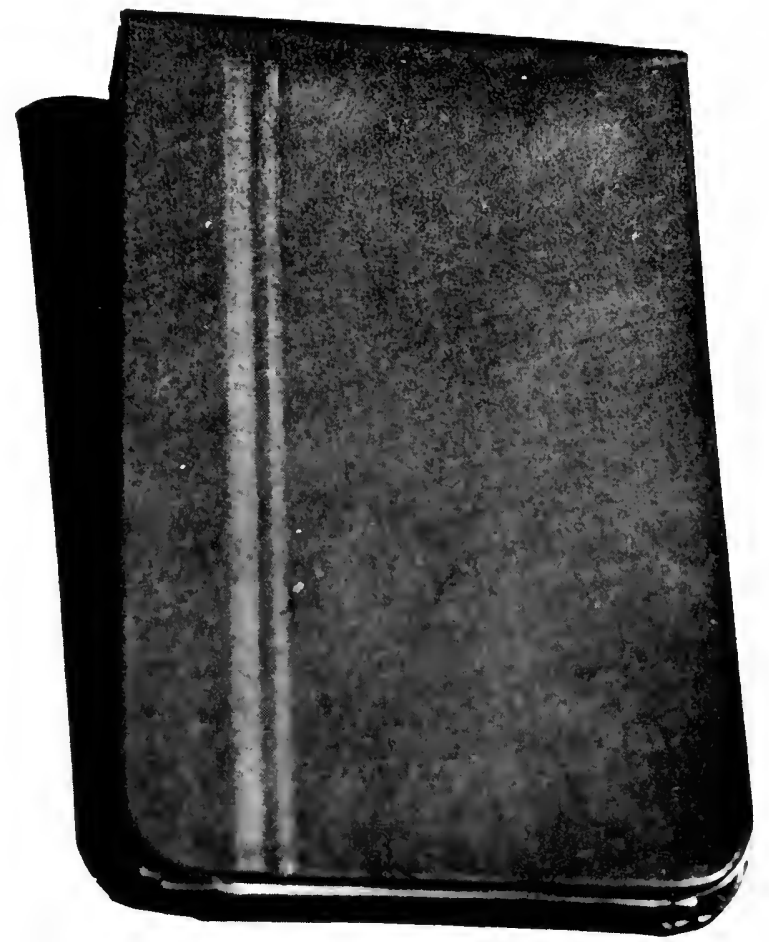

Fig. I. Field Notebook, $33 / 4$ inclics by $63 / 4$ inches, flexible leather looseleaf. 


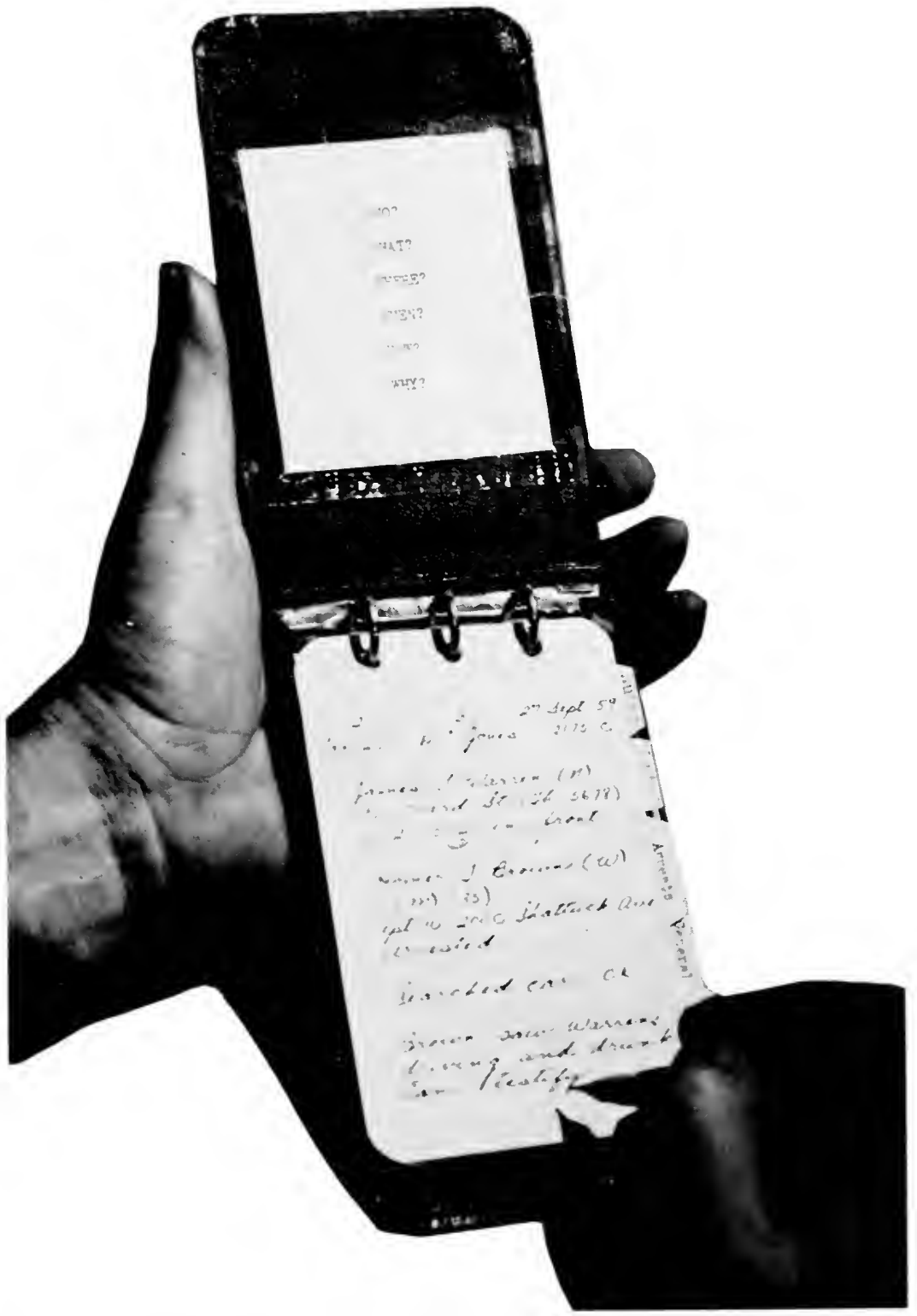

Fig. 2. Field Notebook, $33 / 4$ by $63 / 4$ inches. Note how this small, flexible book fits conveniently into the hand. This notebook can be used effectively under very adverse writing conditions. 


\section{CARE OF NOTE TAKING EQUIPMENT}

Excrcise the same care in the treatment of your note taking equipment as you do of other personal equipment. Two fountain pens are recommended since ink notes do not easily become smudged or illegible. Keep the pen full of ink. Check all of your note taking equipment when you go on duty. Don't allow your notebook to become soiled or torn. An ample supply of ruled paper and forms should always be available. Place your name, telephone number, and home address in the inside cover of the notebook in permanent ink.

Notes no longer in use should be filed in envelopes by month and year and or by case number. Index these notes so that they can be used as reference without difficulty and delay.

\section{OVERALL ARRANGEMENT OF THE NOTEBOOK}

The first section of your notebook should consist of notebooksize forms-miniature forms most frequently used in your routine duties (see Form 1) -and your supply of unused, ruled paper for convenient use in your work. When you open your notebook, you should be able to start writing immediately without fumbling through the whole book.

The second section, the offense section, should contain your notes on all incidents assigned to you, unless you have moved then to the follow-up section. U'se only one page for each incident. No other notes on other cases should be placed on the sheet, not even on the reverse side. When the case is closed, the page or pages of notes on a particular case should be removed and filed.

The third section is the follow'up section mentioned previously. It contains notes on cases that require additional action and notations of any type of business that you need to attend to.

The fourth section, vacation section, contains your list of premises where occupants are absent, including the location of the key or caretaker and a record of the inspections that you have made of the place.

The arrest section should provide a systematic list of all persons whom you have arrested. Along with the name of the arrestee, you 


\section{LOST AND FOUND PROPERTY REPORT \\ Used for:}

LOST-FOUND-PROPERTY FOR IDENTIFICATION

Article

By whom lost

Address.

Telephono

Business cddress

Telephone.

By whom found

Address.

Telephone

Business address

Telephone

Where found.

Doy, dote and time found.

Properly now In custody of

DESCRIPTION OF PROPERTY

FINAL DISPOSITION OF PROPERTY

Owner notified by.

Nome.

Star.

Day, dote and time notified

Form I. Miniature Report Form For Field Note Taking (3: , "Vi:","). 
should include race, sex, occupation, home and business address, telephone numbers, the charge, the place of arrest, and the date. You may transler this information from the offense and follow-up sections of the notebook at the time the arrests are made.

The vagrant section consists of a list, including valuable information, of all persons arrested for vagrancy within the jurisdiction. Information lor this section may be obtained daily from the Daily Police Bulletin.

The wanted persons section contains data regarding persons wanted in the local jurisdiction for crime as well as information on missing persons.

Ontside w'omled persons section should be kept separate from local "wants." It contains data regarding persons wanted or nilssing in other police jurisdictions.

Information for the military wants section can be obtained periodically from military police organizations in the area. It should consist of an arrangement of persons wanted by the military for A.W.O.L., desertion, and other military offenses.

The stolen antomobile section should contain a list of automobiles stolen in the jurisdiction plus a separate list of others stolen throughout the state. Each stolen vehicle should be identified in the notes by license number, followed by model, make, and other identifying information.

The stolen bicycle section should contain a name list and additional identifying information on all bicycles stolen in the jurisdiction.

The general information, or miscellaneons section. may contain certain frequently used sections of the penal code, vehicle code, and local ordinances; excerpts from the manual of rules and regulations; copies of various procedures: list of police aids such as welfare agencies, hospitals, and ambulance and wrecker services; or any other information that will assist you in the performance of your duties.

\section{INTERNAL ARRANGEMENT OF THE NOTEBOOK}

Although there are other methods of internal arrangement of your field notebook, wo particular methods are recommended: 
the alphabetical and daily diary systems. The alphabetical system provides for the arrangement of certain sections of the notebook in alphabetical order. The daily diary system calls for arangenent according to the date the notes were taken. When a combination of the two systems is used, inportant inlormation is easy to locate, a permanent record of activities is maintained for luture reference, and information on vacant premises, wanted and missing persons, stolen automobiles, and stolen bicycles is always at your fingertips.

\section{The Alphabetical System}

The alphabetical system is the simple application of the alphabet to the names involved. The name may be that of a person, bicycle, or a crime as defined in the penal code. Apply the system to the arrest, wanted persons, outside wanted persons, military wants, vagrants, and miscellaneous sections of the notebook. The vacation section may best be arranged both alphabetically according to named streets and numerically according to house numbers and numbered streets.

\section{The Daily Diary System}

The daily diary system works effectively in the arrangement of both the offense and follow-mp sections. As finally arranged, the daily diary applies to the ?nd and 3 rd sections of the notebook.

I'se a separate sheet for each incident reported. If a tour of duty is moventful or without anything of importance to report, it should be accominted for by the usual heading with the words "Nothing of importance" or some similar statement. Account for day or days off by entering the date or spread of dates together with the words "day off" or "dlays off." Each separate entry in the daily diary system contains two principal parts: the heading and the body of the notes.

The Heading. The information that you will use for the heading of each incident page will depend on where you are working, your department, and the type of rork you are doing. Assuming, however, that you are working a beat as a patmolnim, with a partner, and using a department vehicle, each day's heading should contain the following six entries: 
1. The date

2. Case number

3. Shift or watch number

4. Beat number

5. Your partner's name and badge number

6. The rehicle equipment number

The date and case numbers should appear in the upper righthand comer. Enter the beat number and your partner's name and badge number in the center of the sheet. Place the shift number and vehicle equipment numbers in the upper left-land comer.

The heading, when complete, should be printed in ink as shown in Figure 3.

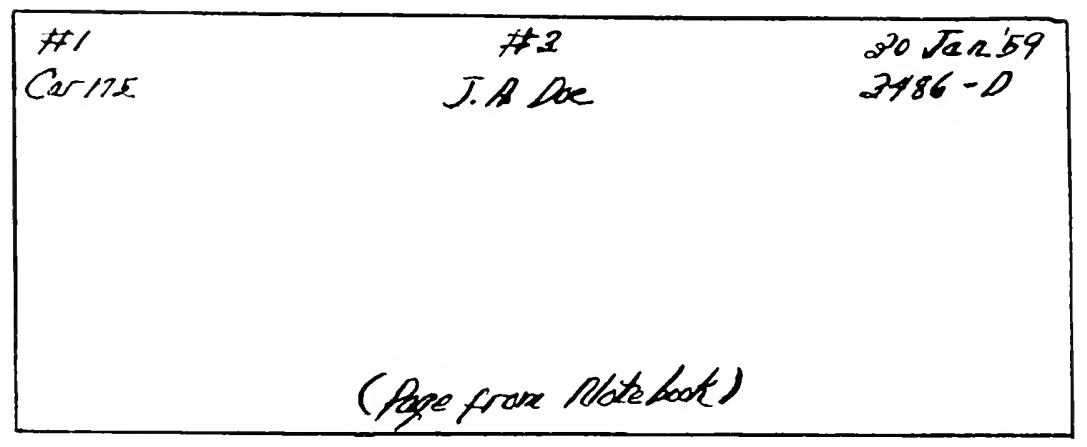

Fig 3. Illustration of heading of a daily diary insert in the field notebook.

The Body. Keep the body of the daily diary entry of activities as brief as possible, preferably in telegraphic form, otherwise in a short time your notebook will become unwieldy and impractical. For example, let us assume the above heading and complete the body of an appropriate entry for the following incident:

About 8:30 A.M. an officer got a call to check a theft report at 856-16th Street. He arrived at that address and got the complainant's name, Mrs. Rosalie Roe, Negro, female, 30 years of age. She gave information regarding the theft of a fur coat which she described as imitation mink.

All information obtained from Mrs. Roe is written in longhand on a clean sheet of paper in the field notebook. The preliminary investigation report is completed from this information. 
The daily diary entry is made in the notebook as shown in Figme 4.

\section{FORMULA FOR OBTAINING NECESSARY INFORMATION}

Here is a formula for obtaining necessary information during a preliminary investigation. Check your field notes against this formula to be sure that you have gotten the necessary facts.

1. Who?

Who was the victim?

Who made the report?

Who discovered the crime?

Who saw or heard something of importance?

Who had a motive for committing the crime?

Who committed the crime?

Who helped him?

Who will sign the complaint:

Who was talked to?

Who worked on the case?

Who marked the evidence?

who received the evidence?

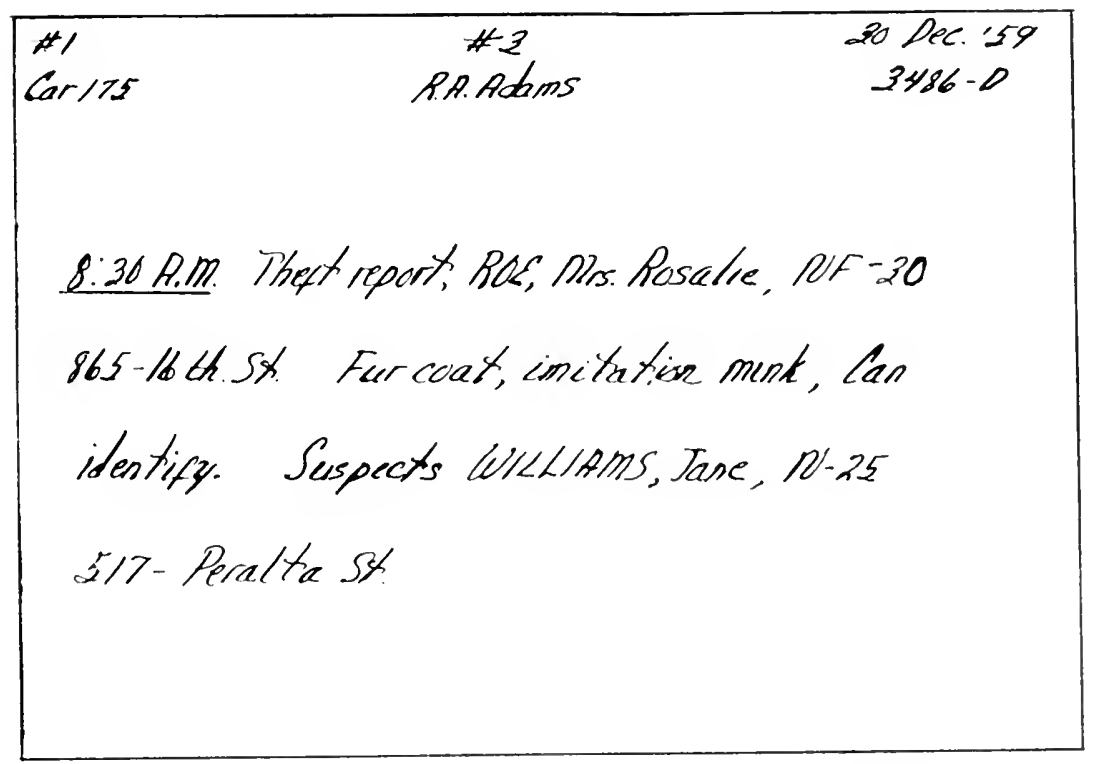

Fig. 4. Illustration of a complete daily diary cntry in the field notebook. 


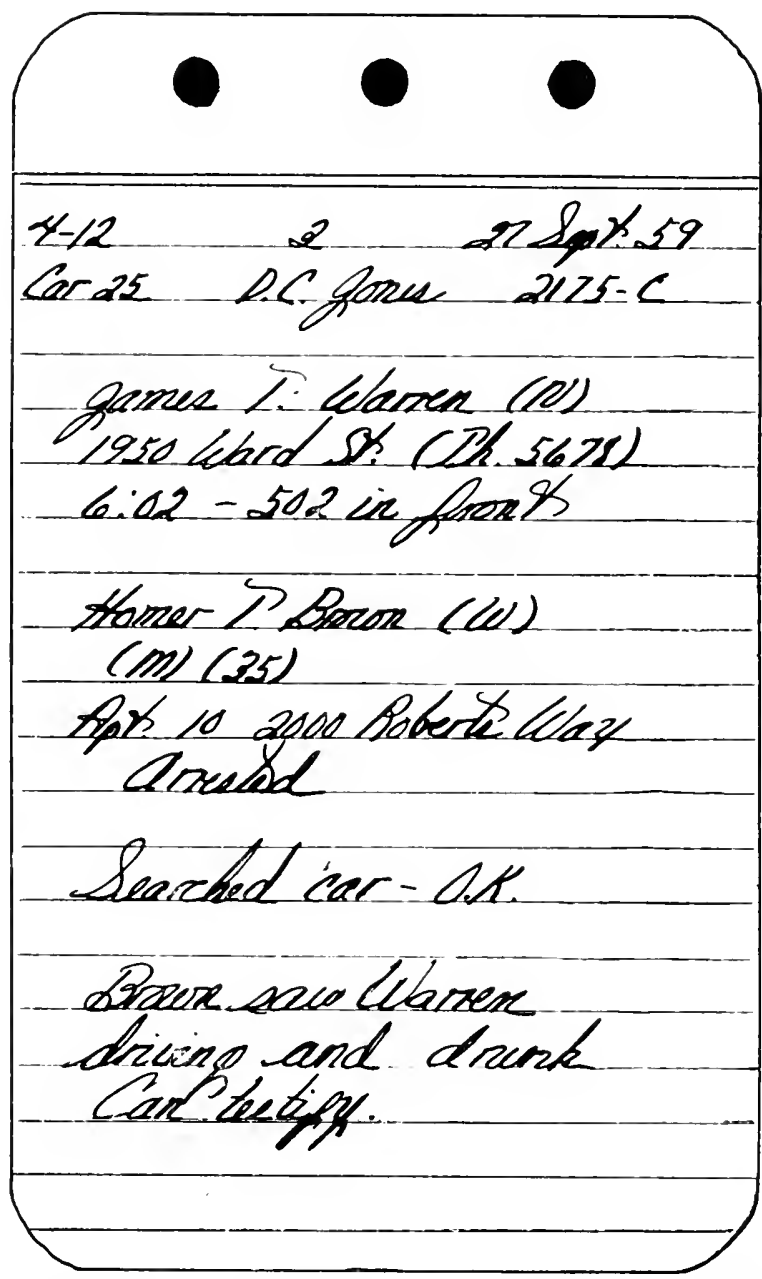

Fig. 5. I page from the offense section of a field notebook. Note the telegraphic style used in recording the information.

2. Whit:

What was the nature of the crime committed?

What actions were taken by the suspect?

What happened?

What do the witnesses know about it?

What cridence was obtained?

What was done with the evidence?

What tools were used? 
What action did the ofhere take?

What further action is neerled:

What knowledge, skill, or strength was needed to commit the crime:

What other ageneies were motificd?

What was reported but did not occur?

What witnesses were not contacted?

What tine was the erine committed?

What time was the crime reported?

What was the time of your arrival?

What time did you contact witnesses?

3. Where:

Where wats the crinc discovered?

Where was the crime committed?

Where were the tools or weapons obtained?

Where was the victim?

Where was the suspeet seen?

Where was the witness?

Where dicl the criminal live?

Where did the criminal hang out?

Where is he now?

Where would he most likely go?

Where was he apprehended?

Where was the evidence marked?

Where was the evidence stored?

4. When:

When was the crime committed?

When was the crime discosered?

When was the authorities notified?

When did the authoritics arrive at the scene?

When was the guilty party arrested?

When was the victim last seen?

When did help arrive?

When will the complaint be signed?

5. How:

How was the crime committed?

How dis the criminal get to the scene?

How did the criminal get awa?

How did the criminal obtain information in order to

commit the crime?

How was the crime discovered?

How were the tools obtained?

How did you get your information regarding the crimc:

How diel you manlage the arrest? 
6. With What?

With what tools was the crime committed?

With what weapons was the crime committed?

With what means did the criminal travel to and from the scene?
a. Auto
b. Bicycle
c. Train
d. Bus
e. On foot
f. etc.

With what trade or profession are the tools associated?

With what other crime is this crime associated?

7. Why?

Why was the crime committed?

Why were the tools used?

Why were certain weapons used?

Why was the crime reported?

Why were witnesses reluctant to talk?

Why was the witness anxious to point out guilty parties?

Why so much time before the crime was reported?

Why did the criminal use a certain MO of entry?

8. With Whom:

With whom did the criminal associate?

With whom was the victim last seen?

With whom are the witnesses connected?

With whom did the criminal commit the crime?

With whom did you talk at the scene and at other places?

With whom did you work on the investigation?

With whom did you expect to locate the suspect?

9. How Much?

How much damage was done?

How much property was taken?

How much knowledge was necessary to commit the crime?

How much money was taken (denomination)?

How much did the victim claim was stolen?

How much trouble was it to carry the property away? How much intormation are the witnesses not giving out? How much is the victim withholding?

How much additional information do you need to help solve the crime? 


\section{Chapter XII}

\section{REPORTING THE CASE}

A

DEQUATE REPORTING AND RECORDs keeping procedures require that your department report and record, in some manner, all incidents that come to its attention. A case or complaint sheet is a basic, permanent, written record of reports of incidents and the action taken regarding them. Only three forms are required in case reporting: the "Ceneral Complaint Sheet," the "Casualty Sheet," and the "Miscellaneous Service Complaint." Our discussion in this chapter will deal exclusively with the procedures and content of these reports.

The case sheet is the foundation of the record for any case or incident since, in the records keeping process, all other related reports are attached to it. In addition, the case sheet is important for purpose of administrative review and control. It gives assurance that complaints have been received, recorded, assigned, posted, systematically dealt with, inspected, and followed up.

\section{Who Prepares the Case Sheet?}

If you are the complaint clerk, it is your responsibility to prepare the case sheet. In a small department you may do this along with the duties of desk sergeant, information clerk, and dispatcher. If your department is large, this nay be your only job. In any event, the work is the type that must be centralized, and you are the only person who can be held responsible for it.

\section{How is the Information Received?}

You may receive information regarding a case in a number of ways. The complainant may telephone. make his complaint in person, or send a letter or telegram. Information may be received in the form of a warrant. When officers initiate their own investigations and make arrests on sight, you will receive your information from investigation and arrest reports. 


\section{When is the Case Sheet Prepared?}

Unless the situation is an emergency, complete the case sheet as soon as you receive the information. On the other hand, if immediate action is necessary, relay the information to the dispatcher and record the information on the data sheet later. If you delay action until investigation oflicers report their findings, some cases will appear so insignificant that you will not record them. This results in an incomplete account of the activities of your department and a loss of control over those incidents that you have not recorded. Remember that a record is required from the beginning of the complaint so that follow-up controls will facilitate proper disposition of all cases.

\section{What Incidents Call For the Case Sheet?}

Almost all incidents reported to your department require that you, as the complaint clerk, shall initiate a case sheet. Make case sheets on the following incidents:

1. Most violations of federal and state laws and city and county ordinances.

2. Nost calls on which officers are dispatched.

3. Reports of lost and found persons, animals, and property.

4. Warrants, subpoenas, and arrests in which a record of arrest is prepared, with the exception of multiple arrests for which a single case sheet is sufficient.

5. Cases in which a police officer is involved in any way in damage to public or private property or injury to any person.

6. Casualties including automobile, public, home, occupational, and firearms accidents; dog bite cases; suicides: attempted suicides; sudden deaths: bodies found; sick cared for: and nental cases.

7. Other cases when administrative orders, rules, and regulations or a commanding officer demand a case sheet.

Don't make a case sheet on the following:

1. Violations of state law and local ordinances which are observed by the police officer and result only in a warning to the violator.

2. Violations of state law and local iraffic ordinances handled by traffic citations.

3. Ninor traffic accidents involving only property damage less than an amount established by your department as reportable. 
1. Calls on which officers are dispalched which are mere requests for information, or which result from traflic violations not endingering human life.

\section{How Many Copies of the Case Sheet?}

If your department has no specialized divisions, only the original of the case sheet is necessary. But if your department has some specialized divisions, make a duplicate copy of the case sheet when you assign a case directly to a specialized division. The original copy will be formarded to the records division and the duplicate to the specialized division. Under this procedure, officers in the specialized division don't have to waste time getting the original from the records office.

\section{How Many Case Sheets Are Made on a Single Incident?}

Since statistical data are derived from the case sheets and accuracy is of prime importance, one of your more important decisions relating to case sheets should be: How many case sheets shall I make on a single incident? The following rules, adapted from Uniform Crime Reporting, ${ }^{1}$ determine the number of case sheets you should make in any case.

In Part 1 cases the rules for offenses against the person differ from those against property; consequently, they are presented under two general divisions.

Offenses Against the Person. Part 1 cases against the person include felonious homicide, rape, and aggravated assault. Make one case sheet for each person against them whom an offense is committed. The number of case sheets you make equals the number of persons killed, raped, maimed, wounded, or assaulted, plus the number of attempts. For example, if one person kills two people, make two case sheets, if two people murder one person, make onty one case sheet.

Offenses Against Property. Part l cases against property include robbery, burglary, larceny, and anto theft. Make a case sheet for each distinct operation that has been undertaken. Observe the following rules:

${ }^{1}$ U. S. Department of Justice, Federal Burean of Investigation: Iniform Crime Re' porting Handbook. Washington, D. C.. Federal Bureau of Investigation, 1955. 
1. Make a case sheet for each distinct robbery. If two persons rob one, or one person robs two at the same time, make only one case sheet.

2. Make only one case sheet for one or several rooms entered in a burglary committed in a hotel or lodging house on the same occasion; make a separate case sheet on each apartment or office suite entered even though it is one of a number of entries made in the same building at the same time.

3. Make a case sheet for each distinct operation in cases of theft. If a thief steals a number of articles. all stored in one place but belonging to different persons, make only one larceny case sheet. If articles or accessories are stolen from several automobiles parked on the street, even though in adjoining spaces, make a separate case sheet on each larceny. However, if they are taken in a single operation from a number of cars in a parking lot or garage, make a single case sheet on the series.

4. Make a case sheet for each automobile stolen, plus the number of attempts. Include cars used for "joy rides." Remember, however, that failure to return a rented or borrowed car, embezzlements, and conversions are not classified as auto thefts.

5 . When several offenses are committed by one person at the same time, make a case sheet for the offense that comes first in the Uniform Classification of Crimes. For example, a burglary and auto theft are committed on the same occasion; make one case sheet for the burglary.

6. Make a case sheet on each Part 1 crime confessed by the offender only when the victim is known and the offense is established.

Part II Cases. All criminal offenses not included in Part I are included in Part II. In Part II offenses against the person, make one case sheet for each person against whom an offense is committed. In Part II offenses against property make one case sheet for each distinct operation. In cases of single violation of state, county, or city ordinances perpetrated by a single person make a case sheet. for each distinct violation of the law.

Make a separate case sheet on each Part II arrest, except in cases when two or more persons are arrested at the same time and place and on the same charge; or when two or more persons are arrested at the same time and place on several charges, the most serious of which is the same in each instance.

Part III Cases. Incidents of lost and found persons, animals, 
and property are recorded as Part III cases. Their classification as Lost or Found depends upon which incident was first reported to your department, not upon which incident first became known. Make only one case sheet on each incident. If the loss was reported first, make a Lost sheet; the act of funding is reported on the same sheet. If something is fomm, the finding is reported on a Found sheet; when the owner reports the loss, the information is recorded on this same sheet.

Part IV Cases. Part IV cases are casualties including motor vehicle, other traffic, public, home, occupational, and firearms accidents; $\log$ bite cases; suicides: attempted suicides: sudden deaths; bodies found; sick cared for; and mental cases.

Make one case sheet for each motor vehicle accident even though several persons are injured. In firearms accidents, $\log$ bite cases, suicides, attempted suicides, sudden deaths, bodies found, sick cared for and mental cases, make a case sheet for each person injured or dead, or each person attempting suicide even though uninjured. The number of case sheets that you make equals the number of suicides, attempted suicides, bodies found, sudden deaths, sick cared for, mental cases handled, persons bitten, and persons injured by firearms. In all other casualties, make only one case sheet for each accident, regardless of the number of casualties.

Part $\boldsymbol{V}$ Cases. If your department requires case reporting of any other matters, the situations and incidents should be recorded as Part V cases. In recording Part $V^{\prime}$ cases, make one case sheet for each incident or matter reported.

\section{GENERAL COMPLAINT SHEET}

Use the general complaint sheet, Form 2, for all cases other than casualties and cases reported on "Miscellaneous Service Complaints." In initiating the report, remember that all data requested on the report form are needed for adninistrative purposes. A useless item would not have been inclucled.

In the following discussion each item of the report is explained in detail, and a number is assigned; proper procedure dictates that you complete each item in sequence according to the number assigned to each explanation. 
CONIPIANT SHELT

CI.ASSIFICATION (I)

Victim

Adelress

Business

Acliress (7) (5) (6) (1) SIB.CIASSIFICATION

C.SE NO.

(3)

(I9)

$(20)$

spec. Invest. (21)

Other Oflicers (2)
Where Commitled $-(8)$

When (9) Persons Arrested $(23)$

How (10)

mrested bs $(24)$ Date (25)

Connect with Case No. - (26)

Suspect (11)

Reported by (1)

Acldress (I3) Phone (14)

Reported to $-(15)$ Platoon and Beat

lime Reported l6)

How Reported: Phone $(17)$ Letter Telegram Patrol olficer Received Complaint by:

Radio _ (18) _ Box On View At Station Citizen

1) plicate to (28)

Classilication indes card corrected:

(29)

Cleared by Arrest Date Clerk

lrop. Recur il-lal. Dite Clerk

Infornded Date Clerk

Classilication Changed _ Date Clerk

F. I'. Officer Notilied Date Clerk Indexed Insperted

Closed

Clerk I.L. OAf F. I , ()If.

Ditle Date Date

Form 2. Complanint Sheet (St/2"x11"). 


\section{Classification (1)}

You will note that Appendix B provides for 18 major uniform classifications of incidents. Enter one of these major classifications as the "Classification." For example, if the incident is crininal homicide, enter the words, "Criminal Honicide," in the space after "Classification."

\section{Subclassification}

Enter the proper subheading in the space following "Subclassification." For example, if the killing was willful, enter "Murder" or "Non-negligent Manslanghter." In entering both the "Classification" and "Subclassification," no distinction is made between offenses committed by juveniles and those committed by adults.

\section{Case Number (3)}

Each complaint sheet must be identified by a serial number, known as the "case number." It is your responsibility to assign this case number. Assign the number next in sequence. Be extremely careful in assigning this number; all subsequent investigation reports and other forms and papers relating to the incident will be given this number by the officer who submits them.

\section{Victim (4)}

After "Victim," list the name of the victim, if there is one. If a person is arrested for an offense in which there is no particular victim or complainant other than the arresting officer, enter the nane of the person arrested as the "Victim." If the victim is a business or institution, leave this item blank.

\section{Address (5)}

Give the complete address of the victim, if possible.

\section{Business or Institution (6)}

If the victim is a business or institution, leave the "Victim" space blank and complete items 6 and 7 . I'se the telephone or city directory as a guide in recording the complete and exact name. 


\section{Acldress (7)}

Also record the exact address of the business or institution as given in the telephone or city directory.

\section{Where Committed (8)}

When the complainant alleges that the offense was committed in a city or incorporated town, record the exact street and building number. If the crime is alleged to have occurred in a rural area, establish its location by using familiar landmarks.

\section{When (9)}

If possible, record the exact day, month, and year that the incident is alleged to have been committed. When there is no degree of certainty as to the time of occurrence, record the time and date as nearly as possible; for example, "between 6:30 P.M. and 9:00 P.M., 1/10/60."

\section{How (10)}

State the way in which the person or property was attacked. In burglary, property is attacked by breaking in. Give the point of entry, as rear window, first-floor side window, etc. In robbery, state the method of attack, as strongarmed, slugged, beaten, etc. In worthless checks, drafts, notes, forgeries, and the like, state if by passing, forging, or raising, or if by fictitious or fraudulent checks, drafts, or notes. In larceny, specify the place from which the property was taken; for example, cash register, bedroom, desk, kitchen, etc.

\section{Persons Suspected (11)}

Complete the "Person Suspected" space only if the victim or person who reported the incident is able to give the name of a person whom he suspects or to give a description of an unknown suspect. Give the full name and or description of the suspect, if possible.

\section{Reported by (12)}

State the full name of the person who originally reported the natter to your department. The name of this person is more important than the name of the officer who relays the report to you. 
Address (13)

Give the complete adehess ol the person who reported the incident to your department.

\section{Phone (14)}

Include both the lome phone and business phome numbers of the person who first reported the incident. This information may save time later in the investigation.

Reported To (15)

Insert the full name of the ollicer to whom the case was furst reported. Include platoon and beat numbers if the officer is a patrolman. If you received the report directly from the victim or complainant, place your initials in the "Reported To" space.

\section{Time Reported (16)}

Give the hom, day, and year that the incident was reported to your department.

\section{How Reported (I7)}

Indicate the method of reporting to the department by placing a check mark after "phone," "person," "letter or telegram."

\section{Patrol Officer Received Complaint By (18)}

If a patrolman received the complaint in the field, indicate the method by checking the appropriate box. Otherwise, leave the space blank.

\section{Assignment of Officers (19-22)}

As the complaint clerk, it is your duty to assign officers who worked or will work on the case. Enter the name of the officer assigned to make the preliminary report in the space "Preliminary Reported By." If you don't know the time of occurrence of the incident, assign the patrol oflicers who covered that beat or patrol dis-

trict during the hours when the offense may possibly have occurred. If a special investigator is assigned, place his name on the appropriate line. If the case is to be handled directly by the detective division, assign the detective regularly assigned to such crimes as well as the patrol officer in the area in which the crime occurred. 


\section{Person Arrested (23)}

Usually you will not know the names of persons arrested when you make up the complaint sheet. In such cases leave the "Persons Arrested" space blank; the information will be inserted in the records division once arrests have been made. In cases involving "on view" arrests or those in which a suspect or suspects are arrested at the crime scene or immediately, record the full names of all persons arrested.

\section{Arrested By (24)}

Enter the name of the arresting officer or officers.

Date (25)

Give the day, month, and year that the arrest was made.

\section{Connect With Case Number (26)}

Insert the case numbers of other cases that are related in some way to the case at hand. For example, a burglary suspect may have been arrested in a stolen automobile, in which event you should connect the stolen auto with the case which records the burglary. Similarly, you should connect the arrest of a person with the cases which record any other crimes he may have committed. Connect all cases on several crimes committed by the same criminal. In the latter situation select one of the cases as the "key" case in order that the personnel in the records division may file other reports with it.

\section{Property Stolen (27)}

Complete the "Property Stolen" space only when the case involves the theft of property. List a description of each item of property (see Appendix C for instructions) along with the present cash vahue. If you do not have enough space, insert "See Reverse" and use the back side of the sheet to complete the list.

\section{Duplicate To (28)}

Incert "Detective," “Traffic," "Vice," or "Juvenile" in the Duplicate To" space when you make a duplicate copy and notify a specialized division of the incident. 


\section{Classification Index Card Corrected (29)}

As the complaint clerk, yot are not responsible for the completion of the "Classification Index Card Corrected" section. Appropriate records clerks will make the corrections or changes in the case sheet ats alterations become necessary. This section provides a permanent record when the clerks indicate the case is cleared by arrest, property has been recovered, or the classification changed.

\section{Indexed, Inspected, and Closed (30)}

Like the "Classification Index Card Correted" section, this section serves an administrative purpose in the records division. When the case is indexed by a records clerk and inspected and closed by the follow-11p officer, the case sheet is initialed by the appropriate person and dated.

\section{Use Scratch Pad or Case Memo}

You will find it helpful to take your original notes on a scratch pad or a Complaint Memo (see Form 3). The complaint memo contains the information necessary to complete the general complaint sheet.

Victin Case No.

Residence Address Jhone

Business or Institution

Business Address Plone

Where Committed IIhen

How

Person Suspected

Reported b) Arliress Plione

Reported 10 Time Reported

Beat othcer can contact complainant at

$$
\text { (Address) }
$$

Beat Oflicer Contacted Complainant at Headquarters

$$
\text { For.t 3. Complaint Memo (8"x5"). }
$$


Hold the complainant on the telephone or at the desk until you get all the information necessary to complete the report.

\section{CASUALTY SHEET}

The casualty sheet, Form 4, is just another form of case sheet; for the most part, the content is the same as the complaint sheet. Apply the same rules and procedures in the completion of the casualty sheet that you applied to the complaint sheet. Use this sheet in lieu of the general complaint sheet in reporting casualties including motor vehicle; other traffic; public, home, occupational, and firarms accidents: $\log$ bite cases, suicide, attempted suicides, sudden deaths; bodies found, sick cared for and mental cases.

Note that this case sheet bears the printed heading. Ciasualty. Insert the major classification of the casualty after the word CIASSIFICATION and the subclassification under the word SUBCLASSIFICATION. Insert the full name, address, and extent of injury of all persons injured in the incident and all drivers involved, if the case involves a traffic accident. Complete the remainder of the report in the same mamer as you would complete a general case sheet.

\section{MISCELLANEOUS SERVICE COMPLAINT}

Third, and last, among the case reports is the "Miscellaneous Service Complaint" (Form 5). This form was designed for use in reporting complaints received and investigations made where neither of the other case reports is applicable. Use the form to report the results of the investigation of noise and domestic complaints, suspicious circumstances, civil matters, assistance provided for persons who are ill, suspicious auto complaints, frightened persons, suspicious persons, miscellaneous traffic complaints, bonfires, services to householders, dangerous non-traffic hazards, requests for assistance from outside departments, and other minor criminal and non-criminal matters where no arrests are made, no citations are issued, and the whole of police activity is completed with the submission of this one report.

Unlike incidents of a more serious nature, matters reported on the "Miscellaneous Service Complaint" do not require prior com- 


\section{CASUALTY SHEET}

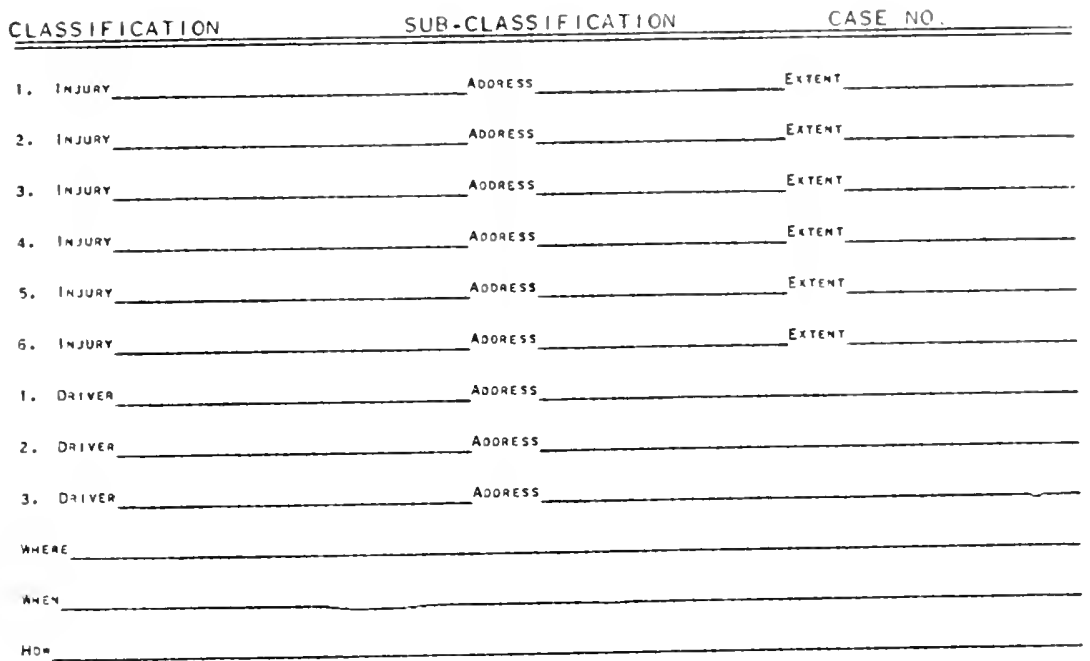

SPEC. INVEST.

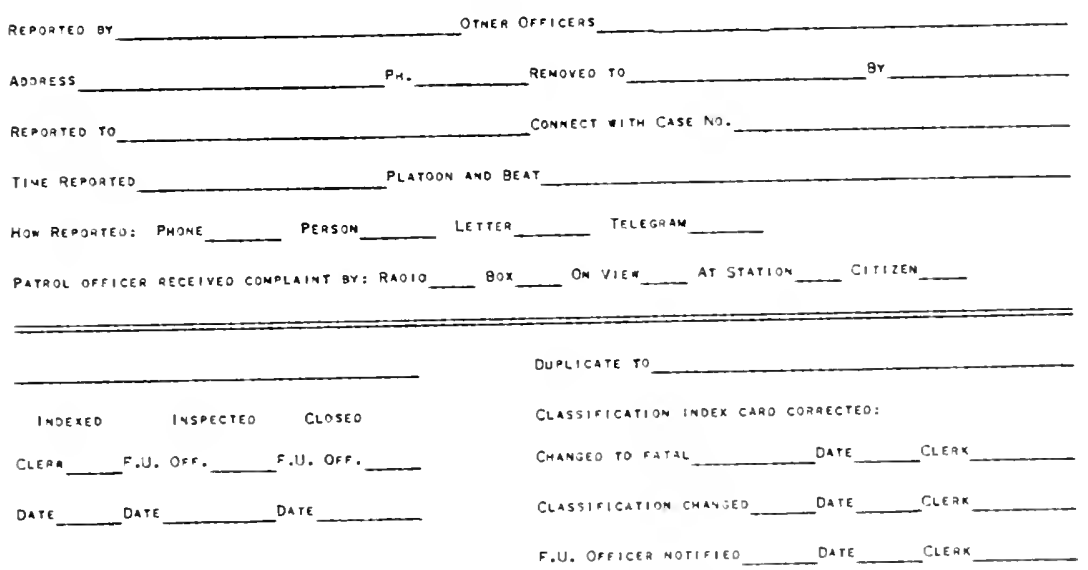

FOr.I 4. Casualty Sheet $(81 / 2, \times 11$ ") .

pletion of a general "complaint sheet" or "casualty sheet." The form serves as both a case sheet and a preliminary investigation report. It is an effective means whereby your department gets complete reporting of all minor situations that are known, with the least amount of paper work. 


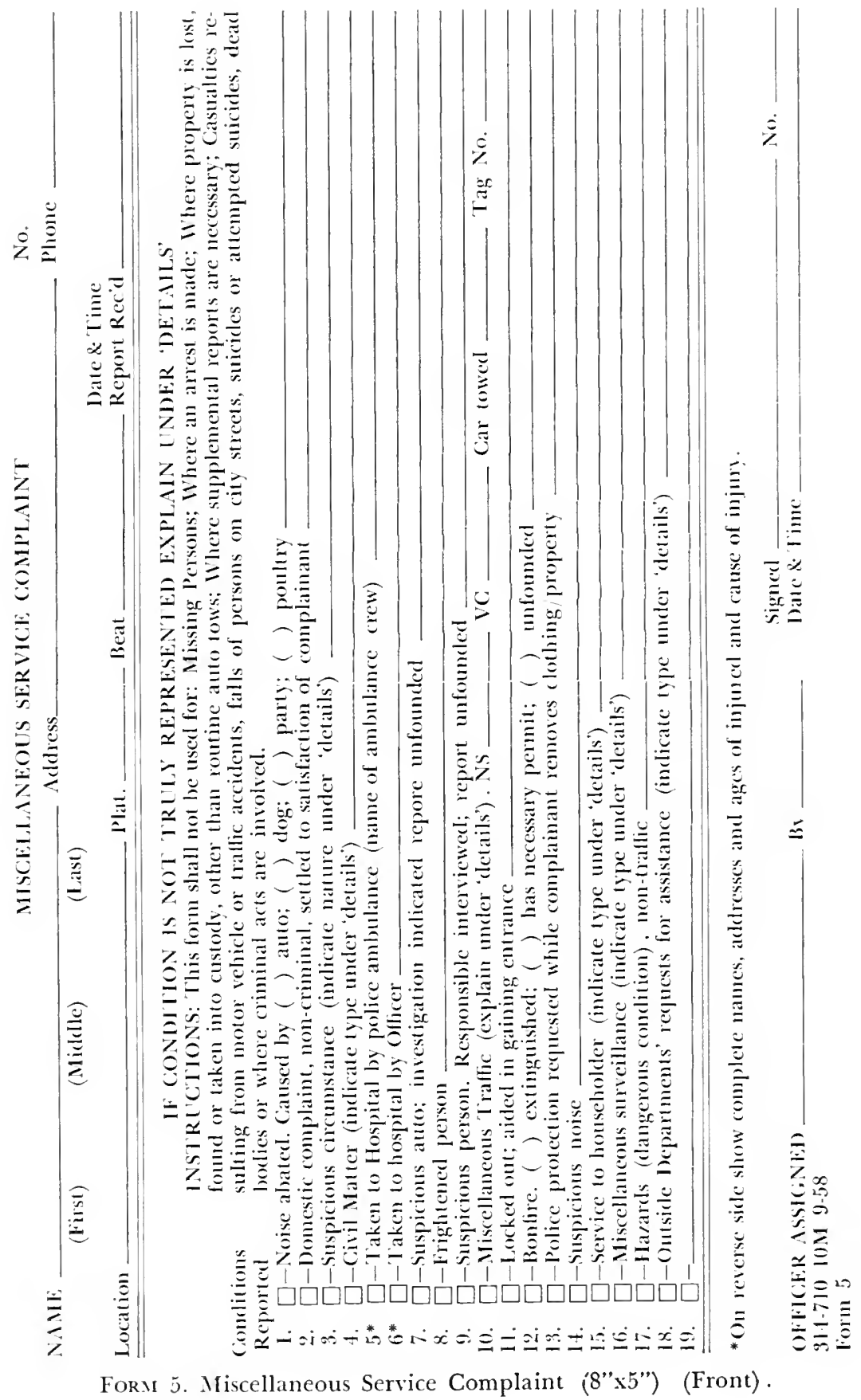


PERSONS RESPONSIBLE:

DETAILS: (Be brief but specific)

Signed No.

Date and Time

TO BE FILLED IN BY SERGEANT

Comments:

Approved Sgt.

Dale

Form 5

Fokм 5. Miscellaneous Service Complaint (Reverse).

The form is initiated by you as the complaint clerk; record the name, address, and telephone number of the complainant; case number; location of the incident; and date and time the complaint was received; and then assign an officer to the investigation.

The assigned officer, reports the condition as discovered in the investigation by checking the appropriate one of the 19 blocks on the far, left-hand, side of a form. On the back of the form, he lists the full name or names of the person or persons responsible for the incident; gives a brief but specific statement of the details of the investigation; signs the report; and records his badge number, time, and date. 


\section{Chapter XIII}

\section{REPORTING THE PRELIMINARY INVESTIGATION}

\section{A}

S STATED EARLIER, THE CONPLANT clerk has the responsibility for receiving information on complaints and completing the "case sheet." In addition, he assigns an officer to the case in order that an investigation may follow. At this point another important phase of the operational reporting process begins.

Isually, the clerk will assign the patrol officer upon whose beat the offense occurred. If the time of the offense is unknown, he will assign the officer or officers who covered the beat or patrol district during the hours when the offense probably occurred. When departmental policy dictates that a particular case in its preliminary stages shall be assigned to the detective division or another specialized division of the department, the clerk assigns the detective or other officer regularly assigned to such crimes as well as the patrol officer in the area in which the crime occurred.

Generally, the desk clerk relays the assignment to the communications staff, and it is the responsibility of a communications officer to notify the officer or officers who have been assigned to the investigation. The assignment may be made immediately by radio, telephome, or in person. However, when the assignment is not of an emergency nature, it may reach the assigned officer or officers through a daily bulletin, an assignment sheet, or through receipt of a copy of the case sheet itself. Regardless of the method by which the assignment is received, it is the responsibility of the investigating officer or officers to report in cletail all action taken.

Most police departments prescribe a regular printed form for reporting the preliminary investigation. Some may call it a Prelimimary Imestigntion Report; others may label it a Crime Report. Except for the special forms provided for automobile and bicycle thefts. missing and wanted persons, lost and found articles, and auto accidents, a general preliminary investigation repont is re- 
elan:KVILLE POLICE DEPARTMENT (1)

PRELIMINARY INVESTIGATION REPCRT

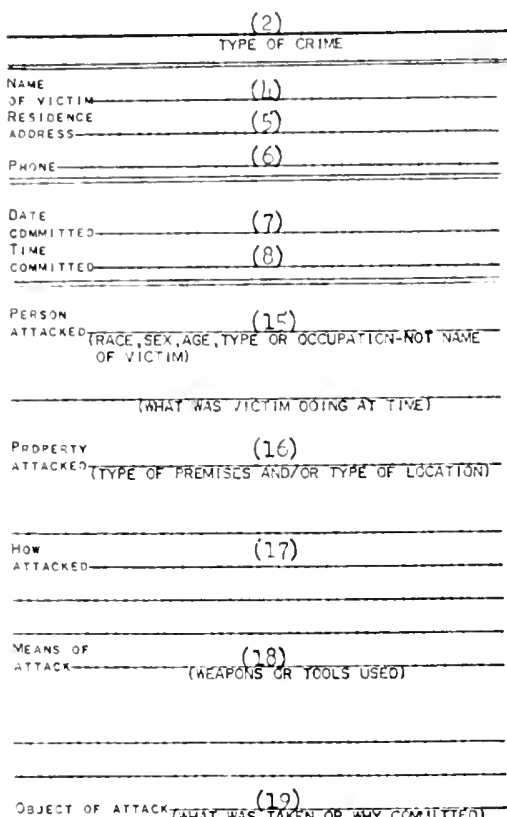

OBJECT OF ATTACK WHAT WAS TAREN OR HAY COMATTIEO

TQADE MAAK OR PECULIARITY $(? 2)$

WMAT DID SUSPECT SAY' (2I)

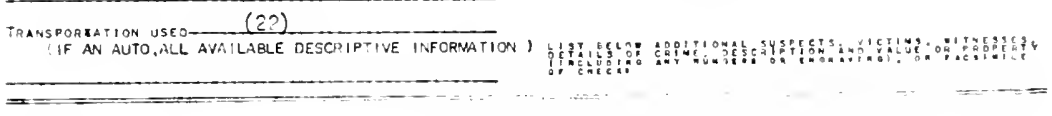

\section{DIAILS: (2h)}

\section{Fon:2 STOLEN: (25)}

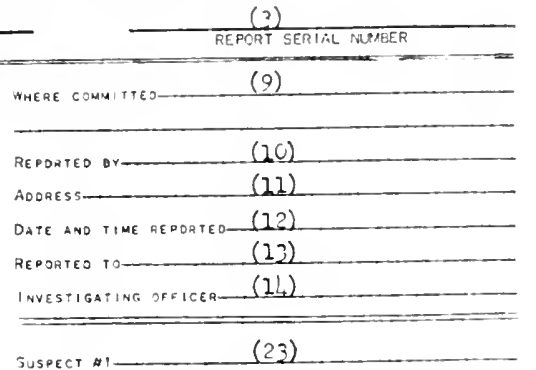
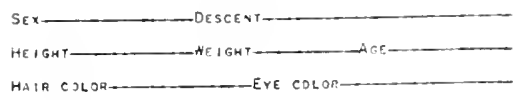

MAAKS/SCARS

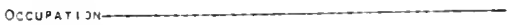

DUSGUISE OR ORESS _

ARRESTEO' TYES CE NOT lOEVIIFICATION NO.-_.......
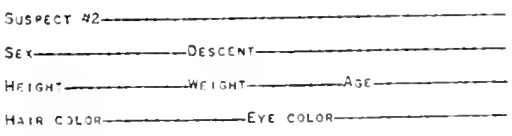

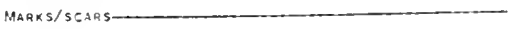
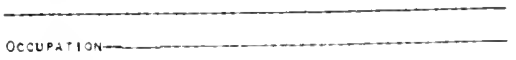

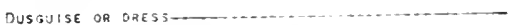

ARRESTEOT- TES CR VET IOEVTIFICATION NO.-.......

bำ 
quired of any oflicer or officers assigned to cases of violence, theft, and fraud.

\section{NATURE OF THE GENERAL PRELIMINARY INVESTIGATION REPORT}

The general preliminary investigation report. Form 6 , is by nature a "modus operandi" report. Modus operandi, literally translated, means "method of operation." In police work, it is understood that the individual peculiarities, methods, techniques, and tools used by the criminal in committing the crime are among the more significant facts which later may lead to his apprehension. The general preliminary investigation nust reveal these characteristics.

The principal theory "pon which the "M.O. system" and the preliminary investigation report have been developed is that the criminal, like all human beings, is a creature of habit. A habit may be started intentionally or accidentally. After the thing has been done once, memory will then assist and will determine whether or not the previous action will be repeated. Repetition will be influenced by the success or failure of the previous act, or the sensation of pleasure or displeasure which was incurred when it was committed. Generally, if a criminal on his first attempt at burglary has been successtul in using a one-half inch pry bar on a rear bechoom window, he is likely to continue using the same pry bar or one of similar dimension. If he is successful in committing his crime during early morning hours, if he gets enough money or other loot to satisfy his desires from the home of a minister, he is likely to continue his burglaries during the same hours and to attack the hones of other ministers. His habits or his metlods will be influenced by the success or failure which he has in his operations.

If you are the officer assigned to a prelinimary investigation, the "M.O. system" of investigating and reporting a crime is one of the tools which you have to assist you in your duty. The preliminary investigation report with emplsasis on method of operation is the means whereby a particular burglar may be set apart from other burglars, a particular robber differentiated from other 
robbers, or a bunco operator or fictitious check passer identified by his habits or methods. Thus, it is important that you understand the specific information which must be obtained during the preliminary investigation in order to prepare a report which cn1phasizes the "modus operandi" of the criminal.

Report forms may vary from department to department, but the "modus operandi" lactors of this report are generally as set forth in the following outline:

1. Time of attack- (or date and time committed)

2. Person attacked

3. Property attacked

4. How attacked

5. Means of attack

6. Object ol attack

7. Trademark or peculiarity

8. What the criminal said

9. Transportation used

The preliminary investigation report also includes information which is not strictly a part of the criminals "modus operandi," such as physical description or description of stolen property which will be of value to you in identifying him for consideration as being responsibile for the crime.

Careful completion of a well-arranged preliminary investigation report is the best guide that you can get to assist you in covering the various phases of the preliminary investigation. The information is arranged in suitable form for ready reference; and later analysis of the "modus operandi" information will often prove to be just the data you need in the solution of difficult cases.

\section{GENERAL CONTENT OF THE REPORT}

Usually, the police department will provicle that the printed preliminary investigation report shall be $8 \frac{1}{2}$ " $\times 11$ " in size. A form of this size offers no particular problems in filing and furnishes ample space for all information necessary to the preliminary investigation.

Make a separate report, in duplicate, of each crime committed. 
Il multiple crimes are committed against one victim, you should make separate preliminary investigation reports for each crime. Horever, if one crime is committed against more than one victim. only one report is required.

In adequate preliminary investigation report should contain general administrative data as well as "modus operandi" information. In general, the administrative data which constitute the heading of the report include: (1) the name and location of the reporting department, (2) type of crime, (3) report serial number, (4) name of the victim, (5) residence address of the victim, (6) telephone number of the victim (both business and residence), (7) date committed, (8) time committed, (9) where the crime was committed, (10) who reported the crime, (11) the address of the person who reported the crime, (12) the date and time the crime was reported, (13) the person to whom the crime was reported and, (14) the name of the investigating officer or officers.

The "modus operandi" information, names and descriptions of suspects, description of lost or stolen property. and the "details" of the crime investigation make up the body of the report. Administrative data at the end of the reports are given in these numbered sections: (26) the signature of the oflicer reporting the information, and (27) the date and time the report was made.

\section{SPECIFIC CONTENT OF THE REPORT}

1 detailed explanation of the various components of the report follows. You will note that each part of the heading, body, and ending is labeled with an identifying number in the illustration Form 6, and the corresponding number has been placed in parentheses alter the title of each part in the text of the discussion. When you need to refresh your memory as to the requirements of any part, turn to the illustration, check the number, and then tumn to the text for the detailed explanation.

\section{Reporting Department (1)}

Note that the report form is so constructed that the name of the city and type of law enforcement agency appear in the heading. It the reporting agency is a sheriff's office, the name of the county should appear in the heading. 


\section{Type of Crime (2)}

On the line, "Type of Crime," you should show the offense committed. In addition to citing the particular code section involved, it is helpful to include the usual name of the offense: for example, "Sec. 21 I PC:-Robbery." Your classification of the type of crime should conform to the lacts of the case as they appean in the body of the report, and the report should reflect the necessary clements of the oflense as defined in the law.

\section{Report Serial Number (3)}

The report serial number is the ase number. Get it from the desk clerk, daily bulletin, or a chuplicate copy of the case sheet. Remember that this number must be recosded correctly for the report to be "hooked up" with other reports relating to the same case, once the original copy reaches the records division.

\section{Name of the Victim (4)}

The victim is the injured party or the person who actually suflered the loss. The victim may be an individual or a business firm. If he is an individual, show the full name of that person. If a firm is the victim, place the name of the firm in this space, rather than the name of an employee who may represent the rictim.

For example, if a Standard Oil Company service station is bunglarized, and money or property belonging to the company is taken, the victim is the Standard Oil Company. If a robbery is committed against the manager or any employee of the same service station in which the company money or property is taken, the fom is the victim. When, in addition to company money or property, the personal funds or property of an employee are taken, you should atso name the employee as a victim.

Thus, if more than one victim is involved in the same oflense, the symbol, "V\#l," should precele the name written in this space: names, addresses, and telephone numbers of additional victims should be listed and indentified as "V\#2," "V\#?." etc., in the " details" of the report. 


\section{Residence Address (5)}

The line, "Residence Address," is intended to provide information as to where the victim may be located. This information is primarily for the use of your department, if it is necessary to communicate with the victim later.

If the victim is a firm, you should record the business address. When the victim firm has various branches or offices, the address listed should ordinarily be that of the branch or firm official in charge of the area for which your department is responsible. Some large firms maintain a security department whose representatives handle the reporting of offenses in which the company is victimized. In these instances you may give the address of the special agent or other person in charge of the firm's security or protection department.

\section{Telephone Numbers (6)}

If the victim is an individual, record both the residence and business phone numbers. When the victim is a business firm, list both the telephone number and extension at which the officer who represents the firm can be called.

\section{Date Committed ( 7 )}

"Date Committed" means the day of the week, date of the month, and the year that the offense was committed, as "Wed., Nov. 7, 1959," or Wed., 11-7-59." If you do not know the precise date, the dates during which the crime occurred should be given as "betreen Wed., 11-7-59, and Sat., 11-10-59." When you include the day of the week you help in the making of a comparison of reports in a series of offenses.

\section{Time Committed (8)}

Report as accurately as possible the time the offense was committed. If you don't know the exact time the offense was committed, report the period during which the crime might have been committed, as "between 6:00 P.M and 9:00 P.M."

\section{Where Committed (9)}

If you are a member of a city police department, list the exact street address of the premises at which, or in front of which, the 
offense was committed. A sheriff's oflice reporting an offense in a town or city will include not only the street address but also the name of the district or community. Report an offense committed in a runal area or on a highway with relerence to crossroads or other known landmarks. In addition to specific addresses, you will fund it of value to describe the location of the premises by name as well as by strcet address, as: "the Cutter Ranch, Rt. I, Box 63, Folsom Blvd.," “City Hall, 1200 Bercndo Blvd.," "City Clinic, 65 First St.," "Plaza Park, Ninth and S Streets."

\section{Reported By (10)}

On this line you should list the name of the person who made the offense known to the department. Remember that in many cases the person who reported the incident is not the victim. If the report was made by the victim, it is necessary only to write "victim" or the letter "V." When the report was made by an employee of a firm, indicate his relationship to the firm, as well as his name and address (11).

\section{Date and Time Reported (12)}

Here the date and time entry is self-explanatory. For example, state the time the report was made to the department as: "Nov. 7 , 1959, 2:46 P.M." or "11-7-59, 2:46 P.M."

\section{Reported To (13)}

In order that your department may have adequate information for future reference, it is desirable that you record the name of the officer who first received the report. In many cases this will be the complaint clerk, but this is not necessarily true. Be certain as to who received the first report of the incident.

\section{Investigating Officer or Officers (14)}

Your name and the names of other officers assigned to the case should be placed on this line. Some departments also require your badge number as a means of identification and for statistical purposes. In any event, later developments in the case may make it necessary for other persons in the department to get additional information from you. 


\section{Person Attacked (15)}

The heading, "Person Attacked," is used because a criminal may habitually select persons of a particular race, occupation, or class as his victims. In this space record the race, sex, age (exact age), descent (if the victim is obviously of loreign descent), and the victim's occupation or usual activity. When the person attacked is a jurenile, be especially careful in recording the age; this is necessary information since elenents of some offenses depend upon the age of the victim. In addition, the qualifications of the victim as a witness may depend on age.

Remember that information in this space should reflect the type of person attacked, not the name of the person attacked. The person attacked may be a disabled veteran, a minister, a retired Chinese merchant, a high school girl, or a carpenter. You will want to record the descriptive information as, "white, female, 35. German, school teacher," or "WF35. German, school teacher." Another example might be "Negro, female, juvenile, high school student, 15 years," or condensed to "NFJ (15), high school student."

Don't forget the fact that a criminal may select a particular person to attack because of the activity of the victim at the tine of the offense. For this reason space is provided for a brief note on the line titled, "What was the victin doing at the time (of offense)?"

\section{Property Attacked (I6)}

In this space describe the place or type of premises at which the offense was committed e.g., "one-story, five-room, frane dwelling" or "two-story, eight-room brick residence," "one-room, tank house, rural area," "railroad refrigerator car on packing house sidling," "drug store, outlying business district."

When a building is used for a number of purposes, first specify the particular purpose for which the room where the offense occurred is used. Then describe the general use of the building, such as, "retail grocery, on main floor of apartment house," "dentist's office, on second floor of office building," "physician's office, on first floor of two-story residence," "airline ticket office in hotel lobby." 
In addition a reporting ahe kind al premises where the oflense took place, it may be of walue to describe the general chanatere of the area or district where the oflense ocomed. This is esperially me when the neighborloosd has any outstanding characteristics. bater analysis of these data maty pore valuable in connceding the crime with a series of erimes. Examples of this lype of information are: "industrial district," "Chinese business district," "xrusire residential area," or "packing house district."

let us assume that you are reporting a rape which occured in front of an apartment house tenanted by Negroes in a Mexican district. The "preperty attacked" should be described like this: "street in front of Negro apartment homse, Mexican district." Thus, you will note that, for reporting purposes, a siclewalk, high. way, strect, want lot, or field may be the "property atracked."

\section{How Attacked (17)}

What you should record in the "how attacked" space is derermined by the type of erime which you are reporting. In oflenses other than burglary, present a general ontline of the manner in which the offense was commited. For example, in robberies you should show what induced the victim to smrender his property. Thus, in these types ol cases the "how attacked" may be "beating." "choking," "drugging," "bound and gagged," "accosted trom behind," etc.

In sex crimes this factor may include "enticement by oflering money," "exhibiting lewd photographs," or "offering a ride."

If your case is an ordinary theft, the best way to describe "how" attacked" is to state specifically where the theft took place, as "taking from basenent of residence," "taking from clothes line," taking from mail box." etc.

In reporting burglaries you should include reference to the point of entry and the mamner by which entry was made. State the location of the door. window, or other place of entry and the floor on which entry was made. This might be "prying rear kitchen door, furst floor," "breaking glass. side window of basement," or "sawing hole through ceiling."

If a sale was burglarized, the "how attacked" also must inclucle how the safe was attacked. For example, the safe might be attacked 
by "drilling," "blowing," "pounding," “punching," “burning," "peeling," or some other method. Remember to specify the part of the safe that was attacked.

In fraudnlent check cases the "how attacked" may be "forged signature of a prominent person." or "counterfeited company pay roll check."

The "how attacked" of a bunco artist may be "begins conversation with victim by asking time of day," "introduces \#2S to victim as prominent person," or "inserts advertisement in newspaper." In any event, when you are reporting a bunco case it is most helpful to record a detailed step-by-step account of the transaction as it was told by the victim and to report how the first contact was made with the victim, particularly the approach.

\section{Means of Attack (18)}

The "means of attack" involves a brief description of any instrument, tools, or other equipment used in the commission of the crime. For example, in fictitious check cases the means of attack might be a "hand-written, protectographed check, rubber stamped with a fictitious firm name."

In burglaries, the "means of attack" is a description of the tools used. If possible, you should describe the tools in detail. A careful examination of the tool marks and other conditions at the point of entry will help you to do this. Obviously, describing the instrument used as a "hexagonal shank wrecking bar," "offset auto jack handle," or a "flat bladed box opener" is more effective than describing it as a "prying instrument." Remember to note any oddities or peculiarities of the tools used, as observed from the marks left at the scene.

Depending upon the type of case, the "means of attack" may be a revolver, club, wrecking bar, rope, hook and line, glass cutter, bolt cutter, or safe combination puller. In fact, in some cases the means may be something other than a physical object, such as "bodily force," "climbing," "wearing," “opening," or "carrying away."

Safe burglaries offer the most complicated situation because they involve two "means of attack" (as well as two "how attacked" 
as mentioned previously). The furst "means of attack" is the tools used to gain entry to the premises, and the second is the instruments or tools nised to attack the safe.

In armed robbery cases give the best possible description of the weapon used. If the victim is able to distinguish the caliber, give the size of the gun as well as the color or funsh and whether it was a revolver or automatic.

In false pretense, trick and device, or bunco cases describe the instruments used in the scheme which induced the victin to part with his money or property, as "marked cards," "loaded dice," "money making machine," or "fictitious title to property."

\section{Object of Attack (19)}

The "object of attack" is the reason the offense was committed or attempted. When property was taken by theft, burglary, frand, or robbery, the "object of attack" is the type of property taken. Be specific in reporting the type of property as, "money and jewelry," "women's clothing," "silverware," "cigarettes," "narcotics," etc. Don't attempt to give a description of the property; this information should be reported later in the narrative section of the report.

In crimes against the person, the "object of attack" is usually the motive of the crime such as "ransom," or "revenge." let, in many homicide cases the motive may be "robbery" or "rape;" in most sex offenses the object of attack is "sexual gratification."

\section{Trademark or Peculiarity}

The "trademark" or peculiarity is one of the more important modus operandi factors that you should discover. These facts will assist you in identifying the responsible person and setting him apart from other offenders who are committing crimes of the same general type.

"Trademarks" may serve to indicate a specific burglan who has his own peculiar habits which he follows in his particular crime and which set him apart from other burglars cumently operating. His trademark may be found in the criminal act itself or in some act which has no commection with the actual crime. It may be some 
outstanding but deliberate action taken by the criminal or something which reflects a personal or subconscions habit.

While committing a burglary, one offender may turn on the house lights; others may burn matches or use flashlights. Some lower the window shades; others do not. Some take time to eat while they are on the premises; others may carry food away with them. In gaining entry some burglars merely tear the screens and open them enough to get in: others may cut neat holes and carefully remove the screens, leaving them alongside the window. There are "party burglars," "daylight burglars," and "barefoot burglars." Each of these may exhibit a great variety of techniques and peculiarities.

During the commission of a crime some offenders may perform sadistic or perverted acts which establish their trademarks. These acts may range from scattering face powder through the house to stealing women's undergarments, defecating on the premises, or performing acts of mutilation in the commission of assaults, rapes, or murders. In general, the more unusual the trademark the greater the assistance in identifying the offender. Diligent investigation should indicate some trademark in almost any offense. When you find it and record it, your report takes on real meaning.

\section{What Did Suspect Say? (21)}

In reporting any offense in which the victim or a witness saw the criminal, you should pay particular attention to what the criminal said, as well as his physical description. He may mispronounce a word or use a unique expression, mannerism, technique, or accent which will aid in his identification. Speech habits seldom change, especially while the criminal is uncler tension. Such comments as "get "em up," "I'll blow your guts out," "reach," "this is a stickup," may become an unconscious characteristic of the criminal's method of operation. Take care to report the actual words used, not the victim's or the witness' paraphrase of what was saicl.

\section{Transportation Used (22)}

If an automobile was used in the crime, report the model, make, body style, color, license number. and any peculiarities such 
as acessories or damaged parts. The transportation used in rely important. and you should be interested in recording as mush information as possible aboun the method of travel used by the criminal in arriving at or leaving the seene, or the methot he used to transport stolen property.

\section{Suspect (23)}

You will note that space is provided on the form for names and descriptions of two suspects: should there be additional oflenders in the case, list them in the "details" section of the form. When the suspect or suspects have been arrested prior to the submission of your report or on other ocasions, it is helpful to include identification numbers in the space provided. This type of notation makes it easy to connect the preliminary investigation report to fingerprints or other identification data which have come or later may come to the department.

If an arrest is made before you submit your report, you should give a clescription of the suspect in as much cletail as possible: even partial descriptions are valuable when they are compared with descriptions given in other reports. If possible, complete every descriptive item on the form. When you have additional identifying information, include it in the "details" of the report. A complete description for purposes of the preliminary investigation report should inclucle:

1. Name, nickname, aliases, it known (If the suspect is a woman record her given name, maiden name, and married name)

2. Color of hair (if bald, note the type of baldness) (if the suspect is a woman, note any artificial hair coloring)

3. Complexion

4. Color of eyes; glasses and type of glasses

5. Height

6. Weight and build

7. Age (known and apparent)

s. Occupation (rocation and arocation)

9. Race (white, yellow, brown, etc.) 
10. Nativity (plące of birth)

11. Any peculiarities (speech, etc.)

12. Mannerisms ((that may be noticeable)

13. Marks and scars

14. Amputations

15. Teeth (missing, false, gold, etc.)

16. Dress, habits

17. Education

18. Relatives and friends (names and addresses)

19. Home town, prior addresses

?0. Identification number

\section{Details of the Crime (24)}

The items previously described give you, in brief, the administrative data and modus operandi information necessary to the report. On the lower part of the report form give in narrative style the story of the offense and its investigation. Use the back of the form, from bottom to the top, and additional clean full sheets of paper, if necessary.

You will note in completing the upper part of the form, you have furnished all the information usually included in the introductory paragraph of a narrative report, but you will need to summarize this information in the "details" of the report.

Your first paragraph should present the details of the complaint. Present your authority for conducting the investigation in the second paragraph. In subsequent paragraphs present the details of the investigation in the same chronological order as the facts were discovered. Be clear, complete, concise, and accurate. Observe all of the mechanical rules as they apply to narrative writing. Also see Chapter XVI for additional rules applicable to "Details" sections of both preliminary and supplementary reports. The following is an example of proper form and content of the "Details" section of the report:

I)ETAILS:

(1) 11:18 P.M., 8559, complainant Dr. ALBERT E. BROW' of 161 Humter Drive, II 9-24t6. called by telephone reporting that his ofhe at 527 Hahn Medical Blrg., $609 \mathrm{~S}$. Summer St. had been burglar- 
ined. Victim satcel that narcotic prescription forms and morpline tablets had been taken.

(2) 11:20 1.MI. Ollicers J. M. JONES and R. R. M1).M.SS were assigned by radio to the investigation.

(3) $11: 28$ P.M.. 8-5-59, reporting oflicers met "V" at the scenc. A side door of the suite had been jimmied by what apjears to be a $11 / 2$ " jimmy bar with a "V" shaped noteh in the blacle. V stated that four tubes ol morphine tablets taken from a cabinet in the treatment room and state narcotic prescription forms were the only articles taken. A valuable watch, which had been left on a desk in V's oflice near the prescription forms, was not taken. 'T he condition of the offe indicated that the suite had been thoroughly searched, but it was left in neat orcler.

(4) 11:50 P.M. Technicians R. E. BLRT and J. M. HALL, were called and obtained three latent fingerprint impressions on the top of "I"s" desk: photographs of the jimmy marks were taken. A cast wals also made of the tool marks.

(5) 12:15 A.M. 8-6-59. Reporting officers contacted the night junitor, JOSEPH (nmi) JONES, 5723 Central Ave., DR 6-3551. He stated that he had seen the above described $\mathrm{S} \# 1$ in the building lobby coming downstairs about 8:00 P.M.

(6) Photos of latent fingerprints and tool marks are on file in the crime laboratory.

Note that each paragraph is given a number. This lacilitates easy cross reference to an entire paragraph later in the report or in subsequent reports. Each chronological step begins with the time and date.

\section{Description of Property (25)}

Follow the "details" of the report with a complete description of all lost or stolen property. A minimum description of an article listed in the preliminary investigation report should cover: the quantity of article, (2) kind of article, (3) physical description (model, style, design, shape, size), (4) material (gold, silver, wool, etc.), (5) color, (6) condition (include age), and ( 7 ) value. (See Appendix C for detailed explanation).

In addition to the above descriptive items, many articles can 
be further and more accurately described as having trade names, identifying numbers or marks, and initials.

If you describe a number of articles, precede the description of each kind of property with an item number. When you do this, later reference to the property can be made by item number instead of having to pick it out from a lengthy list. The following is an example of a correct property entry:

PROPERTY STOLEN:

1. State narcotic prescription forms \#11723 to 111728 ..n.v.

2. (4) tubes Squibb's tablets, morphine sulphate, $1 / 4 \mathrm{gr}$., containing 20 tablets each $\ldots \ldots \ldots \ldots \ldots \ldots \ldots . \$ 6.50$

\section{Signature (26)}

Place your signature at the very end of your report. If you are working with a partner, get him to sign the report.

\section{Date and Time of Report (27)}

As a final entry, give the date and time you completed the report. 
(3) $11: 23$ P.M., reporting officer met "V" at the scene. A side door of the suite had been jimnied by what appears to be a $1 \frac{1}{2}$ " jimm bar with a "vil shaped notch in the blade. "V" stated that four tubes of morphine tablets taken from a cabinet in the treatment room and state narcotic prescription forms were the only articles taken. A valuable watch, which had been left on a desk in "V's" -office near the prescription forms, was not taken. The condition of the office indicated that the suite had been thoroughly searched, but it was left in neat order.

(4) 11:50 P.W., Technicians R. E. BURT and J. K. HAL were called and obtained three latent fingerprint impressions on the top of "V's" desk; photographs of the jimny marks were taken. A cast was also made of the tool marks.

(5) 12:15 P.M., 8-6-59, reporting officer contacted the night janitor, JOSEPH (nni) JONES, 5723 Central Ave., DR 6-3551. He stated that he had seen the abovedescribed $S$ \# in the building lobby coming downstairs about 8 F.M.

(6) Photos of latent fingerprints and tool marks are on file in the crime laboratory.

\section{PROPERTY STOLEN:}

1. State narcotic prescription forms \# 11723 to 11728 . n.v.

2. (4) tubes Squibb's tablets, morphine sulphate, $\frac{1}{4}$ gr., containing 20 tablets each........\$6.50.

Officer Buford White

$8-6-59,2$ A.M. 


\section{Chapter XIV}

\section{SPECIAL PRELIMINARY INVESTIGATION REPORTS}

I $N$ REPORIING THE PRELIMNARY investigation in certain kinds of cases, the nature of the clesired information is such that the general prelininary investigation report is not appropriate or will not suffice. This is true when there is need to report wanted persons; missing persons; lost, found, or stolen bicycles; stolen automobiles; traffic accidents; and a number of other miscellaneous incidents or complaints. Most police agencies provide special preliminary investigation report forms to facilitate reporting in these kinds of cases. This chapter deals with several special preliminary investigation report forms and the problems involved in completing them.

\section{PERSONS WANTED AND MISSING REPORT}

During the course of police business the need for recording information on wanted and missing persons frequently arises. When this happens, the general preliminary investigation report proves not only inadequate in providing the necessary special information but ineffective as a means of communicating to officers in the field. Most police agencies use separate "wanted persons" and "missing persons" forms; but, since the information can be presented effectively and economically in a single form, a combined form is presented in this discussion (See Form 7).

\section{Who Prepares the Persons Wanted and Missing Report?}

The responsibility for preparation of the form varies, depending upon the type of information that is recorded and the stage of the investigation at which the need arises. Oftentimes the complaint clerk will complete the form; at other times the report is a responsibility of an investigating officer.

If your department follows the policy of completing case slicets 
on persons wanted outsicle of your jurisdiction and maintains cross-index information on these "wants," the report is a responsibility of the complaint clerk. Likewise, he is responsibile for the "missing persons report" when the information is received through a complainant other than a member of the department.

\section{PERSON WANTED--MISSING}

(X out inapproptiate word)

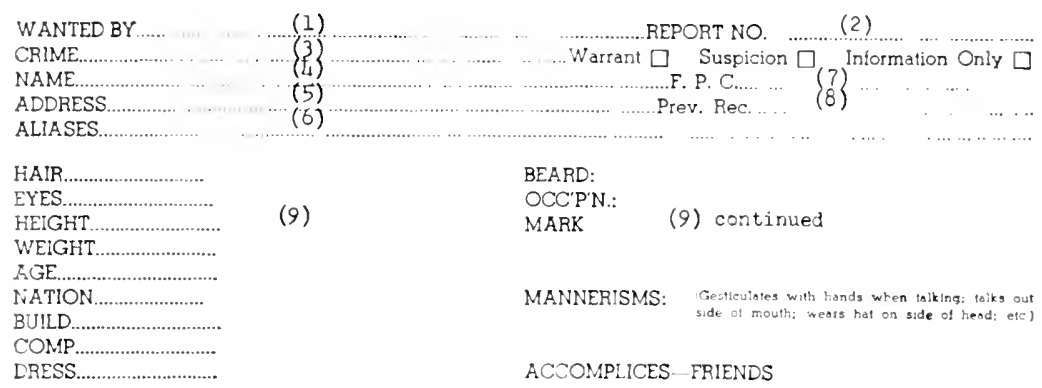

PEKSON \& PROPERTY ATTACKED:

(10)

HOW ATTACKED:

MEANS OF ATTACK:

Gun used (describe)

Auto used (describe)

Other means (describe)

TIME OF ATTACK: Hour. Date Day

OBJECT OF ATTACK:

TRADEMARK:

(12)

(Photo Here)

$314.4 ! 8$
Anv person havine information which may assist in locating this person is requested to notify imediatelv the

Copies.

Date............ BY

Radio No

Oriz: 10 zeport. Dup. and inip to squad rm. hiles; quad to delectuves.

FORM 7. Person Wanted-Missing Report (81/2"xll"). 
On the other hand, the need for the report ofuen develops during the comse of an investigation; in such cases the reporting responsibility rests with the investigating officer.

\section{When Should the Report Be Prepared?}

Unless the situation is an emergency, complete the "Persons Wanted and Missing Report" as soom as you receive the informattion. If immediate action is necessary, relay the data to the dispatcher and complete your report later.

\section{How Many Copies?}

Make the report in triplicate. The original should be attached to your general preliminary investigation report, if you are the investigating officer; if you are the complaint clerk, forward it to the records division. The duplicate must be filed on arch files or clip boards in the squad room, and the triplicate is sent to the detective division to be used by detectives in further investigation of the case.

\section{How Many "Persons Wanted and Missing Reports" Are Made?}

Make one "Persons Wanted and Missing Report" for each person wanted or missing. If two or more persons are missing or wanted in the case, do not attempt to report them on the same form. The report is designed to identify the person and (in cases involving wanted persons) the method of operation of the criminal and the crime for which he is wanted. When information on two or more persons is included in the same report, it becomes confused and worthless.

\section{Specific Content of the Report}

Since the report is utilized for both wanted and missing persons, " $\mathrm{X}$ " out the inappropriate word in the heading.

Wanted By (1). Insert the name of your department or the division investigating the case.

Report Number (2). The "Report Number" is the case or serial number. Obtain this number from the general preliminary investigation report or from the complaint clerk. 
Crime (3). The "Crine" applies only to wanted persons. Record the crime as reported on the case sheet or the general prelininary investigation report, and/or check the additional and appropriate space on the same line.

Name (4). Give the full name of the person wanted or missing. If you don't know the name, write "Unknown."

Address (5). Include the complete address of the wanted or missing person, if possible.

Aliases (6). Insert all other names that the person uses or by which he is known.

F. P. C. (7). "F.P.C." neans the fingerprint classification. Obtain this information from the records division and place it in the appropriate space.

Previous Record $(8)$. At the same time, obtain and enter a summary of the subject's previous criminal record.

Personal Description (9). The personal description, one of the more important parts of the report, include descriptive information regarding the subject's hair, eyes, height, weight, age, nationality, build, complexion, dress, occupation, marks, mannerisms, accomplices, and friends. See the "Personal Description Sheet," Form 44 of this manual, for detailed information.

Modus Operandi Information (10). Since the method of operation of the criminal is significant in cases involving wanted persons, include the person attacked, property attacked, means of attack, time of attack, transportation used, object of attack, and trademark, as obtained from the general preliminary investigation report or the records division. A detailed explanation of these nucolus operandi factors is contained in the discussion of the general prelininary investigation report, Chapter XIII of this mannal.

General Remarks (11). The "General Remarks" section is provided in order that you may include other information essential to the report which is not called for elsewhere. In this section describe hangouts and recreational habits of the subject and state whether or not a warrant has been issued for the arrest of a wanted persoll.

Photograph (12). If available, a "numg shot" of the wanted or nissing person will be attached to the report in the records division. 
Closing Data (13). The "Closing Data" section prosictes space for you to record the mumber of copies of the report, your signa. ture, the date and time the report was mades and the ratio dispatch number.

\section{BICYCLE REPORT}

Lite the "Persoms Wanted and Missing Report," the "Bicyele Report." Form 8 , is a special type of preliminary investigation report. Here, a single form provides for adequate reporting of stolen, lost. or found bicycles. Persons who report stolen. lost, or found bicycles usually all by telephone or appear in person at headquarters. Thus, the complaint clerk prepares the complaint sheet and assigns an officer to conduct the investigation. If you are the assigned officer, it is your responsibility to record the investigation on the "Bicycle Report." Make the report in wiplicate: forward the original to the records division, the duplicate to the spuad room, and the triplicate to the appropriate mit in the detective division. Prepare one "Bicycle Report" for each bicycle stolen, lost, or found. Check the appropriate box on the form as "Stolen," "Lost," or "Found" and enter the case number in the "Report Number" space.

Victim (1). List the full name of the rictim. Remember that the victim may be someone other than the person who reported the bicycle. The owner of the bicycle is the rictim. Give his complete address and telephone number, if possible.

Date Committed (2). Record the exact day of the month that the incident occurred.

Time Committed (3). State the hou that the incident occurred, as nearly as possible.

Day of Week (4). Give the day of the reek that the incident occurred as Mon., Tues. Wed., Thur., Fri., Sat., or Sun.

Where Committed (5). When the complainant alleges that the incident occurred in a city or incorporated town, wite the word "City" on the "Where Committed" space.

Name of Premises and Address (6). When the complainant atleges that the incident occurred at a place of business. recost the name of the business. If the incident is alleged to have occurred in a city or incorporated town, give the exact street and buileling 
BI.ANKVILIE POIICE DEPAR T MENI

\section{BICICIE REPORI}

$\square$ IIOLEN $\square$ LOSI $\square$ FOINIS REPORT NO.

Virtim (1) Where committed and or (3)

Res. Idiress Name of premises and address (6)

Phone

Date Committed (2) Reported b! (7)

Iine Committed (3) Address (i) Daly of Weeh _ (t) _ I' $\mathrm{Pl}$ Date and tinte reported (9)

Description of Bicycle (10)

Iicense No. H.P.I). No. Factory No.

Make TYPE: Girl's _ Boy's Dbl. Bar - single Bar -

standand weight frame? light weight frame: Wheel sime?

Color of frame Color of trim Color of fenders

Locked: Any iolentifying marks or peculiarities:

OFILER'S REPOR' I

(I I)

Record Burcan Bicucle Burean state Burcan sigualroom rile
Signed (12) No.

Date and I Ime

Fokn 8. lingle Report (\$1 2"x $11 "$ ). 
mumbers. If the incident is alleged to have ocemed in a rwal an eat, establish its location by using familiar landmanks.

Reported By (7). State the full name of the person who originally repereed the matter to your department. The nome of this person is more important than the name of the oflicer or complaim clerk who relayed the complaine to yout.

Address (8). Give the complete address of the person who reported the incident to your department.

Date and Time Reported (9). State the homr, day, momth, and year that the inciclent was reported to your department.

Description of Bicycle (10). Like the personal description in the "Persons Wanted and Missing Report," the description of the bicycle is one of the more important parts of the report. Be axtremely careful in reporting the information; these are the only data by which the property later will be identified. Inchude the license number and year of the license, departmental registration number, and lactory number. Give the make, ype of bicycle, wheel size, and color of the frame, trim, and fenders. Indicate the weight of the frame as "standard" or "light weight." and state whether the bicycle was locked or mocked. Ample space also is provided for indicating identilying marks and peculiarities such as accessories, damaged parts, dents, and scratches.

Officer's Report (11). The "Olficer"s Report" section provides space for recording the details of the investigation. Follow the same general pattem in completing this section as you wonld in writing the "Details" section of a general prelininary investigation report. Let your first paragraph contain the details of the complaint, the second paragraph state your authority for conducting the investigation. Present each subsequent investigative step in a sepalrate paragraph and in chronological order.

Closing Data (12). To complete the closing data, sign the report, enter your badge number, record the date and time that you completed the report, and check the appropriate distribution of the various copies.

\section{AUTO THEFT REPORT}

As stated earlier, the theft of an antomobile requires the reporting of specialized information. Almost miversally, police de- 
partments have established a special type of preliminary report for this purpose. So, if you are assigned to investigate an auto theft, you should complete the required form rather than the general prelinimary investigation report form. Use the "Auto Theft Report." Form 9, to report the theft of antomobiles, trucks, motorcycles, and motor scooters. Even joy-ride thef ts are classified as auto thelts. Always remember to make the report in duplicate, or three or more copies if your department plans court action in the case.

\section{Content of the Face of the Form}

The face of the Auto Theft Report contains headings as follows: (1) complainant, (2) address and phone numbers (of the complainant), (3) case number, (4) reported by, (5) report heceived by, (6) stolen from, (7) make, (8) motor number, (9) departments notified, (10) value, (11) remarks, (12) approved by, (13) recovered by, (14) where recovered, (15) owner notified by, (16) other departments notified, (17) condition of car, (18) status of the case-unfounded, cleared by arrest, exceptionally cleared, or inactive, and (19) your signature and the signature of your comnuanding officer.

Complainant (1). Like the complainant on the General Preliminary Investigation Report, the complainant on the Auto Theft Report will, at times, be different from the complainant on the Case Sheet. (See the explanation given under General Preliminary Investigation Report.)

Address and Phone Numbers (2). Give the address of the complainant, including number, street, city, state, and phone mumber.

Case Number (3). Insert the case number as it appears on the rase sheet.

Reported By (4). Give the name of the complainant as it appears on the case sheet, along with the complete address of the complainant.

Report Received By (5). State the name of the officer who receired the original report; include the time and date received and how the theft was reported-"phone," "letter," "in person," or "on view." 


\section{MUO IHFI I REPORI}

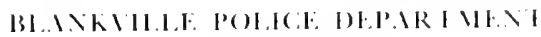

Complatimant

lacal Malues

()hler daliess

Reportcel B! (1) Irlicess

Report Recoived B) (5) - N (i) (7) _sise Model late and lime M. Nate
Calse Vio.

lhome siolen $1.10 m$

Milhe (8) Color linemse

bepes. Ninilued (1) Cils.

Iotor Xo. I. Date and lime

lialic (10)

Approsed 13!

Reroued Bi

Where Recosered

Owner Nolified Bs

(ollee Depts. Notified

Comdition of Citl

fofounded

(IB)

Cileared Bs Mrest

Exceptionall cleared

Inaclive (not cleared)

Form $9-19178$
I)ate and lime (14) late and lime (15) J)ate and l ime (16) l)ate and I ime (17)

sigued (19) Date lunestigating Ollacer signed 1)ate

Commanding Ollncer (ONR)

Foky 9. Nuto rhett Report (81."x11") (Fromt). 


\begin{tabular}{|c|c|c|}
\hline & $\mathrm{No} . \mathrm{I}$ & No. 2 \\
\hline \multicolumn{3}{|l|}{ Viance } \\
\hline \multicolumn{3}{|l|}{ Mlias } \\
\hline Irlaliens & & \\
\hline \multicolumn{3}{|l|}{ Color, tex, Ige } \\
\hline \multicolumn{3}{|l|}{ Ileight, Height } \\
\hline Color, Sex. Age & & \\
\hline \multicolumn{3}{|l|}{ Bearl } \\
\hline \multicolumn{3}{|l|}{ Valisits } \\
\hline \multicolumn{3}{|l|}{ Ocollpation } \\
\hline Dress and Other Manks & & \\
\hline Wh Suspected or Wanted & & \\
\hline
\end{tabular}

Remallk:

$(2)$

Petsins Inested Perams Incested (3) Mrest Vo. mest No.

Rerliahs: (t)

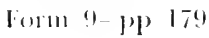

Fok 9. Iuto Thedt Report (Rererse). 
Stolen From (6). (ive the location from which the rehicle mas stolen including numbers, street, city and state. Record the date and time the rehicke mas stolen.

Make (7). Recond the make, year and body style: and liceme information including the yeats, state, and license number. Fin ex-

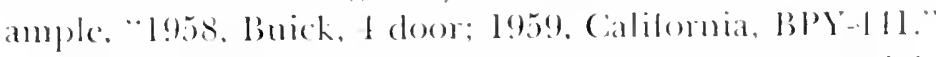

Motor Number $(S)$. (ive the cugine mumber, serial number, or both: color of the atumobile: and the mumber of cylinders.

Depertments Notified (9). Name other pulice lepantments that were uotitied of the thelt, giving the date and time of the motifica(i) $)$.

V'alue (10). Cive your estimated value of the stoten veluicle as determined by the omner or your om knowleclge.

Remorks (11). Presemt a brief smmmary of the details of the thelt as reported by the complainant. Inchude onher descriptive data bat may help to iclentify the vehicle.

Approsed By (12). This line is for the signature of your comulandiug oflicer.

Recozered By (13). Give the name of the oflices who recorered the rehicle if it was recorered within your juridiction. If the vehicle was recovered outside the jurisdiction. give the mame of the department that recosered it. Include the date and time recovered.

Where Recowered (1.4). If the velucle was recovered in the cily give the exact adthess. If it was recorered ontsicle the city. give the mane of the city and state.

Oaner Notified By (15). Give the name of the officer who notified the owner of the recovery. Inchude the ditte and time the onne? was molitied.

Other Departments Notified (16). Insert the names of other lan enloucenent agencies that were notified of the recoresy. (This hombi be the same as section 9.)

Combition of the Car (17). State the comdition of lhe cal at the lime it was recoresed-" damaged." "umdamaged," "smipped," clic

Status of the Case (Mark zeith" $\left.\mathrm{X}^{\prime \prime}\right)(I S)$. Math the casc ats "Infommeded," "Cileared by Arest." "Fxceptiomally Clearede" on 
"Inactive (not cleared.") Classify the case as "Unfounded" when your investigation reveals that there is no truth in the allegations of the complainant. Mark the case "Cleared by Arrest" when one or more persons have been arrested and charged with committing the offense. Classify the case as "Exceptionally Cleared" when the vehucle has been recovered without apprehension of the suspect, or in "joy-ride" thefts when no prosecution results even though the person who took the vehicle is apprehended. The case becomes "Inactive" when the statute of limitations takes effect.

Your Signature and Signature of Commanding Officer (19). After a recovery, you and your commanding officer should sign the report, indicating the recovery. Be sure that all copies are signed.

\section{Content of the Reverse Side of the Form}

The reverse side of the Auto Theft Report contains space for: (1) description of suspects or persons wanted, (2) remarks concerning suspects or persons wanted, (3) persons arrested (and arrest numbers), and (4) remarks concerning persons arrested.

Description of Suspects or Persons Wanted (1). The following data are essential for a complete description of suspects or persons wanted:

1. Name: Give the full name, if possible.

B. Hlias: Give any other names or nicknames that the suspeet may be known by.

C. Address: Give the number, street, city, and state of the suspect.

D. Color, Scx. Age: Example: White male. 25 yrs. of age.

E. Height, Weight: Example: 57", $190 \mathrm{lbs}$.

F. Color Eyes, Hair, Complexion: Example: Blue eyes, dark brown, wavy hatr; ruddy complexion.

G. Beard: Give color, state whether heary, light, clean sharen, mustache, etc.

H. Nativity: Give the date and place of birth and nationality of the suspect. Eximple: 1-2-03; Chicago, Illinois: Italian.

I. Occupation: State the type of employment the suspect usually performs. Examples: Cook, waiter, auto mechanic, carpenter.

J. Dress and Other Marks: Describe what the suspect was wearing. also any visible jewelry, scars, tattous, etc. Example: Felt hat, grey; brown suede jacket; white shirt; brown trousers; brown shoes: yellow gold ring-left hand ring finger: white gold wrist 
watch with expansion band on left arm; tattoes of anchorright outer forearm; cetc.

K. I'hy Suspected or Wanted: Give the reason that the person is a suspect or wanted. Examples: Identified by victim, or ob. served hanging around the scenc on several occasions prior to the crimes being committed.

Remarks Concerning Suspects or Persons Wanted (2). Cive any information or descriptions of suspects or persons wanted that you have not listed above.

Examples: Subject may be accompanjed by white female-no description avalable; or. subject known to frequent bars in vicinity of Itain Suree and joh trenue.

Persons Arrested (3). State the name, sex, race, and arrest number of each person arrested in connection with the auto theft.

Remarks Concerning Persons Arrested (4). G i v e additional information about the persons arrested (associates, circumstances surounding the arrest, etc.) that may be of value in presenting your case in court or may be of assistance in the future apprehension of the suspect should he becone involved in other crimes.

Example: Subject offered armed resistance. had to be taken by force. was in company of other known criminal.

\section{VEHICLE ACCIDENT REPORT}

A foumh, and possibly the most important preliminary investigation report, is the "Vehicle. Iccident Report," Forn 10. Like cases of wanted and missing persons and atto and bicycle thefts, the specialized nature of the information needed for adequate reporting of an acciclent case requires a special form.

Information that you have obtained as a result of an accident investigation must be placed on the established report form. This information, in turn, is delivered to the records division and processed. In the records division the accident forms are cheched, classified, indexed, and copied. In addition, certain information is taken from original reports and placed on maps, file cards, tallies, and other forms, as they flow throwgh the recouds division to their place in designated files. Thus, your original reports, together with oflice forms and othes related materials, accumulate in the records 
office and become the working and guiding basis for your department's traffic control program.

The "Vehicle Accident Report," Form 10, conforms in most detaits with a standard form originally developed by the National Safety Council's Committee on Traffic Records and adopted by the

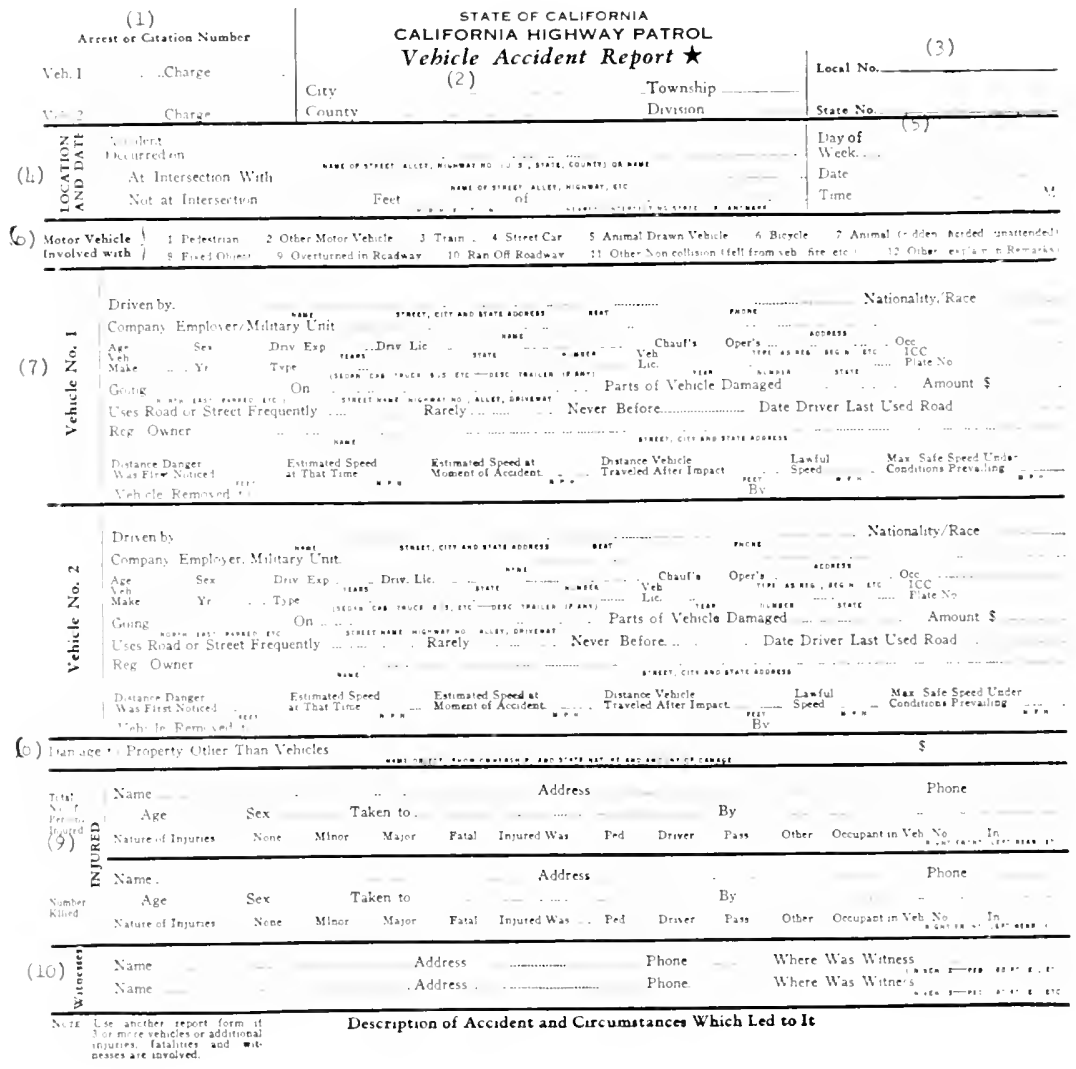

(25)

* Reported in Complance with 484 V C Trever 1

$(-0)$ 


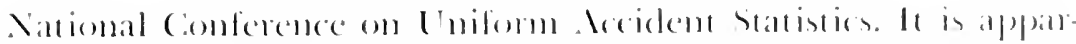

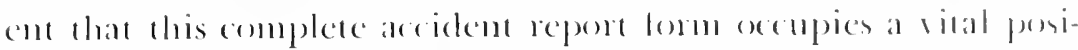

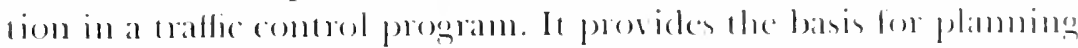

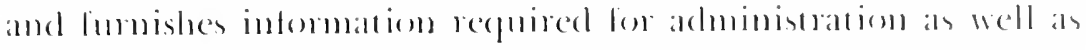
that repuired by law. It follows that many of the benchesel an ex cellent accident investigation will be lost moless the inlommation

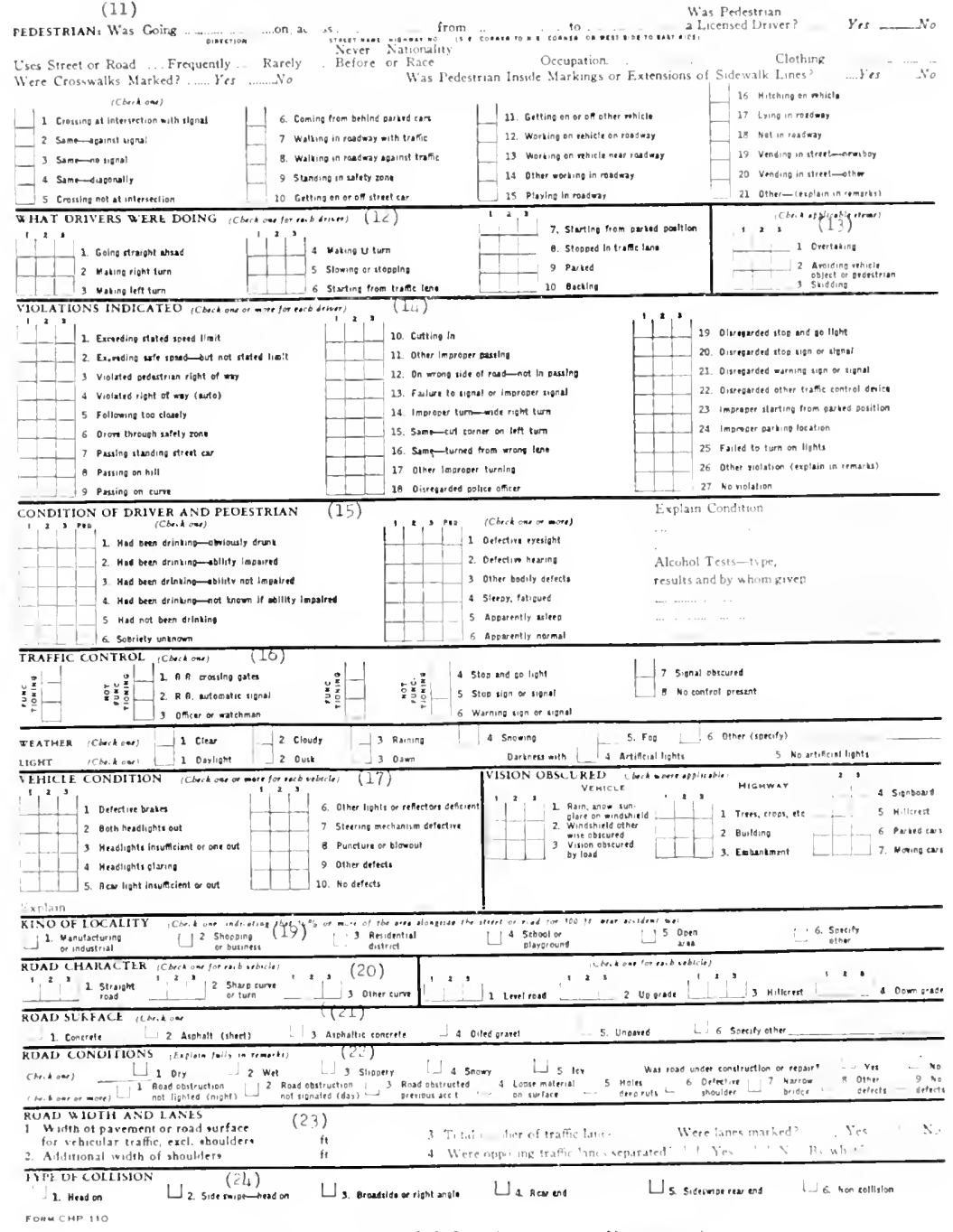

ForV 10. Vehicle Report (Rereré). 
TRAFFIC ACCIDENT REPORT

INTERVIEW AND INVISTIGATION SUMMARY

(27)

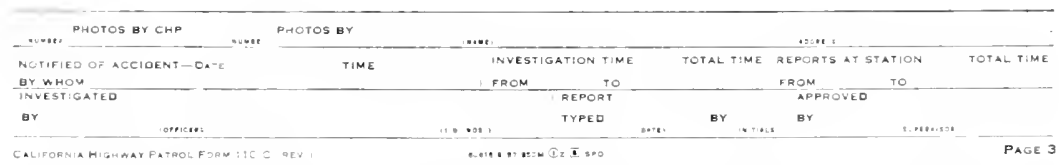

Fonu 11. Intersiew and Investigation Summary (Atachment to Vehicle Ac(ident Report).

you gather is completely and comectly transterred to the "Vehicle Accident Report." Each repont fom and all repuired copies must be lesible, accorate, complete, and lice from contradictory statements. 
Legislation and departmental policy shoutd inclicate to you the type of accictents to be reported on this form. Ordinarily, the form is used on motor vehicle trallic acciclents. Departmental policy also should indicate the mamer by which the accident data are moted at the scene and the subseguent procedure as to the time, place, and mamner of transcribing these data to the accident report form.

For the purpose of discussing the report form itself, it will be assmmed that you have made a thorough investigation of the accident, recorded the essential information in your notes, and that you now are ready to transfer the data to your report form.

While it may appear that a large quantity of information is sough by the lom, much of it can be provided by merely checking certain items appearing on the form. For the mest part, the type of information desired is self explanatory. The following discussion is lor the purpose of clarilying the various sections for you, creating uniformity in recording available data, and emphasizing those sections which are of primary importance to the traffic control program.

Numbers of the following sections will correspond to the typewritten numbers on the illustrated form.

\section{Arrest or Citation Number (I)}

If you have made any arrests or issued citations, space in the upper left-hand comer is provided for recording the arrest or citation number, which vehicle was driven by the cited or arrested driver, and the charge or charges brought.

\section{Reporting Department (2)}

The illustrated form assumes that state law or departmental policy requires reporting to an over-all state agency. Il such is the case, give the name of your city, comty, township, and division.

\section{Case Number (3)}

Space is provided in the upper right-hand comer for recording the case number under "Local No." The "State No." will be recorded by the state agency to which a copy of your report is submitted. 


\section{Location and Date (4)}

Urban or City Accidents. "The location is either "at an intersection" or "not at an intersection." Check the appropriate space (1) indicate which is the case.

If the accident is "at an intersection," you should check the first space, place the mame of the street coming fust alphabetically (m) the line atter the words, "accident occmed on," and then the name of the other intersecting street on the line following the words, "at intersection with." Thus, "accident occured on Maple sueet at intersection with Wind Irenue." If more than two streets intersect at the place, use the name of the two coming first alphabetically. Thus, il the accident acomed at the intersection of Fonm street, solma Ivenuc, and Talbot lane, your entry would read. "accident ocomred on Fromm street at the intersechion with selma drente."

In cases where the accident occurs between intersections. you should check the space "not at intersection" and indicate lhe exact location by distance from an intersection on by the street or house number. A typical example is: "accident ocomed on Nomth Elm Iremue. "2on leet somth of Camerom Road."

Rueal Accidents. (iencally, the abore insmotions will apply in rumal accidents. In certain rumb areas, howerer, it is diflicult 10 give an actual location because ol absence of fixed location points or beasuse distances are much greater hom fixed locanion points.

In a rual accident ocoming at a road intersection. your enty might be "arcident accumed in Sutter Connts, Rusk Tommship) l.f miles east of Rorkille city limis, on I . S. No. Ho at interser. tion with Famm Roid No. siti."

lu locating the rimal aceident not at a road interections yom

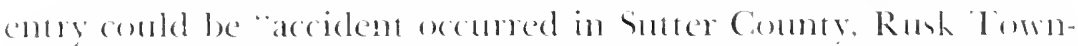
sipe i.t miles somb of Roarkille on Fam Road 10, 175 fere monh af 1 )eer latge."

It is extremely impontant that you define the exale lecation of the areident in terms molerstandable by reconde division perom-

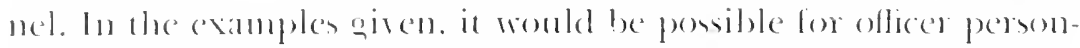

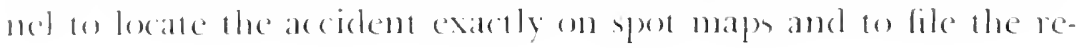




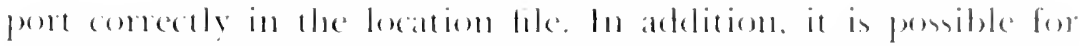

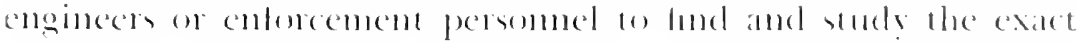

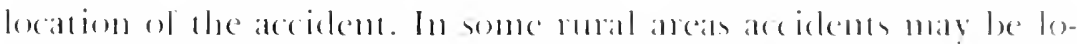

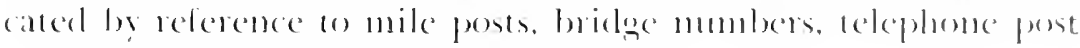
mmmbers. highmay sectiom numbers, ete.

\section{Time of Accident (5)}

Indicane as closely as possible the exact time ot the accielent. In

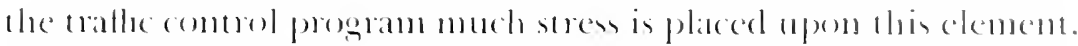
li is important an indicate the momb of the rear by ypelling insead af mombers to eliminate mistahes. It also is important that all iteme be noucel-day of the reeh, momth, day ol momth, yeas.

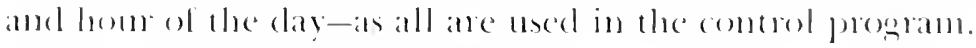

\section{Motor Vehicle Involved With (6)}

In this section you shomld indicate what was stouck bs the

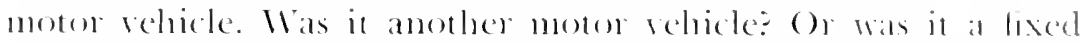
object: lt is highly important in the control plan to huow just exactly what was imsolred in the accielent. You should los anded

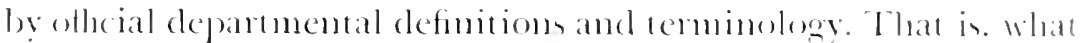

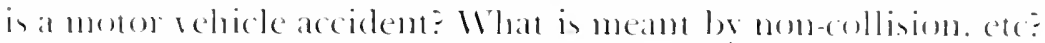

\section{Velicles (7)}

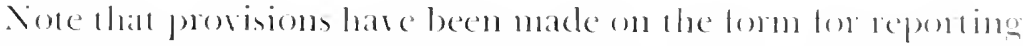
rital infomatom on 1 mo rehiches imsolved. I'se an additimal re-

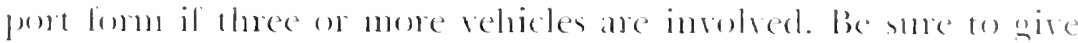

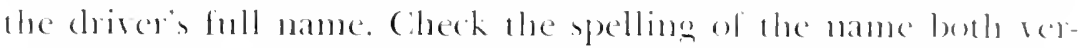

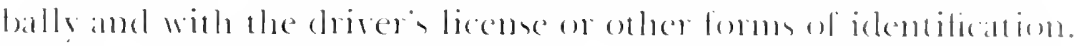

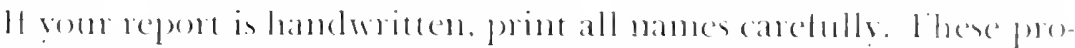

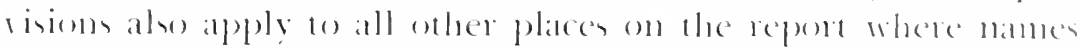

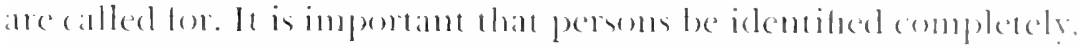

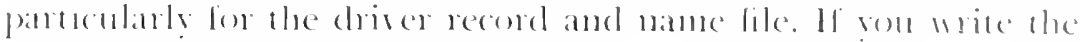

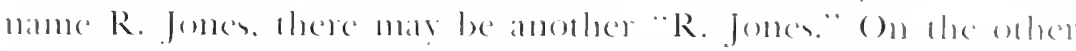

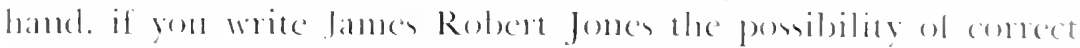

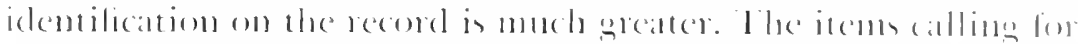

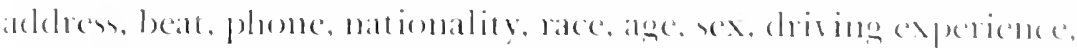

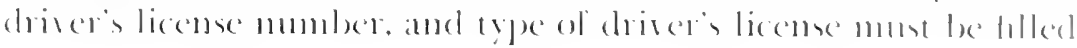


out correctly, as they, too, help identify persons involved and supply important material for use in the control program.

Be careful in recording all information necessary to identify the vehicle, owner, damage, estimated speed, etc. This information is valuable both in the control program and in determining traffic law violations.

Do not hesitate to estimate the speed of rehicles both before and after the danger was sighted. Positive knowledge is not necessary for statistical purposes, but you should make your estimates as carefully as possible, taking into consideration physical evidence and statements of drivers and witnesses. "Lawful speed" means in most cases the stated speed limit applicable.

\section{Damage to Property Other Than Vehicles (8)}

If damage was incurred to property other than the vehicles involved, name the object, show its ownership, and state the nature and amount of damage.

\section{Injured (9)}

List the total number of persons injured or killed. Give the full name, address, and nature of injuries and other identifying information relating to each person injured. If more than two persons are injured, use an additional report form.

\section{Witnesses (10)}

Record the full name, address, and phone number of each witness and state exactly where he was at the time the accident occurred.

\section{Pedestrian (11)}

Report all items in this section accurately and completely when a pedestrian is involved in the accident. This material is needed for specific pedestrian control planning.

\section{What Drivers Were Doing (12)}

Here the desired information is what the drivers were doing before danger was sighted-before danger arose-before their actions or courses were changed by ot her circumstances. For example, 
if a driver was proceeding along a straight thoroughtare, not intending to turn-saw something in his path and, to avoid hitting it, tumed into a side street-you should place the chech mark in the box square before "going straight ahead." The turning in this case was not the intended direction of travel. The driver originally had planned to go straight ahead.

\section{What Drivers Were Doing (continued) (13)}

These specific items are similas to (12) in that they apply to actions prior to the time danger was first sighted. If a car, skickling on slippery paremen before brakes were applied, collides with another object, you should place a check mark in the box square beside "skidding." Check these items, when applicable, in addition to items in (12).

\section{Violations Indicated (14)}

Check all violations committed by the driver of each rehicle involved, even though you have not found sufficient evidence for prosecution. This information is for statistical purposes, and you should list the violation if you honestly believe it was committed and that it caused or was a contributing cause of the accident. Officers are sometimes hesitant to indicate a violation if they cannot prove it, fearing that they may be called upon in court to explain. In such cases they should merely explain that these are their opinions only and that they were indicated for statistical purposes. It is apparent that if you indicate only provable violations much information needed to formulate selective plans of education, engineering, and enforcement will be lost.

Under the spaces for "other violations" aroid the use of general terms such as reckless driving. I'sually the recklessness consisted of one or more specific acts that already are listed or may be added. Aroid inserting "under the influence of alcohol" because this violation is coverd later on the form. Don't use "improper atuo registration;" this type of violation does not cause accidlents.

Difficulties somctimes arise over Nos, 19, 20, 21 in this list of violations. No. 20, "disregarding stop sign or signal," means the 
act of disregarding any sign or signal requiring the (hriver to stop) before poceeting, but does not apply to a red signal in a "stop) and go light." which is covered in No. 19. The distinction here is betwen the sign or a signat which means "stop and proceed with caution alter stopping" and one which means "stop and wait for the green light belore proceeding." No. 2l refers to any waming sign. including the llashing anber or "stop and go signal." If the red and green lights were not operating, and the flashing amber was being used alone. the signal was merely a warning device despite its other capabilities.

\section{Condition of Driver and Pedestrian (15)}

hn this section you should indicate your honest beliet as to condition ol persons involved as drivers of pedestrains even though you do not have sufficient evidence to prosecute. Thoroughness in the investigation, including chose observation and examination, will result in a high degree of accuracy on your part. Xote that space is provided for explanation of the condition of the persons; involved, akong with the results of alcohol tests.

\section{Traffic Control (16)}

The explanation given under "siolations indicated" applies here whin egual force. 11 a stop and go light is llashing amber, the device is classified as a functioning warning signal. If it is flashing rect. it is a functioning stop signat. If it is alternating from red to green, it is a functioning stop and go light. If it is not operatine at all, it in nom-functioning sope and go light.

\section{Vehicle Condition (17)}

Record any defect of the vehicle. alter carelul examination of braken. headlights, rear lights, steering mechanism. or other parts which are likely to have camsed the accident il they were not lumeinoming betore the arcident.

\section{Vision Obscured (18)}

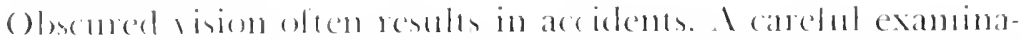
tion of both the rehick and highway or weet is aecessing before son recosd any information in this section of the report. 


\section{Kind of Localit! (19)}

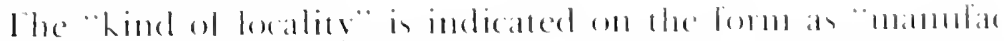

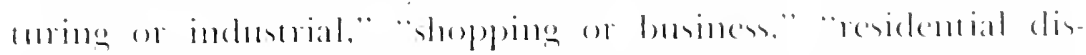

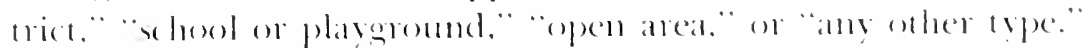
since it is often diflicule te determine the kind of lonalits. mathe

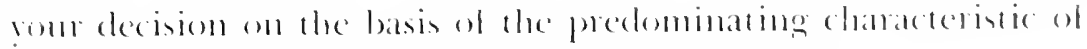
the beality within a 300 lect radiun of the accident.

\section{Road Character (20)}

like the condition of the schictes and the drises, the "roat condition" is rery importan in determinims the ane of mans accidents. Chech the road as either "straight." "sharp curve."

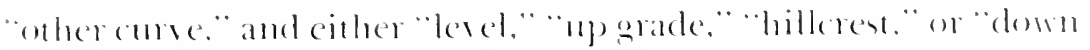
sarcle."

\section{Road Surface (21)}

"Road surlace" means the material o materials with which the

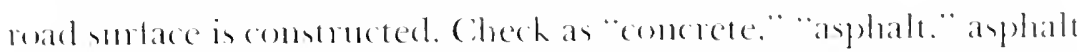
concreate." oniled gravel." "mmpared." or write in any other mpe of mitace.

\section{Road Conditions (22)}

lite the "road chatacter," "rehicle comdition," and "conclition of the dricer. "read conditions" are very inupertant in the

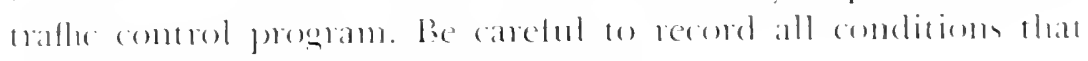
mat hase comtrituled to the accident.

\section{Road Width and Lanes (29)}

Indicate both the width of the parement and the shouklew. 1)

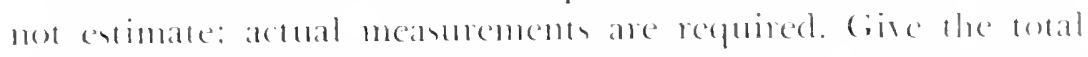

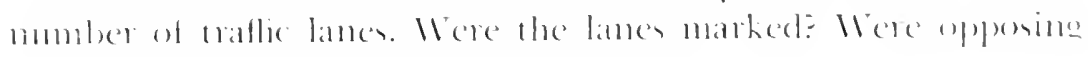

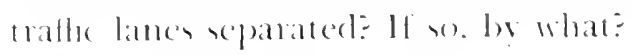

\section{Type of Collision (24)}

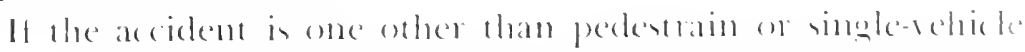

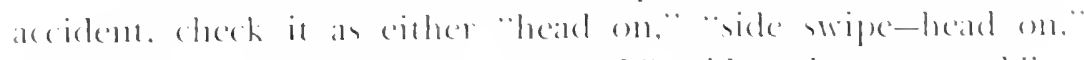

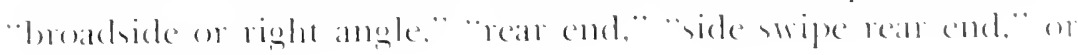
"mon-(n)llision." 


\section{Description of Accident and Circumstance Which Led to It (25)}

This section is a synopsis of the accident. Give a description of the accident and circmustances which led to it in a brief, precise way. When complete, your synopsis should form an introductory paragraph to the "Interview and Investigation Summary," the second sheet of your report.

A sample synopsis of an accident follows:

Vehicle No. 1, driven by Robert C. Adlams of 2208 Arch Way, Blankrille, Calilornia, IV 7-4386, traveling north on Walnut St. at 30 m.p.h.. slowed to about 20 m.p.h. in passing stop sign and collided with vehicle No. 2, driven by Raymond D. Cole of 1842 South Elm, Blankrille, California, GI 4-3567, traveling west on Main Street at about $30 \mathrm{~m}$.p.h. Left front of vehicle No. 1 struck left rear wheel of vehicle No. 2. Driver of No. I stated he thought it sulficient to slow down and underestimated speed of No. 2.

\section{Closing Data (26)}

The "closing data" of your report include the information which is normally termed the "ending." Obtain the signatures of all drivers involved; sign your report; give your badge number; and indicate the date and time that the report was completed. The report also provides space for the signature of the superior officer who will review and approve your report.

\section{Interview and Investigation Summary (27)}

Complete this section of the report if your investigation reveals personal injury, hit and run, a fatality, or if prosecution for any major misdemeanor or a felony is contemplated.

Follow the same format as provided for the narrative section of the "General Preliminary Investigation Report." Depending upon the nature of the investigation, several or all of the following headings may be inserted and completed: (1) details, (2) undeveloped leads, (3) conclusions, (4) recommendations, (5) list of exhibits, and (6) diagram of the accident.

In any event, when you complete this "Interview and Investigation Summary," the "details" and "diagram of the accident" sections must be completed. Let your first paragraph of the "details" present the details of the complaint. Give your authority for 
conducting the investigation in the second paragraph. I.et each subsequent paragraph of the "details" represent a significant step in the investigation.

Place the cliagram of the accident on the back of the "Interview and Investigation summary" page, or add another page for this specific purpose. Draw the diagram with north at the top of the page wherever possible. The diagram may not be clawn exactly to scale, but it should give a graphic picture of what occurred. It must tie in with the description of what happened, covered earlier in your report. 


\section{Chapter XV}

\section{PATROL SERVICE REPORTS}

\section{I}

YOU ARE A PATROLMAX, Iouk services are of thee general typer: (1) called-for services, (2) routine patrol, and (3) inspectional serices. Preliminary investigation reponts. previously discussed, are largely the result ol called-for services. There are, however, a mumber of reports necessary to eflective performance of routine patrol and inspectional duties. These so-called patrol service reports are the topic of discussion in this chapter.

\section{VACATION HOME REPORTS}

For example, your department may follow the progressive policy of inspecting homes left racant while the occupants are ont (o) town on racation. Residents of the city recognize the value of this service. and it is raluable to your department both as a crime deterrent and as a means of establishing good public relations Citizens become aware of this service thromgh newspaper notices, radio and television broadcasts, and departmental publications. Many citizens report their forthoming racation departure by calling the department or appearing in person.

The completion of Fomm l' 2 is a responsibility of the complaint clerk. He makes an original and two copies when the information is received.

The 5"xy" candboand lom is excellent for foling and providen adeguate spate for: (1) date of departure of the ocoupart. (2) dateot retumi. (3) the occupant's mame. (1) his address. (5) who reported the racancy. (6) the mane and atchess of the person to motily in the erent of emergency ( 7 ) the forwarding address of the ocrupant. (S) the date the residence was cheched by the sergeant with the beat wlicer, and (9) the date the occupant was interiewed by the sergeant to determine means of gaining entrance during an emeroency and other infomation necessany to proper strieillance while the ocempant is away. 


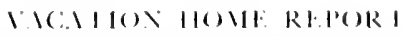

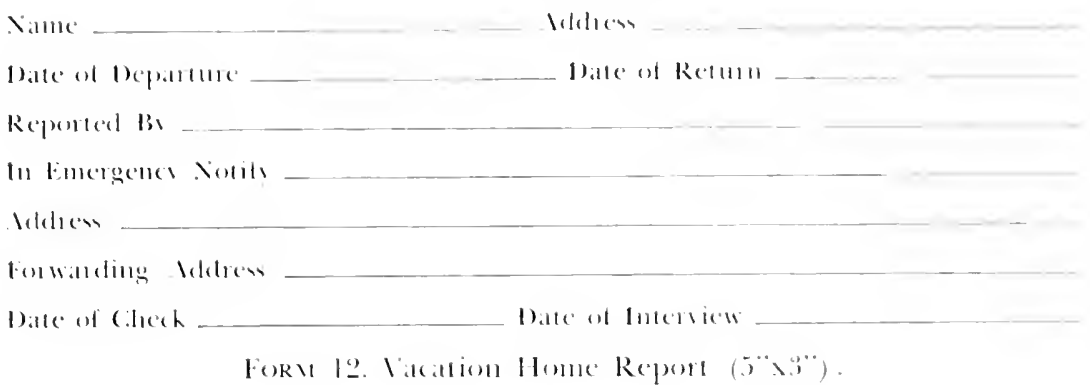

The complaint clesk sends the original to the records division

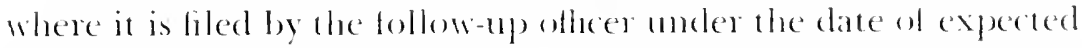
retum. The complaint clert then files the duplicate copsen in a file at the complaint clesk according to the approprate beat on the night shifts. The file is reatily arailable to both the complaint clerk and patrol sergeants.

If you are a beat patrolnam, it is your respomsibility we check the daily bulletin for vacation lome assignments and recond these assigmments in your mobosk. When you complete earh impertion, record the date of the inspection, tinne condition of the residence, and the time reguired to complete the check. Prior to the

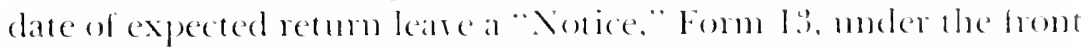
door at the residence. Once the vacationing occupant hat remoned. complete Form 11, "Repont of Vacation Home Luspections." For-

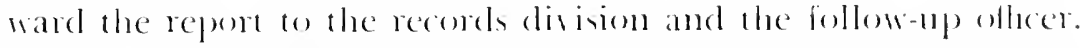
The bollow-up oflece will remose the vacation home repent from his file and file it permanenty whth your rejort in the records dis $\mathrm{i}$ sions.

\section{STORE REPORTS}

store reports, such as Form t5, are also your respomibility as a patrolman. They serve a number of puposes. They facilitate periodic contacts with businessmen on your beatt. assme periodic inspertion of every commercial establishmem in the aty. and provide the residence addresses and telephome mumbers of the promprietor and his assistant for emergeney use. 


\section{NOTICE}

Will you please report your return from vacation at your earliest convenience, so we may discontinue surveillance.

POLICE DEPARTMENT

OFFICER \#

\section{Phone THornwall 5.8000}

314.812

Form 13. Vacation Home Notice (5"x3") .

Headquarters will notify you when commercial buildings are newly occupied on your beat. Contact the manager of the establishment. Get the name of the store; the address; the manager's full name, home address. and home phone number; and the same information from the assistant manager. Record this in your field notebook.

Request of the manager that you be allowed to make a tour of the building to inspect and record security information. Inspect the adequacy of the locks on all doors, the security of the roof entrance, the location and security provided for the safe, the burglar alarm and other security system used. Ask such questions as: Can I reach all entries withont climbing fences? Is your back yard lighted at night? Are blinds and shades raised to facilitate my seeing into the building at night? Do you employ a night watchman or utilize the services of a private patrol? What precautions do you take against holdups?

After completing the contact and inspection, offer suggestions as to added security for the establishment. Prepare a "Store Report," being careful to summarize the results of the inspection and your suggestions on the back of the form. 


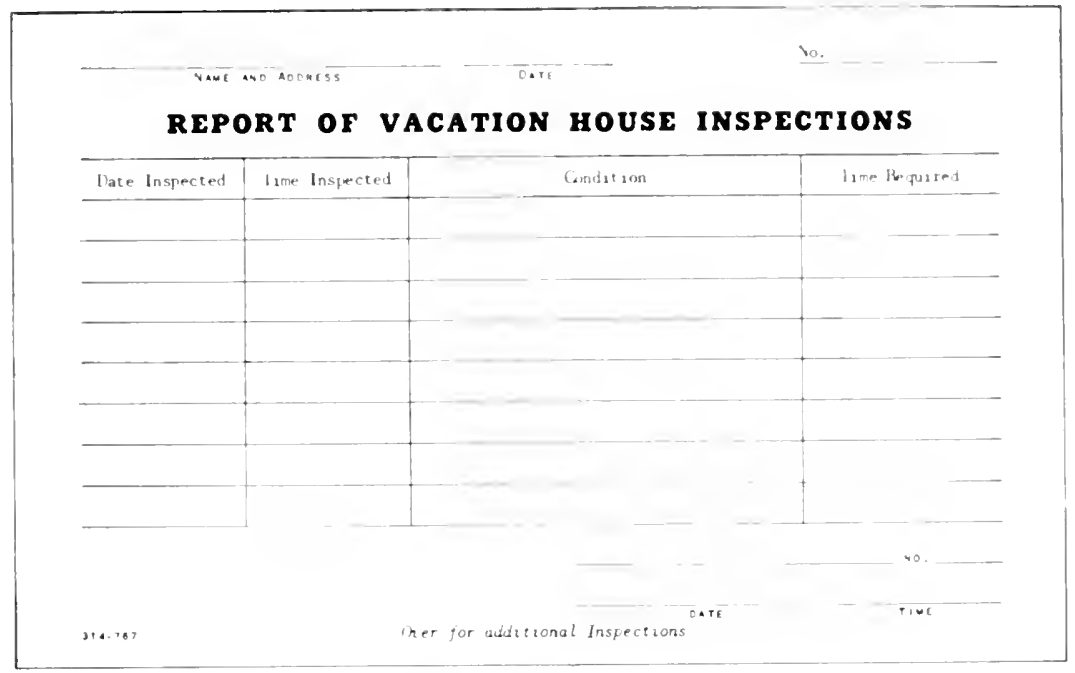

Fom 14. Repont of Vacation House Inpections ( $\left.8{ }^{*} \times 5^{*}\right)$. (Fromt)

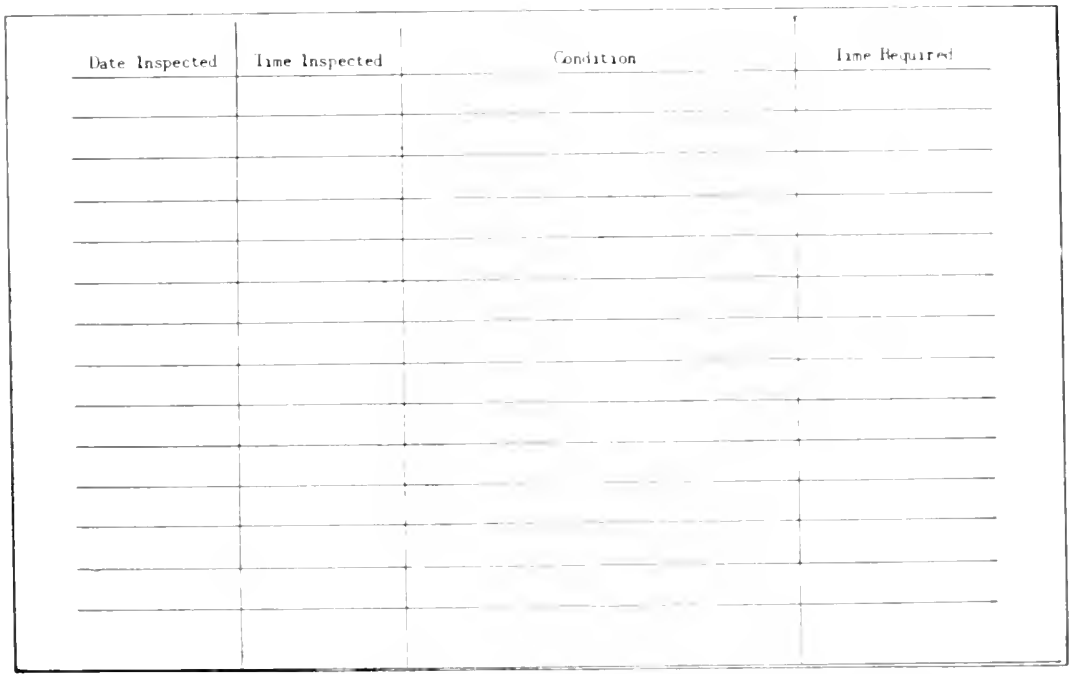

Form 14. Report of Vacation House Inpections (Revere). 
Store reports are filed acording to street number under the names of the streets arranged alphabetically. The store file is kept in a location convenient to the dispatcher in order that he may use information regarding the proprictor or his assistants in case of emergency, regardless of the hom.

from time to time you will receive groups of Store Reports. When you do, it is your responsibility again to contact the managers of the establishments and conduct inspections. If changes have becn made in the management of the stores or in secmity conditions, make new Store Reports.

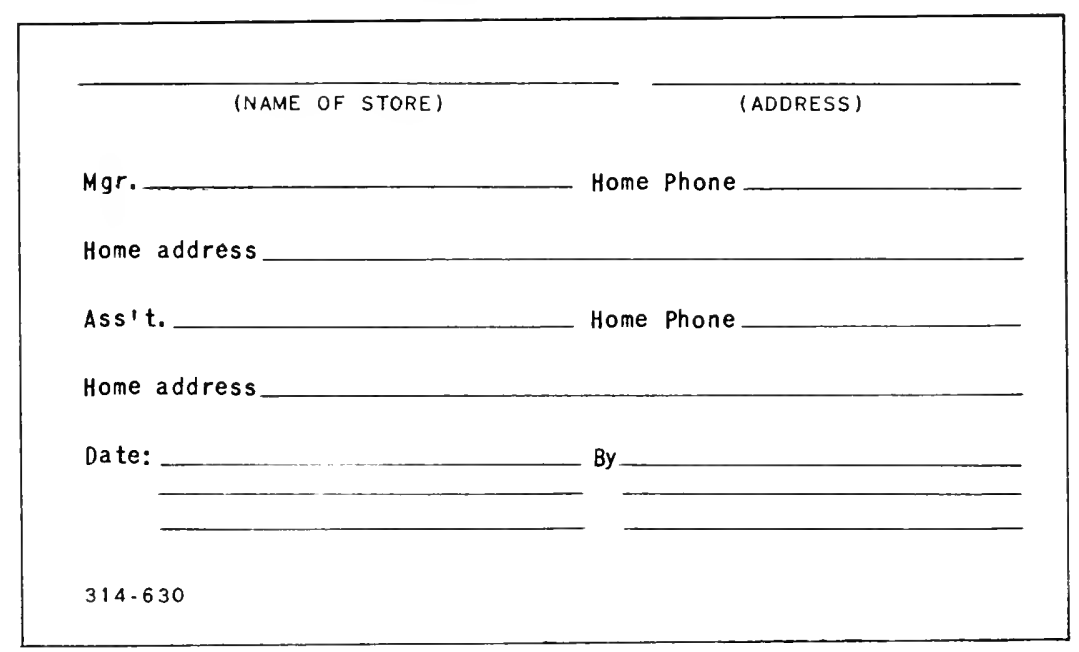

Fonm 15. Store Report (5"x"')

\section{SECURITY CONDITIONS REPORTS}

Is a matter of routine, you should conduct conscientions and thorough inspections of all commercial establishments during the hours when the places are closed to the public. Check front, rear, and side doors and windows. Look for defective locks and safe. and for alley and store lights that are ont. Be alert for open doors, transons, and skylights, and keys lelt in doors.

When you find any of these conditions. help to build good public relations and eliminate crime opportunities by completing a "Security Condition Repont," Form 16. Simply record the name 
and adelessol the fom and the dateand time of wour tepent. Cherk the improper security condition on the form and sign the report. giving your barlge number.

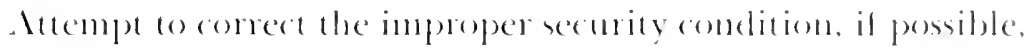

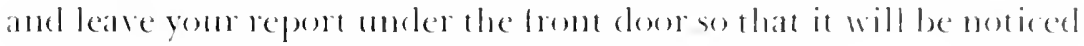
when the place is opened lom husiness.

This sante kind of exvice also can be renelered for the negligent motorist who leaves his auto mulorked on keys in the ignition. In thene cases complete the "Invitation to Thieves Repent, "Fom 17, and leave it moler the wimblicel wiper or lace-up on the driver's ide of the liont seat.

\section{SPECIIL SERVICE REPORTS}

While on routine patrol you will observe many othes reportable conditions that are ol interest to other police units, other aity deparments, and private mility companies. This kind of condition calls for the completion of a "Special service Report," Form เ. When properly filled $\mathrm{in}$, the report serves as a reminder that you hould be alert for any of the conditions listed om the form and assures motice to the interested agencies.

When you as a patrolman discoser any imesularity listed on

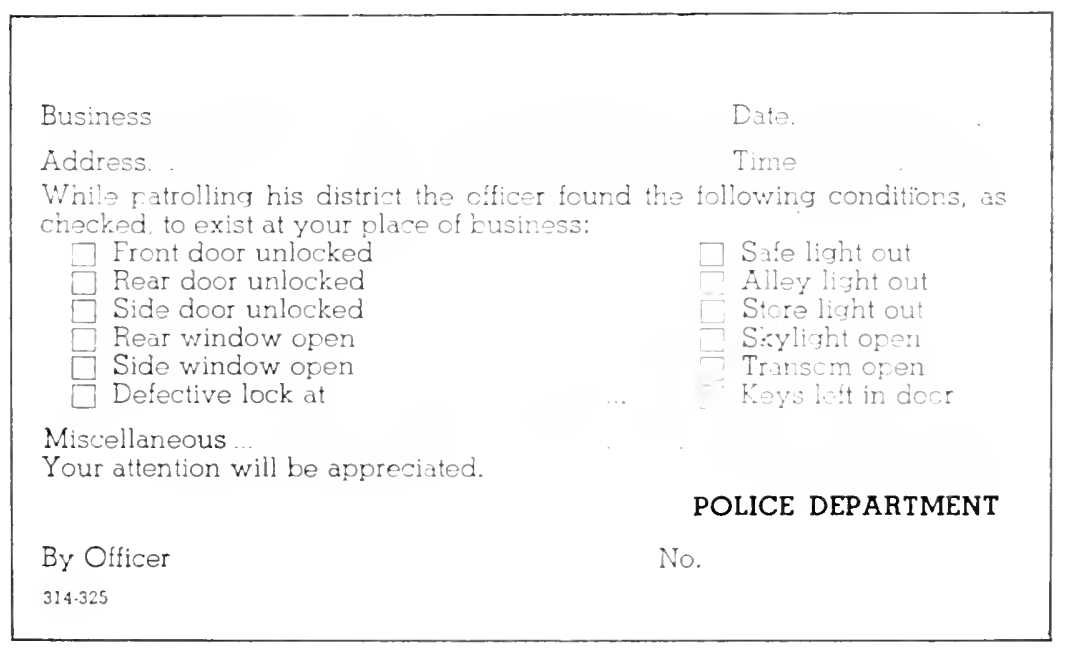

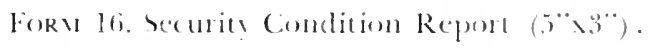


the Special Service Report, fill in the report and take the necessary immediate action. If you observe the condition during business hours, you may be able to notify the agency. Later the clerk will check the condition indicated on the report. List the pertinent information, note the action he has taken, and send your report to the records division at the end of his tour of duty. A clerk on the day shift in the records division will telephone the information to the proper agency and place the report in a file under your name.

When you have reported a condition on the Special Service Report, you also have completed your obligation in the matter. Any further follow-up may result in friction between your department and the department or agency concerned.

\section{An UNLOCKED AUTO is an}

\section{Invitation to Thieves}

\section{REGARDLESS OF LOCATION PARKED}

We solicit your cooperation in keeping the ignition and doors of your auto locked at all times that the car is parked.

THANK YOU,

POLICE DEPARTMENT,

314.720 , Officer No.

For:I 17. Invitation to Thieves Report (5"x3")

\section{FIELD INTERROGATION REPORTS 1}

In the course of your patrol activity you also will find reason for completing the "Field Interrogation Report," Form 19. A field interrogation is just what the words imply: a conversation held in the area where you first encounter a subject. It is an attempt to learn the identity of the subject. his business in the area, and his

\footnotetext{
'Information on this topic was adapted from Allen P. Birstow: Field Interrogation,
} Springfield, Charles C Thomas, Publisher, 1958, with consent of the publisher. 
pessible comnection with any criminal activities. Reporting interrogations is a vital part of your routine partol activity.

Field interogations cuable you lo lean about the persoms living in your districe who have aininal records or tendencies. Canversely, field interrogations give you an opportmity w neet local residents and businessmen, develop informants, and create farorable public relations sinuations. Frequent stopping and fuestioning of suspicious persons tends a reduce the crime rate in your district. Word will travel quickly by the criminal grape vinc that your area is being well partolled. Criminals rarely frequen areas where they are continuously stopped for interogration, and tend not to choose these districts for criminal activity. The thind and most important purpose of your field interrogation is to record the presence of the subject in your district at a particular time and place. This information may be utilized when a crime is later cliscovered in the district. The development of an adequate reporting system for field interrogations often bridges the communications gap between detective and patrol persomel.

After you have satisfied yourself as to the identity and purpose of a subject whom you have contacted in the field, you should take

\section{SPECIAL, SERVICE REPORT}

Beal No. 1)ate Houl OHticer

Location) Date Hol11

To RECORDS DIVISION:

Reporting Officer tequests that sou notifs the proper agency of condition indicalted below

Reporting Ollicer reports that agenc? was notilied of condition indicatted below

Name of Department or Agencs

Nature of Condition

Person Responsible

Action Taken B) Beall Offuces

Information on Velicte Involied:

License No. Owner Adiless

Drivel I). I.ic. No. Miliess

Telephone Notice to Records Cilerk 1) ille 11011

Fonu 18. Special Service Report (8"x") 


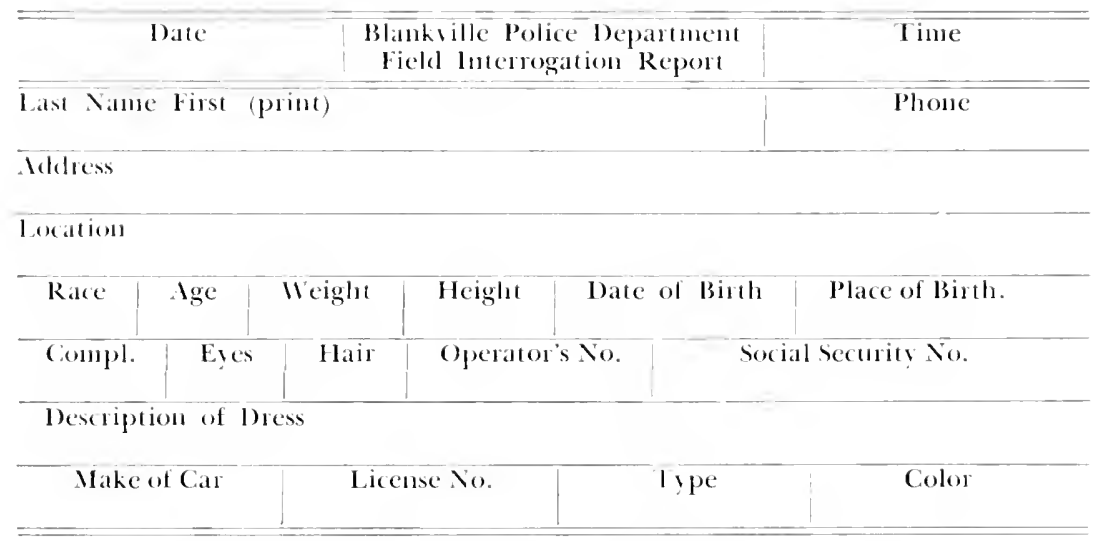

FORM 19. Field Interrogation Report (5"x3") (Front).

care in reporting the interrogation to satisfy the funal objective of your actions.

\section{Objectives of Field Interrogation Reports}

Notes regarding a contact in the field are of little value when they remain in your notebook. Detective and other follow-up officers as well as fellow patrolmen have no access to notes tucked away in your locker. Furthermore, others are not likely to leam of the existence of these notes muless you enter the contact in your log slieet.

For a program of patrol field interrogation to be really effective, a systematic method of recording each contact must be instituted. This record system must be available to detectives, followup oflicers, administrators, and other patyolmen il it is to achieve maximum effectiveness.

Establishing a field interrogation recording system insures that each patrolman will gather the same information for each subject and onit nothing of importance.

\section{The Report Design}

The fondation of a records system for field interogation lies in the adoption of a standardized report form. Devising such a form, and making it an oflicial departmental report. have the psy- 
Companions

R. (.. 1). Chech

1)isposition

()Hicer

Forv 19. Field Interrogation Report (Revere).

chological advantage of impressing patrolmen that the department not only favors and enconages field interrogations, but also requires them. Because such a form is an oflicial report, signed by the patrolman, it tends to prevent the practice of "padding" patrol logs by officers with fictitions field interrogations.

Form of the Report. The field interrogation report as presented in this manual is printed on a $3 "$ by 5 " cardboard card, both sides. This size is used because it will fit conveniently in your notebook, is more easily handled in the field. and is readily adaptable to filing. Cardboard or heary paper is durable and facilitates writing under field conditions. Both sides of the card have well marked "fill-in" spaces for the necessary information to insure miformity.

Contents of the Form. The information regarding the subject that you should note on the card includes: (1) name, (2) adcless and telephone number, (3) physical description. (4) age and date of birth, and (5) a description of his clothing. When the subject has no middle name, use his mother's maiden name as an aid in filing.

Information that you record regarding the location should include the time, day of week, and date. In addition to listing the intersection or address of the interrogation, the census tract or grid division of occurrence should be listed for later evaluation. If the location is connected with a possible or potential victim or 
area of criminal activity, this should also be listed, for instance: "Gth and Ehm, Garfield School," or "826 Short St., Frank's Licpuor Store."

When an automobite is involved in the field interrogation, you should describe it by: (1) make and year, (2) license number, (3) style, and (4) color. Any companions found with the subject should be listed in the appropriate space, but the main subject on the card should be the chiver, when a group is found in a car. It is also wise to list the seating location of the subject's companions in the automobile for future reference.

Supplementary information that you should list includes: (1) any identification number found on the subject's documents; (2) any serial numbers found on property carried by the subject; (3) results of a record check, if made; and (4) your reason for interrogating the subject. Sign the card before you assume it is complete.

\section{Making Entries on the Report Form}

All entries should be made in ink; and, for this purpose, a fomtain pen is most successful. Fill out each space; or, when a space does not apply, line it out to prevent any possible omissions. Do not rely on various pieces of identification for information as to the subject's physical description; they are often inaccurate. Make the entries on the basis of your own observations and judgment.

Special Entries. List the amount and denominations of money carried by the subject and the mileage of the automobile he is driving. Any companions should be listed as completely as space permits.

Mollifying Irate Subjects. The best technique in field interrogation reporting is never to permit the subject to know that a report is being made. The card may be concealed in your notebook, and the subject may be told that you always keep personal notes on each person with whom you talk. This statement tends to explain to the subject the reason for your taking the notes. When possible, your partner should distract the subject or keep him at a distance to prevent his leaming that a report is being written. 
The subject may, however, leam that you are witing the report: and, if so, he must be assured that the ficld interrogation report is not a criminal record, is not an indication of arrest, and will be held in strict confidence by the department. Howerer, in your attempt to prevent such situations, you should not adopt the policy of wring the field interrogation card at a later time on the basis of your notes; this practice invites omissions.

\section{The Filing System}

At the end of your tom of duty you should make a recond check on any subjects or companions listed in the field interogation report when the check was not made in the field. Any lumber information thus found should be listed on the card. If you feel strongly that the subject is a sex offender, pervert, burglary suspect, or narcotics user, or you find that he is mentally unstable, identify the card with an appropriately colored tab along its upper edge. Place the card in the incoming report bin for processing.

Supplementary File Cards. A file clerk examines the card and prepares any supplementary file cards that are necessary. Six supplementary file cards are developed to separate the most indexable information found on the card. A different color is used for these supplementary cards as well as the original field interrogation card, and the color scheme is changed annually so that the filing system may be cleared. Cards are kept no longer than one year; thus on Jan. 1, 1960, all cards for the calendar year, 1958, are removed from the files.

Supplementary file cards are of great value to the detective division in obtaining leads and suspects for crimes. The cards in this file are indexed by census tract, map grid district, or other geographical divisions. When a crime has occurred in a district, the detective may gain a valuable lead by leaning who has been the subject of a field interrogation in that area recently.

Date and time files may be used in the same way by detectives. When a crime sequence or criminal's modus operandi indicates a time or date pattern, the detectives may learn which subjects were in circulation on the dates and times indicated. The time file is in- 
(lexed by hour and contains 24 divisions-1:00 P.M. to 1:59 P.M., 2:00 P.M. to 2:59 P.M., etc. Date files are indexed numerically by the day of the year-i.e., $265,266,267$, etc.

Two supplementary anto files list a vehicle by color and style. These files are of great value in cases involving sex offenders, as well as in all other crimes where an antomobile is involved. Witnesses are usually correct as to the color and style of an automobile, but they are notoriously umeliable when describing year, make, or license number. The color file is indexed by major automobile colors, while the style file is indexed by body type and number of doors-i.e., sedans ( 2 door), sedans (4 door), coupes, pick-up trucks, etc.

A companion file is of most use to detectives when interrogating an arrested suspect. These records provide a valuable list of the suspect's prior social or criminal companions, who may also be the suspect's crime partners at present. The file is alphabetically indexed.

After the clerk completes entries on the supplementary cards they are indexed and filed. Your original field interrogation card is filed alphabetically in a master file. The color tag system permits special types of subjects to be located quickly. 


\section{Chapter XVI}

\section{THE SUPPLEMENTARY PROGRESS REPORT}

I

X OUR DISCUSHOX OF THE PRLLMIXARY investigation we placed emphasis upon the fact that most cases should be assigned, in their initial stages, to beat patrolmen. It is well to note. however. that certain cases may be assigned directly to specialized divisions. Regardless of the division to which the preliminary investigation is assigned, it is the responsibility of the officer who conducts an initial investigation in the case to complete one of the various kinds of preliminary investigation report forms. If the case is one of a minor nature or one completed in its entirety by the officer or officers first assigned, the preliminary report may terminate the reporting of the investigation.

All officers who do any work or have any information on a case are obligated to report any information which they possess. If the work done or the information received is subsequent to the making of the preliminary report, the information should be reported on a supplementary investigation form, Form 20. Also, if officers other than those assigned do any work on a case, they, too, should conplete a supplementary report form.

The reporting of supplementary information actually calls for two types of supplementary reports; progress and closing reports. Our discussion in this chapter deals with the progress report, but the same form may be used for either kind.

The progress supplementary report arises from the fact that many cases are prolonged. Some may be terminated in a few weeks. others not for months or even years. In these situations, your department must be appraised of the progress of the case so long as it remains pending. Many progressive agencies solve the problem by keeping close check on all cases through the activities of a follow-up oflicer who exercises staff supervision over the reporting activities of officers in the field. Under this plan, rules and regu- 
lations require that progress reports shall be submitted at fixed intervals unless actual developments in the case require earlier reporting. These progress reports serve the added purpose of setting forth undereloped leads which will be investigated by men assigned to clear varied facts of the case.

\section{BLANKVILLE POLICE DEPARTMENT \\ SUPPLEMENTARY INVESTIGATION \\ REPORT}

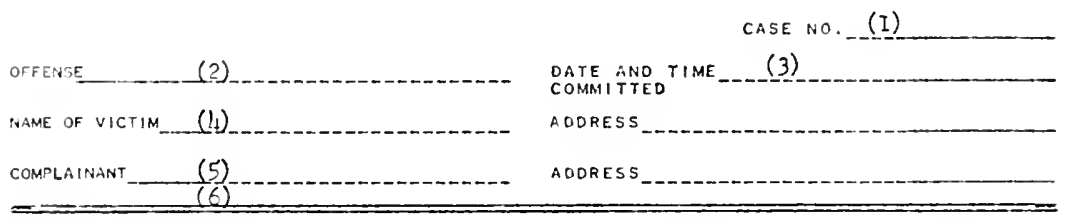

SYNOPSIS: (7)

DETAILS: (8)

Undevelcped Leads: (9)

Conclusions:

(10)

Recormandations:

List of Exhitits: (12)

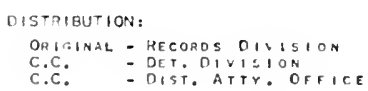

For:I 20. Supplementary Investigation Report (81/2"xll”). 
On the other hand, a closing or prosecution report is one of a slightly different nature; it beromes necessary only when the case is conchuded. One person, usually the detective who originally was assigned to the case, must assume the responsibility of stmmarizing, analyzing, and bringing the loose ends of the investigation together into a composite picture. Generally, the closing report will be the final one, but submission of it does not preclude reopening the case when additional information is received. This report is discussed in detail in Chapter 18 of this mannal.

\section{NATURE OF THE PROGRESS REPORT}

The title of the supplementary progress report is highly indicative of its nature. When you write a supplenentary progress report, the case sheet and preliminary investigation reports have been made or will be completed. The incident has not only been reported, but the modus operandi of the criminal usually has been determined. Any facts in your report are supplementary to the basic ones which have been established. So, if you have information to give, state it briefly, concisely, accurately, and fairly. You can best do this in a narrative way, reporting your fundings in the same order in which you discover them.

\section{THE REPORT DESIGN}

The nature of the report naturally influences its size and content. The illustrated form presented as Form 20 is adequate. In completing this form you are merely adding another part to the entire case picture. Later your progress report will be filed in the records division along with the case sheet and the preliminary report. For this reason the progress report is $81 / 2$ " $\times 11$ " to correspond conveniently with others in the same fite. You will also note that the illustrated form contains a printed heading. This kind has advantages when compared with a blank sheet. It is easily identified once it reaches the records division, which makes for fewer errors in filing and use.

A complete supplementary progress report has three parts: heading, body, and ending.

The first part, or heading, is designed to present helpful ad- 
ministrative data and includes the case number, the offense, date and time the offense was committed, victim, complaint, and a salutation. It is throngh this identifying information that the necessary processing is facilitated in the records division.

The principal content of your report is in the body. Here, in narrative form, you tell everything you did and learned about the case which you and others have not previously reported.

The ending of the report is its closing administrative data. It includes the date and hour you completed the writing, status of the case, the period of investigation, your signature, and the distribution of the various copies.

\section{Specific Content of the Heading}

Case Number (1). The case number is the same number that appears on the claily bulletin, case sheet, and preliminary investigation report. Take it from any of the above sources.

Offense (2). The "offense" is the classification of the crime. It should correspond with the crime classification as recorded on the case sheet and preliminary report. State the specific nature of the crime; lollow with the applicable section of the penal or other code. When you are reporting two or more offenses in the same report, the most serious of the crimes will determine the classification and the offense which you report on the form.

Date and Time Committed (3). The date in the heading of your report is that date on which the complaint was received, the date which appears in the, Daily Bulletin. Don't confuse it with the date of the report which comes later. Write the date in one of the following ways: "1/10 60," "1-10-60," or "Jan. 10, 1960." Record the time on the same line.

Victim, Address and Phone Number (1). This part of the supplementary progress report refers to those individuals listed as "victims" in the preliminary report. If additional victims or aliases are uncovered in your supplementary investigation, insert the word "correction" on the "victim" line. This aids persons who later will review the case and the records division personnel. Explain the correction in the "details" section of your report.

Capitalize the lull name of the rictim as follows: "GEORGE 
D. J() N lis." (ive his complete adchess including house mumber, street, cily and state. Include home and busines telephome munbers. if they are available. It is comect to list the names, adeleseses, and aliases of all persoms who are the victims of the crime, or you may list the name of the principal victim and follow it with the worel "et al." If the victim has several aliases, all of them should lave been presented in the preliminary report; in your supplemen. tary progress repont follow the victims name with the words "and aliases." Yon may tater reler to the victim in the details of the report as "Victim" or give his last name in capital letters. When you are unable to identily the victim, you should wite the word "IXK.XOWX" and follow with some identifying infomation including the nature of the crime and location of it-for example. "I'XKNOWX. WMA, victim of amed robbery at $3+18$ Marla Drive, Jan. 3, 1960."

Complainant and Address (5). Record the full name and address of the complainant. Reinember that he may be a person other than the rictim.

Salutation (6). Since it is understood that your progress report is directed to the chief of police, usually no salutation is necessary. However, if you wish to call the attention of some oflicer to yom report, you should include a sahutation as follows: "Attention Officer - - -." The officer to whom your report is directed should later insert his initials immediately following his mame. When this is done, all persons concerned will know that he rereived and read your report.

\section{Specific Content of the Body}

The body of the progress report may contain the following headings: synopsis, details, mndeveloped leads, conchusions, recommendations, and list of exhibits.

Don't be confused by the fact that preliminary reports may contain many of these same headings. Headings are used in inrestigation reports in the interest of completeness and accuracy. I'se them if and when you need them.

Symopsis (7). Note that space is provided on the title page for a symopsis. This should be a single paragraph, witten in marrative 
style, which sums up the details of your report, indicates the investigative steps thus far accomplished, and the result you have obtained. In fact, the synopsis is the essence of your whole report. A complete synopsis also will inchude the value of stolen or damaged property; the perpetrator's name, if known; and the name and address of the victin. Following is an example of a synopsis in a report of a burglary:

Investigation reveals that on June 24, 1960, ROBERT R. SMITHI entered the GENERAL HARDIVARE COMPANY at 3387 Marlow St., and took three rifles and wo shotguns. On July 9 , he was apprehended at his home, 318 Maple Way, Blankville, California. Smith presently is in custody in the Blank County Jail.

Value of property stolen: $\$ 780$.

Value of property recovered: $\$ 780$.

You should be warned: writing a good synopsis is not easy. It requires practice. Yet, since it offers the reviewing officer a "bird's eye view" of all of your findings, your time is well spent. A suggested procedure for writing an acceptable synopsis involves careful reading of your field notes and listing certain sentences which seem to summarize various phases of the investigation. After this, a number of revisions may be necessary before the essence of your investigation is set forth. But once you accomplish a proper synopsis, it becomes an excellent guide to any person who may review the investigation or write a closing report. A good synopsis facilitates subsequent reference and filing of the case.

Details (8). The"Details"section of the supplementary progress report is the same as the "Details" section of the preliminary vestigation report. Present a step-by-step narrative of the work you did in the case. If your details section is complete, it will answer the questions essential to the investigation: Who? What? When? How? and (probably) Why? As with the heading and synopsis, you may complete the details on the title page. On the other hand, if your report is lengthy, you may continue on the reverse side of the title page. If additional paper is required for completion, just add pages.

'Capitalization is used in eutering the name of the subject and the victim to facilitate work in the records division. 
like the details section of the preliminary repott, your furst paragraph should contain the basis for the investigation. The second paragraph will cover your authority for the investigation. Each subsequent paragraph should represent a separate investigative step that you took. Number your paragraphs and pages accurately to provide for subsequent reference to particular pages and paragraphs. Follow the basic principals of accuracy, completeness, brevity, conciseness, faimess, and form. Parenthetical reference should be made to all exhibits which support the details of your report.

The following rules are applicable to the "Details" section of both progress and preliminary investigation reports:

I. Capitalize all firm names and the name of any person when the name is first mentioned in the details of the report.

2. Any subsequent reference to the name of a person may be done by use of the last name only.

3. When subsequent reference is made to a firm name, it is sufficient to refer to it by a short name.

4. When referring to a person who is unknown, make the reference as "UNKNOWN, white male," or UNKNOWN, WM" etc.

5. Precede all women's names with MISS or MRS.

6. Be very specific when recording time and dates. Example: 9:00 A.M. I-24-60 (Mon.)

7. When information is obtained from a particular person, set this information out in a separate paragraph. Be careful to give the full name, title, and address of the person.

8. Preserve the secrecy of identity of a confidential informant. For eximple, refer to the person as "I-1," or "I-2" etc. Do not reveal identity by including address, occupation, or any other identifying data.

9. When juveniles are interviewed, indicate in the report that consent of the parents was obtained. An additional statement as to the competency of the child is advisable.

10. If you take a statement from a suspect, take it word for word. Include information as to the place where the statement was taken and the present location of the statement.

11. Statements of witnesses may be recorded in the details section in substance, but you should give the exact location of the true statement. 12. When mentioning an important record in the details of the report, include the name of the person who revealed the record, the title of the record, and the location, date, and content. If you preserved the record as evidence in the case, give the name of the custodian of the 
record and information regarting the need for a subpoena to obtain it.

13. Be specific and detailed in presenting descriptions of person and property. (Sec Appendix C for a detailed explanation of property descriptions)

14. Specific details relating to time, place, and identification should be given in relation to all facts discorered in the investigation and presented in the details of the report.

Undeveloped Leads (9). An undereloped lead is an uncontacted somce of information which appears necessary to bring your case to a logical conchusion. This part of your report is especially helpful to other officers who may work on the case later. Indeveloped leads may exist because you didn't have time to investigate further or were mable for other reasons to develop the sources to the fullest extent, but you must set them out to indicate to the reviewer that you are cognizant of them and have given consideration to them. Ipon reviewing the report, your commanding officer may wish to make additional assignments to other officers, requesting that they follow up on the leads indicated in your report. A request of this kind may describe the character of the lead, the type of information desired, and the name and address of the source of information. For this reason the information you present must be specific, indicating exactly what information may be expected from the lead and where to find it. Iny investigator should be able to follow your suggestions from the information presented in the "I'ndeveloped Leads" section of your report.

Here is an example of an "undereloped leads" section of a report:

Further investigation should involve location and interviewing Richard 1. Roe, 3842 Armond Drive, GL 5-3471. Sammel Howe's statement (paragraph 4) inclicates that Richard Roe is an associate of the suspect and probably was wh him on the night the crime was committed.

Samuel Howe's statement (paragraph 4) further indicates that Mary Coe, 2478 Lake Drive, GI-3432, is a girl friend of the suspect. Suspect is likely to contact Miss Coe at her apartment and possibly could be apprehended there.

Conchusions (10). The "Conclusions" section is a controversial one. Some agencies require it. Others forbid expression of opinion 
in any part of the report. In this mantal we recommend that yon include a "Conchusions" section unless your deparment forbicls it. When you have conducted a thorough investigation, you should be qualified and privileged to say what you think about it. Yous opinions may prove extremely valuable to others who munt continue the investigation or make important decisions reganding prosecution. You may want to express opinion as to the reliability of witnesses, how certain physical evidence may prove vahuable in prosecution, weaknesses in the cridence as presented. or the type ol investigative technigue which may produce additional infonmation. Just onc waming, when you state your conclusions, be aneful to restate or summarize the facts upon which your opinions are based. Otherwise, your opinions may be ignored or carry rery little weight. The following sample statements, with actual names excluded. are excerpts from the conclusions section of a supplementary progress report:

Investigating officers are of the opinion that the statement of Rich. ard Roe (paragraph 6) is not entirely reliable. Mr. Roe and the unpect were business partners from September of 1948 until Jamuary of 1957. Investigation further reveals that suspect continues to maintain an interest in the General Hardware Company, owned and managed by Richard Roe. If the suspect were convicted under the present charge. Richard Roe believes that the suspect would withdraw his investment in the firm and the business would ultimately be dissolved.

Investigating officers are of the opinion that a detailed atudit of the books of the General Hardware Company would reveal the supect's actual investment in the firm.

Recommendations (11). Recommendations logically follow conclusions, for the latter section establishes a basis upon which valid recommendations can be made. I'sually, your recommendations should relate to the disposition of the case. You may recomnend prosecution, closing the case, further investigation, or offer other suggestions regarding remedial action which may be taken. Contrary to the policies of some police agencies, this kind of information is necessary to good police work and effective reporting. Another word of cantion is offered, howerer. You must understand that both conclusions and recommendations must be given 
with the realization that they may be accepted or rejected at the discretion of the officer who reviews your report.

The following statement was taken from the recommendations section of a progress report:

Investigating officers recommend further investigation. Undeveloped leads, indicated earlier, must be followed. The neighborlood should be canvassed with a view to locating a witness or witnesses who can place the suspect at the scene of the crime.

List of Exhibits (12). Although a "list of exhibits" takes on a more specific meaning in a prosecution report, your attention is called to the fact that a progress report can be made more meaningful to a reviewing officer if you include this kind of information. When you provide a list of exhibits in the progress report, it means that those who review the case will have an opportmity to take a first-hand look at important evidence that you have gathered or will be told where it is located.

Since original evidence must be kept secure, your actual inclosures should include only evidence that can be copied, photographed, or photostated. Number each copy in its lower right-hand corner and attach it directly to this report. Give each exhibit a separate letter, describe it, and tell how it applies to a particular paragraph in the details of the report. Further information should explain where the original evidence is located. Examples are as follows:

Exhibit A: Copy of criminal record of John Doe (paragraph 6) is attached.

Exhibit B: Copy of a sketch of the crime scene (paragraph 7 ) is attached. Original copy in custody of the evidence clerk.

\section{Specific Content of the Ending}

As mentioned earlier, the title page of your report provides for ending information at the bottom. Like the heading, the ending furnishes valuable administrative data. In addition, it fixes responsibility for the report.

Period of Investigation (13). The "period of investigation" means the actual time you used in the investigation. It also inclucles all the time you consumed in writing the report. For example, "Feb.1,3-7," means that the investigation started on Feb- 
ruary 1, was conducted on February $3,1,5,6$, and the report and or imestigation was completed on the 7 th.

Status (1.1). Status of the case refers to its condition in relation to the depatment. Ill cases must be classified as either "Pending" or "Closed." Cilose the case when the suspect dies, your investigation is complete, or when you receive specific orders from your superior oflicer to close it. Classify all other cases as "Pendiing."

Date and Time (15). The date of the report means the actual date your report was made. If you wrote the report on more than one day. the date of completion is the day you should record. If you dictated the contents of the report, you should record the date of the dictation. The date and time should include the day of the month. year, day of the week, and the hour. You may write the dite and time in either of the following ways: "1/15/60 (Tues.). 7:30 P.М.,"“-1-15-60, (Tues.) 7:30 P.M.," or "Jan. 15, 1960 (Tines.), 7:30 P.M."

Report Made By (16). Sign your name on the "signature" line. This fixes responsibility for the content of the report and serves to notify the prosecuting attorney as to his principal witness. Other oflicers who worked on the case, but were not assigned to it, should be mentioned in the body of your report.

Distribution (17). "Distribution" indicates the disposition of the original and all copies of the report. Check the distribution and mark your report clearly. Direct the original to the records division. Carbon copies may be distributed to the detective division and the prosecuting attorney's office, and a final copy may be retained for the files of the division where your report originated. 


\title{
BLANKVILLE POLICE DEPARTMENT
}

\author{
SUPPLEMENTARY INVESTIGATION \\ REPORT
}

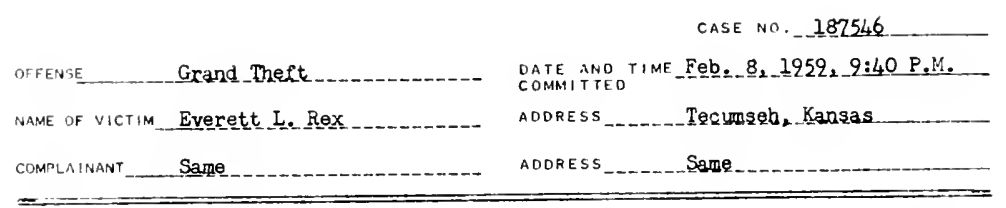

SYNOPS15:

At 9:49 P.M., 2-8-59, reporting officers received a call to investigate a theft at Room 109, Blankville Inn. Contacted the victim, Mr. Everett I. Rax, of Route 1 , Tecumseh, Kansas and Gold City Motel, 1951 West 8th Ave., City. Victim stated that he had taken a waitress by the name of "Kathy" (WFA, 23, blond hair, 5'7", 131 Ibs) to the Blankville Inn in an Ace cab driven by a "George". They were to spend the night. Upon returning from the shower at approximately 9:40 P.M., the girl had left and his watch (valued at \$25) and thirteen $\$ 20$ bills (\$260) were missing. Later contacted Mary Helen Sobel at $2011 \mathrm{EJ}$ Si. She and two female companions accompanied reporting officers to the Cold City Motel where the victim identified Mary Helen Sobel as the girl who was with him at the Blankville Inn at the time the money and watch were taken.

Value of property stolen $\$ 285$.

DETALLS:

(1) 10:15 A.M., 2-9-59, reporting of ficers contacted the local cab companies and learned that an $A C E$ CAB, driven by ROBERT HERN, had been dispatched to the Blankville Inn to pick up a fenale passenger who had asked for "Bob" personally.

(2) 10:30 A.M., 2-9-59, reporting officers talked with cab driver, ROBERT HERN, at the ACE CAB COMPANY, 782 Mathis Ave. Hern related that "Kathy" made a personal call for him to go to the Inn; later when she called upon leaving the Inn, he dropped her of at 8th and Roberts Ave. He stated she paid him with a $\$ 20$ bill. He also stated that the fare was $\$ 2.10$, and she gave him a $\$ 2.40 \mathrm{t1p}$. Hern claims he does not know the girl very well but worked with her previously at HERMAN'S CLUB. He relited that she might live at 20 th and Elm Sts.

DISTRIBUTION:

XOGIGINAL - REGOROS DIVISIOA

- DET. DIVIETON

C.C. - DIST. ATtY. OF, ICE
PERIDD OF INVESTIGATIONFEb-2, 1952

STATUS _.....Pending

DATE___2-9-59_...... TIME_4 $4: 00$ P.M.

SIGNATURE loholo Ttendrix

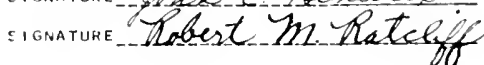


(3) $11: 15$ A.X. , reporting officers talked with NEWIL CFOWELL, bartender for Hernan's Club at 1016 5th St. Crowell stated that "Kathy" tended bar from 2 P.Y. to $6 ? .2,2-8-59$. He also said that he did not know her last name nor where sho iives. He stated that the owner of the PAIGUIN CLUB at 817 4th ive. would know where she now lives.

(4) $11: 35$ A.M. , reporting officers talked with HuMA: HiH, owner of Herman's club and the Fenguin Club. Hr. Hern stated he did not know the blond's nume nor where she lives. He stated that she previously worked for him and was fired because she and Robert Hern (the cab driver and also his nephow) were going out together and did not take care of the business at the bar.

(5) 1:35 P.K, reporting officers contacted the owner of the apartments at 2011 Elm St., Hr. ROB.RT T. ROMA, FL 2-2493, of 1036 Stem Court. he related that a "Katiny" was living at 2011 Elr. St., apartment ff5 and that her deseription was the sume or similar to that of the suspest. Roman stated that he had last seen the subject at the apartment house on Friday, Feb. Eth.

(6) 2:50 E....., reportine cffizers contacted Kathy Roe (19), Bernice iilliams (is), and $\mathrm{J}$.ckie Roe (22) at $201 \mathrm{i} \mathrm{Im}$ St. In response to guestioning by reporting officers, the thres firls reizted that they had been to a movie together on the

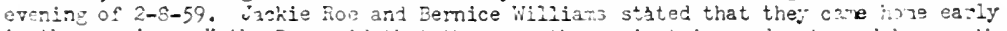
in the evenine. rathy Roe said that the; saw the aovic twie ard returned hom ratie: I3.e. She stated surtier thet her true name is Yary Helen Sobei and submitted identifiction bearing the sice name. Feporting officers otserred that the blord (Kathy Noe), "ar : Helen Sobel, ankwered the description of the suspect and asked the three subjects to accontang then to the fold City Votel where the victim is living.

(i) 3:55 F..., reporting officers contacted the victin and asked hin to observe the above three subjecs. ir. Rex stated that Vary helen Sobel (hathy Roe) lookec axactly like the suspect and that she was the giri who was with him at the Blaniville Ins at the time the moner and watch were taken. Mr. Pex furtier stated tist he will be in tite office of the chief of letectives at 9 A...., 2-10-59 to gu to the District ittomey's office to sign a corflaint.

\section{CONCLUSTO::}

Wary Ellen Sobel (alias hathy Roe) of 2011 Elm st. is the girl whom the victim met at the Surb Club and who later accompanied the victim to Room 169 of the Blankvilie Inn. She is also the person who tock the victin's watch and $\$ 26 \mathrm{C}$ in cash.

\section{PDCANONDTIONS:}

Reporting officers recomend that the case remain open, pending the filing of a complaint by the victir and further investigation. It is further recomenced that Yary Zien Sobel, Jackie Roe, Bernice Villiams, and the cab driver, Robert Hern, be interrogated extensively regarding discrepancies in their statements. 


\section{Chapter XVII}

\section{SPECIAL SUPPLEMENTARY INVESTIGATION REPORTS}

I

N THE MATTER OF REPORTING investigations, most police agencies have discovered that the standard supplementary investigation report form, such as Form 20, is not completely adequate for recording special procedures applied in the investigation. This is true when investigators need to place special empluasis on the obtaining of detailed descriptions of suspects from witnesses and victims, suspects are presented in a line-ıp, physical evidence is examined in the crime laboratory, the suspect is subjected to a polygraph test, or the social backgronnd of a child is investigated in a juvenile case. This chapter presents the forms and content of forms necessary to the reporting of these specialized phases of an investigation.

\section{SUSPECT DESCRIPTION SHEET}

The "Suspect Description Sheet," Form 21, is a supplementary investigation forn designed to assist you, as the investigator, in getting a complete and accurate description of a suspect in a systematic manner. You may also use it for witnesses or victims to record in their own handwriting descriptions of the suspects. After it is signed by a witness or victim, it is made a part of the investigation report and can be used at a later date, if necessary, to refresh the memory of the witness or victim. If this technique is used, the witness or victim experiences some difficulty in denying the description as the one he gave at the time of the crime was committed. A physical description picture such as that presented in Figure 6 may assist the witness in being more specific.

In obtaining the description, be systematic; get as many details as you can: race, sex, age, height, weight, hair, eyes, complexion, build, etc. The subject's physical characteristics, mannerisms, posture, movement, attire, and even speech are important. Don't 


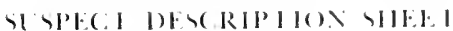

Offerise: ( I)

( alse No. (2)

I ime and hate Ofleme Commitled: (3)

I. M. I'.M. 19

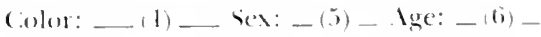

c.lores:

Height: (7) IIeight $\ldots(x)-$

Inolleres:

Il.1i1: (1) Eies: - (10)

Fars: (11)

Nose: (II)

Mulli: (1.3)

lectl): (14)

(lin: (15)

Build: (16)

Complexion: (17)

Voice-speech: (18)

Morements: (19)

Vehicle I sed: (24)

Posture: $120)$

Scars-Marks: (21)

Remarks: (25)

Attire:

llat or Calp:

Submitted b!:

$(26)$

Shirt or sweater:

Time \& Date:

$(27)$

lie or balst:

Received by:

(28)

1)itle:

$(2)$ 19

Vote: If additional space needed for an of the alowe. use reverse vide.

For.I 21. Suspect Description Shect (St,"xll"). 


\section{NOTICE}

Should you be attacked, defrauded or for ony reoson be suspicious of someone, obtain oll information indicated below and immediately notify the POLICE or the SHERIFF

CLOTHING
HAT color, type
SHIRT
color, sport, dress
COAT
color, type, style
TOP COAT, color, type, style
PANTS
SOCKS
SHOES
IF YOU LIVE IN THE CITY

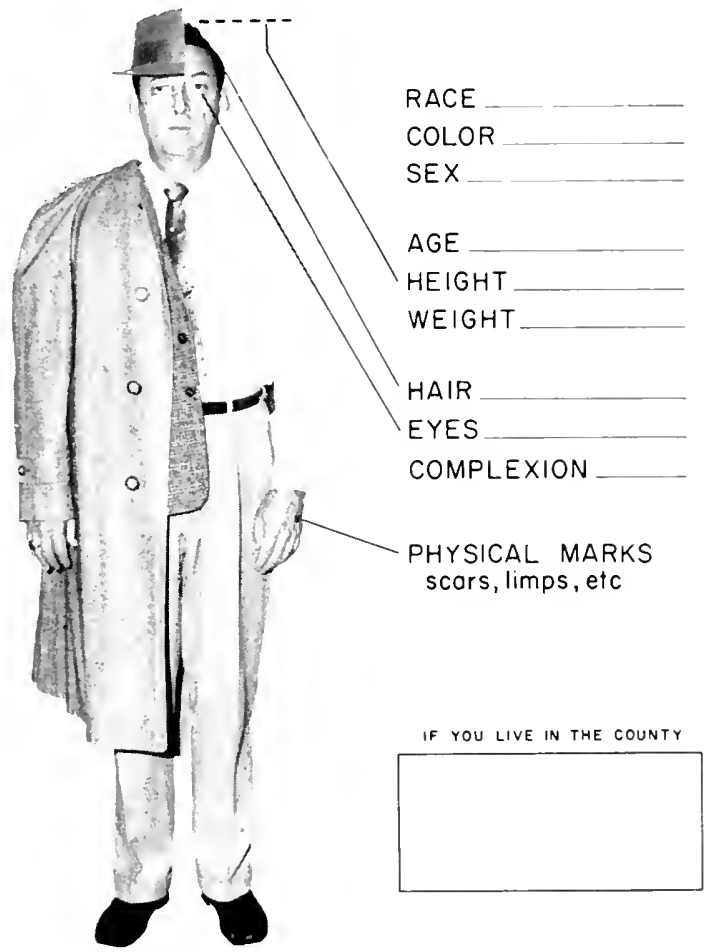

If vehicle involved complete the following information License number (all or partial)

make year $\overline{\text { body type }}$ color number occupants (male,female)

Fig. 6. Phisical Description Picture. In your efforts to get an adequate description of a suspect from a witness, you may fond that presenting him this kind of picture will help hin to recall many of the physical characteristics of the individual. 

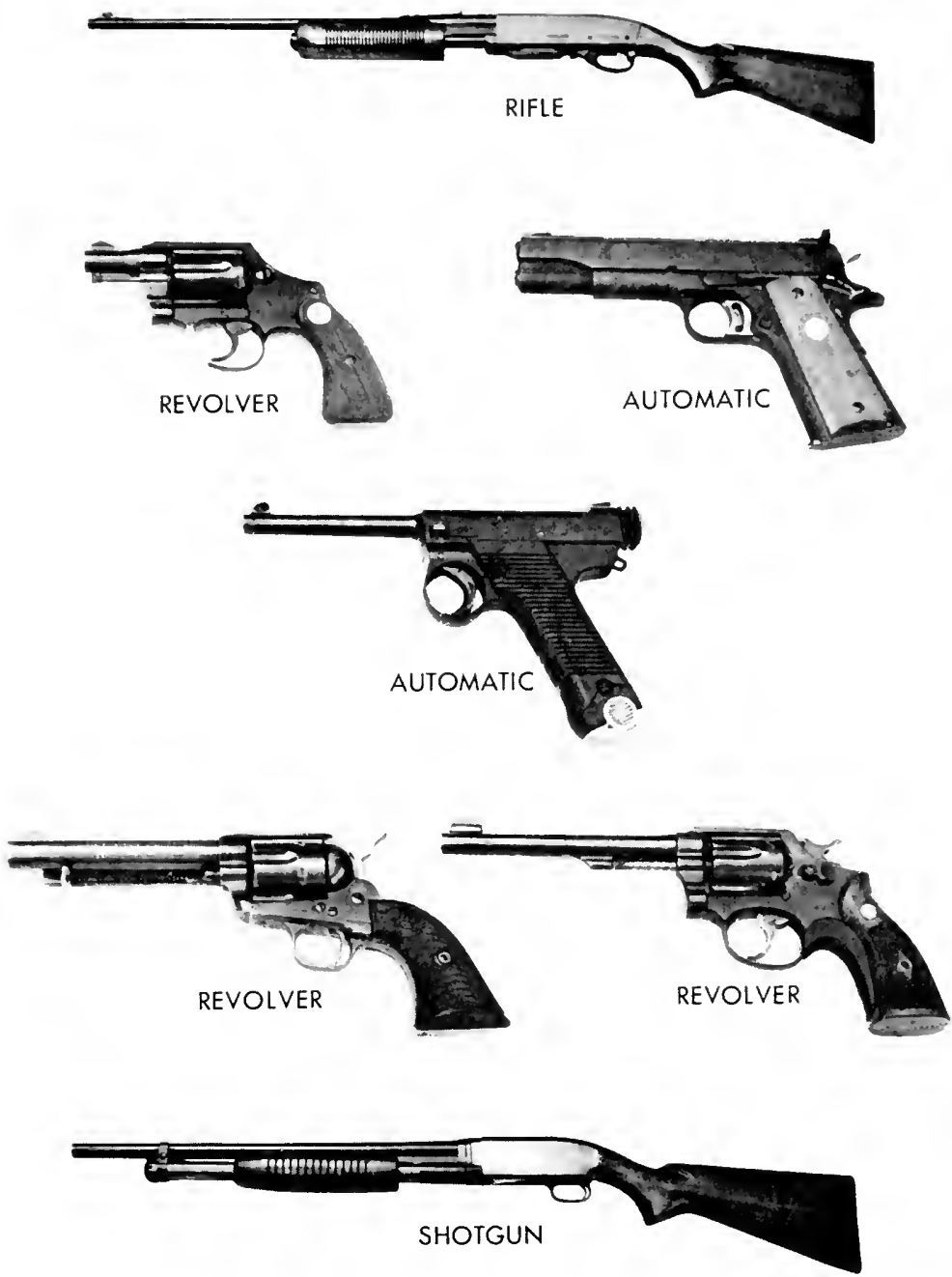

If weapon is used circle or check picture most similar to type used by suspect.

Fig. 7. Plysical Description of Weapon. When a witness experiences difficulty in expressing the ype of weapon used, ask hin to circle the appropriate weapon on the sheet. 
trust your memory; it can deceive you. Be sure to include everything. every detail, regardless of how insignificant it may seem at the time. The agility and movements of the subject are important. These characteristics frequently assist in determining the age of the subject or in determining various body ailments. A complete cliscussion of each item necessary to the "Suspect Description Sheet" follow's.

\section{Offense (1)}

The offense is the same as that which appears on the complaint sheet.

\section{Case Number (2)}

Get the case number from the case sheet or the complaint log.

\section{Time and Date Offense Committed (3)}

Record the same time and date as entered on the "Complaint Sheet."

\section{Color (4)}

Color indicates the race of the subject. This is usually apparent. However, there are a few instances when full head masks and gloves might make it impossible for the witness or victim to determine the race of the suspect. In this kind of situation, try to determine the race of the suspect from the witness' description of the suspect's mannerisms and speech. Record the race as white. black, yellow, etc.

\section{$\operatorname{Sex}(5)$}

Enter the sex as male or female. This, of course, is usually apparent to the sight. However, there are times when a man may impersonate a woman, or a woman may impersonate a man. In these situations, the sex must be determined by mannerisms and speech.

\section{Age (6)}

Record the age as " 36 years," "45 years," etc. It is often difficult to obtain an accurate estimate of age from a victim or witness. However, if several descriptions of the suspect are available, arrive at an average for the age. As stated earlier, agility and movements may prove helpful in determining age. 


\section{Height (7)}

State the height as 5'10," 5'll," etc. Ask the witness to determine height by comparing the suspect with someone of known height. If several witnesses give an estimate of height, take a general average.

\section{Weight (8)}

Use the sane techniques in arriving at an accurate estimate of weight as for the height.

\section{Hair (9)}

Describe the suspect's hair as light, medium, dark, brown, black, blonde, red, gray, white, red-brown, salt and pepper, etc. It may be described further as long, short, thin, thick, or curly. Describe the hairline as square, pointed, rounded, higher on one sicle, etc.

With the new hair dyes available, it is possible for a suspect to dye his (her) hair in just a few minutes, and the dye can be washed out in even less time. On the other hand, many sprays and quickdrying dyes make the hair appear sticky, which in most cases is apparent on close observation.

\section{Eyes $(10)$}

The suspect's eyes may be described as to color, shape, size, and unusual characteristics. Describe the color of the pupil as blue, hazel, grey, brown, maroon, etc. Size may be described as small or large. Peculiarities may include close set, far apart, slanted, etc.

Glasses or contact lens are just about the only means by which eyes can be disguised. However, the use of certain eye drops and drugs can cause the pupils to expand or contract. The shape of the eyes can be changed by the use of llesh-colored transparent adhesive tape or by reshaping the eyebrows.

\section{Ears (11)}

A thorough description of the suspects ears can be one of the better means of identification. Ask the witness to describe the general shape and size, the ear lobes, and whether the ears are set close to the head or stand out from the head. 
Nose (12)

The nose should be described as Roman, pug, turned up, long, small, large, broad, etc.

\section{Mouth (13)}

Describe the mouth as large, small, wide, thick lips, hair lip, etc.

\section{Teeth (14)}

Ask the witness for only the peculiar or outstanding characteristics of the teeth, such as sharp, short, long, broken, gold, braced, stained, uneven, missing, etc.

The teeth may be altered by the use of putty, false teeth, tooth caps, and gum pads. However, the use of tooth caps and gum pads has a tendency to cause slight impediments of speech.

\section{Chin (15)}

The chin should be described only as to shape: square, broad, narrow, pointed, long, deep cleft, shallow cleft, etc.

\section{Build (16)}

Build should be presented as small, large, medium, slender, stocky, slumped, large stomach, small waisted, etc.

\section{Complexion (17)}

Don't confuse complexion with the racial coloring of the subject. Describe the complexion as light, dark, medimu, sallow, pale, ruddy, white, llushed, scarred or pitted, splotched, pimply, etc.

\section{Voice or Speech (18)}

The voice or speech of the suspect may be clescribed as educated, meducated, loud, low, high, shrill, deep, lisp, foreign, accent, etc. The suspect may have used certain expressions repeatedly; record these.

\section{Movements (19)}

Ask the witness if the suspect's movements were slow, fast, nervous, calm, direct, confused, hesitant, etc. Attempt to deter- 
mine any peculiar mannerisms: pulling on the ear lobe, scratching the head, rubbing the eyes or lorehead, shuffling the feet, we of the hands to emphasize commands or speech, ete.

\section{Posture (20)}

posture should be described as mormal, erect, slouchy, romelshouldered, etc.

\section{Scars and Marks (21)}

Attempt to obtain specific intomation from the witness. Describe all visible scars, tattoos, moles, warts, birthmarks, missing fingers, deformities, etc. Give the location as exactly as possible.

\section{Attire (22)}

Describe clothing generally as to color. material, style, new, old, clean, dirty, worn. etc. Have the witness describe the suspect's clothing systematically from head to foot as follows: (1) hat or cap, (2) shirt or sweater, (3) tie or scarf, (4) coat or jacket, (5) gloves, (6) trousers, (7) socks, (8) shoes, and (9) jervelry and watch. A number of agencies have developed a hand-out description sheet such as that presented as Figure 6. Asking the witness to complete this sheet may be helpful in the description of clothing.

\section{Weapons and Equipment (23)}

Many witnesses experience great difliculty in describing weapons. A description sheet of weapons such as that presented in Figure 7. may prove helpful. Il a gun was used in the crime, ask the witness to describe it as a rifle, revolver, automatic pistol, or shotgum. Equipment might include acetylene torch, explosives, etc.

\section{Vehicle Used (24)}

Ask for as detailed a description of the rehicle as possible: make, year, body type, color, number of occupants, sex of occupants, accessories, body damage, etc.

\section{Remarks (25)}

In the "Remarks" section, list any additional information that will assist in identifying the suspect. 


\section{Submitted By (26)}

Ask the witness or victim to sign his name on the line, "Submitted By."

Time and Date (27)

Record the time and date that the witness submitted the information.

\section{Received By (28)}

Sign your own name here. If some other officer received the description from the witness or victim, ask him to sign the "Suspect Description Sheet."

\section{Date (29)}

Record the month, day, and year that you received the descriptive data. (Submit this special supplementary report along with either the preliminary investigation report or regular supplementary report.

\section{SUSPECT LINE-UP FORM}

In all criminal offenses in which suspects are apprehended and the victim or witnesses were able to observe the perpetrator, suspects should be identified by the victims or witnesses at the earliest possible moment, while the appearance of the criminal is fresh in their minds. Standard procedure requires that the identification shall be made from a group of suspects rather than a single individual. At least one of the subjects used in the line-up should be quite similar to the suspect in appearance and dress. Others should vary in height, build, age, complexion, and other physical characteristics. This technique makes the final identification of the suspect more positive.

If you are the detective assigned to the case, follow the above simple rules in arranging the line-up. In addition, have a group photograph made of the subjects and suspects as they are assembled in the line-up. The picture, which presents positive proof of the position of the suspect in the line-up, may be used as evidence if the suspect is identified by the victim or witnesses. 
I'se the "Sispect Line-Up Report," Fom 2e, to recond the names of the subjects, suspects, victims, or witnesses and the results of the identification. Prepare the form in two or more copies: forwand the original to the records division and retain a copy for the detective division files. The following discussion offers a more detailed explanation of the items contained in the report.

\section{Date (1)}

Give the month, day, and year the report was made.

\section{Victim (2)}

Record the name of the victim only in cases in which the injured party is an actual person. Leave the line blank if the victim is a firm or corporation.

\section{Complaint Number (3)}

Give the complaint or case number as shown on the "Complaint Slieet."

\section{Arrest Number (4)}

Record the arrest number assigned to the suspect on his "Record of Arrest."

\section{Time and Date (5)}

Enter the exact time and date that the line-up took place, for example, "9:50 A.M., January 7, 1960."

\section{List of Subjects Used in Line-Up}

Present the full names of all subjects used in the line-up.

\section{Position Numbers of Suspects (7)}

Give the number of the position of each suspect in the lineup.

\section{Identifying Witnesses-Identified Number (8)}

Present a complete list of names of all witnesses and the number of the subject or suspect that each witness identified. 
BI. INK IIIE POICE DEISTR IMENT

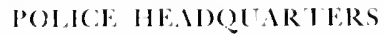

DEIFCIIVE DIVISION

Blanhille, Califomia

Date (1) 19

Iictiill $(2)$ (omplaint \# (3)

Arresi \# (4)

I his line-up took place at (time) _ (5) M_ Mon $-19$ at Police Headquarters, Blankille, California.

The line-up was composed of the following persons and their positions according to number as indicaled below:

(6)

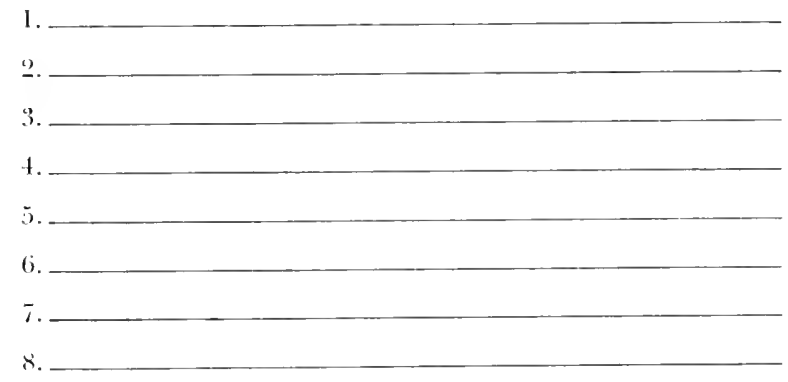

suspects are numbers

(7)

Identifing Witnesses Identifed Number

(8)

].

2.

3.

1.

5.

6.

Ploorographed b! $-(9)$

sigucal bi (11) Rink

Make live (j) copies)

form 22. Suppect line-L Form (8!/2"xll"). 


\section{Photographed By (9)}

Enter the name of the identification oflicer or jailer who made the photograph of the subjects and suspects in the line-up.

\section{Signed By-Rank (10)}

Complete the repont by entering your signature and rank.

\section{POLIGRAM ENVELOPE}

If you are the polygraph operator, use the "Polyoram Enrelope," Form 23, for reporting a summary of your specialized phase of a criminal investigation. This 8 "x5" manila envelope is useful for protecting and filing the polygram and facilitates the completion of your monthly report.

Niter performing a polygrapl examination, prepare in duplicate a regular supplementary investigation report, Form 20, and complete all applicable space on the face of the "Polygram Envelope:" case and polygram examination numbers; date; name, address, phone number, age, sex, and color of the subject; the crime charged; criminal record of the suspect; questioned before the examination; questioned on the polygraph; confession obtained; other crimes admitted; property recovered, and a general summary of the examination results.

\section{POI.YC,RIII ENTEI.OPE}

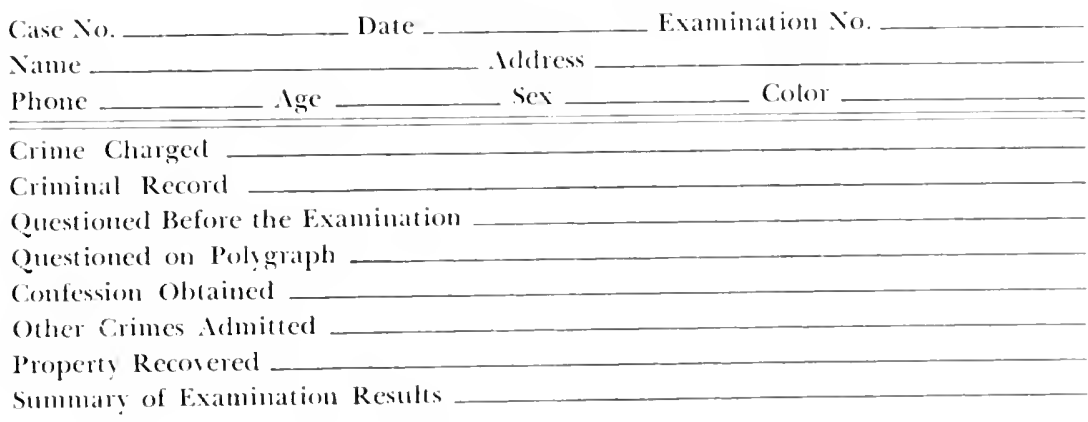

Plea: Result of livial: 
Place the duplicate copy of the supplementary investigation report, along with all polygrams on the same person and the same case, in the "Polygram Envelope," and file the latter in your files according to the polygraph examination number. Forward the original of the supplementary investigation report to the records division where it will be filed with other investigation reports in the case.

The results of the plea and trial will be reported later. Record this information on the face of the "Polygram Envelope" when you receive it. Space is provided at the bottom of the form for your signature as the polygraph operator.

\section{REPORT OF LABORATORY EXAMINATION}

When evidence is received in the crime laboratory, the technician in charge initiates the "Report of Laboratory Examination," Form 24. From evidence tags or envelopes he records, in duplicate, the type of case, case number, victim, the date the case was reported, and the date the evidence was received in the laboratory. After entering his own name on the line "Assignment Made By," he records the name of the technician to whom the assignment was made.

If you are the laboratory technician who received the assignment, enter in detail a description of the evidence submitted, and note its condition, a summary of the examinations conducted, and a synopsis of the results obtained. In addition, enter in an evidence ledger a description of the evidence, the nature of the examinations, and the results obtained. Forward the original "Report of Laboratory Examination" to the field investigator who requested the examination, and file the duplicate in the laboratory files.

The field investigator attaches the laboratory report to the original of his field investigation; thus the laboratory report becomes a vital document in the case file.

\section{JUVENILE CASE HISTORY}

Previons discussion has emphasized the fact that criminal complaints and investigations involving jureniles are handled in the sane manner as cases involving adult offenders. On the other hand, 


\section{BI.INKIIILE POLICE DEPIRIMEXI}

\section{REPORT OF I.IBOR.IIORY FXIIINIIION}

I ipe of Ciase Calse Number

Victim Irlicss

Date Reported Dalle Eridence Receired

Examination Requested by:

Assigmment Made by:

Assignment Macle to:

Description of Evidence:

Condition of Evidence:

Examinations Conducted:

Results of Examinations: HouI

Form 24. Report of Laboratory lixamination (81 "xhl"). 
progressive police agencies recognize the need to investigate the social aspects of any case involving a jurenile either as a suspect or victim. The investigation of the social aspects of the case is a specialized task assigned to an officer of the jurenile division. After the investigation of the criminal aspects of the case is complete, jurenile officers look into the cause of delinquent conduct with a view to intelligent referral to other agencies which can help the child solve his problems and become a normal, useful person.

The "Jurenile Case History," Form 25, guides the juvenile oflicer in recording personal data regarding the juvenile, his family history, associates, parents, and community enviromment. Once the social investigation and "Juvenile Case History" are complete. this permanent record, maintained in the juvenile division, assists the officer in making an intelligent referral, both in the present and future cases in which the juvenile may be involved.

If you are the juvenile officer assigned to the case investigation. complete the "Juvenile Case History" in conjunction with the over-all investigation and interviews with the parents, school authorities, and the child.

Note that the form is presented in five parts: (1) heading, (2) family history, (3) friends, (4) parents, and (5) child.

\section{Heading ( $\mathrm{I}$ )}

In the heading, record your name and the date. Enter the name, birth date, sex, address, phone number, race, religion, birthplace, school, and school grade of the juvenile under investigation. Complete this section of the report by entering the name of the person with whom the child is living, along with the length of time he has resided at that location.

\section{Family History (2)}

The "Family History" section provides for the name, age, address (business and home address of father and mother), religion, and occupation of the father, mother, and other members of the houschold.

\section{Friends (3)}

As the investigation and interviews reveal the identity of associates, enter the name, age, address, and school each is attending. 
JIIVIJE (.ISE HISIOR)

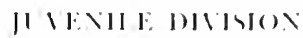

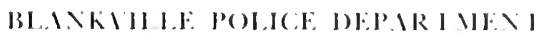

()hicer

1)ilc

(1)

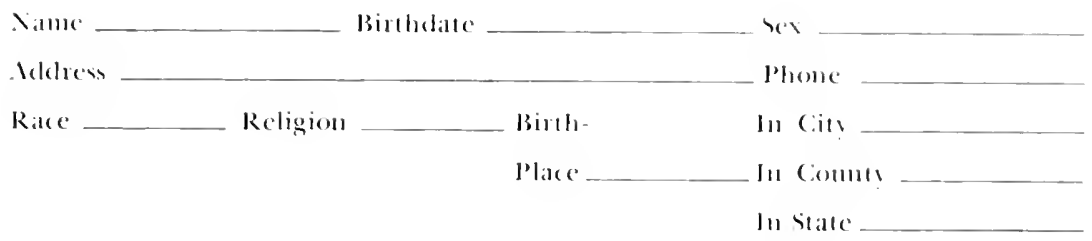

ichool Giacle

Living With How Long?

(2)

FAMILY HISTORY

Name Age Address Religion Ocoupation

\begin{tabular}{l} 
F. \\
\hline I. \\
\hline I. \\
\hline 2. \\
\hline 3. \\
\hline 5.
\end{tabular}

Bus. Address Father Wother

Ohers in Housetrold

(3)

Friends

Name Age Address School

1.

2.

3.

1.

5.

6.

FonM 25. Jusenile Cise History (81, "xll") (Front). 


\section{Parents}

Iising Fogether:

Separated:

Divercerl:

F. Idd

F. Add

I) ead F. Date-Cause

Drinking: Father

Nental: Father

Working: Father

Habits: Father

(5)

How Long?

II. Adel

II. Add

II. Date-Cause

Mother

Mother

Mother

Mother

\section{Child}

Number Arrests and Reasons

\section{Resentful}

I)isconraged

Adrenture

Sex Curiosit!

Sex Abnormality

Need Emplorment

Sick

Nental

Gang Activits

Community Hazard

Nilut Influence

Others

Ford 25. Juvenile Case History (Reverse). 


\section{Parents (4)}

The "Parents" section is designed to reveal the attitules, habits, and general living conditions provided by the parents, which frequently contribute to delinquency on the part of the child. Answer the following questions: Are the parents living together? How long? Separated? Divorced? Is the father dead? Cause? Is the mother dead? Cause? Does the father and/or mother drink? What is the mental condition of both the father and mother? Does the father and /or mother work? What are the general habits of the father and mother?

\section{Child (5)}

The section on the "Child" involves an attempt to summarize the criminat record of the juvenile, along with the attitudes, habits, and envirommental influences which seem to have influenced or caused his antisocial behavior.

\section{Summary Supplementary Report}

Use a general supplementary report, Form 20, to report a summary of your findings, conclusions, and recommendations. Recommendations made in this final summary report serve as a basis for ultimate decision as to the disposition of the juvenile in the case. Make at least one duplicate copy of both the "Juvenile Case History" and final summary report so that a complete set of reports may be forwarded to the juvenile court, probation department, or case work agency to which the juvenile is referred. 


\section{Chapter XVIII}

\section{FINAL INVESTIGATION REPORTS}

A

FIER THE INVESTIGA HOX OF A MAJOR case is complete, il you are the investigating oflicer, it becomes your duty to prepare a prosecution report for the prosecutor. The prosecutor is the person who represents you and presents the people's case to the court. He is part of the people's team and complete cooperation is necessary.

Many departments do not require prosecution reports from their officers; it appears that the use of these reports is not only valuable to the administrator and supervisory personnel of the department but of great help to you in presenting the case to the prosecutor. If the facts necessary to prove a case are placed before the prosecutor in brief, concise form; and if he is able to extract the important points without reading through many pages of reports, it is much easier for him to molerstand the case and to reach a prompt conclusion as to prosecution.

When you investigate a case involving a death, you also should forward a copy of the report to the coroner or medical examiner. Inquests must be held in all coroner cases, and the information you have developed may be of value in the determinations of the coroner's jury. You may be required to give testimony in such cases, and your testimony will be based on the same facts as those prepared for the prosecutor's oflice.

If you set forth the necessary facts in proper sequence and in brief form, the prosecutor or the coroner may ask questions as necessary and review the entire case in a very short time. In assisting the prosecutor in the preparation of the case, it is your responsibility to provide all information necessary to justily a complaint

'Information for this chapter was adapted from Chapter V'II, Fosd X. Hetlron: Eardence for the patrolman. Springfield. Charles C Thomas, Publisher. 1958, with consent of the publisher. 


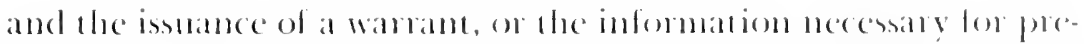
sentation to a grand jury. After the complaint of indientemt hat been filed and the warant of artest exeruted, you must then supply all information necessary for surecestul presentation of the case in (ollit.

\section{GENERAL CONTENT OF PROSECUTION REPORTS}

To do this, prosecution reports, such as form 26, are necessary and should be used in the absence of depantmental ordere to the commary. To be of ralue to both you and the prosecutor, these reports should follow a set pattern, comesponding to the prosecution sequence as nearly as possible. The report should present the necessary points in a mamer similar to the prescutation in the following discussion. It should. like other operational reponts, include a heading, body, and ending. Non all points will have to be included in every report, Jum all necessary elements must be presented in order to outline the case properly for the prosecutor.

\section{Heading of the Report}

The heading of the report shonld include: (1) the type of offense; (2) the date and time the offense was committed: (3) name. address, and bricf description of the suspect; (4) criminal record of the suspect, if any (if extensive, attach the criminal record sheet to the report and so indicate: (5) name and address of the victim: (6) name and address of the complainant; and (7) your name, badge number, precinct, and department.

\section{Ending of the Report}

The ending of the report, which is contained on the first sheet. will include: (1) the distribution of the copies of the report, (2) the status of the case, (3) the date and time the report is sulmitted, and (4) a place for your personal signature.

\section{Body of the Report}

The body of the report, which immediately follows the heading information, should contain: (1) the reasons for the change. (2) a list of witnesses, and (3) the list of exhibits.

Reasons for the Charge. The "reasons for the charge" section 
is a brief statement of the charge and the reason for it. In order for you to justify a complaint or a criminal charge, the report must show that all of the elements of the offense are present, and that you believe that the suspect did commit the act. If all of the elements necessary to establish the corpus delicti of the offense are not present, the prosecutor will necessarily alter the charge to correspond to the elements present.

\section{BLANKVILLE POLICE DEPARTMENT \\ PROSECUTION REPORT}

Case No.

offense Date and Time Committed

Victim Address

Complaimant Address

Sitspect Address

Criminal Record of Suspect

Reasons for the Charge: 
Example: "Burglary:" John Doe entered the residence occupied by Henry Roc and family at 1234 Jay St., City, between the hour of 9:30 P.X. and 11:30 P.M. On Wed., Oct. 26, 1959, without permission and with the intent to commit theft (indicated by extensive scarchi), by use of fore applied to a bedroom window, and was apprehended by Oflece Black and White as he left the prenises.

You should note that all of the elements necessary to establish the corpus delicti for "burglary" and the degree of the crime are present in the above brief resumé. Elements present are:

1. That John Doc, suspect, did enter an occupied dwelling during the nighttine. (To establish the offense and the degree.)

2. That he entered without permission and by use of force. (Force is not always necessary.)

3. With intent to commit theft. (Implied by the act of searching the premises.)

In most states these elements are sufficient to establish the of fense and the degree of the offense. Other information included in the above paragraph, showing how the suspect was apprehended. further corroborates the offense charged.

List of Witnesses. Under this heading, you should list all known witnesses at the time of the report and give a brief statement to show their relation to the offense and the testimony that can be given by each.

Example: "Burglary."

1. ROE, HENRY, occupant of 1234 Jay St.. will testify as follows: That at 8:30 1'.M. on Wed., October 26, 1959, he and Mrs. Roe left their residence: that at that time the residence was properly secured, doors and windows locked, and the bedroom window was not broken; that the drawers, closets, and cabinets were in their normal orderly condition; that when he returned shortly after 11:30 P.M. he found that the bedroom window had been forced. and the house had been ransacked; that screw driver found on the kitchen table, after the crime had been discovered, was not his property and was not on the table when he left the house; that he observed the suspect in custorly of Olficer Black, but did not recognize him as anyone he knew or had ever given permission to enter their dwelling.

2. (OFFICER WHITE, JOSEPH, badge 317, precinct 7 , will test ify as follows: That about 8:30 P.M., on Wed., Oct: 26, 1959, while on patrol beat 16 , he observed people leaving the residence at 1234 Jay St., that about 11:30 P'.M. while again passing the residence, he observed an 
open bedroom window; that he approached the window and Officer Black covered the opposite side of the house; that shortly after arriving at the open window, Officer Black called to him, and he ran around the house to Ollicer Black's position; that on arrival he observed that ()ticer Black had a man in custody; that the suspect was searched, secured, and left in custody of Otficer Black: that White then entered and searched the interior of the residence; that no other person was found on the premises and although the house had been searched, it appeared that nothing had been taken; that an identification expert was requested, and Sgt. Roy Jones responded; that a serew driver lound m the kitchen table could not be identified by Mr. Roe, and this wat marked for identification and turned over to Sgt. Jones on his arrival; that White wrote the report.

3. OFFICER BLACK, R.ALPH, badge 643, precinct 7. will testify as follows: That his testimony will be basically the same as that given by (officer White up to the time they approached the house after noticing the open bedrom window: that he apprehended the suspect, John Doe, as the latter left the premises by way of the back door; that he transported the prisomer to jail and booked him for investigation of burglitry.

4. SERGEANT JONES, ROY, badge 27. Identification Officer, will testily as follows: That latent prints found on top surface of the dresser in the bedroom, near the point of entry, are the fingerprints of the supect. John Doe: that the screw driver, turned over to him by Officer White, has the same shape and sige as the tool used to lorce the window in question and could be the tool used for this purpose; that criminal records indicate that the suspect was previously consicted of burglary in Jan. 1957, and served a tem in State Prison as a resalt. (Copy of criminal record attached.)

List of Exhibits. The prosecution report should contain an accurate account of all evidence relating to the offense. It is not your responsibility to determine whether the evidence is relerant or material and whether it can be introduced or established. This is the duty of the prosecutor, but he must have a complete report of all evidence before he can determine its valtue. You can generally determine the value of evidence, if you are experienced, but even though your knowledge of evidence is better than arerage, you should set forth all information on each bit of evidence for the prosecutor to consider. Oltentimes, articles of evidence that do not appear to have any direct commection with the offense will be of value to the prosecution, if the defense lays the groundwork for its admission. 
Each article of evidence and the package in which it is packaged, should be given a letter corresponding w the sequence in which it was found. In the report itself, give a briel description of the anticle. including by whom and where it was mathed for ielentification, and the number of the package in which it an be found List each piece of evidence in a sequence corresponding to the package numbers.

Include a general description of the location of the evidence when found and its location in relation to other evidence found at the rene. (Measurements to show its exact location should be considered as part of your personal notes. You must be able to show the location of the evidence when the ase is presented in court.)

If you took measurements by triangulation, this should be noted. If it was necessary to take them by some other method. the reason should be explained. For measmrements of any distance longer than normal reach, which require one person on each end of the tape, give the name of the other person. Also explain how the measurements were verified; for example. "Triangulation measmements taken by Officer Brown (317) and White (914) and rerified by altering positions and rechecking."

State the time the eridence was found in relation to the time of the offense; whether it was found on arival, during the search subsequent to arrival, or later during the investigation: the name and badge number of the oflicer or the name and adchess of any other person who found the evidence and can testily.

If photographs were taken, give the name of the person who photographed the crime scene and the articles of evidence. In brief. give the number and sequence of the pictures taken.

When a rough reproduction of the original crime scene is arailable. submit a copy with your report. Show the base points and inchude the articles of evidence to indicate the scene area and the location of the evidence. Give the name and badge number of the oflicer who prepared the original stetch. Also include identilying information on those who assisted.

It is assumed that persons who lound evidence at the scene cann establish that fact. You should be especially areful to inchude the name and other identifying information relating to any witness 
who can identify the evidence as stolen property or property belonging to the suspect, etc. This part of evidence identification is often important in the prosecution of a case and more difficult to establish than other facts. The means used by the witness to identify an article are most important; include this information in the report. The following is a list of exhibits in a robbery report:

Exhibit A.

Man's, Y.M., Bulova, w.w. No. 1368739, with brown leather band, bearing monogram initials, F.N.H., on the back, can be identified by: a. HUGHES, FRED N., Victim as having been taken from his person by unknown suspect in a robbery on Tues. evening, Dec. 15. 1959. Identification by monogram initials on back.

b. CASH, E. R., pawn broker, as having been purchased from suspect, Smith, for $\$ 2.50$ on WVed., Dec. 16, 1959. Idenfified by serial number. c. GREEN, OFFICER JOE, as identified from APB description and numbers on Dec. 20, 1959, and recovered by him from Cash on that date.

Exhibit $B$.

Man's signet ring, Y.M., with black stone, bearing initial "H" in Y.M., can be identified by:

a. HUGHES, FRED N., victim, as property taken from his person during robbery on December 15, 1959.

b. GREENE, OFFICER, JOE, as having been found on the person of suspect, Smith, at the time of his arrest, Dec. 20, 1959.

Your prosecution report is intended to familiarize the prosecutor with the basic facts of the case so he can determine whether there is sulficient evidence on which to base a complaint or information. After the warrant has been issued, it must be served on the defendant; and the case is generally set for a preliminary hearing. The information that you set forth in this report should be sufficient to present at the preliminary hearing. The magistrate conducting the preliminary hearing need only satisfy himself that just cause exists to hold the defendant for trial or for grand jury action.

\section{ADDITIONAL SUPPLEMENTARY REPORTS TO THE PROSECUTOR}

Between the time of the preliminary hearing and the trial of the case or presentation to the grand jury, you, as the investigator, will have a great amount of work to do. In addition to seeking new 
evidence and new witnesses, yous should follow through to sec dhat all arailable evidence has been subjected to proper examination. Mso rou should assist in the preparation of the case for presentation to the comt and jury. In this regand, it may become your duty to prepane exhibits for the court or to coomelinate the preparation of this material. You should report supplemental information and prepanatery ponodures to the prosectutor on supplementary investigation report forms. The following exhibits and reports may be necessiry: (1) a scale drawing of the crime scene for the countromm. (2) photographs, and (3) reports of laboratory and othe? examinations conducted subseguent to the prosecution repont.

\section{Scale Drawing for the Courtroom}

Is the investigator in a case, you should see that a sale drawing is prepared for use by the prosecution in the courtrom, and it must be exact in detail and measmement. If the services of a draltsman or architect are avaibble, he should be considered best qualified to prepare this drawing. When no one with special training is available, it may be necessary for you to prepare the drawing. If this becomes your responsibility, you should be extremely careful in making measurements, checking and rechecking them. Measurements should be reduced to the selected scale and roughed in on a separate sheet before you prepare the final drawing. The final drawing should be made large so that the comt and jusy will have no dilliculty in seeing it. Make the drawing on white drawing paper. All lines and entries should be made in black India ink.

If you are not a draftsman, a brief résumé of your experience in this type of work should be inchuded at any appropriate place on the drawing. You may have had a course in mechanical drawing or similar training, or you may have prepared these types of drawings for presentation on previous occasions. When the drawing is in proper proportion and measurements are according to scale. there is generally no objection to its acceptance. Its purpose is to denomstrate to the court and jury the appearance of the room, building, yard, or area where the crime was committed, and the objects within the area and their location. It will indicate the location of objects at the scene as found by you and others on arrival, 
and will serve to supplement photographs of the scene and the area. Remember, however, that the drawing can show only the crime scene and objects other than evidence that it contained at the time the rough sketch was made. Don't locate the evidence on the drawing. This must be done during the giving of testimony alter the scale drawing has been accepted by the court. Each witness who found evidence may be requested to mark its location on the drawing while he is giving his testimony.

\section{Photographs}

Include, along with your additional supplementary reports, fair-sized enlargements of all photographs taken at the crime scene. These should be marked by the person who took them to show their sequence. Also inchude the photographer's resume of the pictures taken. Il photographs are to be introduced as evidence, they will be established by the oral testimony of the person who took them.

\section{Scientific Examinations Conducted}

You should include information in supplementary reports to indicate what has been done toward increasing the value of evidence. Il any evidence has been taken to the laboratory for examination subsequent to the submission of the prosecution report, you need to report the results. Indicate on the supplementary report the ase, case number, charge, who found the evidence. who delivered it to the laboratory for examination, and what examinations were requested. Attach a copy of the expert's report to your supplementary report.

In most police cases where death results, or where death occurs under unnsual conditions even in the alssence of evidence of violence, the body is taken in charge by the coroner or medical exaninar. The normal procedure is to have a complete post-mortem examination (autopsy) conducted even though the cause of death may be quite evident. This is considered proper procedure and should include the examination of all of the organs and fhids of the body for possible signs of violence or the presence of poisons.

In any case. where there is the slightest possible doubt as to 
the canse of death, you should be presem during the autopy. In

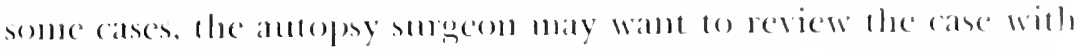

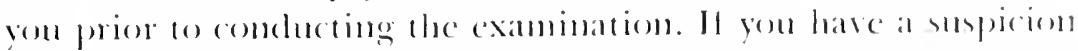
as to the cause of death. you shomlel ectl the strgeon about it we special attention can be given to the susperterl cause.

It is pessible for you to gather a great amommt of valualsle information and take some notes while the autopsy is in progress. The surgeon will often remark on his findings as he progresses. Yost surgeons are not only interested in the police problem, but are also very cosperative.

If you diel not attend the antopsy. you shonlel note this on your prosecution report. In any case, a copy of the surgeon's post-mortem examination report should be requested for the prosecutor: and, if arailable, you should attach it to a supplementary report which you submit after your prosecution report has been received by the prosecutor. 
BLANKVILLE POLICE DEPARTMENT

I - PROSECUTION REPORT

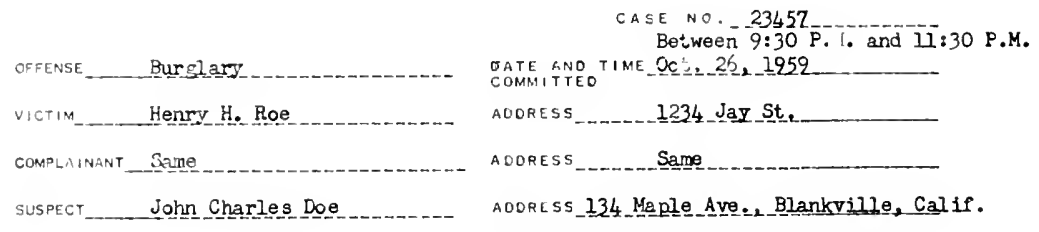

CRIMINAL RECORO OF SUSPECT _... See COPY_Of_criminal__record attacheded.

\section{REASONS FOR THE. CHARGE:}

John Doe entered the residence occupied by Henry Roe and family at 1234 Jay St., City, between the hours of 9:30 P.M. and 17:30 P.M., on Wednesisy, October 26, 1959, without permission and with the intent to ccmmit theft (Indicated by extensive search), by use of force applied to a bedroom window, and was apprehended by Officers Black and White as he left the premises.

\section{List of Witnesses:}

1. Roe, Henry, occupant of 1234 Jay St., will testify as follows: "That at 8:30 P.M. on Wed., October 26, 1959, he and Mrs. Roe left their residence; that at that time the residence was properly secured, door and windows locked; and the bedroom window was not broken; that the drawers, closets and cabinets were in their normal orderly condttion; that when they returned shortly after 11:30 P.M. they found that tha bedroom wintow had been forced, and the house had been ransacked; that a screw driver found on the kitchen table, after the crime had been discovered, was not his property and was not on the table when he left the house; that he observed the suspect, in custody of officer Black, but did not recognize him as anyone he knew or had ever given permission to enter his dwelling."

2. Officer White, Joseph, badge 317, precinct 7, will testify as follows: "That about 8:30 P.M. on Wed., Oct. 26, 1959, while on patrol on beat 16, he observed people leaving the residence at 1234 Jay St.; that about 11:30 P.M., while again passing the residence, he observed the bedroom window open; that he approached the open window, and Officer Black covered the opposite side of the house; that shortly after arriving at the open window, Officer Black called him, and he proceeded around the house to Officer Black's position; that on arrival he noted that Officer Black had a man in custody; that the suspect was searched, secured, and left in custody of Officer Black; that White then entered and secured the interior of the residence; that no other person was found on the premises with then, and al though the house had been searched it appeared that nothing was missing; that a screw driver found on the kitchen table could not be identified by

(Over) 
Hr. Roe, and that this was marked for identification and tumed over to Sgit. Ralph Jones on his arrival; that white wrote the report."

3. Officer Black, Malph, badge 643, precinct 7, will testify as follows: "That his testimony will be basicaliy the same as that given by officer white, ux to the time they apprached the house after noticing the bedroom window; that he apprehended the suspect, John Doe, as he left the premises by way of the back door; that he transported the frisoner to jail and hooked him for investigation of burglary."

4. Sergeant Jones, Roy, badge 27, Identification Officer, will testify as follows: "That latent prints found on the top surface of the dresser in the bedroom, near the point of entry, are the fingerprints of suspect. John. Doe; that the screw driver, tumed over to him by Officer white, has the same shape and size as the tool used to force the window in question and could be the tool used for this purpose; that crimiral records indicate that the suspect was previously convicted of burglary ir. January, 1957, and served a term in State Prison as a result." Copy of criminal record of John Doe attached.)

\section{List of pxbibits:}

Ixbibit A: Criminal record of John Doe (attached).

Exhibit B: Latent prints found on top surface of dresser in home of henry Roe, 1234 Jay St., City. Identified by Sgt. Roy Jones as prints of suspect, John Doe. Photographs of latent prints attached; original in custody of property clerk.

Exhibit c: One 1/4" screw driver found on kitchen table of home of henr: Roe, 1234 Jay St., City. Evidence in custody of the property clerk. Can be Identified by:

a. Orficer white, Joseph as having been found by him on kitchen table at 1234 Jay'St. Identification by "X" mark carved in wooden handle by officer white.

b. SEt. Roy Jones, as the screw driver turned over to him by officer white and the possible instrument used in galning entry. 


\section{Chapter XIX}

\section{ARREST REPORTS}

C

RMINAL INESTIGATIONS OFTEN RESULt in arrests. When persons are arrested, adequate reporting procedures demand that reports shall be initiated which will provide institutional knowledge of the location and condition of all prisoners at any time, assure departmental care of prisoners, furnish adequate control of them while they are in custody, and provide for their release at the proper time by proper authority. The reports necessary to the accomplishment of these parposes include: (1) an arrest sheet which provides an arrest record, disposition sheet. commitment, and order for release: (2) alcoholic influence report: (3) hold for investigation report; (4) request to the comt for change in the booking of prisoners: (5) request for internment; and (6) injured prisoner report.

\section{THE ARREST SHEET}

If you are the booking officer, you must record, in duplicate, information regarding the offender, charge, and the circumstances of arrest before the prisoner is locked in jail or released on bail. This information, along with other useful data, must be recorded on the "Arrest Record," Form 27.

In preparing the "Arrest Record," note that the first required item is an arrest number. The number series for arrests starts on the first day of the year and runs consecutively and continuously to the end of the year, at which time a new series starting with number one is inaugurated. I'se a numbering machine to record arrest numbers: this eliminates most of the opportunity for error in number selection.

Although the full name of the prisoner may be diflicult to obtain, try to get it from his personal effects. Give the prisoner's complete address. State where he was arrested, the date and hour of 


\section{ARREST RECORD}

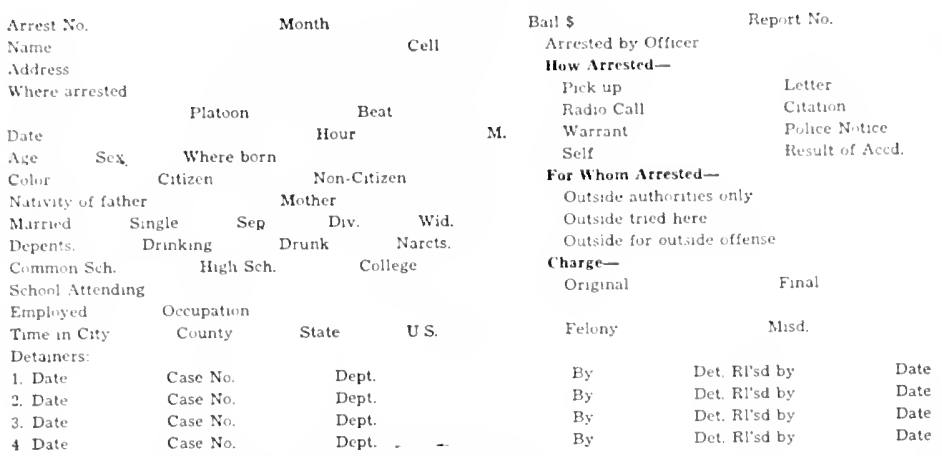

Department Dispo.' Hold for D.D. Hold for Comp. Re! when sobet

Other Dispositions

ringer Print No.

\section{FonM 27. Arrest Record (8"x5") (Font).}

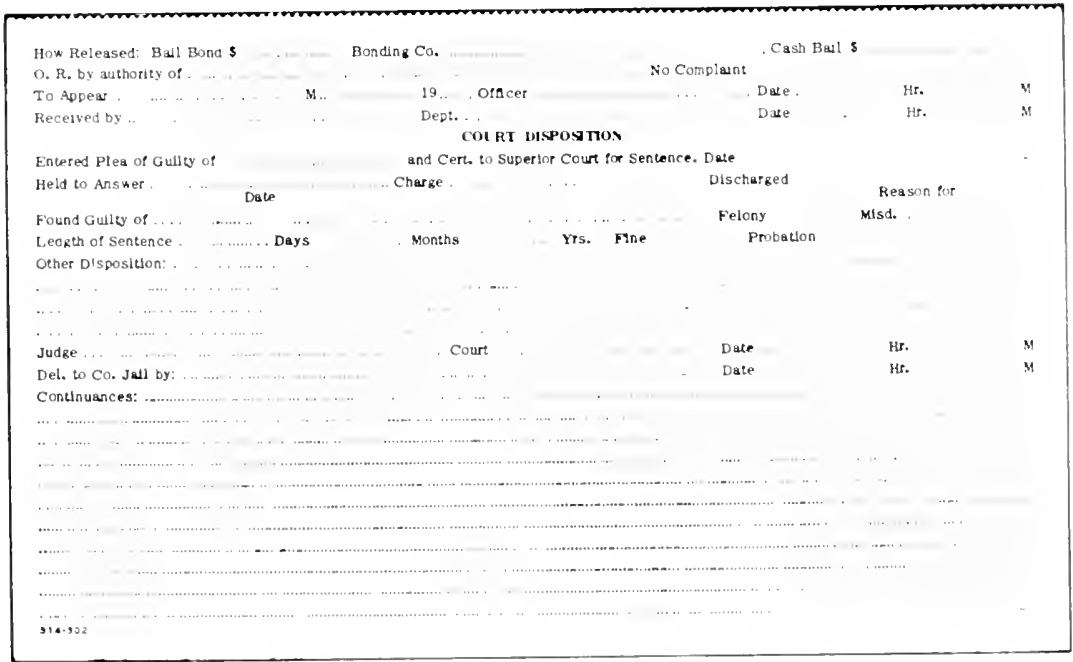

Fors 27. Arrest Record (Rererse). 
arrest, nanc of the arresting officer, case number, how arrested, for whom arrested, and the cliarge. Record the departmental disposition as "hold for the detective division," "hold for a complaint," "release when sober," or other dispositions.

Necessary sociological data which you must record include age; sex; place of hirth; color; citizenship; nativity of father and mother; marital status; dependents; physical condition (drinking, drunk, or under the influence of narcotics) ; extent of education; school attending; where employed; occupation; and time in the city, comnty, state, and nation.

If the arrest was nuade "on sight" by an officer in the field, send the complete record to the complaint clerk for the preparation of a case sheet. Then forward it to the records division where clerks will search the files in order to determine and insert the fingerprint number, criminal record, any "wants" on the prisoner in other cases, and return it to the booking clesk.

Require any commanding officer who authorizes outright release or release on bail to sign the report. If the prisoner is released on bail, insert the amount of bail on the front of the report at the proper place and indicate on the back the name of the bonding company or the amount of cash bail. Get the officer who received cash bail to sign the report and record the date and hour that he received it.

When the case must go to court for trial, forward the original of the arrest record to the proper court; this provides information necessary for the court clerk to prepare his docket. In any event, file the cluplicate copy of the arrest record in the jail file where it serves as a jail register.

The reverse side of the arrest record is a disposition sheet. When the case is disposed of in court, the court clerk records all information necessary for tabulating dispositions in the police monthly statistical report. Space is provided for recording a plea of guilty, certification to court, date of trial, charge, reason for discharge, the offense of which the prisoner was found guilty, length of sentence, other dispositions, the judge and court in which the prisoner was tried, who delivered the prisoner to jail after commitment, and continuances. Forward the arrest record, with com- 
pleted disposition, to the records division where, after monthly talbulations, it is filed with the case.

When the prisones is released from your custody, send the duplicate (jail file copy) to the records division where it will be filed according to the arrest mumber in a pending file. After the dispostion section has been completed, the record is filed in the arrest file.

\section{ALCOHOLIC INFLUENCE REPORT}

Since experience has proved that possible defenses of drunk drivers are mumerous and drumk driving cases are difficult to prosecute, you should, as an arresting officer, utilize the "Alcoholic Influence Report." Form 28, as a guide in the investigation when the arrestee is a drunk driver. This report, formulated by the National Safety Comncil's Committee on the Intoxicated Driver, offers excellent security against the usual defense attacks. If you keep an adequate supply of these report forms with you, your investigation and most of the report can be completed in the freld.

Get a witness, conduct your investigation, and complete the report in accord with the steps as presented on the report form. Begin by designating the prisoner as either a driver, pedestrain, or passenger. Record the incident as either an accident, traffic violation, or other situation. After recording the name, address, age, sex, race, approximate weight, and driver license number of the prisoner, proceed to ask questions and record answers on the form.

In completing the "examination" section of the report, observe the subject carefully to determine alcoholic breath, color of face, condition of clothing, attitude, musual actions, and the condition of his eyes. Draw circles around words on the form that describe observed conditions. Add other words of your own which seem to describe the arrestee's condition most adequately.

Instructions are given on the back of the form for administering a number of practical coordination tests. With the prisoner's consent, administer the tests. Follow the instructions and record the results of the tests in the "examination" section of the form.

Present your own opinions as to what led you to suspect the prisoner was under the influence of alcohol, his unusual actions or 


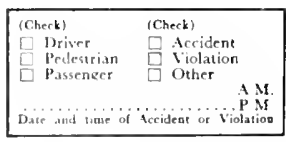

\section{ALCOHOLIC INFLUENCE REPORT FORM}

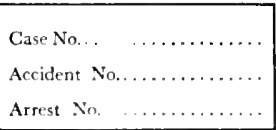

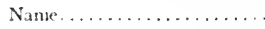

Age ....... Sex...... Race...........Approx. Weight.

Address. . .

\section{QUESTIONS:}

NOTE: Get witnesses to prove driving.

Were you operating this motor vehicle?.

Where were you going?....

Where did you start fiom?

When did you leave?

Time now?.......

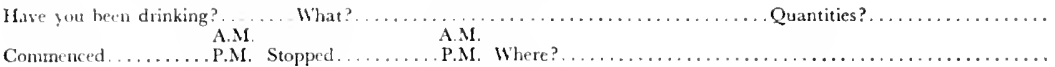

Are you ill?.......... Ilave you been to a doctor or dentist recently?........ If so, when?..

Who? (name of doctor or dentist) ... . . . . . . . . . . . . . For what?

Are you taking medicine?....... If so, what?.

Do you have diabetes?

Are you taking insulin?

. Last dose.

Are you hurt?.

How much sleep did you have last night?

. Did you get a bump on the head?.

Have you been drinking since the accident?

What?

How much today?

EXAMINATJON:- Draw circles around words describing observed conditions. Add other words of your own.)

\begin{tabular}{|c|c|c|c|c|c|c|c|c|}
\hline \multicolumn{2}{|c|}{ BREATH } & \multicolumn{3}{|c|}{ Odor of alcoholic liquor - Apparently none } & fain & & & strong \\
\hline \multicolumn{2}{|c|}{ COLOR OF F.ICE } & \multicolumn{2}{|c|}{ Apparently normal } & Flushed & Pale & (Other) & & \\
\hline \multicolumn{2}{|c|}{ CLOTHES } & Orderly & Mussed & Soiled & Disarranged & Disorderly & (Describe) & \\
\hline \multicolumn{2}{|c|}{ ATTITUDE } & $\begin{array}{l}\text { Polite } \\
\text { Cooperative }\end{array}$ & $\begin{array}{l}\text { Excited } \\
\text { Indifferent }\end{array}$ & $\begin{array}{l}\text { Hilarous } \\
\text { Antagonistic }\end{array}$ & $\begin{array}{l}\text { Talkative } \\
\text { Cocky }\end{array}$ & $\begin{array}{l}\text { Care-free } \\
\text { Combative }\end{array}$ & $\begin{array}{l}\text { Slecpy } \\
\text { Insulting }\end{array}$ & (Other) \\
\hline \multicolumn{2}{|c|}{ UNUSUAL ACTIONS } & Profanity & Hiccough & Belching & Yomiting & Fighting & (Other) & \\
\hline \multicolumn{2}{|c|}{ EYES } & \multicolumn{2}{|c|}{ Apparently normal } & Watery & Bloodshot & & & \\
\hline \multirow{3}{*}{$\begin{array}{l}= \\
\end{array}$} & $\square$ PUPILS & \multicolumn{2}{|c|}{ Apparently nosmal } & Dilated & Contracted & \multicolumn{2}{|c|}{ Poor reaction to light } & \\
\hline & $\square$ BAL.INCE & Sure & Swaying & Wobbling & Sapging Knees & Falling & (Other) & \\
\hline & $\square$ WALK \& & Sure Fair & Swaying & Stumbling & Staggering & Falling & (Other) & \\
\hline \multirow{4}{*}{ 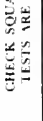 } & TURNING & Sure Fair & Swaying & Lncertain & Staggening & Falling & (Other) & \\
\hline & \multicolumn{2}{|c|}{$\square$ FINGF.R.TO-NOSE TEST } & Right-Sure & Lncertain & Left-Sute & Uncertain & (Other) & \\
\hline & \multicolumn{2}{|c|}{ PICKING UP COINS } & Sure & Slow & Lncertain & U'nable & (Other) & \\
\hline & $\square$ SPEECH & \multicolumn{2}{|c|}{$\begin{array}{l}\text { Fair Slutred } \\
\text { Choice of words }\end{array}$} & Stultering & $\begin{array}{l}\text { Confused } \\
\text { Clearness and c }\end{array}$ & $\begin{array}{l}\text { Incoherente } \\
\text { ectness of en }\end{array}$ & $\begin{array}{l}\text { (Other) } \\
\text { ation }\end{array}$ & \\
\hline
\end{tabular}

What first led officer to suspect alcoholic influence?...

Unuisul actions or statements.

..................

Signs of illness or injurs:

\begin{tabular}{|c|c|c|c|}
\hline CONCLUSION & $\begin{array}{l}\text { EFFECTS OF ALCOHOL Apparently none } \\
\text { ABILITY TO bRIVE-Apparently fit }\end{array}$ & $\begin{array}{c}\text { Slight } \\
\text { Ability impatred }\end{array}$ & $\begin{array}{c}\text { Obvious } \\
\text { Greatly impaired }\end{array}$ \\
\hline
\end{tabular}

Witnesses to exanunation

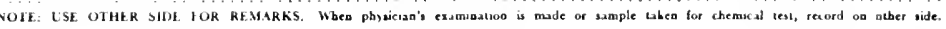

Fok.1 28. Alcoholic Influence Report Form (81/2"xll") (Front). (Courtesy of National Safety Comncil. 425 North Michigan, Ave.. Chicago, Illinois.) 


\section{RF.MIIRKS}

INSTRICTIONS FOR COORIMIIITON IISTS

Do not have suspect perform any test action unless he is willing.

When tests are made, record results and chech squares on other

side. When tests are not made, record conditions from genetal

chervations but do not

1. Pupils of eves-flash a bright light in the eves of the suspect and compare the reation of his pupils with the reaction obtained when a light is flashad in the eyes of another perann. There should be the sam tration.

2. Balance-Stand erect with heels together, eyos closed, and head bach, to obsere balance.

3. Walking and turning-Walk a straight line, toe of one foot againgt the herel of the othet. then turn and walk bath again. Watch closely for evidences of incoosdination. epecially when turning around.

f. Finger-to-Nose Test-Stand errct. exes closed, extend ams horizontally to side, then, ore anm at a time, touch the tip of nose with the tip of the index finger.

5. Conin Test-Pich up coins from Hoor. If desired have suepect place coims on table and antange in order, with laterest sized crins on right. Identify larads or talk. (bberse abilits:)

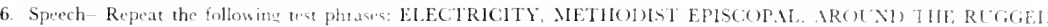
ROCK THE RAGGEI) RASCAL RAN.

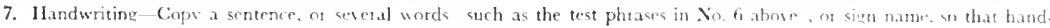
writing can be compased. Spate at top of this shere mal he used for this pur pos.

\section{PIIYSICIAN'S REPOR'T}

Examining physician, if any .... vime

Addiess

Physician's Diagnosis.

\section{Sicnature of Phisictan}

\section{CHEMICAL TESTS}

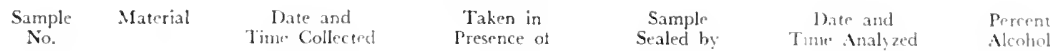

Tests made by

Wirnecses

Rep ExM 45 W:

Nathodal Saloty Council, 25 Nortb Macbigar Ave Chicaqa 11, lil.

Printed in E.S A

ForM 28. Alcoholic Influence Report (Reverse). 
statements, and signs of illness or injury. Circle the appropriate words relating to your conchusions as to the effects of alcohol on the prisoner as a driver and his ability to drive. Continue with any additional remarks on the reverse side of the form. Sign the report and ask your witness to alfix his signature to it.

When you reach headquarters, contact the complaint clerk, booking oflicer, or jailer, and request that he administer the coordination tests and complete the appropriate section of the second "Alcoholic Infuence Report." When the two of you concur, you have established adequate reason to hold the prisoner on a drunk driving charge.

With the prisoner's consent, it also is proper policy to have him examined by a physician and to take blood samples for the determination of alcoholic content. When a physician has examined the prisoner and blood samples have been taken, ask the doctor and laboratory technician to complete and sign the appropriate sections on the reverse of the form. Case, accident, and arrest numbers will be recorded in the records division where the alcohol report is filed with the case.

\section{HOLD FOR INVESTIGATION REPORT}

As an arresting officer you will often find that immediate release of a prisoner on bail or permitting him to communicate with outsicle persons will interfere with continuous investigation which must be done by the detective division. In this kind of situation you should initiate a "Hold For Investigation Report," Form 29. This form, when properly executed, assures the department that the prisoner will be held by proper authority under adequate restrictions according to law and the rules and regulations of the department.

Prepare the "Hold For Investigation Report" in duplicate when you think that the circumstances justify holding the prisoner for the detective division with or without communication.

Give the full name of the prisoner, case number, date and hour of arrest, arresting officers, the charge, reason for holding the prisoner, and instructions to the booking officer. Obtain the signature, and note the date and hour of the signature, of the commanding officer who authorized you to hold the prisoner. 


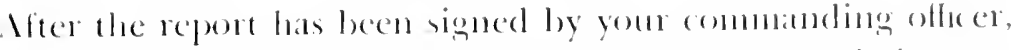
present it to the boshing ollicer, who will note me restrictions on the arrest record. file the duplicate in a "l Iold For Investigation File," and forwat the original to the detective division.

Nante Gase Xo.

1)ate of hirest IJom ol Arrest

Mresting ollucer

Charge

Reasom tor Request

Imestigation Muthoried by Date Ho1, Inscitigation Released l)itc Hol1

Fory 29. Hold For Investigation Report (8"x 5").

By the time the detective division receives the original. a duplicate of your investigation report will have arrived, explaining in detail the reasons and extent of need for further invesigation. When the detective division has completed the investigation, the detective who worked on the ase will complete the line, "Investigation Released," and retum it to the booking officer. The latter will cross out the "hold for investigation" note made on the arrest record. make changes in the charge as indicated by the detective. and record his initials, time, and date as indication that he has followed the prescribed procedure.

If you later discover that there is need for further restrictions on the prisoner, make a second set of "Hold For Investigation" forms indicating the necessary restrictions.

The oflicer who has charge of the jail will make daily inspections of the "Hold For Investigation File" in an effort to discover prisoners who are being held for investigation longer than the law or departmental policy allows. Violations of these regulations are reported to the proper authority. 


\section{REQUEST TO COURT FOR CHANGE}

As the booking officer, you will often need to provide written notices to the court of booking changes which require alterations in the court docket when the count is some distance removed from your office. The prisoner may have been released without prosecution, his availability delayed, or the charge changed. A "Request To Court," Form 30, is useful in forwarding this information.

\section{REQI EST TO COTRT}

belendant Arrest No. Case No.

Docket No. Date of trost

Original Charge

Request for Dismissal Comtinnance Change in Charge

Cinarge Changed to

Continue to

Reasons

IVas Count Clerk Notified b Phone:

Lnable to execute warant on abose subject; please attach complaint and renum to Records loivision for filing

Date and $11011 \mathrm{r}$ Booking oflicer

Forv 30. Request To Gourt (8"xi").

When you need to provide a written request for dismissal, continuance, or change in the charge, get the name of the defendant, docket number, arest number, ase number, and original charge from the arrest record and present this information on the "Request To Cont." Mark the request as one for dismissal. contimuance, or change in charge. If the request is for a change in charge, record the new charge. Give the suggested clate for trial, if your reguest is for a change in date. In any event, explain your reasons for the request. If the change of circumstances came about suddenly, you also will want to indicate that the court derk was notified by plone. When a dismissal request is due to the inability of yom department to serve the warrant on the subject. request 
that the comm attach the complaime to yout reguest and returt both to the reconds division lor filing. Record the date and houn of the report and sign it.

On receipt of the reguest, the comm clest makes the proper notation in his docket and staples the "Re(puest To Comte" to the arrest record and disposition slecet. and retmons lhen to you. later you will send them to the records division lor filing.

\section{REQUEST FOR INTERNMENT}

Either state law of the policy of your depantment will require that prisoners suspected of reneral disease shall be examined by health atthorities and that those who are diseased shall be treated. If you are the arresting oflicer and you suspect or the prisoner states that he is infected, initiate a "Request for Intermment," Fomm 31. This form, prepared in duplicate, gives yom reasoms lor repuesting an examination, places responsibility lor detention on the commanding officer. infoms the bosking oflicer of restrictions on the prisoner, and notifies health authorities that the person is being held for examination.

Adeguate space is provided for recording the date: case number: name and address of the prisoner; the prisoner's age sex,

\section{REOIESI IOR INIERNIENI}

Dalle

Gase No

Nance of Prisoner Idrem

iex Age Color (ocupation

Married Dirased line of Arres

place of Arrest Will Who. Arrested

Charge Prior Record

Circmuntances of Iroest

Plusician's Diagnosis

Date of luterument Negative Renults Dale Begin lreament Date I reatment Terminated Signature 
color, occupation and marital status; time and place of arrest: with whom arrested; the charge: prior criminal record: and the circumstances of the arrest. The most significant part of the report is your reason for requesting the examination.

Complete the form, affix your signature, and forward the report to your commanding oflicer for his approval.

The "Request For Intermment," Form 31, is in essence an "intermment order." space is prorided for the physician's diagnosis, date of intemment, negative results, date of first treatment, the date treatment was temminated, and the signature of the physician.

Send the approved report, both original and duplicate, to the booking officer. The latter will insert the words "Held for Internment" in the space for "Charge" on the arrest record and place both copies in the front of the jail file. Either the booking officer or a clerk will send the original to the health department and the duplicate to the rocords division to be filed with the case.

At the health department the physician conducts the examination and records his diagnosis. If he gets negative results, he notes this fact on the form and returns the signed report to the police department. If the prisoner is found contagiously infected, the physician records the date of internment and the date treatment began, and retains the form. At the conclusion of the treatment, he notes the date treatment was terminated and returns the "Request for Intermment" to the booking desk, where it is retained until a monthly report is prepared.

\section{INJURED PRISONER REPORT}

Prisoners often are injured before or during an arrest or suffer from some informity, prior injury, or disease. Others may be injured in jail. If you have a prisoner in custody, as the arresting officer or jaider it is your responsibility to have him examined by a physician at a hospital or at the jail when he exhibits any evidence of serious injury or illness. Take every unconscious person to a hospital immediately. No prisoner should be taken to a hospital for examination or treated at the jail unless you have initiated an "Injured Prison Report," Form 32. This report protects both the prisoner and your department by giving assurance that the former has been examined and treated. 
If you are the office who has him in custody at the time of the examination, enter the prisoner's name and the case mumber at the top of the report. Answer the question, "Has the prisoner an alcoholic breath?" Requess of the physician that he complete the remainder of the report, which includes the nature and extent of injuries, treatment given, time entered hospital, date. time and date discharged, and the names of the nurses in attendance. The most important question to be answered by the physician is: "In your opinion is the physical conclition of this prisoner such that he may be held in custody in (name) Jail without endangering his life or health?" Sign the report and request that the doctor sign it, giving the name of the hospital where the prisoner was examined and treated. Forward the report to the records division where it will be filed with the case. Make a supplementary investigation report if you are in possession of facts not heretolore reported.

\section{INJI'RED PRISONER REPORT}

Name of Prisoner Case No.

Has the Prisoner an Alcoholic Breath? Nature of Injuries

Treatment given

In yonr opinion is the physical condition of this prisoner such that he mas be held in custody in the jail without enclangering his life of health:

Answer ves or no

Time Entered Hospital I)ate Time I)ischarged Date

Ninses in Attendauce

()tlicer Signed M.1). or Interne

Name of Hospital

FORM 32. Injured Prisoner Report $\left(8^{\circ} \times 55^{\prime \prime}\right)$. 


\section{Chapter XX}

\section{PROPERTY CONTROL REPORTS}

A

S IN CASES OF ARRESTED PERSONS, your department is the custodian of recovered and found property, evidence, and personal property which comes into its possession through arrests, criminal investigations, and other ways. In the performance of this custodial function, the department must maintain a system of reporting which will assure a chain of possession, identify property, provide for its protection and safekeeping. prevent mauthorized release or loss, and establish responsibility for release.

The combined reports necessary to proper property control include 5"x8" property record. 5"x8" property envelopes, 5"x3" property index cards, 5"x" general and prisoner property receipts, 5“x9" antomobile receipts, and 8 " 10 " prisoner property envelopes. Property records, tags, envelopes, and index cards are prepared when the department receives any property of any kind except property that it owns or prisoner's property of a size that will fit into a prisoner's property envelope. General and prisoner property receipts are initiated when property is received at departmental headquarters, and automobile receipts are prepared when automobiles are stored at police or public garages.

If you are the oflicer who brought property in to police headquarters, it is your responsibility to complete the property record, property tags or envelopes. and a property index card.

\section{THE PROPERTY RECORD}

Is stated earlier, the "Property Record," Form 3.3, is a 5"x8" card designed as the lundamental control record for all property received by the department other than its own property and property of a size that will fit into the prisoner's property envelope.

Complete only one property record for all property on a case tumed in at any one time. reardless of the number of pieces. 


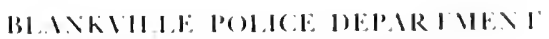

PROIPIRIS RIC(ORI) ( $I$ ISI)

Record Nis. Bill Vo. C.ase Vo.

On the report form, recond the tan number and case number and identify the property as evidence, personal property, found property, or recovered goods. Give the hull name and adchess of the owner of the property. Describe the property (see Appendix C for information), giving the number of pieces. Sign the property record and give he date and hour that you completed the report.

If the property involves more than one piece or bundle, attach the property record to one of the pieces. Yon can tie the other pices into the property record by the use of property tags.

\section{PROPERTY TAGS AND ENVELOPES}

Property tags and property envelopes are used to identity each individual piece of property. Make use of the "Found property" envelope, Form 91, or the "Evidence" envelope, Form 35, depending upon the size of the article and the reason property is being held. I'se the "Found Property" lag, Form :3t. or the "Evidence" 


\section{FOUND PROPERTY \\ CASE NO.}

Fd. By

DATE

Address.

Where Found.

Article.

Officer.

No.

Date

Hour.

Additional data or remarks

POLICE DEPT., PROPERTY DIYISION

$3: 4.29: 4754$

Fokn 34. Found Property Envelope (5"x 8 ") 


\section{EVIDENCE}

Deft.

Case No.

Name

Offense.

Date.

Date.

Articles.

Prop. of Def?

Prop of Comp.

Prisoner. Arr. by.

Officer.

Additional Remarks 
tag, Form 37, to identify articles too large to fit into a "Found Property" or "Evidence" envelope. Use a plain shipping tag or a plain manila emvelope to identily property that is neither "found" or "evidence." Tags and envelopes are identical as to required data. The required information on both is self-explanatory.

\section{PROPERTY INDEX CARD}

The property index card is a plain 5"x3" card. It you are the oflicer who brought the property in, copy all of the essential information from the "Property Record" on this card (see Form 38).

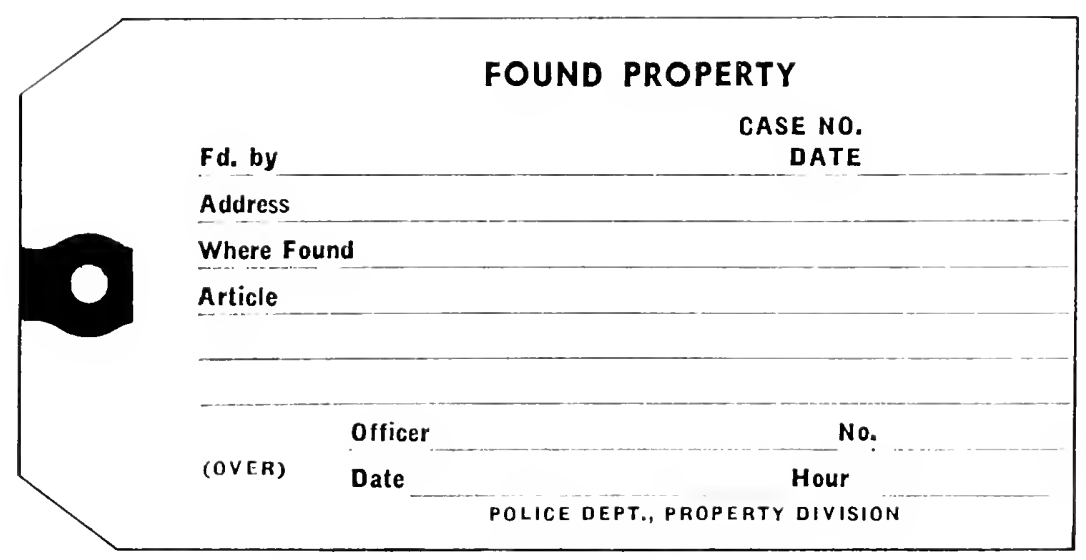

Ford 36. Found Property Tag (3"x5").

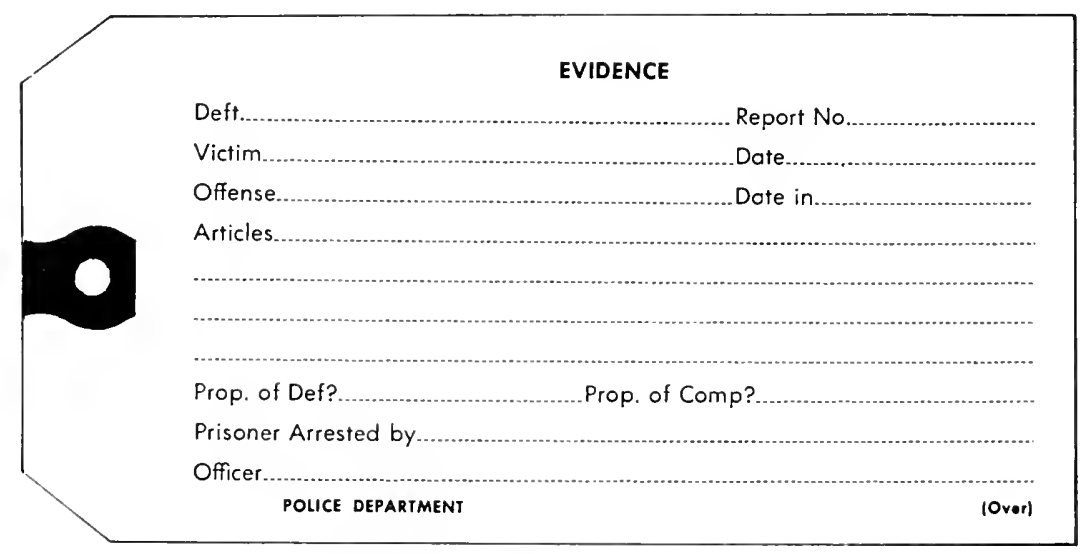

FORM 37. Evidence Tag (3"x5"). 
Deliver the property, aloms with the property recond, posperty tage orencelopes, and property index and wo the person in the property dis ison who has been designated an receive it. Fuler in a ploperty ledger a brief elescription of the property and the tas or envelope number, and initial your entry.

\section{RECORISS DIVISION PROCEIOURE}

Il property is being held lor the prisoner, the receiving ollices will check the property against the entries in the ledger and sign his name immediately below the last entry as evielence that he has received the property. Each subseguent change in custody will be recorded in the same mammer mut the property clert takes charge of the property, and each change tollows the same procedure.

The property cleck stores the property after noting the bin number on all of the essential reports. He sends the Property Record to the records division, where it is filed with the case. He then files the Property Index card in his own oflice according to the tag or envelope number. class, or description. This file serves as the property clerk's inventory of the property on hand.

If property is to be held as evidence, follow a slightly different procedure. Make your entry in the property ledger and leave the evidence and reports in a locked cabinet for the laboratory technician. The laboratory technician will handle the reports in the same manner as the property clerk handles other property reports.

\section{PROPERIY INHEN C.IRI)}

Record No. Bin Xis. Casc No.

1). El. Per. Prop. Found Pro. Rec. $\cos (\mathrm{s})$

No. of Pieces

Description of Propert?

\footnotetext{
Name of Owner

Sdelress

Date Clamed bi Owner

bate sold at Auction
}

ollicer I)ile 110111

Form 38. Property Index Card (5"x3"). 


\section{RECEIPT FOR AUTOMOBILE}

Since an automobile can't be delivered to headquarters like other property or evidence, you should take it directly to a police or public garage. At the garage complete a "Receipt For Automobile," Form 39. In completing the face of the form, record the case number; owner's full name (registered owner); the address where the car is stored; the date and lour of storage; your name; the make, type, model, motor number, license number, and accessories on the attomobile; the name and address of the storage garage; name and address of the company that towed the automobile, and the signature of the person at the garage who received it. On the reverse side of the form state the condition of the automobile at the time of storage and the circumstances which necessitated the storage.

Deliver the "Receipt For Automobile" to the property clerk as though it were the vehicle itself. Complete the same records that you would complete if the car were any other property.

The property clerk dates and signs the receipt, completes the necessary index cards and files the receipt in his office. Once the automobile is to be released, the receipt is delivered to the owner, who presents it to the garage for release of the automobile to him. The garage has instructions not to release the car except upon presentation of the receipt.

\section{RECEIPT FOR AUTOMOBILE}

Case No.

Name of Owner

Received at

Date

Nake

Motor No.

Accessories

Stored at

Garage

Address

Towed by

Address

Received by

ForM 39. Receipt For Automobile (5"x3") (Front). 
Date B)

Property Clerk

For. 39. Receipt For Automobile (Reverse).

When you find personal property in a stored automobile, remove the property from the car and complete the same reports required for any other property or evidence. Make a notation on the "Receipt for Automobile" in order that the property clerk will release the other property when he releases the automobile. The property record cards for both the personal property and the auto are stapled together in the records division and filed with the case record.

\section{GENERAL RECEIPT FOR PROPERTY}

Don't release any property from the possession of the police department without obtaining a receipt. The "Receipt For Property," Form 40, is used for the release of all property other than automobiles and the personal property taken from the prisoner by the booking officer. This receipt assures the release of the right property to the right person by proper authority. It also contains an achnowledgment of the receipt of the property by the orner and the conditions under which it was released.

If you are the officer who is ordering the release, identify the property on the form by listing the case, record, and bin numbers and a complete description. State the conditions of release, sign the receipt on the line "Approved by," and require the person to 
whom the property is being released to sign his name and give his address in order that the property clerk later may identify him by the signature.

The property clerk will indicate the name and address of the person to whom the property is released, sign his name on the line "Released by," and require the person who receives the property to sign for it. Later he will forward the receipt to the records division where it is filed with the case record.

\section{BLANKVILIE POLICE DEPARTMENT RECEIPT FOR PROPERTY}

Case No. Record No. Iate Time

Plipsical Evidence (_) Personal Propert (_) Recovered Propert! (

Found Propert! (-)

Name Address

Description of Property Released

Released to

Released by
Aderess

Approned by
Rank Properts

Received from the Blankrille Police Department, this date, the above described bigned

Forv 40. Receipt For Property $(8 “ \times 5 ")$. 


\section{PRISONER'S PROPERTY RECEIPT}

11 you are the booking oflicer, it is your responsibitity to initiate a "Prisoner's Property Receipt," Fomm 4l, for all small property and cash taken from the prisoner at the time of hooking. This receipt. prepared in triplicate, scrves fom purposes: (1) it provides the prisones a list of the property titken lrom him, (2) it protects you against any claim that you took more popenty hom the prisoner than was delivered on release, (3) it gives you any opportumity to check property with mmblers and inscriptions against the stolen property file, and (4) it may help in identilying evidence in the present or subsequent cases.

At the time the prisoner is searched, list the name and address of the prisoner on the first line of the receipt. Follow the name and address with a complete list and description of all property found in his possession (see Appendix C: for instructions on description of property). Present the receipt to the prisoner for his signature. If he is mable to sign, write "Unable to Sign" and initial the line designated for the prisoner's signature. Utilize the arresting ollicer as the searching oflicer and ask him to sign the receipt wimessing

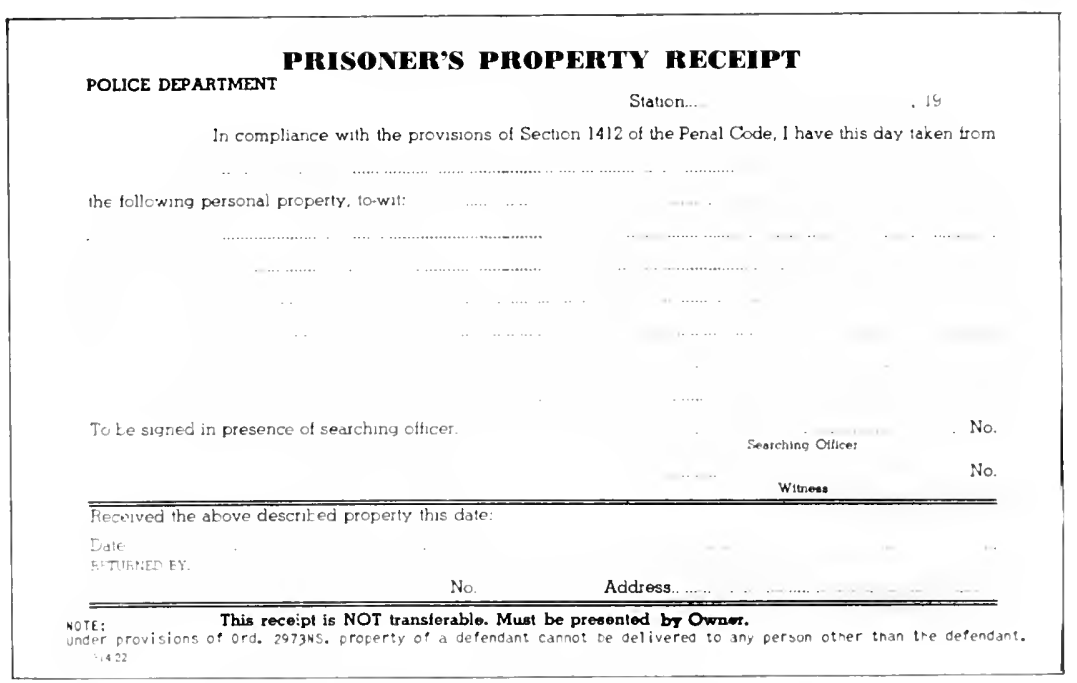

FORM 41. Prisoner's Property Receipt (8"x5"). 
the lact that the listed and described property was taken from the prisoner. Sign the receipt yourself as the second witness.

Deliver the original to the prisoner, retain the duplicate in a file at the booking desk. If the prisoner has property which is clearly idcutifiable by number or inscription, send the triplicate copy to the records division to be checked against the stolen property file.

In the event that an identification is made in the records division, the clerk who made the identification will prepare an investigation report in duplicate. The original of the investigation report

N.INE

RECORD NUMBER

D) ATE

Lокм 42. Prisoner's Property Envelope $\left(8^{\prime \prime} \times 10^{\circ}\right)$. 
will be sent to his commanding officer who will cause the property so identified to be held for evidence and send the duplicate to be sent to the detertive division.

On release, require the prisoner to produce his "Prisoner's Property Receipt." space is provided on the form for him to sign his name as acknowledgment of receipt of the property. Record the date of release of the property, and sign the receipt yourselt, giving your badge number and the address of the prisoner.

Keep the prisoner's receipt and forward it to the records division where it will be filed with the case recorl. In the event that the prisoner has lost or destroyed his original receipt, mate a supplementary investigation report containing a list of the property obtained from the duplicate copy on file, and a note that the original receipt was lost or destroyed.

\section{PRISONER'S PROPERTY ENVELOPE}

After you initiate the prisoner's property receipt, place the prisoner's property (property taken from his person) in a "Prisoner's Property Envelope," Form 42. Space is provided on the property envelope for the prisoner's name, the property receipt number, and the date. Spaces are provided over the entire face of the envelope for the insertion of this information in order that it may be used a number of times. 


\section{Chapter XXI}

\section{IDENTIFICATION REPORTS}

\section{$\mathrm{T}$}

IIE COMPLETION OF IDENTIFICATION reports is often the last important phase of operational reporting. These reports are the very fommdation of the identification phase of any criminal investigation. Once they are incorporated into the records of a police agency, they become a veritable storehouse of information useful in the determination of the identity of dead persons and prisoners and in establishing identity in relation to traces left at the scenes of crimes.

In recent years the fingerprint report form has become the most significant of a number of reports in this category. However, this report is not always available to establish identity or the res lationship between the suspect and the crime scene. Description cards, photographs, and criminal history or "rap sheets" also serve their purpose in fulfilling the intention of identification reports. Some agencies also require the completion of single-fingerprint report forms in particular situations; and, in musual circumstances, a photograph order may be necessary to cause photographs to be taken when otherwise departmental policy does not require a photograph.

Regardless of the type of iclentification report, there is one item that is common to all of these reports-the identification number. An identification number is assigned to each subject and is placed on each identification report in order that separate files may be maintained for identification purposes. This number, usmally inserted in the upper right or lefthand comer of the report, is assigned to each criminal to identify all identification reports relating to him. He retains this mmmber regardless of how many times he may be arrested, fingerprinted, or photographed.

\section{THE FINGERPRINT CARD}

The fungerprint report form or fingerprint card, Form 43 , is the most important of all identification records. It combines the quali- 
fies of simplicity, speed, accuracy, and objectivity which are so necessary to identification records.

"The standard fingerprint card, 8 "x" in size, is used in almost all jurisdictions thomglout the comntry. This card, made of dur. able material, provides adequate space for essential infomation and withstands natmal wear and tear from use in the police files.

Mlthough police agencies diller as to the repuired 13 mulser of copies of this report, adequate fingerprint reporting demands thee: one for the local files, one for the state bureau files, and a fual copy for the Federal Burean of Investigation. Adolitional

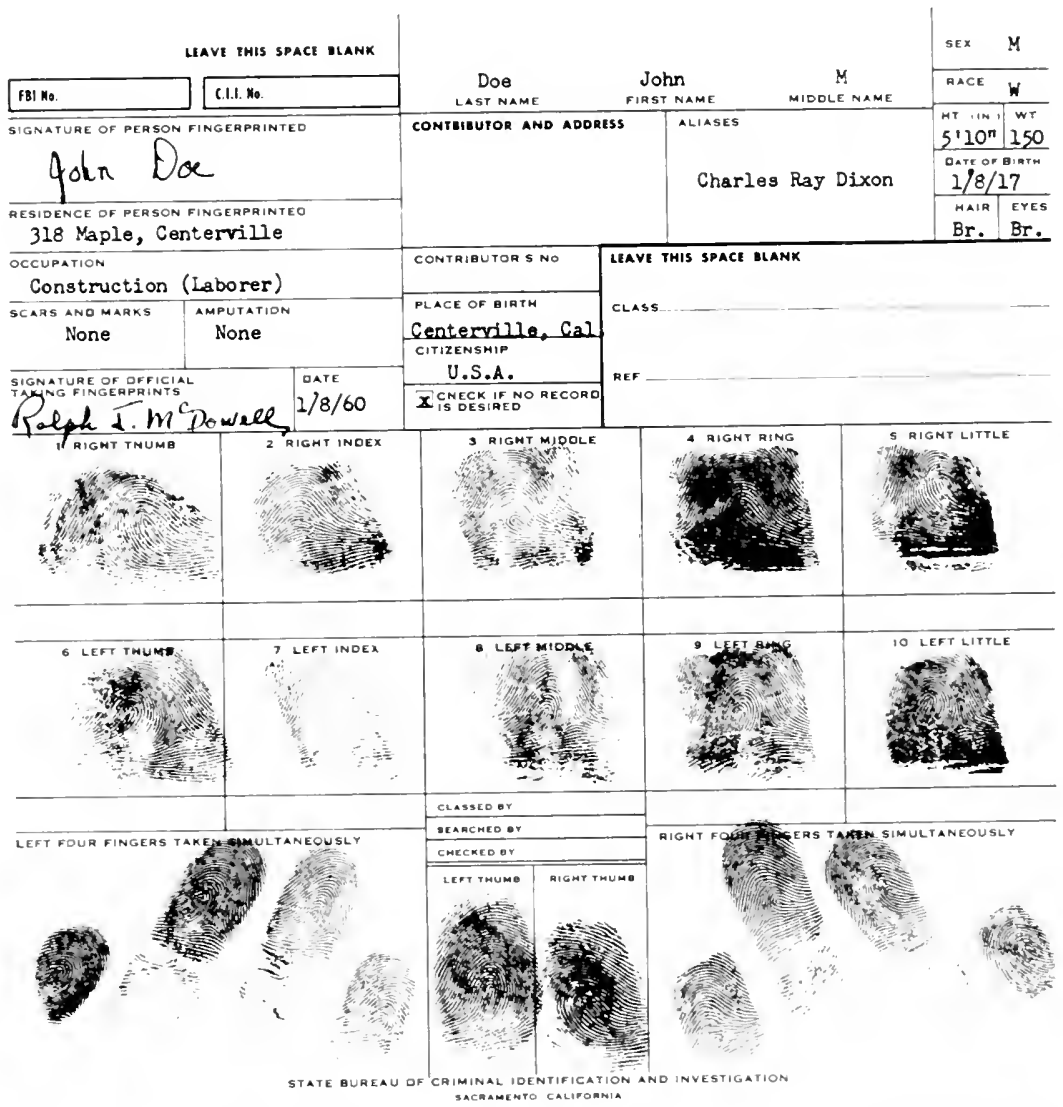

Fok 43. Standard Fingerprint Card (8"x8") (Font). Courtesy of State Buren of Criminal Identification Aud Insestigatom Sacramento. Calitornia.) 


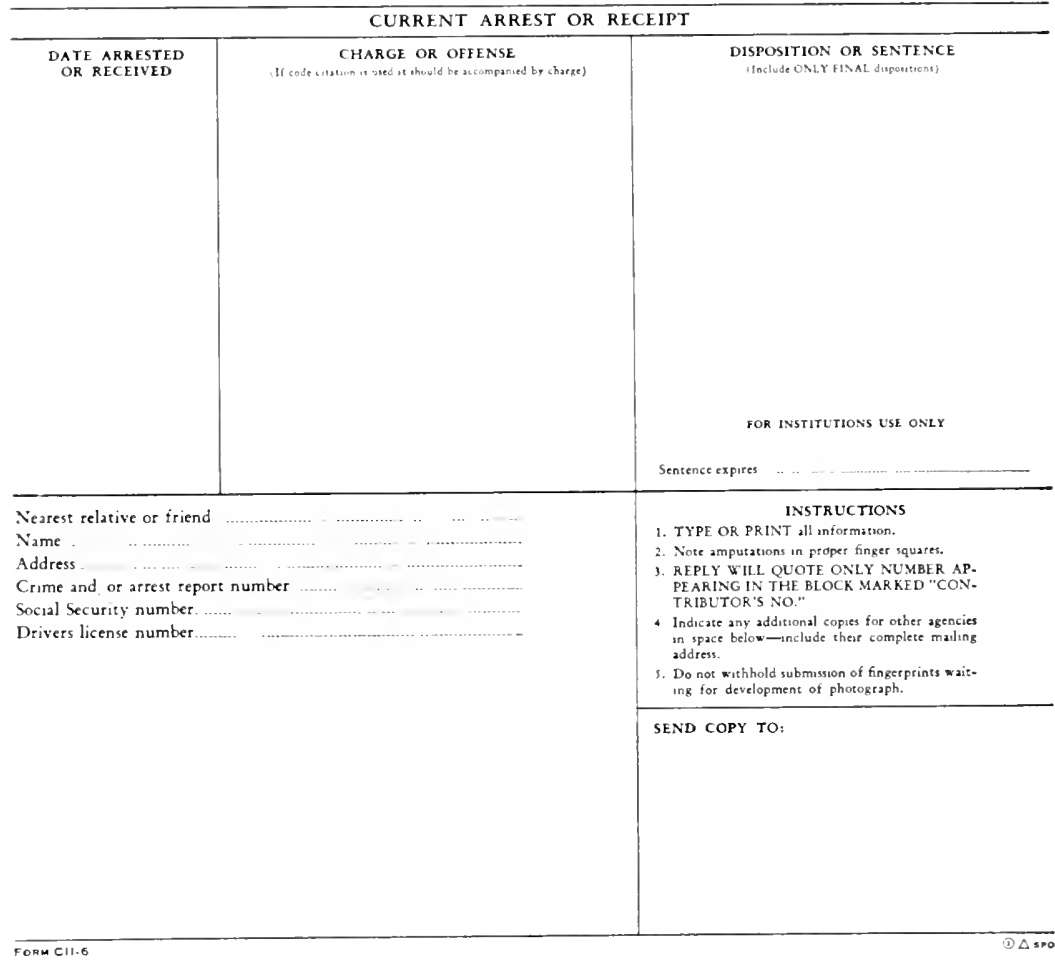

For.r 43. Standard Fingerprint Card (Reverse).

copies nay be provided if the agency maintains an exchange of prints with other local, state, or federal agencies.

\section{Who Should Be Fingerprinted?}

Police agencies also disagree as to who should be fingerprinted, but proper reporting seems to dictate that all persons, with the exception of traffic violators and those charged with the violation of city and county ordinances, should be subjected to the process. Any prisoner who is subject to fingerprinting on the basis of an offense for which he is arrested should be printed each time he is arrested in order that his criminal record may be kept current and 
complete. I police agency that does mot have cotablished rules tegarding this matter would do well on adept those indicated above since all other identification reports depend, to a great degree, on setted poficies in relation to the fingerprint record.

\section{Who Should Be Responsible for the Fingerprint Report?}

Many police agencies require that the matter of completing the fingerprint ard shall be the responsibility of the identification bureau in the records division. (Others place this responsibility on the arresting ollicers. Either of these policies results in the loss of tine and energy, increases the possibilities of escape, and has other general inconveniences. I mumber of progressive agencies have discovered that the jobs of fingerprinting and photographing prisoners can be performed effectively by members of the jail force. Neither of the jols is diflicult and both can be performed by jailers with a great amount of efliciency after some training in these procedures.

\section{Fingerprinting Procedure}

After the completion of the booking procedure and before processing for incarceration in jail or release on bail, you should, if you are the jailer on duty, take the prisoner into custody for the purpose of fingerprinting and photographing through facilities provided inside the jail.

The matter of completing the fingerprint card is not a difficult task, but the value of this report depends upon the legibility of the ridge detail of the prints that you take. Faulty or careless taking of the prints will render the report useless.

The inked impressions of the fingers that you should record on the standard fingerprint card fall into one of two categories-rolled or plain. The ard provides for ten individual squares in two rows; place rolled impressions in these squares. Make these impressions by a rolling motion of each individually inked finger of the suspect, rotating the finger approximately 180 degrees.

Generally, it is possible for fingerprint technicians to arrive at a proper classification of fingerprints from these rolled inpessions; but, since this is not always possible, provision is made for includ- 
ing plain impressions on the same card. Take plain impressions of all four fingers of a hand simultaneously on the bottom of the fingerprint card. Make impressions of the left four fingers on the left side of the card and the right four on the right. Take thumb prints separately to the right and left of the midline of the card in a position on the ard corresponding to their position on the hands. It is also good practice to take the plain impression at a slight angle to the verticle in order to bring the short little finger up into a position where it will show on the fingerprint card. When you take plain impressions, you should be careful not to superimpose the impressions over the area designated for the signature of the prisoner on the card: the signature is often used for purposes of handwriting comparisons. Finger impressions conllict with and detract from handwriting specimens.

These plain impressions serve at least two useful purposes in establishing the fingerprint card as a valid identification record. The person who classifies the prints often uses them as a means of verification of the position and sequence of rolled impressions. If the ridge detail is not clear in the rolled impressions, the plain impressions afford another opportunity for funding clear ridge detail necessary to correct classification.

Although you need not be an expert in fingerprinting, you should have the knowledge of what constitutes a fingerprint pattern and what constitutes a single, legible, classifiable pattem. Knowledge of the points required for proper classification is also an aid in the taking of good impressions. Points which are often missed in rolled impressions, and which are very essential to correct classification, are the dellas. If, in taking the prints, you have been taught to look for the deltas in those which contain deltas and to make sure that they are clear in the rolled impressions, the patterns should be classifiable.

\section{How To Take The Prints}

The following rules should prove helpful in the taking of good inmpressions:

1. Be sure that the inking plate, card holder, and roller are thoroughly clean. Denatured alcohol is a good cleaning fluid. 


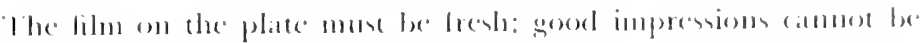
mate with a hlun ol iuk that is dry or latrel.

2. 1)atub a small anomut of printers ink on the plate. roll the inh ind com-roll it in oreles to prevent excende inking.

3. Insert the lingerprint and securels in the cardholder.

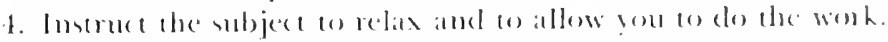

i. Ilave the peroon being printed stand immediately in lromt of the cordholder or between the inking plate and the eitrdholder in order that impreniom will be stratght on the and when rolled. 6. Roll each funger individually on the inked slab, making certain that it is inked over the main surlace of the finger tip ind below the first joimt.

7. Roll each linger on the designated spuare from "nail to mail" on the lingerprint and, beginning with the thomb of the right litul.

s. Roll all fout finger toward the litule finger of the subject h hand.

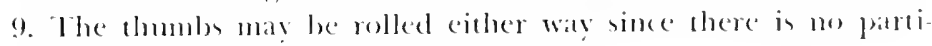
(ulat stain on them when extended.

10. The four fingers should remain together and extended for the taking of plain inpressions. Re-ink the finger betore taking the platin impressions. Place the plain impressions in the appropriate plates on the fingerprint card. l'ress lightly on the subject hamd with your tree hand in order to cause the impressions to be cleat.

11. Be sure on ign the card and have the subject sign it all the alppropriate plater on the late of the card.

\section{THE DESCRIP'TION CARD}

Althomgh the "Description Card," Form 1t, al first glance, may seem mnecessary reporting and a repetition of information provided on the fingerprint card (reverse side), you should com-

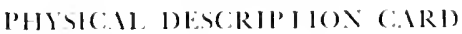

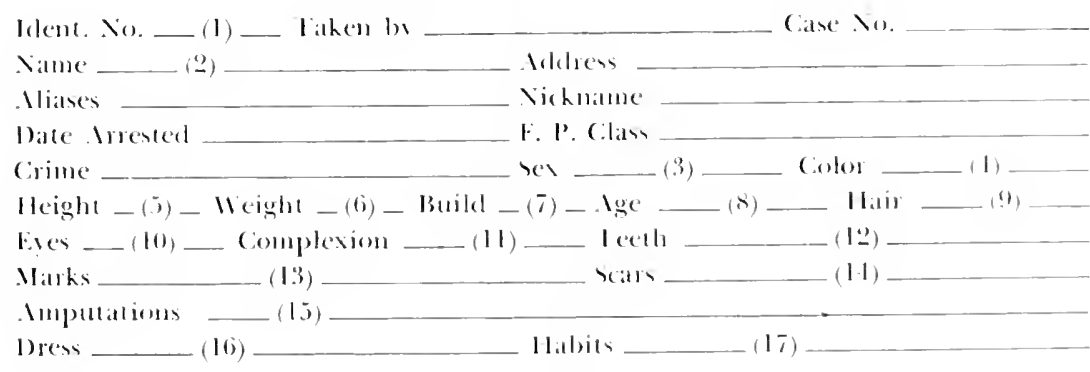

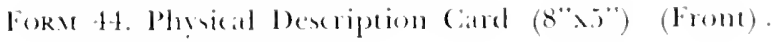


plete this form in ink when you do the fingerprinting and photographing. The description card, il properly constructed and maintained, mat be used as a guide in completing the descriptive infornation on the fungerprint rard once it reaches the records division. The original copy should later fund its way to the case file to be used by oflicers in the overall investigation of the case; and, if separate persomal description files are maintained, it can be useful in establishing identification in subsequent investigations.

\section{Identification Number (1)}

The iclentification number is the same as that which appears on the fingerprint card. This number is inserted by the fingerprint clerk in the records division.

Name, Address, Aliases, Nicknames, Date Arrested, Charge, and Case Number (2)

Obtain the name of the prisoner, his adclress, aliases, nicknames, date arrested, charges, and case number from the arrest sheet. In addition, you should question the prisoner regarding most of these matters in order to detect any discrepancies recorded at the time of booking. In case the prisoner is a woman, exercise care to record her given name, maiden name, and manied name. Calpitalize the full name of the prisoner.

\section{Sex (3)}

Indicate whether male or female.

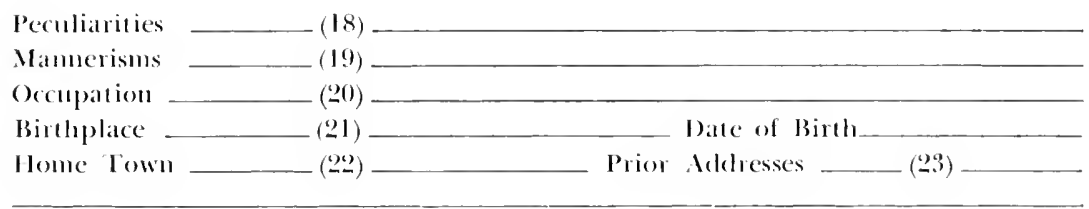

$(24)$ 


\section{Color (4)}

Color indicates race and may be presented at white (W), Negro (X). Oricutal (O), or Indian (I). Note that abbreriations are permitted.

\section{Height (5)}

Do not guess at height. Facilities for nueasurement of exact lreight should be arailable in the jail.

\section{Weight (6)}

Determine the exact weight of the prisoner. Scales shonld also be arailable in the jail.

\section{Build (7)}

The prisoner may be described as large, medium, slim, or stocky. A large person may be described further as stout or very stout. Any person may be described as stooped or square-shouldered if either of these characteristics exist.

\section{Age (8)}

Take the prisoner's word for his age: for example, record the age as "25 years, claimed."

\section{Hair (9)}

This descriptive item calls for color and condition of the hair. Hair may be described as light blond, blond, dark blond, brown, black, red, white, mixed grey, or grey. Baldness and degree of baldness should be specified as frontal, occipital, top of head, or total. If the prisoner is a woman, you may need to note artificial coloring of the hair.

Eyes (10)

Indicate the color of the iris of the eye as blue, grey, maroon, yellow, light brown, brown, or dark brown.

\section{Complexion (II)}

Complexion may be described generally as dark, fair, or ruddy. Peculiarities such as freckles, pockmarks, or pustulous skin should be noted. 
Teeth (12)

1)on't give a description of teeth unless you observe a peculiarity or peculiarities such as missing, false, or gold teeth.

Marks (13)

Notations of marks should include distinctive marks such as large moles, tattoo marks, and birthmarks. Be careful to note the exact location of these marks.

Scars (14)

Indicate the type of scar, length, and the exact location.

\section{Amputations (15)}

State the exact member of the body that is missing and whether the loss was accidental of by surgery. Note missing fingers, toes, arms, or legs.

\section{Dress $(16)$}

The manner of dress may be described in general as neat or careless. Specific information may include "wears hat, casual or sport clothes, often dresses formally," etc.

\section{Habits (17)}

Personal habits of the prisoner may inchude drug addiction; heavy drinker or smoker; gambler; frequenter of race tracks. pool halls, dance halls, baseball parks, resorts, etc.

\section{Peculiarities (18)}

The prisoner's peculiarities may include lameness, bowlegs, pigeon toes, knock-knees, cauliflower ears, twitched features. rapid or slow gate, wearing of glasses, carrying a cane, and stuttering or other speech defects.

\section{Mannerisms (19)}

Classily as mannerisms any unusual gestures such as continuous pulling of the cars, picking or scratching the nose, or scratching the body. Inusual signs or gestures with the hands and arms maly also be listed in this category. 


\section{Occupation (20)}

list the prisoner's occupation an famer, rancher, carpenter, jeweler, etc. Take his word as to his occupation. Il the prisoner states that he has mo occupation, hist the occupation which he states that he has lollowed in the patst. In the event that the prisoner gives no information as to his occupation, list it as "unknown."

\section{Birthplace and Date of Birth (21)}

Is in the case of the occupation, take the prisoner's word for this infomation. Indicate the city, state, or nation and the date and year of birth. For example: "Oklahoma City. Okhahoma (claimed), August 24, 1914 (claimed)."

\section{Home Town (22)}

Give the location of the city or commmnity in which the prisoner states that he lived doming his youth or the place that he names as his home town; for example, "Kansas City, Kansas (claimed)."

\section{Prior Addresses (23)}

List the prisoner's complete addresses for the past five years. If enough space is not provided on the face of the form, make a notation and give the added information on the reverse side of the lorm.

\section{Names and Addresses of Relatives and Associates (24)}

like much of the other identilying data, you must get this information from the prisoner. In listing relatives give complete information, including full name, relationship, street, house $13 m$ ber, and city. Give like information for associates. Personal associates include those with whom the prisoner was arrested or those he gives as his personal friends.

\section{THE PHOTOGRAPHIC REPORT}

The photographic report necessary to identification records includes both a front and profile "mug shot" of the prisoner and the "Mug Form" which is stamped on the reverse side of the "mug shot." (See Form 45 and Form 46.) 


\section{Who Should Be Photographed?}

Police agencies differ as to their policies on photographing prisoners. However, one thing is certain: a department should establish a specific policy regarding this matter and include definite rules in its manual of procedure. It is the opinion of most authorities that it is sound policy to photograph all persons charged with felonies; misdemeanants who are charged with larceny, confidence games, and prostitution; and all persons upon whom photographic orders have been issued.

A photograph order such as the one which appears below, Form 47, should be completed by the investigating officer in situations where photographs are needed and departmental policy does not otherwise provide for the taking. The order includes the date, case number, the capitalized name of the person to be photographed, and the charge. The commanding officer must affix his signature before the order is valid. You, as the photographer, should complete the form, after taking the photograph, by signing your name on the line, "Taken by," and inserting the date, mug number, and comments in the appropriate places.
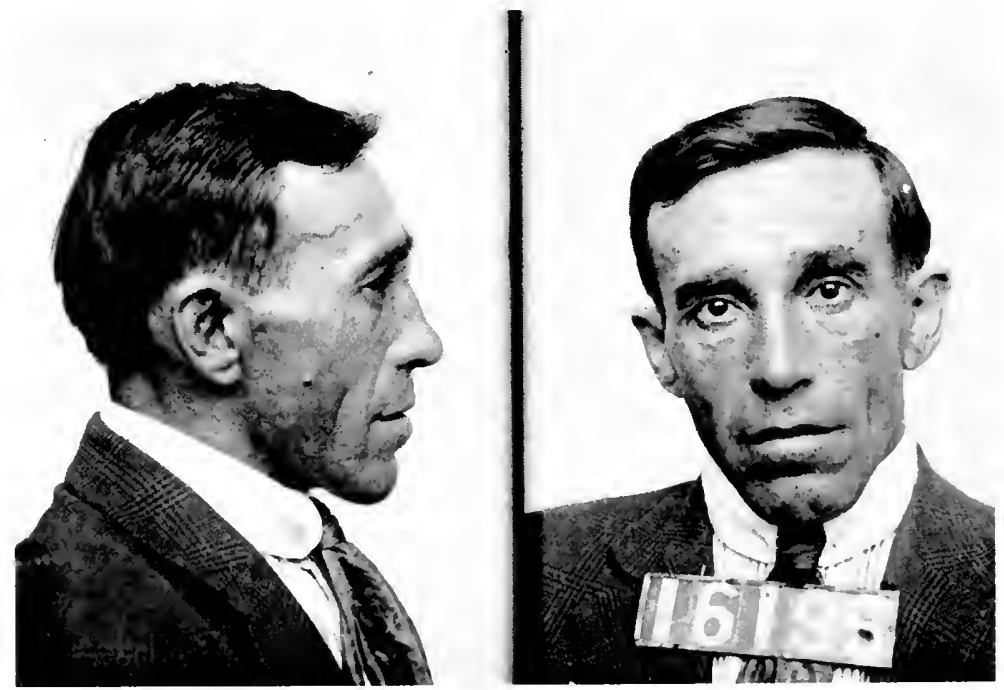

ForM 45. Mug Shot (5"x3"). 
Name Ident Vio.

sic Colot $\operatorname{lgc}$ $11 \mathrm{t}$

WI. Build Hair

Eves Cimp () (111)

Maths, scats

Date Arested Charge

Criminal specially F. l'. Class

Forn 46. Mug Fom (Reverse of llug Shot).

PHOIO(,RIPH ORIOER

Ciase No.

Please lahe at photograph of Held on charges of

Date

Taken bs

late

Mug Nimber

Forir 47. Photograph order $\left(8{ }^{*} \times 5{ }^{\circ}\right)$.

\section{The Procedure}

Your first step in the photographing of the prisoner is to check with the records division to determine whether the prisoner has been previously photographed by the department. If previous photographs were taken over three years ago, or the existing "mug shots" are a poor likeness of the prisoner as of the present time, departmental policy should allow you to take new photographs without a photograph order.

Photograph the prisoner in a frontal view and in profile on the sance film. The front view permits ready recognition of the indivi- 
duat by witnesses, but the profile is necessary to certain other identification.

One of the secrets of good "mug shots" is the proper position of the head of the subject. In order to obtain this position, draw two lines crossing each other at an angle of 75 degrees on the ground glass with a pencil. The head of the subject in the profile photograph should occupy such a position that the intersection of the lines is at the onter corner of the eye and the horizontal line passes through the center of the ear. In the frontal view the lines should intersect at the point where the nose meets the forehead.

A black background will prove most satisfactory for photographing white persons. Use a grey background for photographing colored people. If possible, the light should be uniform for all photographs. You can accomplish this by using artificial light, which should come chiefly from above with some from the front and sides.

Place a 4" by 5" studio camera equipped with a portrait lens on a studio camera-stand. Seat the subject in a straight-backed chair looking immediately forward. The camera lens should be approximately on a level with the eyes of the subject. It is very important that you adjust speed and lens openings and that the camera is properly focused, but these adjustments must be made in accord with the conditions under which the photographs are taken. 


\section{APPENDICES}




\section{Appendix A}

\section{ELEMENTS OF GRAMMAR}

\section{W}

ORD ARE IHE MOST IMUOR RAN tools of repont writing. They are visible evidence of thomghts, and the means whereby thomghts are conveyed to whers. Your suceess in wring depends upom the conticlence with which you apponach the writing of a report as well as the clarity with which you express your ideas. Since success is your goal, yout must be effective in your choice of words, consmot your sentences properly, and punctuate to the atrantage of the reacter. The very foundation of such accomplishments is the knowledge which you possess of the parts of speech.

\section{Nouns}

A nom is a name word; it names a person, place, thing or quality.

The suspect gave us a statement.

A proper nomm is the particular name of a person or thing. Ratrmond Holl gave us a statement.

I rommon nom is the name of a class of persoms or things. seremal trees were growing along the roadside.

\section{Pronouns}

A promomm is a worel used in place of a nomm. He came to the door of the cabin and shouted at the group.

A personal pronom indicates the person speaking, the person spoken to, or the person or thing spoken of.

$I$ am asking you or drop il.

The relative promoum relers 10 a $n 0 m$ or promomu used previously in the sentence.

.1I anticles which were on the lable were cheched for fingerprims.

Ile who was injured was transported to the hospital. 
The imlerogative pronomn is used to ask a question.

"The suspect shouted, "Who are you?"

The demomstralive promoun points out directly a person, place, (1) thing.

This is the best report that I have written.

The indefmite pronoun points out a person or thing less exactly than a demonstrative pronomn does.

Ereverbody left the scene at two o'clock.

Compound personal or reflexive pronomms are used to empliasize or to indicate reflex action. They are always used with nom or other pronomns.

The suspect himself admitted responsibility for the accident.

The gum itself was in full view.

\section{Adjectives}

An adjective is a word which describes or limits the meaning of a nom or promoum.

The victim described the suspect as a tall, heary man dressed in dirty, unkempt clothing.

The boy was large for his age. (His is a possessive adjective).

\section{Adverbs}

An adverb is a word which describes or limits a verb. adjective, or another adverb.

'The victim stated that a rather tall boy ran wery' quickly' down the strect.

\section{Verbs}

A terth is a word which expresses action, being, or state of being.

Hendrix called the police station. (Action)

Ihese were his last words. (Being or state ol being)

A resbal (participle, infmilize, or germud) is a word formed from a verh, but used as another part of speech. A participle is a verbal adjective; an infmilive is a verbal used as a 110111 , adjective or adrerb; a germond is a rerbal nomm.

Lomging (patriciple) for his treedom, he tried to improse (infinilive) his lying (gerund). 


\section{Conjunctions}

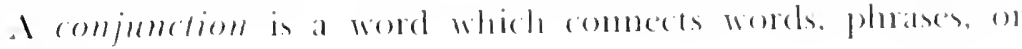
(datises.

Condimating comjunctions comneet words, phases, or dauses of explal valuse.

Roberts and Rhelm arried an the secole, but they did mot insentgate the storeroom.

subordimatimg romjumetioms commect clauses of unequal value.

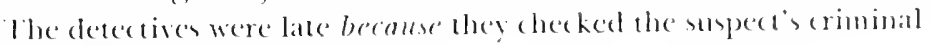
recond betore their departure.

\section{Prepositions}

I preposition is a word used on show the relationship between a nomorom pronom (the object of the preposition) and some other word in the sentence.

The prowler hid ander ahe house.

combiderable eridence was discosered in the antomobile.

\section{Interjections}

An imterjection is a word which expresses strong os sudden leeting and has no grammatioal comsection with the rest of the sentence.

The witnem exclaimed, "Oh, what a terrible accident!"

\section{CASE}

Care is the lomm or use of a $130 \mathrm{~m}$ or promome that shoms its relation to other words in the sentence. There are three cases: nomimative, possessize, and objective.

\section{Nominative Case}

The subject of a verb is in the nominative case.

The retetim was a juente.

He was a jurenile.

Catution: Do not be confused by intervening patsuthetical expressions.

Ilrome: 11 hom diel you saty inestigatted the ane?

Right: Iflo did you say insertigated the calse?

The predicate nominative on subject complement is also in 
the nominative case. This is a word that completes the verb and refers back to the subject.

It is $I$.

The culprit might have been he.

\section{Objective Case}

The direct object of a verl) or verbal (a word that receives the action of the verls or verbal) is in the objeclieve case.

The witness told the officers her story.

To give the public good srevice was the officer's only desire.

The object of a preposition is in the objective case.

1 group of us officers went to the game.

The subject and the object of an infmitive is in the objective case.

We want him to be an ofhcer's friend (subject).

The witness believes the suspect to be him (object). (In this sentence him is in the objective case to agree with suspect, which is the subject of the infunitive.)

\section{Possessive Case}

A nom or promoun expressing ownership is in the possessive case.

The suspect's fingerprints were taken.

The gun was his.

Caution: Ordinarily, do not use the possessive with intangible terms.

Ilrong: The suspect's appearance was cleceiving.

Right: The appearance of the suspect was deceiving.

A noun or promoun which modifies a gerund (verbal nomm) is in the possessive case.

The anthorities were surprised about the prisoner's leaving.

Certain expressions, sucl, as those of time and measmre, require the possessive form.

After two days" work we located the wituess.

The suspeet bought the child a dollats worth of candy. 


\section{IGREEMENT}

Agreement is the grammatical relationship ol werds in respect 10 their person. number, gender, or case. The person of a pronoun inclicates whether one is speaking (I), is spoten to (you), or is spoten of (he, she, it). Number is the form of a nom or pronoun which indicates whether one or more persons or things are named. (The singular indicates one; the plural, more than one.) Gender indicates the sex or sexlessness of a person or thing named by a noun or pronoun.

A subject and its verb must agree in number and person, regardless of intervening modifiers (adjectives, adverbs, etc.) .

$A$ large group of cars was parked outside the lideont.

This officer, as well as his associates, is interested in the public.

Singular subjects joined by and take a plural verb: however, if the singular subjects represent a collective idea, a singular verb should be used. The singular verb is also used if a compound subject is modified by each or every.

The gun and cartridge were on the floor.

Your friend and protector is here to serve you.

Each boy and girl in the class was questioned.

Every man and woman at the scene a'as questioned.

Singular subjects joined by either. . or, neither. . . nor take a singular verb; however, if the subject is made up of a singular and a plural noun or pronoun, the verb agrees with the nearest subject.

Seither the witness nor his employee is sure of the facts.

Either he or his associates are responsible.

A collective nom takes a singular verb when the group is regarded as a unit, but plural verb when it indicates individuals within the group.

The crowd has dispersed.

The crowd a'ere on their respective ways a their homes.

In a sentence containing there is or there are, the verb should agree with the subject which follows:

There are a loop. whorl, and an arch in the fingerprint patterns.

There is a number of witnesses arailable. 
A pronoun must agree with its antecedent in number, gender, and person.

livery boy in the neighborhood volunteced his assistance.

Demonstrative adjectives (this, that, these, those) must agree in number with the noms they modify.

The police department wants this kind of pictures.

The police department wants these kinds of pictures.

\section{FORMS OF THE VERB}

The various lorms of the verb indicate time.

\section{Principal Parts}

The principal parts of a verb are the present tense, the past tense, and the past participle. From these all other forms are deriverl.

A regular verb forms its third person singular by adding $s$ or es; it forms its past tense and past participle by adding $d$ or $e d$.

$\begin{array}{ll}\text { desire } \ldots . . \text { desires } & \text { desired } \ldots . . \text { desired } \\ \text { drown ... drowns } & \text { drowned } \ldots \text {. drowned } \\ \text { flow ... flows } & \text { flowed } \ldots \text { flowed } \\ \text { reach } \ldots \text { reaches } & \text { reached } \ldots . \text { reached }\end{array}$

An irregular verb forms the past tense and the past participle by changing its vowel or by changing its form completely.

am, is

come, comes

drink, drinks

liide, hides was, been

came, come

drauk, drumk

hicl. hidden

Caution: Do not confuse the past tense and the past participle of irregular verbs. The past tense is used alone; the past participle is used with some form of the auxiliary verb be to form the passive voice and the auxiliary verb hate to form the perfect tenses.

\section{Principal Parts of Commonly Used Verbs}

$\begin{array}{lll}\text { Present } & \text { Past } & \text { Past.Participle } \\ \text { arise } & \text { arose } & \text { arisen } \\ \text { awake } & \text { anoke } & \text { awaked } \\ \text { bear } & \text { bore } & \text { borme } \\ \text { beerme } & \text { becane } & \text { become } \\ \text { begin } & \text { began } & \text { begun }\end{array}$




\begin{tabular}{|c|c|c|}
\hline Prexenl & P'als & Past l'anticiple' \\
\hline$b x+t$ & bect & bet \\
\hline blow & blew & blown \\
\hline break & broke & loreken \\
\hline bring & brought & browght \\
\hline burut & burst & burst \\
\hline cheose & chose & chosen \\
\hline$(\lim b)$ & $(\lim b) d$ & $(\lim 1 x \cdot c \mid$ \\
\hline dise & dival & diverl \\
\hline do & diil & done \\
\hline draw & $\operatorname{drew}$ & drawn \\
\hline driven & drove & (hiven \\
\hline calt & atte & calten \\
\hline fall & fell & fallen \\
\hline fly & flew & flown \\
\hline freese & lrose & troten \\
\hline set & got & $g 0 t$ \\
\hline give & gitre & given \\
\hline 30 & went & sone \\
\hline grom & grew & grown \\
\hline hang (to execute) & hanged & hanged \\
\hline hang (to suspend) & hung & hung \\
\hline know & knew & known \\
\hline lal! & laicl & linicl \\
\hline lic & liay & lain \\
\hline prove & proved & proved \\
\hline ralise & raised & raised \\
\hline rive & rose & risen \\
\hline ride & rote & ridken \\
\hline ring & rang & roms \\
\hline run & ran & run \\
\hline see & Silw & seent \\
\hline sliake & whook & slaticen \\
\hline shine & shonce & shome \\
\hline strink & shrank & shrunk \\
\hline sing & sillng & $s t 119$ \\
\hline sink & sitnk & $\checkmark u n k$ \\
\hline sit & sill & bilt \\
\hline upeith & spoke & spoken \\
\hline prings & uplatng & sprung \\
\hline steal & stole & solen \\
\hline sweat & swore & worn \\
\hline wim & "w:all & swuml \\
\hline tarke & toosk & lithen \\
\hline
\end{tabular}




$\begin{array}{lll}\text { Present } & \text { Past } & \text { Past Paticiple } \\ \text { teach } & \text { taught } & \text { taught } \\ \text { tear } & \text { tore } & \text { torm } \\ \text { throw } & \text { threw } & \text { thrown } \\ \text { wear } & \text { wore } & \text { worn } \\ \text { weave } & \text { wore } & \text { woven } \\ \text { wring } & \text { wrung } & \text { wrung } \\ \text { write } & \text { wrote } & \text { written }\end{array}$

\section{Tense of the Verb}

The tense of a verb means its time. The present, past, and future tenses (the simple tenses) indicate action, being, or state of being that is or w'as or will be.

He practices with his revolver each day. (present tense)

He practiced every day. (past tense)

He will practice every day. (future tense)

The perfect tenses (the present perfect, past perfect, and future perfect) are used to express action which is completed in the present, was completed in the past, or will be completed in the future. These tenses are formed with the corresponding form of the auxiliary verb have plus the past participle.

He has practiced an hour. (present perfect)

He had practiced an hour. (past prefect)

He will have practiced an hour at this time tomorrow. (future perfect)

The future lenses make the following distinctions between shall and will:

To express a simple future tense, shall is used in the first person and will in the second and third.

I shall investigate the case tomorrow.

W'e shall investigate the case tomorrow.

You will investigate the case tomorrow.

He (or they) atill investigate the case tomorrow.

To express determination, threat, or promise on the part of the speaker, will is used in the flrst person and shall in the second and thircl.

I promise that I will write the report tomorrow.

lle are detemined that he shall write his report within thee days. 
Note: The same rules apply whould and anenld, except when shonld implies an obligation or when aromld implies habitual atetion or a wish.

lon should write your report.

fivery evening we arould write our reports.

W'ould that I hard completed my shift..

A progressize reerb phase indicates action continuing at the time referred to.

He is uriting his report. (present progressive)

He u'as ariting his report. (past progressive)

He will be uriting his report. (future progressive)

He has been writing his report. (present perfect progressive)

He had been writing his report. (past perfect progressive)

He will have been ariting his report. (future prefect progressive)

\section{Transitive and Intransitive Verbs}

V'elss may be classified as transilize and intransitive.

A verb is transitive if it has an object (active voice) or if the subject is acted upon (passive voice). All other verbs are intransitive.

He laid his gun on the table. (transitive verb, active voice)

The gun was laid on the table. (transitive verb, passive voice)

The guns were bying on the table. (intransitive)

Lie, sit, and rise are intransitive verbs; lay, set, and rise are transitive verbs.

\section{Mood of Verbs}

Mood, or mode, indicates the mammer in which a verb states its action. Verbs are classified also according to mood as indicative'. imperative, and subjunclive.

The indicalive mood states a fact or asks a question.

The officer worote his report.

Has the gun been fired?

The imperalive mood expresses a command or a request.

cierase fire.

Please be quiet.

The subjunctive mood expresses a wish, a condition contrary to fact, a demand, or a state of necessity. 
I whish I were a sergeant.

If he were my partner, I would disown him.

It is necessary that a report be made.

I demand that the subject hate another chance.

Caution: Do not use the subjunctive after if when the idea is not definitely contrary to fact.

The witness stated, "Il he ares there, I did not see him." 


\section{Appendix B}

\section{UNIFORM CLASSIFICATION OF CRIMES}

\section{PART I CASES}

1. Criminal Homicicle

a. Morder and Nommegligent Mamblamghter

b. Manslaughter b) negligence

2. Ratpe

a. Forcible

b. Statutory

3. Robbery

a. Highwal!

b. Commercial homse

c. Oil station

d. Chain store

e. Residence

t. Ballk

g. Miscellaneous

1. Aggravated Assault

a. Assault with intent to kill or murder

b. Assatult with a dangerous or deadly weapon

c. Maiming. mayhem, and astult with intent to main or commit mayhem

d. Assault with explosives

c. IVilful obstruction of rabload

1. All attempts to commit any of the above

5. Burglary-Breaking or Entering

a. Resiclence

I. Night time burglary

2. Daty time burglary

b. Nonresidence

1. Night time burglary

2. Day time burglary

${ }^{3}$ Federal Burean of Insesigation: L'niform Crime Reporting Handbook. Washington D. C... lederal Bureatu of Investigation, 195.5, pp. 11-45. 
i. Larceny-Theft

a. $\$ 50$ and over

b. Under $\$ 50$

7. Auto Theft

a. Joy riding

b. All other

\section{PART II CASES:}

8. Other Assaults
a. Simple Assault
b. Assault and battery
c. Pointing a gun in jest
d. Injury caused by culpable negligence
e. Intimidation
f. Coercion
g. Resisting or obstruction of an officer
h. Hazing
i. Wile beating
j. Drawing a clangerous weapon
k. All attempts to commit the above

9. Forgery and Counterfeiting

a. Forgery (except checks)

1. Forging wills, deeds, notes, bonds, seals, trademarks, etc.

2. Possessing or uttering forged instruments

3. Using forged labels

4. All attempts to commit the above

b. Counterleiting

1. Counterfeiting coins, plates, bank notes, checks

2. Counterfeiting instruments

3. Possession, manulacture, etc, of counterfeiting apparatus

4. Selling goods with counterleited trade-marks

5. All attempts to commit the above

c. Checks (torged and fictitious)

10. Embealement and Fraud

a. Emberdement-conversion

b. Conficlence games

c. Fratud

1. Fraudulent conversion, appropriation, conveyance, entries accounts, registration, use of trade-marks, emblems, misbranding, etc.

Ibid., pp. $14-17$. 
2. False personation, pretanse, statentent, document, representation, claims, evidence, elc.

3. Gross liatul, cheat, on swindle

1. Checks (insulficient fumbls or mo atcommt)

5. Fraudulent use of telophone, telegraph messages

6. Instrance frauds

7. Use of latse weights and measures

s. False alvertising

d. Nll attempts to commit the above

11. Siolen Property

a. Buying

b. Receiving

c. Possessing

d. All attempts to commit any of the above

12. Neapons

a. Carrying

b. Possessing

c. Manufacture or sale

d. Using, mantafacturing, etc. silencers

c. Furnishing deadly weapons to minors

f. All attempts to commit any of the above

13. Prostitution And Commercialized Vice

a. Prostitution

b. Keeping bawdy house, disorderly house, or house of ill fame

c. Pandering, procuring, transporting or detaining women for immoral purposes

11. Sex Offenses (except rape and prostitution)

a. Adultery and fornication

b. Abnomal sex relations

c. Intercourse with insane, epileptic, or venerally diseased person

d. Indecent liberties

e. Miscellaneous

1. All attempts to commit any of the above

15. Offenses Against the Family and Children

a. Desertion, abandonment, or nonsupport of wife and children

b. Neglect or abuse of clitd

c. Nonparment of alimony

d. Nll attempts to commit the abore

16. Narcotic Drug Laws

a. Unlawful possession, sale, etc. of narcotic drugs

b. Keeping or frequenting an opium den 
c. Habitual users

d. All attempts to commit any of the above

17. Liquor Latws

a. Manufacture, sale, transporting, furnishing, possessing, etc., intoxicating liquor

b. Matintaning unlawlul chinking place

c. Advertising and soliciting orders for intoxicating licpuor

d. Bootlegging

e. Operating still

f. Furnishing liquor to a minor or intemperate person

g. Using a vehicle for illegal transportation of licfuor

h. Drinking on train or public conveyance

i. All attempts to commit any of the above

18. Drumkenness

a. Drunkenness

b. Drunk and disorderly

d. Common or habilual drunkard

d. Intoxication

19. Disorderly Conduct

a. Allray

b. Unlawful assembly

c. Disturbing the peace

(1. Disorderly conduct

e. Disguised and masked persons

f. Prize fights

g. Blasphemy, profanity, and obsrene Language

h. Desecrating llag

i. Refusing to assist an officer

20. Vagrancy

a. Begging

b. Loitering

c. Vaigrancy

d. Vagabondage

21. Gambling

a. Kecping gambling place

b. Common gambling

c. Owning gambling resort

d. Frequenting gambling resort

c. Lotteries

f. Nll attempts to commit any of the above

22. Driving While lntoxicated

a. Operating a motor vehicle while intoxicated 
b. ()perating ant chginc, llain, street cal, scambeat, ele, while intoxicatcel

2.3. Violation of Roal and Driving Laws
a. Speceling
b. Reckloss driving
c. Right of waly
d. Violation of signs and signals
c. Olher violations

221. Parking Violations
a. Overtime
b. Other illegal parking

25. Other Violations of Trallic and Moton V'chicte Laws
a. Hit and run-personal injury
b. Hit and rum-property damage
c. Leaving scenc of accident
d. N1l others

26. All Other Oflewses (not chassified above)

a. Abduction and compelling to marry

b. Abortion

c. Admitting minors to improper places

d. Arsoll

e. Bigany and polygany

l. Blackmail and extortion

g. Bribery

h. Burglatry tools (possession, etc.)

i. Malicions mischied

j. Obscene literature

k. Parole violation

l. Public muisances

m. Subversive activitics

n. Trespass

o. Miscellaneous (not otherwise classified)

"s. Suspicion

\section{PART III CASES \\ (LOST ANI) FOUNI)}

2s. I.ost
a. Persolls
b. Animals
c. Property

3O. W. Wilson: Police Records. Chicago, Public Administation Service, 1942, P. 257. 
29. Found

a. Persons

b. Animals

c. Property

\section{PART IV \\ (CASUALTIES')}

30. Fatal Motor Vehicle Traffic Acridents

a. Collision with pedestrian

b. Collision with another motor vehicle

c. Collision with railroal train

d. Collision with strect car

e. Collision with animal-drawn vehicle

f. Collision with bicycle

g. Collision with animal

h. Collision with fixed object

i. Non collision; overturned on roadway

j. Non collision; ran off roadway

k. Other non collision

l. Miscellaneous

31. Personal Injury Motor V'enicle Traltic Arcidents (Same subdivisions as appear under Item 30)

32. Property Damage Motor Vehicle Traflic Accidents (Same subdivisions as appear under Item 30)

33. Other Traffic Accidents (except motor vehicle)

a. Railroad accidents

b. Street car accidents

c. Other tratfic accidents

34. Public Accidents (except fireams and dog bitc)

a. Drownings

b. Falls

c. Burns, conllagrations, explosions

d. Motor vehicle non-traffic

e. Other vehicular non-trafhe

f. Other types

35. Home Accidents (except fircarms and dog bite)

a. Falls

b. Burms, scalds, comblagrations, explosions

c. Poismoms gas

'Ibid., $257-259$. 

d. Mechanical sullowation
e. Poison (except gais)
f. Nester velincle
11. (inl or scratch
g. (O)her typess

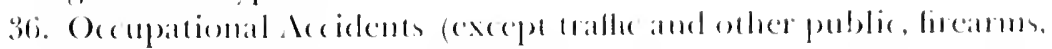
and (tog bitc)
a. Hambling objects
1). Valls
c. Machines
a. Motor vehicles
c. Other vehicles
f. Falling objects
g. Using hamel loots
h. Burms, conflagrations, explosions
i. Other types

37. Fiream Accidents (not suicide)

a. 11 omme

b. Occupational

c. Public:

38. Dog bitcs

a. Home

b. Occupalional

c. Public

39. Suicides

40. Suiciele Attempts

41. Sudden Death and Bodies foumd

42. Sick Ciared For

13. Mentall Ciases

\section{PART V CIASES \\ (MISCELLANEOUS")}

11. Miscellancous Service Reports

15. Miscellancous Public Reports

ti. Special Orders

17. Gencral Orders

18. Rules and Regulations

Tlbid., p. 259. 


\section{Appendix C:}

\section{DESCRIPTION OF PROPERTY}

$\mathrm{O}$

NE OF IHE RIVE PRINCAPAL activities of the police, along with prevention and repression of crime, apprehension of criminals, and regulation of conduct, is the recovery of lost and stolen property. This function serves the public well by cutting down the cost of crime, aiding the department's public relations, providing good officer contacts and fumishing leads which frequently result in the apprehension of theives. The efficiency of an individual officer, and consequently his department, in the recovery of property depends almost entirely upon how accurately property is described in field notes and subsequcut investigation reports.

System and logic are especially important in describing property. Since most people natmally take faniliar things as a matter of course and pay very little attention to them, it is frequently necessary, figuratevly, to drag lrom then descriptions of their most prized possessions. It is commonplace for officers to have to interrogate at length the victim of a burglary to obtain even the most meager description of the property he has lost. Thus, in order that none of the questions which might disclose some point of identification is overlooked, a formula for the description of property las been developed.

\section{THE FORMULA}

1. Assign a number to each article in the list of lost or stolen articles.

2. State the quantity of the article.

9. Indicate the kind of article.

1. Note the material from which the article is made.

5. Record the physical description of the article.

6. State the physical condition of the article.

7. Determine and record the value of the article. 
The above fommla may be applied to describe any article, even a domestic animal; it may be pasted in the front of the officers ficld notelook as a guide while interrogating a victim.

\section{The Order of Articles Listed in a Report}

ln carrying out the theme of system and logic in property descriptions, some recognition must be given to importance, value, and ease of identification of articles by listing them in predetermined order in the report. Articles should be listed in order ats follows:

1. Articles bearing numbers.

2. Articles bearing initiats or personal nances.

3. Articles bearing identifying marks.

4. Articles bearing identilying characteristics.

5. Articles without market value.

\section{Number of the Article in the List of Articles}

Each separate article must be given a list number in the entire list of articles. This number identifies the article should it become necessary to refer to it in other reports, correspondence, and teletypes. For example, list the articles as follows:

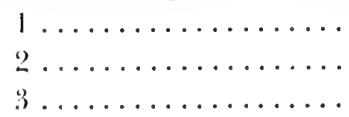

\section{Number of the Quantity of the Article}

A number should follow the number of the article in the list of articles. This number indicates the quantity of the article. If one article was lost or stolen, the quantity of the article is (1). Note that this number is placed in parenthesis. For example:

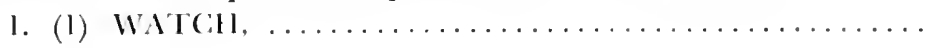

\section{Kind of Article}

The number of the article in the list of articles and the number of the quantity of the article should be followed by the kind of article. This includes the name, designation of whom or what the article is clesigned for, trade name, manufacturer and/or seller. For example:

1. (1) WATCH, man's wrist, Figin $\ldots \ldots \ldots \ldots \ldots \ldots \ldots \ldots$ 


\section{Material}

The kind of article is followed by the material from which it is roistricted.

If the material is metal it should be designated as yellow metal, white metal, gold metal, green metal, brass, copper, etc., followed by the kind of metal claimed by the victim, for example: WM, platimum (lamed. It is unwise to take the responsibility for judging. from the victim's description, exactly what kind of metal is inrolved. Note that the material may be abbreviated.

In the identification of jewcls, the same procedure is followed: red stone, green stone, etc., followed by the kind of stone claimed.

Dianonds are designated as white stones. ${ }^{2}$ When a white stone is taken to a pawnshop, the pawnbroker will call it a diamond if it is a diamond; however, if it is not he will usually show it as a white stone in his records. For example, describe the material as follows:

1. (1) WATCH, nan's wrist, Elgin, YH, $2+\mathrm{K}$ gold clnimed ...

Great care should be exercised in describing other materials. Cloth generally is described lsy the victim as "silk" may be rayon, bemberg, taffeta, pongee, shantung, satin, crepe, or nylon. "Leather" may be artificial leatherette, cowhide, horsehide, sealskin, ostrich, alligator, snakeskin, calfskin, or a number of others. "Wool" may be all wool, half wool, virgin wool, or reclaimed wool.

'Solid gold is 24 karat gold. "Karat," when used as a designation for gold, is a unit of quality of fineness and means that, in the case of 24 karat gold, there are 24 grains-a minit of weight-to the pemyweight, also a umit of weight. Since pure gold is soft, it is mixed with a base metal to give it better wearing quatity. Therefore, 18 karat gold means that there are 18 grains of gold and 6 grains of base metal to the pennyweight. " $K$ " is the abbreviation for karat. 'Twenty-four grains equal pennyweight in Troy measure. Metals may be gold-filled, rolled gold, gold-plated, or gold-washed. Goldhlled and rolled gold articles are those with a veneer of gold metal on a base metal. Both processes are the same except that the gold on a gold-filled atticle is of greater harat value than on a rolled gold article. A gold-filled article is $.03 \mathrm{~K}$ or more. $\mathrm{A}$ rolled gold article is $.015 \mathrm{~K}$ to $.03 \mathrm{~K}$. Cold-plated or gold-washed articles are electro plated with gold of below 015 karat value.

${ }^{2} \Lambda$ " caral," when used in connection with diamonds or other precious stones, is a unit of weight amountimg to about $3-1 / 10$ grains, which makes slightly more than 155 carats equal to 1 omce. The carat in diamonds and other stones has nothing to do with quality. Dianonds are often designated as so man! points, and a "point" means $1 / 100$ of a carat. The abbreviation for the stone carat it "ct." 
Silver ware may be sterling, which is $25 / 100$ pure silver and $75 / 100$ copper or other metal, or it may be plated ware.

\section{Physical Description}

In the interest of accuracy and increased possibilities of later identification. the physical description of property should include such items as model, size, shape, color, pattern," measurements, style, and idcnifying marks.

Identifying marks may include numbers, ${ }^{5}$ initials, marks placed on the article by the owner, damage, repairs, and scratches. ${ }^{B}$ For example:

1. (1) WATCH, man's wrist, Elgin, YM, $24 \mathrm{~K}$ gold claimed, size 10, "Lord Elgin," case\#675342, movement \#365471 ......

\section{Physical Condition}

Noting the condition of the article involves recording the time when it was purchased; whether new or used when purchased; the state of repair, such as shabby, dirty, worn, mended, patched, clean, etc. For example:

1. (1) WATCH, man's wrist, Elgin, YM, $24 \mathrm{~K}$ gold claimed, size 10, "Lord Elgin," case \#675341, movement \#365471 purchased Robert Jewelry Co., 1210 Main St., St. Louis, Missouri 1950, several scratches on back of case.

${ }^{3}$ For example, watches come in sizes classified by the diameter of the face and the thickness of the movement. Swiss watches are measured in lignes (1 ligne equals $1 / 32$ inch). Swiss watches are manufactured in sizes from 3-3 4 to 14 lignes. American watches are assigned arbitrary numerical sizes from $26 / 0$ to 18.5 . Most common American pocket watch sizes are 12, 16, and 18.

${ }^{4}$ Flat silver, which is table silver, has a pattern name; it is important to know what company made the set, since there are duplications of names among the various lines. Whether the set is sterling or plate should be ascertained.

${ }^{5}$ Typewriters, tools, radios, television sets, and many pieces of equipment hate serial numbers. For example, the popular American-made watches, such as Elgin. Howard. Hamilton, Waltham, and Hlinois, have both a case number and a movement number. Cheap watches do not have either. Bulova, Cruen, Tarannes, Westfield, and some others have a case number only. Silver services, silver dishes, and travs have a number on the bottom and usually a haltmatk or trademark.

"Expensive jewelry frequently will have a jeweler's scratch mark engraved by the mamufacturer near the trademark under a 10 power glass, which makes it practically imisible to the naked eye. The seller will usually have a record of this mumber. Jewelers ustally mark watches with a distinctive mark at the time of repair. 


\section{Value}

Recording of the value of an article involves a listing of insurance coverage and name of the insurance company if the article is insured, original cost, and current market value.

\section{Example of Complete Description}

An example of a complete description of a lost or stolen watch might be as follows:

J. (1) W.TTCH, nan's pocket, Walthan, huncing case, purchased at kily Jewelry Co., 25 6th St., S.F., in 1940, YM, $18 \mathrm{~K}$ gold clained, "V'agabond," si/e 16. 23 jewel, double back inner snap, hinged onter screw back, screw crystal, stem wind. white face. Irabic numerals, second hand at 6 o'clock, back bearing embellished script intials "ABC." Case \#1234567, morement \#765431. Last repaired by A. R. Brown, 146 Powell St., in 1947. Owner's own mark. three dots in triangle above inside inner back cover. Small dent on left edge. Purchase price $\$ 110.00$. Market Value $\$ 65.00$.

\section{Directory of Descriptions of Articles Most Commonly Lost or Stolen}

Police records indicate that the following kinds of articles are most frequently lost or stolen: (1) binoculars; (2) cameras; (3) clothing: (4) lirearms; (5) handbags; (6) jewelry; (7) lnggage; (8) musical instruments; (9) radios; and (10) tools. Due to the difficulty most persons, including police officers, experience in describing these common articles, a directory of descriptions follows:

\section{Binoculars}

1. Number of the article in the list of articles.

2. Quantity of the article.

3. Kind of article.

4. Material.

5. Physical description.

Power and size. The first number indicates power; the second number indicates the sie of the lens in millimeters. for eximple: $8 \times 30$.

Type of focusing. Central or single eye.

bridge. Hinged or solid bridge. 
Barrels. Describe the length and coresing matterial of the baturels.

lines. Conterlecte.

bessiption of the (arrying case (it any).

6. Condition

Harks.

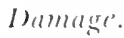

signs of wear.

Repairs.

i. Inlur

Where and when parchased.

Provehase price.

Market inalue.

\section{Cameras}

1. Number of the article in the list of articles.

2. Onamity of the article.

3. Kind of article.

4. Material.

5. Phrsical description.

Numbers. Locate and recort two numbers on valuable cameras: one on the lens, another on the camera itsell.

Oane's l bescription. Accept and record the owner's description of the camera.

Description of the camying case (it any).

6. Condition.

Marks.

I) amager.

Signs of w'ar.

Repairs.

i. Vilue'.

Ithere and when purchased.

Purchase price.

Market ialue.

\section{Clothing}

Suits-men's and a'omen's.'

1. Number of the article in the list of articles.

2?. Quantity of the article.

3. Kind of article.

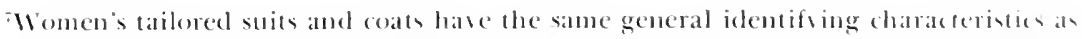
men's snits and orercoats. The word "taibored," when applied to ans antile of women's wear, means plain or without decoration.
} 
4. Material.

Description of pattern in weave.

Describe as: whipcord, serge, gabardine, flannel, tweed, broadcloth, worsted, etc.

5. Physical tescription.

Color. Get color as exactly as possible.

Size. Women's suits are described by size number.

Men's stits come in three lengths: short, medium, and long, plus the size number. For example, size 40 will be found in short, medium, and long.

Labels. State the manufacturer's label, usually found inside of inside coat pocket of men's suits. State the retailer's label, ustually found outside of inside coat pocket or at the nape of neck of men's suits. In women's suits there is no uniform placement of labels."

Cleaning marks.

Owner's name."

6. Condition.

Damage.

Repairs. Mended, patched, etc.

Signs of wear.

7. V'alue

Where and when purchased.

Purchase price.

Market value.

Coats-men's and women's suit coats, ${ }^{10}$ ouercoats, or topcoats.

1. Number of the article in the list of articles. ${ }^{11}$

2. Quantity of the article.

3. Kind of article.

Jacket.

Cardigan, etc. Men's sport coats and women's suit and top coats are of this kind.

1. Material.

Describe as in the case of suits.

5. Physical description.

Style.

Single or double breasted. Record how many buttons

${ }^{8}$ See further description of coats and trousers for additional description of suits. Include description of coat and tronsers in the suit description when an entire suit is lost or stolen.

${ }^{8}$ Tailor-made suits frequently have the owner's name or initials on the imner coat pocket. Some tailors and furriers have the customer sign the inner lining of the coat near the front; it is necessary to Ioosen the lining to see the name.

${ }^{10}$ Describe any coat of waist lengtls as a "jacket."

${ }^{11}$ If the coat is a part of a suit, describe the coat along with the entire suit. 
and how many butoms will button in double breasted coats.

Lapels. P'athed, semi-peaked, notched. Wimman's conts mal have a wing lapel.

shawl. (On tuxcelos.

Button hole's in ome or more lapels.

Pockets. Patch or inset: with or without flaps; piped: extra cash pocket; number and location of inside pockets.

Lining. Color and type of material; full, half, or quarter lined.

Bnck. Box, with or without seam; conservative, slightly form litting; form fitting; pronounced form fitting; drape, extrenely form fitting: lounge, hangs from shoulders to hips, where it is snug; wedge shaped. non-form fitting at waist: sport back, half belt with pleats-may or may not have "Iree swing or vent"-may have two vents.

stitched or welted edge.

\section{Condition.}

See men's and women's suits.

7. V'alue.

Se' men's and a'omen's suits.

Orercoats and topcoats-men's and women's

1. Number of the article in the list of articles.

2. Quantity of the article.

3. Kind of article.

Oiercoat.

Topcoat.

4. Material.

Describe the same as men's and women's suit couts.

5. Physical description.

Describe generally as you would a suit coat.

Lining. May be removable, zipper, or button.

Pockets. May be slasherl.

Sleeves, Niay be split, adjustable cuff tabs. In women's coats only, they may be leg-o'-mutton, fitted to elbow. or all the way: length of sleeve-short, elbow, three-guarter or long. Trim. Nay be found on women's coats only. The trim mat be different collar, cuffs, bottom. The trim may comsist of pleats, front or back.

Fly front.

l'ent.

Reversible.

Reglan shoulders. Hangs from the shoulders.

Chesterfield. 
6. Condition.

See men's and women's suits.

7. Value.

See men's and women's suits.

Trousers-men's and women's slacks. ${ }^{12}$

1. Number of the article in the list of articles."

2. Quantity of the article.

3. Kind or article.

Men's trousers.

liomen's slacks.

4. Material.

Describe as in the case of suits.

5. Physical description. ${ }^{\text {s }}$

Waistband. Regular, with waistband and loops at the top;

drop belt loops, with waistband and belt loop on waistband and the other end below:

French waistband, no visible waistband and belt loops below the top of trousers; extended waistband, waistband continued beyond fly, and buttoned.

Cuffs or none.

Pleats. Give the number and whether turned in or out.

Pockets. Patch or inset, with or without flaps, etc.

6. Condition

See men's and women's suits.

7. V'alue.

See men's and women's suits.

W'omen's Clothes, generally

1. Number of the article in the list of articles.

2. Quantity of the article.

3. Kind of article.

Dress.

Blonse, etc.

4. Material.

kind.

Color. Plain or figured, including color and design of figure.

5. Physical description.

Size.

Trim.

Color.

Buttons.

\footnotetext{
"Men's and women's tailored slachs in many cases are similar even to the fromt lly. ${ }^{13}$ If the trousers are a part of the suit, describe them along with the entire sunt.

${ }^{14}$ Apply the phusical description of trousers 10 the description of the entire suit if thes are a part of a suit.
} 
Braid or piping.

Embroiders or c at work. Skit.

Describe as part of a suit if such is the case.

length.

Fit.

Slashed or slitted. Give Jocation and length of slit.

Pockets.

Number of pancels or gores.

6. Condition.

Neze or used.

Signs of we'ar.

Repairs. Mended, etc.

7. I'alue.

Where and when purchased.

Purchase price.

Warket inher.

Hosiery

1. Number of the article in the list of articles.

2. Quantity of the article.

3. Kind of article.

Lady's

Man's

Child's

4. Malerial.

silk.

Nylon.

Rayon.

Silk and wool.

Iirool.

Colton top and/orfeet.

j. Physical Description

Sizc.

Foot sire.

Length.

Color. Clocks or heel decorations.

Wright.

sheer.

Medium weight.

Service weight.

benier or giluge.

II'are'.

Ruin-proof weave, etc.

Sream or seamless. 
6. Condition.

New.

Signs of wear.

Repairs. Mended, etc.

7. Value.

Where and when purchased.

Purchase price.

Market price.

Jackets, men's.

1. Number of the article in the list of articles.

2. Quantity of the article.

3. Kind of article.

4. Material.

Gabardine.

Melton.

Leather. Describe the kind.

5. Physical description.

Color. Design and weave.

Size.

Pockets.

Number. Inside and outside.

Kind. Slash, inset, patch, muff-type, flap.

Fastenings. Zipper or button.

Collar.

Knitted. Also describe cuffs on leather jacket.

Fur or pile.

Lapels. Describe as in coats.

Detachable.

Parka hood.

Lining.

Color.

Material. Rayon, quilted, sheepskin, blanket. Back.

Plian, half-belt, swing shoulders.

6. Condition.

Damage.

Signs of wear.

Repairs.

7. Iralue.

Where and when purchased.

Purchase price.

Market price.

Shirts, men's

1. Number of the article in the list of articles. 
2. Quantity of the article.

3. Kind of article.

l)ess.

Iroik.

coneboy.

t. Material.

Cotton.

liool.

líayon.

Rayon gabardine.

Nolent

Oxford areave.

․ Physical description.

Color.

Pattern.

Brand.

Collat style.

llith or without collar.

Size. ${ }^{15}$

Collar size.

Sleeve length.

Bullons. Number on cuffs if more than one, as cowboy shirts; button down collar; number of buttons down the front.

Pockets. Number, with or without llaps.

Cuffs. Regular, for cuff links, Frencl cuffs.

6. Condition.

Damage.

Signs of wear.

Repairs. Mended, etc.

7. Value.

Where and when purchased.

Purchase price.

Markel value.

Sweaters

1. Number of the article in the list of artirles.

2. Quantity of the anticle.

3. Kind of article.

Man's.

IVoman's.

Child's.

4. Material.

All wool.

${ }^{15}$ Sport shirts come in small, medium and large. 
Half wool.

l'irgin wool.

Reclaimed wool.

Cotton.

Nylon.

Orlon.

Angora.

Cashmere.

5. Physical description.

Size.

Style.

Coat. Button or zipper.

pull over.

Pattern.

Color.

Design.

Weave.

Neck.

Crew neck.

Turtle neck.

$\checkmark$ neck.

Roll collar.

Sleeve or slecucless.

6. Condition.

Damage.

Signs of wear.

Repairs. Mended. etc.

7. I'alue.

Where and when purchased.

Purchase price.

Warket aralue.

Friss

1. Number of the article in the list of article's.

2. Quantity of the article.

3. Kind of article.

Cont.

Stole, cetc.

4. Material.

Rabbit."

rasince furs are so diffeult to recoser, it is res necessiry to get as complete a description of the piece as possible.

${ }^{17}$ Rabbit has been given man! trate names: coner, bearerette, lapin, sealene, Arotic seal, Belgium bearer, bluette, casterette, hinchillette, erminette, French sable, Galland spuirrel. mamotine, minkons, moline, nutrietle, twin beases, or Baltic leopard. 
Skunk."

Manchurian doge. ${ }^{19}$

Iludson seal. (This is plucked. dyeel muskrat.)

llowtom. (This is sleatred lamb and lowks like beaser).

squimel.

Fox.

llink.

etc.

5. Phusical descriptiom.

Colon. (Indieate whether dyed or naturall.)

Liming.

Material. (Color, bindiugs and piping.)

Pockets.

labels.

length. The length is measured from the bottom of the collar down the back. It may be $3 / 4$ length, fingertip, or a "(hulbl)y."

Fasteners. Frogs. hooks and eyes. buttons, or snaps.

How many skins. It the fur is a neckpiece. are heads and or tails sewed on.

6. Condition.

New or used.

Signs of wear.

Repairs. Who made the repairs.

7. Value.

Where and when purchased.

Purchase price.

Marketialue.

\section{Firearms}

1. Number of the article in the list of articles.

2. Quantity of the article.

3. Kind of article.

4. Material.

5. Physical description.

Make.

Caliber.

Serial number. Some sum have hidelen serial number

Vam toreign makes have no serial number at all.

Finish. Nicked plated. blue, rough, or samelblasted.

l.ength of barrel. 2in.. \$in.. bin., etc.

"Shmoh ma! be called civet cat, Mlashas sable. blach manten.

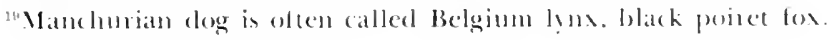


Grips. Give the material, color, and type.

Loaded or unloaded.

(i. Comdition.

Marks.

Damage.

Repairs.

Signs of we'ar.

7. J'alues.

Where and when purchased.

Purchase price.

Market ualue.

\section{Handbags}

1. Number of the article in the list of articles.

2. Quantity of the article.

3. Kind of article.

4. Material.

Leather.

Patent leather.

Sulede.

Sealskin.

Ostrich.

Calfskin.

Cowhide.

Reptile. Mlligator, lizard, snake.

Cloth. Cord, petit point, moire, etc.

Plastic.

5. Physical description.

Style. Pouch, box, envelope, underarm, shoulder strap.

Handles. Pannier and clouble pannier, cuff, wrist, plastic,

chain, cetc.

Fasteners. Zipper, turnlock, lift lock, snap lock.

Inside description. Lining, material and color; label; number of divisions; attached coin purse, etc.

Contents. Accessories, comb, lighter, lipstick holder, address book, etc. Give a complete list of contents.

6. Condition.

Marks.

Damage.

Signs of weer.

7. Ialue.

Where and when purchased.

Purchase price.

Market ralue. 


\section{Jewelry, Generally"u}

1. Number of the article in the list of articles.

2. Quantity of the article.

3. Kind of article.

Figure.

charm.

Scalter pin.

Breastpin or brooch.

cilip.

Cutf buttons.

Ciufl links.

studs.

Locket.

1. Material.

Yellow metal.

White metal.

Other material.

5. Physical description.

Kind.

Novelty..$^{21}$

Costume.22

Size.

Shape.

Design.

Stones.

6. Condition.

New.

Damaged.

7. Value.

Where and when purchased.

Purchase price.

Market value.

\section{Bracelets and Anklets}

1. Number of the article in the list of articles.

2. Quantity of the article.

${ }^{20}$ Jewelry, in general, includes all types of jewelry except rings, necklaces, earrings, bracelets, and watches.

${ }^{21}$ Novelty jewelry may include figures, charms, scatter pins, bracelets, necklaces, rings or any other jewelry. Novelty jewelry is of litule value and is usually gandy and set with cheap rhinestones of varions colors.

2"Costume jewelry is difficult to distinguish from novelty jewelry. That noselt! jewelry which is more expensive and inticates better workmanship may be called costume jewelry. 
3. Kind of article.

Bracelet.

Anklet.

1. Material.

Yellowe metal.

White metal.

Gold metal.

万. Physical description.

Find.

Expansion.

Link.

Bangle or charm.

Novelty.

Costume.

Sellings.

How the settings are mounted.

Distance between sets.

Number of sets.

Kind and color of sets.

6. Condition.

Nere or old.

7. Value.

IVhere and when purchased.

Purchase price.

Market walue.

\section{Earrings}

1. Number of the article in the list of articles.

2. Quantity of the article.

3. Find of article.

4. Material.

Yellou' metal.

Ithite metal.

Other material.

5. Physical description.

kind.

Novelty.

Costume.

Type.

Clip.

Screw.

Hoop.

for picued ears.

style.

I eardrop. 
Dangle.

petal.

Button.

Design. Describe the design.

stemes.

6. Comdition.

Nere or Old.

7. Value.

Where and when purchased.

Purchase price.

Market ralue.

\section{Necklaces}

1. Number of the article in the list of articles.

2. Quantity of the article.

3. Find of article.

costume.

Novelty, ets.

4. Material.

Yellow metal.

White metal.

Gold metal, ctc.

5. Physical description.

Kind.

Chain. Give size and design of links.

Snake.

Lariat.

Pearl.

Crystal. Artificial, tin cut, rock.

Stones. Number of stones and space between them.

Number of Strands.

Length of Strands.

Kinotted.

ciboker.

6. Condition.

New or Old.

7. I'alue.

Nhere and when purchased.

Purchase' price.

Market price.

\section{Watches}

1. Number of the article in the list of articles.

2. (Ollantity of the article.

3. Kind of article. 
Lady's.

Wrist.

Lapel.

Man's.

Wrist.

Pocket.

4. Material.

Yellow metal.

White metal.

5. Physicial description.

Name of manufacturer.

Name of the watch. (brand)

Distinctive brand name.

Lord Elgin

Vagabond, etc.

Size.

Shape.

Number of jewels.

Descriptive characteristics of case and movement.

Case number.

Novement number.

Initials or engravings.

6. Condition.

Scratches.

Dents.

Identifying marks.

Damaged.

Repairs. The person who last repaired the watch.

7. Value.

Where and when purchased.

Purchase price.

Market prcie.

\section{Rings}

1. Number of the article in the list of articles.

2. Quantity of the article.

3. Kind of article.

Man's.

Woman's.

Baby's.

4. Material.

Yellowe metal.

White metal. 
5. Physical desription.

Kind.

Emblem. Lodge, fraternity, class, shool.

Signet. Give initials and type of letters.

Block.

Old Euglish.

Script.

Scall ring.

Dinner ring.

Wedding ring.

Engagentent ring.

Size. Size 1 is $15 / 32$ in. inside dianeter:

carch size increases $1 / 32$ in.

Mounting.

Belcher. ${ }^{23}$

Bezel. ${ }^{24}$

Gypsy:

Tiffany. ${ }^{29}$

Claw. ${ }^{27}$

Basket."

Settings.

White stone.

Birthstone. ${ }^{30}$ Describe as red stone, green stone, etc.

Cameo. ${ }^{31}$

Intaglio. ${ }^{38}$

${ }^{23}$ The Belcher mounting involves a round stone set into a slightly raised mounting consisting of six heary prongs holding the set in place.

${ }^{24} \mathrm{~A}$ Becel mounting is one in which the set is held in the ring, brooch, or pin by a groove or flange. The groove or thange may extend all around the mounting or be on the corners or sides only.

${ }^{25}$ A Gypsy mounting is one in which the stone is set directly into the ring all the way around by use of the Bezel or groove.

${ }^{2 "} \mathrm{~A}$ Tiffany mounting is one in which the stone is set on a high mounting and held in place by 6 to 8 rather delicate prongs.

${ }^{27} \mathrm{~A}$ claw mounting is any prong mounting other than a Tiffany.

${ }^{2 \times}$ In the Basket mounting the stone is set into the mounting as in the Gypsy mounting but has filigree work around the stone.

${ }^{29}$ All diamonds nust be described as white stones. There are some black, pink, blue, green, and brown diamonds, but these are so rare; they are musemm pieces. Describe a diamond as white stone, diamond claimed.

${ }^{30}$ Birthstones may be garnet, amethyst, bloodstone, ayumarine, emerald, or others.

${ }^{31} \mathrm{~A}$ Cameo setting is a carved, raised figure, usually a head.

${ }^{32}$ An intaglio is a tigure carved into a stone. 
Type of cut.

Balguette

Chip

Ciut stone.

Marks, engratings, etc.

6. Condition.

Scratches.

Signs of wear.

Repairs. Give name of jeweler.

7. V'alue.

Where and when purchased.

Parchase price.

Market value.

\section{Luggage}

Bags.

1. Number of the article in the list of articles.

9. Quantity of the article.

3. Kind or article.

Gladstone. A suitcase-size bag which opens flat.

Club bag. A box bottom bag with the top forming the apex of a triangle, closes with zipper or locks.

We'k-end bag. May be fitted or fortnighter-a small trumk carried like a suitcase.

4. Material.

Leather.

Patent leather.

Plastic.

Top grain cowhide.

split cowhide.

Rawhide. ctc.

5. Physical description.

Size or measurements.

Handle's.

Fasteners.

Inside description. Lining and color, number of partitions. pockets, etc.

6. Condition.

Name or initials.

Hark.

Damage.

signs of w'erar.

7. ralue.

Il'here and when purchased. 
Purchase prose.

Maliel inluer.

Tiunkis

1. Number of the article in the list of articles.

2. (Guantity of the article.

3. Find or arlicle.

Foot locker. With or without tray.

stemere of wardrobe trunk. Number of hangers and drawers.

box trumk.

1. Material.

Le'alhirr.

Metal, etc.

5. Physal description.

Size or measurements.

Handles.

Fasteners.

locks.

Inside destription. Lining and color, number of compartments. etc.

Name or initials.

6. Condition.

Marks.

Dents.

Damage.

Signs of wear.

7. Value.

Where and when purchased.

Purchase price.

Market talue.

Brief cases and brief bags

1. Number of the article in the list of articles.

2. Quantity of the article.

3. Find of arlicle.

Brief rase.

Brief bas.

1. Makerial.

Lealher. Top grain cowhide, split cowhide. rawhide. ede

Patent leather.

Imilation leather, ete.

5. Physal description.

Size or measurements.

Handles. Single or double handles.

Fasteners. 
Straps. With or without straps. Do the straps go all the way around?

Inside description.

Number of compartments.

Contents.

\section{Musical Instruments}

1. Number of the article in the list of articles.

2. Quantity of the article.

3. Kind of articles.

Saxophone.

Clarinet.

Flute.

Trumbone, etc.

4. Material.

5. Physical description.

Make. Manufacturer.

Serial Number.

Pitch. Most wind instruments are made in varying pitch; e.g., saxophones are in C, E flat tenor, and B flat baritone. Clarinets are in A, B flat tenor and bass. The same applies to many string instruments.

Finish. Brass, silver, gold, rough or sandblasted. Gold or brass with silver design or vice versa, silver with gold bell.

Description of case. Give complete description, including attachments and other articles in the case.

6. Condition.

Marks.

Dents.

Scratches.

Signs of wear.

7. Value.

Where and when purchased.

Purchase price.

Market value.

\section{Radios $^{33}$}

I. Number of the article in the list of articles.

2. Quantity of the article.

3. Find of article.

Portable.

\footnotetext{
${ }^{3 a}$ In descriptions of television sets use the same information as radios. In addition, give size of screen and number of control knobs under plysical description.
} 
Table model.

Comsole, ete.

1. Material.

linol.

Mrla!

Plessir .

Number of tubes.

5. Physeal description.

Brand or Malie.

Table model.

Deal. Horiental or vertical slot, roumel, slicke rule or hall circle.

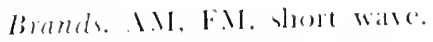

Number of linobs.

bescription of rase. Color and matcrial.

Recordplayes (il any).

serial mumber. In small radion the serial mumber is moulls imicle. out of siglit.

6. Condition.

llarks.

Inents.

Soratches.

Signs of wear.

7. Value.

IThere and when purchased.

Purchase price.

Market value.

\section{Tools}

1. Number of the article in the list of articles.

2. Quamtity of the article.

3. Find of article.

Hammer.

Handsaze.

Carpenter's learl. ete.

4. Material.

5. Physical description.

Standard information. Include all standand information is obtained from the owner. The owner ustally kuows such tools, their names and uses.

Description of chest or box (if aury).

Serial numbers. Give serial numbers of thene tools that hase them.

Electrically operated. Designate any tool that is electrically operated. 
6. Condition.

Damage. Indicate marks and scratches, stating what and where.

7. Value.

Where and when purchased.

Purchase price.

Market aralue. 


\section{BIBLIOGRAPHY}

Aucherly, Itewlyn W., and Brook, F.: Modus Operandi. Iondon, His Majesty's Stationery Office. 1932, 90 pp.

Aurner, Robert R.: Effectian Business English, Brol ed. Cincinnati, SouthWestern, 1919, 582 pp.

Bristow, Allen P.: Field Interrogation. Springfield, Charles (: Thomas, Publisher. 1958. J01 pp.

Brooks. Philip C.: Public Records Management. Chicago, Public Administration Service, 1949, 19 Pp.

California Department of Elucation, Burean of Tratle and Industrial Education: Description of Property. Sacramento, 1952, 24.4 Pp.

- - Field Notetaking. Sacramento, I950. 24 pp.

--, Modus Operandi Report Writing. Sacramento, 1949, 22 pp.

- - Police Records. Sacramento, 1949. 28 pp.

- Traffic Accident Records and Analysis. Sacramento, 1949, 14 pp.

- - L'se of Records. Sacramento, 1949, $28 \mathrm{pp}$.

California Department of Justice. Division of Criminal Identification and Investigation: Modus Operandi and Crime Reporting. Sacramento, 1955, $23 \mathrm{pP}$.

Dienstein, Nilliam: Techmics for the Crime Iniestigator. Springfield. Charles (: Thomas, Publisher, 1952. I82 pp).

Gabard, E. Caroline and Kenney, John P.: Police lliting. Springfield. Charles C: Thomas, Publisher, 1957, $93 \mathrm{pP}$.

Gregg Publishing Division: Ta'enty, Thousand Words. New York. McGraw Hill Company, 195J, 244 Pp.

Hallett, John C.: Police Report IJriting. Springfield, Charles C: Thomas, Publisher, 1960, $238 \mathrm{pp}$.

Heffron, Floyd X.: Evidence for the Patolman. Springfield. Charles C Thomas. Publisher, 1958, $182 \mathrm{pp}$.

Hollywool Police Department: Summary Explamation of Report Fomms. Hollywood, Forida. Hollywod Police Department, 1957.67 pp.

International Association of Chichs of Police. Committee on L'nifom Crime Records: L niform Cirme Reporting. Rev. eal. New Iorh. The Association, $19.9 .16 .1 \mathrm{pp}$.

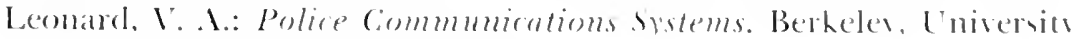
ol California prese, $1938,589 \mathrm{pp}$. 
Northwestem University 'Trafle Institute: Accident Investigation Mamual. Evanston, Northwestem University Traffic Institute, 1948, $211 \mathrm{pp}$.

Odell, Margaret K. and Strong, Earl P.: Records Management and Filing Operations. New York, McGraw-Hill Company, 1917. 312 pp.

O'Hara, Charles E.: Fundamentals of Criminal Inzestigation. Springfield, Charles C, Thomas, Publisher, 1956, 722 pp.

Perrin, Porter G. and Smith, George H.: The Perrin-Smith Handbook of Current English. Chicago, Scott, Foresman and Company, 1955, $591 \mathrm{Pp}$.

Ross, J. L.: Suggested Rules for Report Writing. Berkeley, Berkeley Police Department, 1957, 4 pp.

Santmyers, Selby S.: Practical Report Writing. Scranton, Laurel Publishers, 1950, 120 pp.

Scott, Walter R.: Fingerprint Mechamics Handbook. Springfield, Charles C Thomas Publisher, 195I, 442 pp.

Soderman, Harry and O'Connell, John J.: Modern Criminal Investigation. New York, Funk and Wagnalls Company, 1952, 557 pp.

U. S. Department of the Air Force. Air Force Manual No. 11-3, Guide for Air Force IIriting. Washington, D. C.., Department of the Air Force, 1953, 133 pp.

U.S. Department of Justice, Federal Bureau of Investigation. Mammal of Police Records. 1953, $56 \mathrm{pp}$.

--: Uniform Crime Reports, a quarterly bulletin. Washington, D. C., Federal Bureau of Investigation.

--: Uniform Crime Reporting Handbook. Washington, D. C., Federal Bureau of Investigation, 1955, $55 \mathrm{pp}$.

Wilson, O. W.: Police Administration. New York, McGraw-Hill Company, 1950, $540 \mathrm{pp}$.

--: Police Records: Their Installation and Use. Chicago, Public Administration Service, 1942, $336 \mathrm{pp}$.

Young, Richard: Report Writing and Descriptions. Berkeley, Berkeley Police Department, 1954, 28 pp. 


\section{INDEX}

\section{A}

Albuesiations, 57-61

capitalization of, 54,59

dates and places. 58

general, 61

names and titles, 58

plinals of, 60

punctuation of. 59

Afretuction, classification of, 277

Accident, tratfic

classilication of, 278-279

description of, 166

1)pe of, 165-160

rural. 161

usban, 160

violations indicated, 163

Accidents, classitication of

firearms, 279

bome, 278

occupational, 279

public, 278

trallic, 278

Accident, investigation of Iescription of, 166

jeport, 155

Adjectives, 264 demonstrative, 268

Arljectives, proper use of, 29

Adierbs, 264

Aggravated assault, classification of, 273

Agrecment of noms and pronouns, 267 number, 267 persom, 267

Alcolnol inlluence report, 227-233

Ambiguity, 65

Amputations, descriptions of, 250

Anklets, description of, $295-296$

Apostrophe, use of, $74-75$

Arrest record, 204-235

alcohol inlluence report, 227-2933 a11est vhect, 2021-2027

loskl for insestigation report, 230-231

injured prisoner report. 234.235

request for comrt chinge, 232.233

request for intermment, 233-234

Arrest shect, 221-2027

Assaults, classification of, $273-274$

Atlack of suspect, 127, 132-136, 147-149

low attarhed, 133

means of attack, 134

object of altach, 135

person attacked, 132

Auto theft report, 147-149

\section{B}

Bags, description of, 300

Bicycle report, 147-149

Binoculars, description of, 284

Bracelets, description of, $295-296$

Brackets, use of, 76

Brief cases, description of, 301

Build, description of, 255

Burglar, classification of, 273

C

(amcras, description of, 285

Capitalization, $51-56$

capilalization of abbreviations, 54

cases calling for, 5

cases not calling for, ist

in the sentence, 51

proper adjectives, 52

proper noms, 52

words of

family relationship, 53

names of time, 53

sections of commtry, 53

tilles of books, is

Case of nomus and promouns, 265

nominative, 265

objective, 266 
posicasive. 260

Carse sliects, 109-129

111 mber of copies, 111

preparation of, 109

Castalities, classilication of, 278-979

Calstlalts sleect, 120

Charge, reasoms for, 213

Clothing, description of, $285-293$

Colnerence, $6 t$

Collision, type of, 165-166

Cinlon. use of $72-73$

Comma, 69-72

Complaint memo, 119

Complaint sheet, general, 113 alsualty sheet, 120 content of, 115 miscellancons, I20

Complexion, description of, 255

Conjunctions, 265 coordinating, 265 subordinating, 265

Consonants, 32

Copscreading marks, 86

Commerlieting, classification of, 274

Costs, description of, $286-287$

Crime, details of, 138

Criminal homicide, classilication of, 273

\section{D}

1)ash, use of, 74

Description of bicycle, 149

Description card, $253-254$

Description of propert!, 237, 245, 280 . 304

Dictionars, use of, 31

Dictiomary, list of abbreviations, 57

Disorderly comduct, classilication of, 276

l)og bites, classification of, 279

Domble negatives, 20

1)ress. description ol, 256

briving while intoxicated, $276-977$

1)rnukcuness, classification of 276

\section{E}

Farbings, description ol, 296r-agt

Elitimg. methods of

copurcalling. 8.5

patrtuer, 84

persmal, s"2
Emberlencut, classification of, 274

Fulphasis, it

Eridence en elopes, 237, 239

Evidence tags, 237, 240

Exclamation maths, 69

Exhibits for court, 219

F

Fact-linding report, 7

Ficld interrogation reports, 174-180

coutents of, $17 \%$

design of, 176

form of, 177

filing of. 179

objectives of, 176

Field mote taking. 93-10\%

equipment, 97

formula for, 105

interrogitions, 95

principles of, 94

Fingerprint card, $248-253$

content of, 249

procedure. 251

Fingerprinting, rules, 252-253

Firearms accidents, classification of, 279

Firearms, description of, 293-294

Forgery, classification of, 274

Found property envelopes, 237.238

Found property tags, 237, 240

Frand, classification of, 274

Furs, description of, $292-293$

G

Gambling, classification of, 276

Grammar, elements of, 263-97 agreenent, $267-268$

case, $265-268$

forms of verbs, 268

parts of speech, $263-265$

Isc of, 28

\section{H}

Habits, description of, 256

Hair, description of, 255

Hamllatgs, description of, 294

Hold for investigation report, 230.231

Homc accidents, classification ol, 278. $27 !$

Homomnms, $41 \cdot 49$

Hosiers. Acscription of. 289 
I

lolentifuation reports. $2(8.26)$

timgerprint carrl. 248.25.9

photographic repert. 257

phosial description card, 259

Infintires, split intmitives, 29

Injured prisoner report. 231.235.

Interjections, 26.5

Internal business reports. 8

Interrogation reports. ficld. I7t-180 content of. 177-1

definitions of, 171

devign of $17 \%$

forms of 175

objective of, 176

Interrogations, techniques of. 95-97

Italics, use of. iti-is

Interiew and imestigation summan. $166-167$

Intransitive rerlss, 271

lusitation to thieves report, 173

\section{J}

Jachers. description of. 290

Jewelly. general descriptions of, gys

[usenile case history. 206.21]

\section{K}

Kind of localiu, meaning of. 16.5

\section{L}

Laborator examination report. 206-207

Larcens, classilication of, 27

Liquer laws, classitication of. 271

I.ist of exhibits. 190, 216-201

Lest and formed. classification of, 277.278 animals, 27T-27心

persome. $27 .-5-2$

properts. $27 .-278$

l.tggage description of, $300-30$ ?

\section{II}

Manmerisms, description of. 2.sti

Malks, description of, 2.56

Merhanics of report writing. I! (-8!!

ab)eriations, $57-61$

capitali/ation. $51-55$

division of words. 19-5)

ediling, 829.89 paragraph a coustructsems. Fx.81

punctuation, 6i- -7 -

selection of words. 31-19

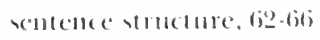

spedling. $31-19$

nese of mumbers. 5.5.

Mental cases, classitication of. 22-9

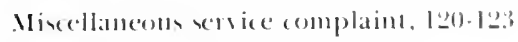

Missing persons report. 193.197

Misspelled words, 37

Modiliers. 6.?

clangling. 133

spuinting, 69

Modus operaneli factors, 127. 13013 - 137

how attalked, 193

means of attack. 13t

object of allach, 135

persom altacked. 1.32

properts altached. 139

trademark. 135

tramsportation tesed, 136

Noxl of verbs, 271-273

imperative. 27

indicative, 227

subjunctive. 27

Motor vehicle accidents, classitication of. 278

Mug form. 257. 259

Mung shor. 257

Musical instruments, description of, 302

\section{$\mathbf{N}$}

Narcotic drug riolations, classification of. 275

Nechlaces, description of. 297

Notebeok. licld. 93.95-98

alphabetical istem. 10.3

care of, $10(x)$

daily diam wem, 119

incmal arrangeneme of , 10!

sections of

arresl, 100

follow-11p. 1001

militars wants, 10 )

miscellaneous, 102

oflense. 100

outsicte wanted persoms. I1te

stolen altur, III'

solen bicriter. 112 


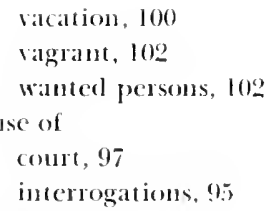

Nou11, 263

case, 265

collective, 267

common, 263

delinition of, 263

proper, 263

Nimubers, 55

militars unit names, 5.5

munerals. 55

numbers spelled out, 56

\section{O}

Ocupation, description of, 257

Occupational accidents, 279

Offenses, uniform classification of, 111 . $273-279$

oflenses against person, 111

oflenses against property, 111

part I cases, 111

past II cases, 112

part III cases, 112

part IV cases, 113

part 1 cases, 113

Omissions, proper clesignation of, it

Operational reports, 7

Oercoats, description of, $287-288$

\section{P}

Paragraplis, 78-81

arrangement of , 79, 85

principles of construction. 78,85

types of

introluctors, 81

short, 78, 8;

stmmars, si

transition, 81

Parentheses, use of, $7.5 \cdot 86$

Parts of speceh, 263-26,

110u11s, 263

promol11s, 263

Patrol services, 168

ratrol service reports. 168.180 field interugation reports, $174-180$ security conditions reports, 172-173 special service reports, 173-174 storc reports, $169-170$

vacation home reports, $168 \cdot 169$

Peculiarities, description of, 256

Performance report, 7

Period, the, 68

Personal description sheet, 146

Photographing prisoners, 257.259 procedure, 259

Photographs, identification, 220

Pluasing, indirect, 64

Plysical description card, 253

Phisical deseription picture, 194-196

Police communications, 5-6

Preliminary investigation report, 124-141

content of

general, 127

specific, 128

how mam, 115

number of copies, 145

persons missing. 143

persons wanted, 143

specific content of, $1+5$

when prepared, 145

Prepositions. 265

Principal parts of verbs, 268-270

Prisoners property envelope, 247

Prisoner's propert! receipt, 241-245

Problem determing report, $T$

Problem solution report, 7

Pronouns, 263-264

agreement, $267-268,29$

calse, $265-266$

componum personal, 264

delined, 263

demonstrative, 204

inclefinite, 264

interogative, 264

persomal. 263

relative, 263

Propert! control reports, 236-247

eridence envelopes, 239

forut properti enclopes, 238

general receipt for propert!. 243

prisoner property enselope, 247 
prisoner popents recoipl. 215

propers enclopes, 237

properts indes card, 2010

properes recosel, $236 ;$

preperes tags, 237

receipt lor antomolnile. 242

recomels procedure, 211

Propert description of, 139, $280-301$

discctors of, $284-303$

lormula lor, 280-281

hind. פRl

malerial, 282

mumber of articles, 281

mumber of quantit!, 28]

order of articles, 281

phrsical condition of, 283

phrsical descripliom of, 283

value of ast

Prosecution repouts, $212-218$

general content, 213

parts ol. 213

bods of, 213

ending of, 213

heading of, 213

Prostimion, classilication of, 275

Public accidents, classilication of, 278

Punctuation, 67.77

apost rophe, 74

brackets, 76

colon, 7?

comma, 69

dash. 74

cxclamation matks, 69

hiphen. 76

ilalics, 76

omissions. 77

parentheses, 75

perioul. (is

question matks, 68

quotation marks, 73

semicolori, 72

\section{()}

Question matks, 6x-70

(Ouolalion matks, 73-7t

\section{R}

Radios, description of, $302-303$

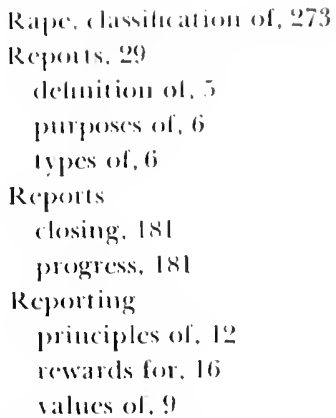

Report of laboratory exalll. 206-207

Reports. police

arrest reposts, 2024-2355

ase reports, 109-123

limal investigation, 210-2323

identification, 248-260

patrol semice, 168-180

prelininary investigation, 124-142

property control, $236-247$

special preliminary investigation, 113. $16 \%$

special supplementary insestigation. 194-211

supplementary progress, $181-193$

15 pes of, $6-8$

Repost writing, mechanies of, 19-89

Request for court change, 239

Request lor intermurut. 239?

Rewriting, 83

Rings, description ol, 2988-29)9

Road

character, meaning of, 165

conclitions, meaning of, 165

surlace, meaning of, 16.)

width and lanes, 165

Roblsery, classilication of, 273

\section{$S$}

Scale drawiugs, 219

Scats. description of. 256

reicutife cyaminations, 200

comeluct of, 220

reporting of, 2son

securits comblitions reports, $172-17,3$

semicolom, nse of, 7 ?

serulculces, $63-67$ 
types of

clear, 62

eflective. bij

simple, $i_{-}^{\prime \prime}$

(4) allenses, classifnation of. 275

blints. description ol. 29(1)-29)

trecial seriec reperts, 173.174

yperial smpplementan! insestigation se ports, 19.2.21

jurenile case history, 206

phrsical clescription pictuse. 196

phrsical description of weapon, 197

polygran encelope. 205

repont of laboratory examination. 206

smpeet description sheet. 19.

smpect line-np form, 202

speech, parts of, 263-265

spelling. 31-50

rules. 39

sione reports, 169

stolen propert!, 275

buying, 275

possessing, 275

receiving, 275

Suicides, classification of 279

attempt, 279

summary reports, 8

Summary supplenentary report, 21

supplementary insestigation report, 219. $220-235$

supplementary progress reports, 181-193

(ontent of, 181

clesign of, $1 \times 3$

details ol, 186

flintribution of, 191

list ol exlibits, 190

nature of, 183

palts of

conclusions, I8Y

cording. 190

hearling. 184-185

recommendations, 189

undereloperl leads. 18

supect, description ot, 137

bispect descriptiom sheet, 191-20!'

sweaters, description of , 29) -292"
$\mathrm{T}$

lechnical repouts, 7,8

1 eeth. description of, 256

I clevision sets, desciption of, 302

1 aols, description of $3093-304$

1 openats description of, 287.288

I radenath of suspect, 135-136

I ratlic control, meaning of, lot

lathe law solations, classification of 27

1 ramsitive verbs, 27

1 ranspertation of suspect. 136.137

l rousers, description of, 288

T jumhs, description of, 30]

1 yographical st!le, 86

\section{U}

Lindereloperl leads, 188

(ontent of, 188

(lelmition of, 188

purpose of, 188

Cuform classilication of crimes, 273-279

V

Vacation home inspections report. 17]

Vacation hounc reports, 168-169

Vacation home notice, 169.170

Vagrancl, classitication of, 276

Vehicle acrident report. 155-167

Vehicle conclition, meaning of, lot

Verbak. 264

inlinitive, 264

gerund. 264

participle, 264

Verlos. $26+272$

forms of, $268-272$

intransitive, 27

irregulat, 268

mood of , 271-272

principle parts of. "268. 270

regulat. 268

teuse of , 270.27

mansitive. 27

Vision obscmed. meaning of, 164-165

Voabulars, 21

vaice al verbs. 271,63 


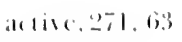

pamile. 271,69

lomel, 82

\section{W}

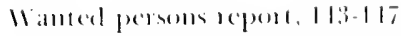

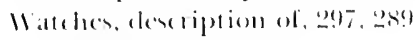

Wituesere, list of, 215

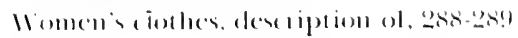

Worcle

boohish. 29!

(hoice o) 85 amosele, $2: 3$

semite. 2:3

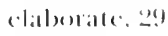

legall. :5

mimpellenl. 3.5

satterbation. 27

selection ol, 201

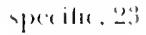

ledurical. 20;

nite. 27

11pe (1).2.3

une ol. 2-1 


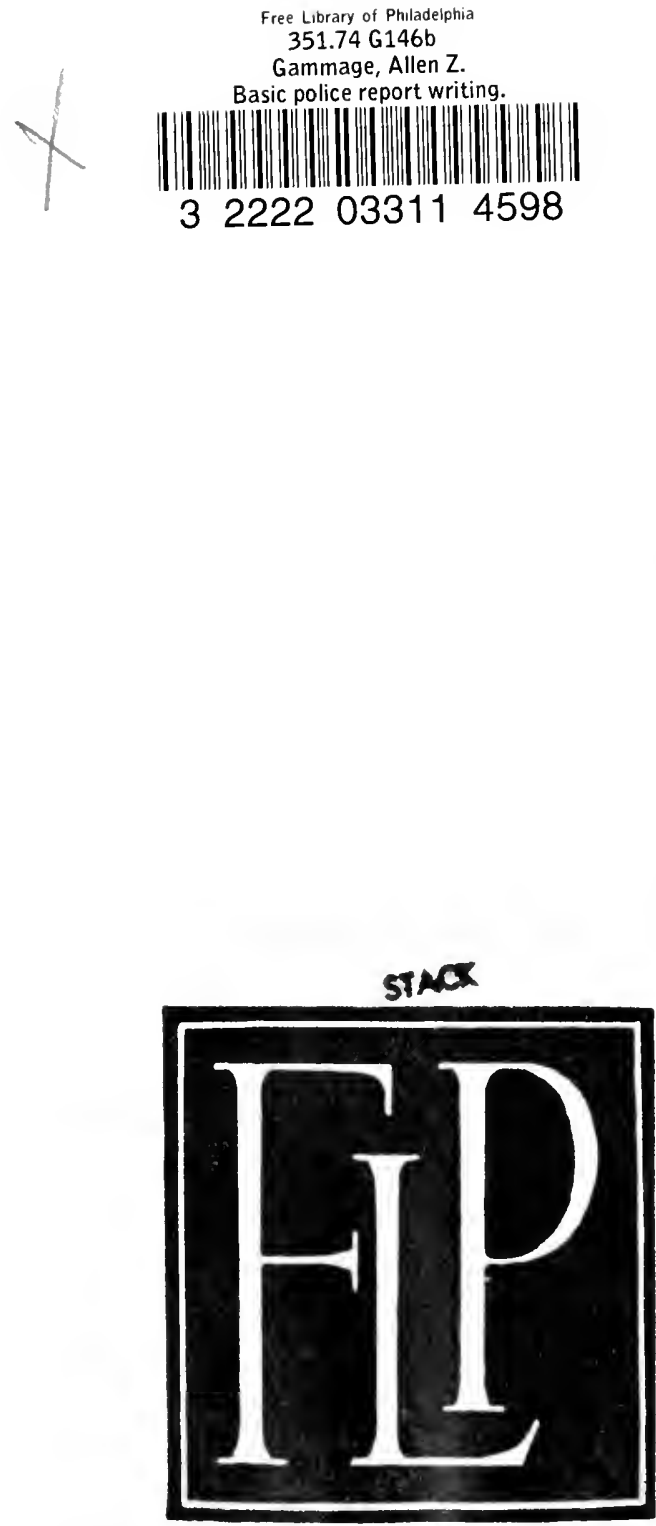


\begin{tabular}{|c|} 
BASIC POLICE \\
REPORT WRITING \\
is a Monograph in \\
THE POLICE SCIENCE SERIES \\
Edited by \\
A. LEONARD \\
Professor of Police Administration \\
Washington State University \\
Puliman, Washington
\end{tabular}

SOME OTHER TITLES

IN THIS SERIES

Myrl E. Alexander - JAIL ADMINISTRATION: A Record of the Experiences and Best Practices

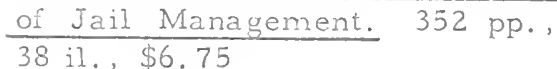

James V. P. Conway - EVIDENTIAL DOCUMENTS. 284 PP., 80 il. $\$ 7.50$

John E. Davis - AN INTRODUC TION TO TOOL MARKS, FIREARMIS AND THE STRIAGRAPH. 302 pp., 145 il., $\$ 8.50$

H. S. Dewhurst - THE RAILROAD POLICE. 224 PP. , $\$ 5.50$

John Drza za - SEX CRIMES. $250 \mathrm{pp} ., \$ 7.50$

George J. Dudycha - PSYCHOLOGY FOR LA W ENFORCEMENT OFFICERS. 2nd Ptg., 420 pp. , 13 il. $\$ 7.50$

Annita T. Eield - EINGERPRINT HANDBOOK. 194 pP., 267 il., $\$ 5.75$

John C. Hazelet - POLICE REPORT MRIING. $256 \mathrm{pP}, 105$ 11. $\$ 9.90$
Floyd N. Heffron - EVIDENCE FOR THE PATROLMAN. 192 pp., 16 il., $\$ 5.75$

Floyd N. Heffron - THE OFEICER IN THE COURTROOM. 176 pp., \$4.50

E. M. King - THE AUXILIARY POLICE UNIT: Its Formation, Training and Use. 232 pp., 27 il. $\$ 8.75$

Everett M. King - THE OFEICER SPEAKS IN PUBLIC. 184 pp. $\$ 5.75$

Walter D. Ladd - ORGANIZING FOR TRAEFIC SAFETY IN YOUR COMMUNITY. 224 pp., 30 il., $\$ 7.75$

Clarence D. Lee - THE INSTRUMENTAI DETECTION OF DECEPTION: The Lie Test. 269 pp., 55 il., $\$ 6.50$

Donald K. Merkeley - THE INVESTIGATION OE DEATH: An Introduction to the Medicolegal Criminal Investigation for the Police Officer. 150 pp., 34 il., $\$ 4.50$

A. T. Nelson and Howard E. Smith - CAR CLOUTING: The Crime, the Criminal and the Police. 180 pp., 32 il., $\$ 4.75$

Clifford L. Scott and Bill Garrett - LEADERSHIP FOR THE POLICE SUPERVISOR. 212 pP. 67 il., $\$ 7.50$

Paul B. Weston - COMBAT SHOOTING FOR POLICE. 224 pp., 103 il., $\$ 7.50$ 